OAK RIDGE NATIONAL LABORATORY

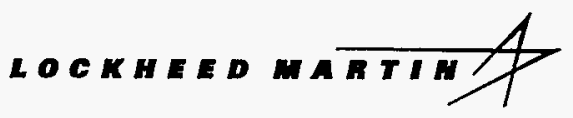

\title{
Termination of Light-Water Reactor Core-Melt Accidents with a Chemical Core Catcher: The Core-Melt Source Reduction System (COMSORS)
}

\author{
RECEIVED c.w. Forsberg \\ OCT 291996 \\ G. W. Parker \\ OSTI \\ J. C. Rudolph \\ I. W. Osborne-Lee \\ M. A. Kenton
}


This report has been reproduced directly from the best available copy.

Available to DOE and DOE contractors from the Office of Scientific and Technical Information, P. O. Box 62, Oak Ridge, TN 37831; prices available from (423) 576-8401, FTS 626-8401.

Available to the public from the National Technical Information Service, U.S. Department of Commerce, 5285 Port Royal Road, Springfield, VA 22161.

This report was prepared as an account of work sponsored by an agency of the United States Government. Neither the United States Government nor any agency thereof, nor any of their employees, makes any warranty, express or implied, or assumes any legal liability or responsibility for the accuracy, completeness, or usefulness of any information, apparatus, product, or process disclosed, or represents that its use would not infringe privately owned rights. Reference herein to any specific commercial product, process, or service by trade name, trademark, manufacturer, or otherwise, does not necessarily constitute or imply its endorsement, recommendation, or favoring by the United States Government or any agency thereof. The views and opinions of authors expressed herein do not necessarily state or reflect those of the United States Government of any agency thereof. 


\title{
TERMINATION OF LIGHT-WATER REACTOR CORE-MELT ACCIDENTS WITH A CHEMICAL CORE CATCHER: THE CORE-MELT SOURCE REDUCTION SYSTEM (COMSORS)
}

\author{
C. W. Forsberg, G. W. Parker, J. C. Rudolph, and I. W. Osborne-Lee \\ Chemical Technology Division \\ Oak Ridge National Laboratory* \\ P. O. Box 2008 \\ Oak Ridge, Tennessee 37831-6495 \\ Tel: (423) 574-6783 \\ Fax: (423) 574-3431 \\ Email: forsbergcw@ornl.gov
}

\section{A. Kenton}

Dames \& Moore

Nuclear Industry Services Group

Suite 426, 770 Pasquinelli Drive

Westmont, Illinois 60559-1200

September 1996

DISTRIBUTION OF THIS DOCUMENT IS UNLIMITED

*Managed by Lockheed Martin Energy Research Corp., under contract DE-AC05-960R21400 for the U.S. Department of Energy. 


\section{DISCLAIMER}

Portions of this document may be illegible in electronic image products. Images are produced from the best available original document. 


\section{CONTENTS}

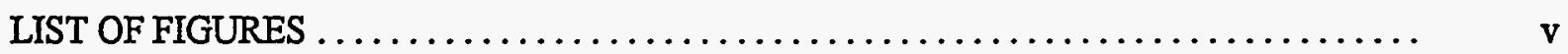

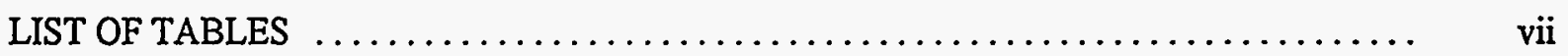

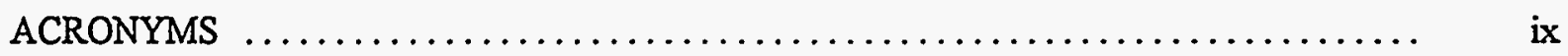

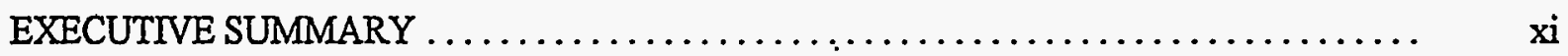

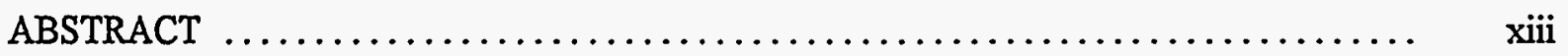

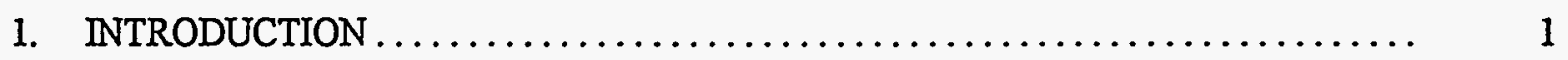

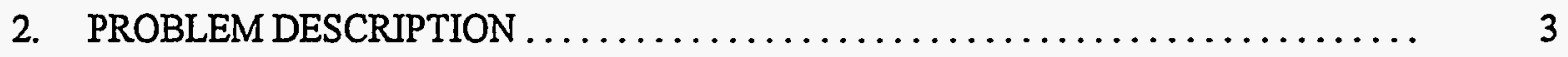

2.1 REQUIREMENTS FOR CONTAINMENT INTEGRITY: WHAT COMSORS MUST ACCOMPLISH ................................ 3

2.2 REPRESENTATIVE ACCIDENT SCENARIO ................... 4

2.3 ALTERNATIVE APPROACHES TO TERMINATE A CORE-MELT

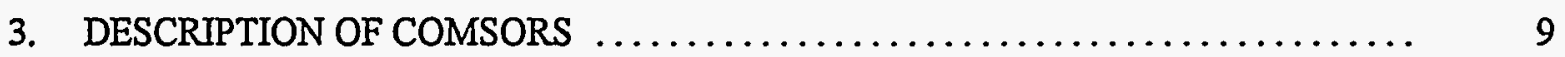

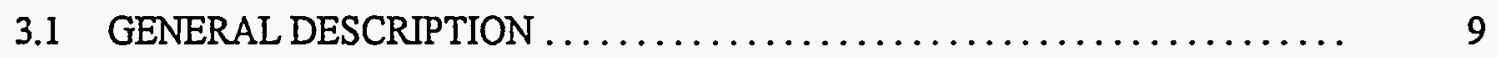

3.2 DETAILED DESCRIPTION $\ldots \ldots \ldots \ldots \ldots \ldots \ldots \ldots \ldots \ldots \ldots \ldots \ldots \ldots \ldots \ldots \ldots, 12$

3.2.1 Prevention of Penetration of the Core Debris Into the Containment ..... 13

3.2.2 Control of Reactive Metals and Avoidance of Generation of Combustible Gases ........................................ 14

3.2.3 Control of Accident Temperatures ......................... 14

3.2 .4 Control of Radioactivity $\ldots \ldots \ldots \ldots \ldots \ldots \ldots \ldots \ldots \ldots \ldots \ldots, 16$

3.2.5 Long-Term Cooling ............................... 16

4. THERMODYNAMIC AND EXPERIMENTAL RESULTS $\ldots \ldots \ldots \ldots \ldots \ldots . . . \ldots 19$

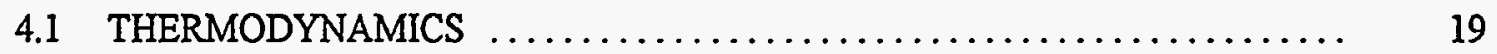

4.2 EXPERIMENTAL INVESTIGATIONS $\ldots \ldots \ldots \ldots \ldots \ldots \ldots \ldots \ldots \ldots \ldots \ldots \ldots \ldots \ldots, 21$

4.2.1 Chemical Reactions Between Core Debris Components and Glass ....... 22

4.2.2 Physical Property Measurements ........................... 22

4.2.3 Solubility Limits of Core Debris in Glass ................... 22

4.2.4 Chemical Reaction Rates ........................... 24

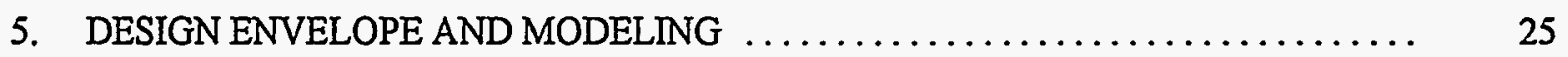

5.1 EXCESS MOLTEN-GLASS TEMPERATURES $\ldots \ldots \ldots \ldots \ldots \ldots \ldots \ldots \ldots$ 


\section{CONTENTS (continued)}

5.2 EXCESS LEAD TEMPERATURES $\ldots \ldots \ldots \ldots \ldots \ldots \ldots \ldots \ldots \ldots \ldots \ldots \ldots \ldots \ldots \ldots$

5.2.1 Solubility Limits of Core Debris in Glass .................. 28

5.2.2 Dissolution Rate Limits of Core Debris in Glass .............. 28

5.2.2.1 Expected Operation $\ldots \ldots \ldots \ldots \ldots \ldots \ldots \ldots \ldots \ldots \ldots . \ldots \ldots$

5.2.2.2 Engineering Solutions To Accelerate Debris Dissolution ..... 30

5.2.2.3 Engineering Solutions To Cool Lead .............. 34

6. OTHER CONSIDERATIONS $\ldots \ldots \ldots \ldots \ldots \ldots \ldots \ldots \ldots \ldots \ldots \ldots \ldots \ldots \ldots \ldots \ldots \ldots \ldots \ldots$

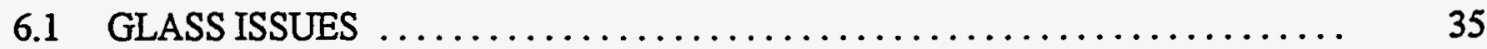

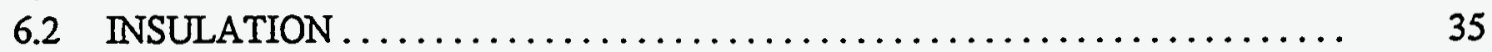

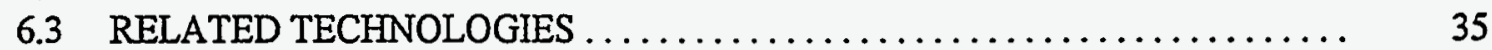

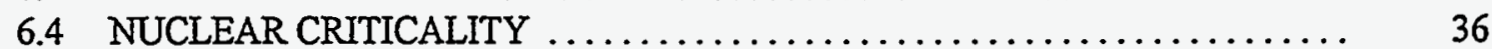

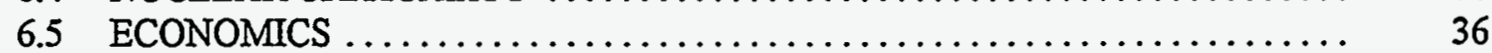

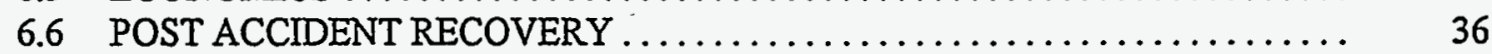

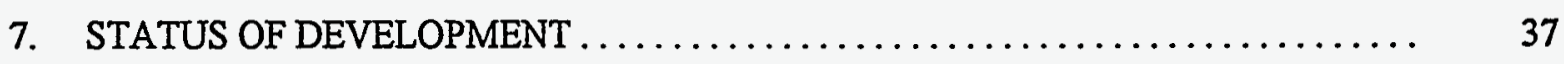

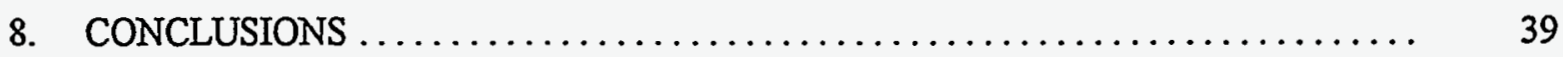

9. REFERENCES $\ldots \ldots \ldots \ldots \ldots \ldots \ldots \ldots \ldots \ldots \ldots \ldots \ldots \ldots \ldots \ldots \ldots \ldots \ldots \ldots \ldots \ldots \ldots \ldots \ldots \ldots$

Appendix A: $\quad$ DESIGN OPTIONS $\ldots \ldots \ldots \ldots \ldots \ldots \ldots \ldots \ldots \ldots \ldots \ldots \ldots \ldots \ldots \ldots \ldots$

Appendix B: $\quad$ PHYSICAL AND CHEMICAL PROPERTIES $\ldots \ldots \ldots \ldots \ldots \ldots \ldots$ B-1

Appendix C: $\quad$ THERMODYNAMICS $\ldots \ldots \ldots \ldots \ldots \ldots \ldots \ldots \ldots \ldots \ldots \ldots \ldots \ldots \ldots$

Appendix D: $\quad$ EXPERIMENTAL DATA $\ldots \ldots \ldots \ldots \ldots \ldots \ldots \ldots \ldots \ldots \ldots \ldots \ldots \ldots \ldots \ldots$

Appendix E: THERMAL HYDRAULIC ANALYSIS OF COMSORS IN THE

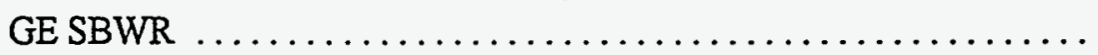

Subappendix SE.1: THERMAL HYDRAULIC MODEL FOR COMSORS LONG-TERM

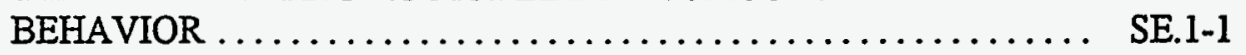

Subappendix SE.2: $\quad$ SENSITIVITY OF DOWNWARD HEAT FLUX TO UNCERTAINTIES IN THE CONVECTIVE HEAT FLUX ....... SE.2-1

Appendix F: $\quad$ MASS TRANSFER RATE DETERMINATION FOR CORE DEBRIS IN GLASS IN SUPPORT OF COMSORS ............. F-l

Appendix G: RELATED TECHNOLOGIES 


\section{LIST OF FIGURES}

Fig. 1 Alternative core-catcher concepts $\ldots \ldots \ldots \ldots \ldots \ldots \ldots \ldots \ldots \ldots \ldots \ldots$

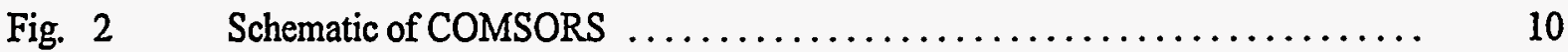

Fig. 3 Operation of COMSORS $\ldots \ldots \ldots \ldots \ldots \ldots \ldots \ldots \ldots \ldots \ldots \ldots \ldots \ldots \ldots \ldots \ldots \ldots$

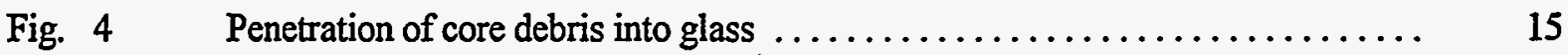

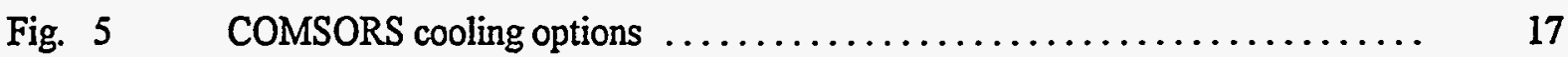

Fig. $6 \quad$ Oxygen potential in the lead-borate glass system $\ldots \ldots \ldots \ldots \ldots \ldots \ldots \ldots \ldots$

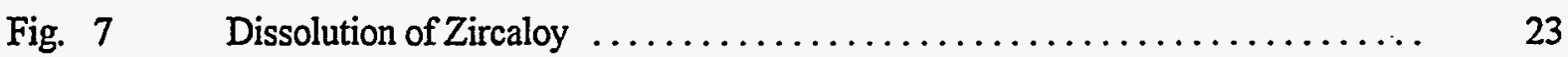

Fig. 8 COMSORS Stage 2 operation with molten glass and molten lead ......... 26

Fig. 9 COMSORS worst-case analysis with core debris between molten glass and molten lead ......................................... 29

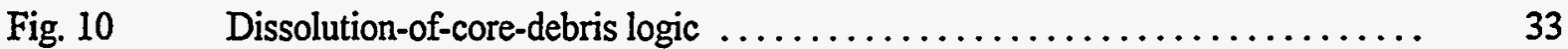

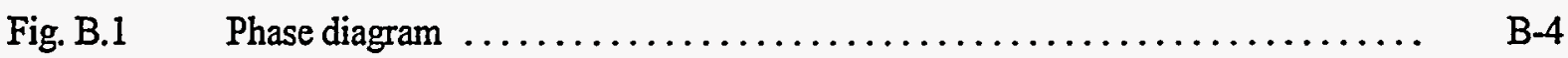

Fig. B.2 Platinum-lead phase diagram .................... B

Fig. B.3 Density and molar volume of lead borate glasses vs the lead oxide content $\ldots \ldots$ B-6

Fig. C.1 Activity coefficients of $\mathrm{PbO}$ and $\mathrm{B}_{2} \mathrm{O}_{3}$ vs mole fraction $\ldots \ldots \ldots \ldots \ldots \ldots \ldots$

Fig. C.2 Oxygen-potential diagram $\ldots \ldots \ldots \ldots \ldots \ldots \ldots \ldots \ldots \ldots \ldots \ldots \ldots \ldots \ldots \ldots \ldots$

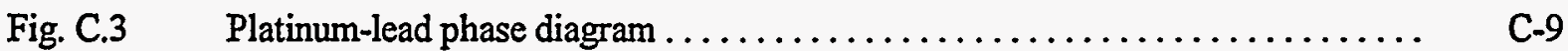

Fig. D.1 Lead-borate glass-melting furnaces for COMSORS $\ldots \ldots \ldots \ldots \ldots \ldots \ldots$ D-5

Fig. D.2 Pouring of lead borate glass into platinum dish $\ldots \ldots \ldots \ldots \ldots \ldots \ldots \ldots$

Fig. D.3 Dissolution of Zircaloy-2 in lead borate glass at half-way point . . . . . . . D D-9

Fig. D.4 Standard Brookfield viscometer fitted with a platinum cup and spindle

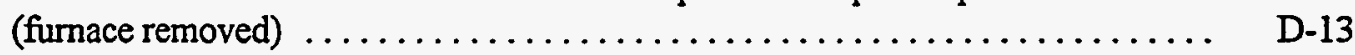

Fig. D.5 Lead pellet formed by the reaction between cerium metal and lead borate..... D-22

Fig. D.6 Experimental apparatus to measure thermal expansion coefficient of glass .... D-26

Fig. D.7 Density vs mol \% PbO for borate glasses between 600 and $900^{\circ} \mathrm{C} \ldots \ldots \ldots \ldots$ D-29

Fig. D.8 Density vs temperature for $1: 2.7$ to $3: 1$ molar ratio $\mathrm{PbO}: \mathrm{B}_{2} \mathrm{O}_{3}$ glass melts $\ldots . \quad \mathrm{D}-30$

Fig. D.9 Thermal expansion coefficient vs $\mathrm{PbO}$ content in borate glasses at $700^{\circ} \mathrm{C} \ldots \ldots$ D-31

Fig. D.10 Thermal expansion vs temperature for $27-75 \mathrm{~mol} \% \mathrm{PbO}$ in $\mathrm{B}_{2} \mathrm{O}_{3}$ glass $\ldots \ldots . \quad$ D-32

Fig. E.1 Proposed base-case configuration just after vessel failure $\ldots \ldots \ldots \ldots \ldots \ldots$ E-4

Fig. E.2 Comparison of the Fieg and Werle correlation for upward heat transfer to that of Steinberner ................................... 


\section{LIST OF FIGURES (continued)}

Fig. E.3 Comparison of the Fieg and Werle correlation for sideward heat transfer to that of Steinberner . . . . . . . . . . . . . . . . . . . . . . . . . . . .

Fig. E.4 Comparison of Nusselt numbers used for upward, downward, and sideward

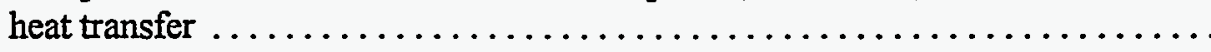

Fig. E.5 Effect of insulation effectiveness on concrete basemat temperature

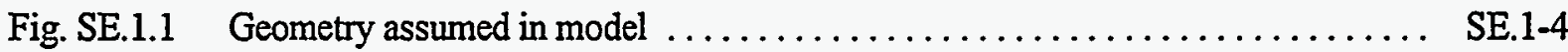

Fig. F.1 A conceptual diagram of the COMSORS core catcher $\ldots \ldots \ldots \ldots \ldots \ldots$

Fig. F.2 Proposed base-case configuration just after vessel failure

Fig. F.3 Relative importance of various parameters in determining the rate of mass transfer for core debris in a molten glass reservoir

Fig. F.4 Variation of mass transfer rate of core debris with bulk velocity in a molten glass reservoir for velocities under $1 \mathrm{~m} / \mathrm{s}$

Fig. F.5 Variation of mass transfer rate of core debris with bulk velocity in a molten glass reservoir for velocities up to $100 \mathrm{~m} / \mathrm{s}$

Fig. F.6 Variation of mass transfer rate of core debris with bulk velocity and viscosity in a molten glass reservoir for velocities up to $10 \mathrm{~m} / \mathrm{s}$

Fig. F.7 Log-log plot of the variation of mass transfer rate of core debris with viscosity

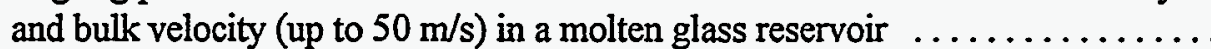

Fig. F.8 Alternative glass reservoir geometries: a single slab (Case 1), a series of monolithic slabs (Case 2), and an array of vertical rods (Case 3)

Fig. F.9 Comparison of $n$ monolithic slabs (Case 2) to the baseline (Case 1) for values

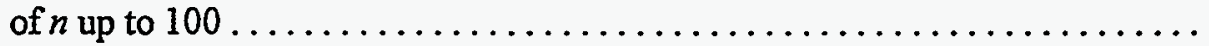

Fig. F.10 Comparison of $n$ monolithic slabs (Case 2) to the baseline (Case 1 ) for values

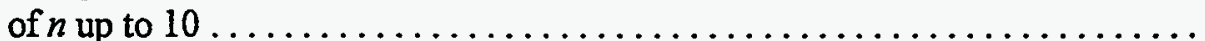

Fig. F.11 Comparison of $n$ vertical rods (Case 3) to the baseline (Case 1) for values of $n$

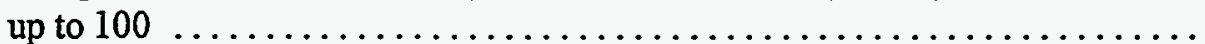

Fig. F.12 Comparison of $n$ vertical rods (Case 3) to the baseline (Case 1) for values of $n$ up to 10

Fig. F.13 Predicted dissolution times for alternative geometries in Case 2 and Case 3 for values of $n$ up to 100

Fig. F.14 Predicted dissolution times for alternative geometries in Case 2 and Case 3 for values of $n$ up to 10

Fig G.1

Borax internal core catcher for gas-cooled fast reactor

Fig G.2

Schematic of joule-heated, liquid-fed HLW vitrification plant

G-6

Fig G.3

GMODS batch processing of wastes to borosilicate glass

G-8 


\section{LIST OF TABLES}

Table 1 SBWR design parameters and COMSORS design parameters $\ldots \ldots \ldots \ldots \ldots .5$

Table 2 Vapor pressure of $\mathrm{PbO}$ in the $\mathrm{PbO}-\mathrm{B}_{2} \mathrm{O}_{3}$ system $\ldots \ldots \ldots \ldots \ldots \ldots \ldots \ldots, 21$

Table 3 Temperature $\left({ }^{\circ} \mathrm{C}\right)$ and viscosity [centipoise (cp)] for different molar ratios of lead borate glass and $w t \%$ uranium oxide in glass .................... 24

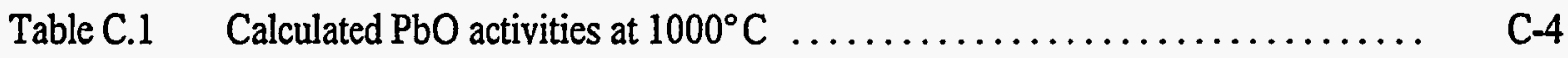

Table $\mathrm{C} .2$ Vapor pressure of $\mathrm{PbO}$ in $\mathrm{PbO}-\mathrm{B}_{2} \mathrm{O}_{3}$ system $\ldots \ldots \ldots \ldots \ldots \ldots \ldots \ldots \ldots \ldots \ldots \ldots \ldots \ldots$

Table D.1 Lead borate mix for the 2:1 type solvent glass ................... D-7

Table D.2 Solubility of $\mathrm{UO}_{2}, \mathrm{Al}_{2} \mathrm{O}_{3}$, and $\mathrm{ZrO}_{2}$ in lead borate glasses $\ldots \ldots \ldots \ldots \ldots$ D-8

Table D.3 Measured lead borate densities .......................... D-11

Table D.4 Calculated vitrified lead borate densities ...................... D-11

Table D.5 Physical property measurements of various materials in lead borate glass with

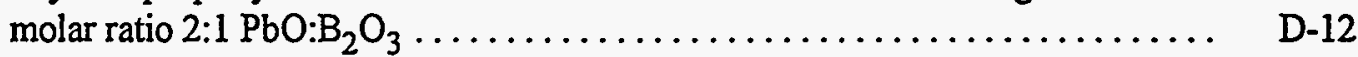

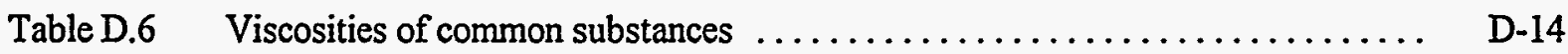

Table D.7 Viscosity (in $\mathrm{cp}$ ) of $1: 1$ and 2:1 $\mathrm{PbO}: \mathrm{B}_{2} \mathrm{O}_{3}$ glass at low temperatures ....... D-16

Table D.8 Viscosity (in $\mathrm{cp}$ ) of 3:1 and 4:1 $\mathrm{PbO}: \mathrm{B}_{2} \mathrm{O}_{3}$ glass at low temperatures $\ldots \ldots \ldots \quad$ D-16

Table D.9 Viscosity (in cp) of $20 \mathrm{wt} \% \mathrm{U}_{3} \mathrm{O}_{8}$ in 2:1 $\mathrm{PbO}: \mathrm{B}_{2} \mathrm{O}_{3}$ glass at low temperatures.. D-17

Table D.10 Viscosity (in cp) of $10 \mathrm{wt} \% \mathrm{ZrO}_{2}$ in $2: 1 \mathrm{PbO}: \mathrm{B}_{2} \mathrm{O}_{3}$ glass $\ldots \ldots \ldots \ldots \ldots . \quad \mathrm{D}-17$

Table D.11 Viscosity (in cp) of $10 \mathrm{wt} \% \mathrm{U}_{3} \mathrm{O}_{8}-10 \mathrm{wt} \% \mathrm{ZrO}_{2}$ in 2:1 $\mathrm{PbO}: \mathrm{B}_{2} \mathrm{O}_{3}$ glass .... $\quad$ D-19

Table D.12 Viscosity (in cp) of $13.3 \mathrm{wt} \% \mathrm{U}_{3} \mathrm{O}_{8}-6.7 \mathrm{wt} \% \mathrm{ZrO}_{2}$ in 2:1 $\mathrm{PbO}: \mathrm{B}_{2} \mathrm{O}_{3}$ glass ... D-19

Table D.13 Comparison of literature and experimental viscosity data for $1: 1 \mathrm{PbO}: \mathrm{B}_{2} \mathrm{O}_{3} \ldots \quad$ D-20

Table D.14 Summary of viscosity measurements (in $\mathrm{cp}$ ) vs temperature for several GMODS

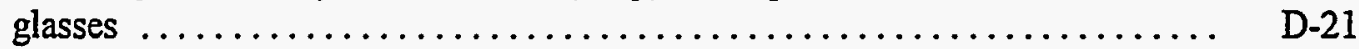

Table $\mathrm{D} .15$ Density and thermal expansion of $\mathrm{PbO}: \mathrm{B}_{2} \mathrm{O}_{3}$ glasses $\ldots \ldots \ldots \ldots \ldots \ldots \ldots$ D-24

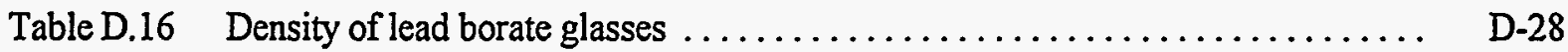

Table D.17 Thermal expansion coefficients $\left(1 /{ }^{\circ} \mathrm{C} \times 10^{4}\right)$ for lead borate glasses $\ldots \ldots \ldots$ D-28

Table E.1 Reference design parameters . . . . . . . . . . . .

Table E.2 Composition of core melt debris, initial post-accident conditions, and final post-accident conditions $\ldots \ldots \ldots \ldots \ldots \ldots \ldots \ldots \ldots \ldots \ldots \ldots \ldots \ldots \ldots \ldots \ldots \ldots, \quad E-6$

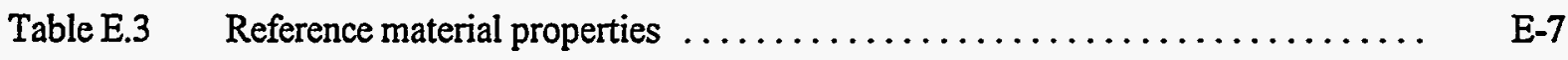

Table E.4 Glass viscosity vs temperature $\ldots \ldots \ldots \ldots \ldots \ldots \ldots \ldots \ldots \ldots \ldots \ldots \ldots \ldots \ldots \ldots$, E-8

Table E.5 COMSORS thermal-hydraulic model pool parameters $\ldots \ldots \ldots \ldots \ldots \ldots$ E-15 


\section{LIST OF TABLES (continued)}

Table E.6 Base-case glass-fuel mixture property values for well-mixed pool cases .......

Table E.7 COMSORS thermal-hydraulic model output for reference case .............

Table E.8 Summary of results for reference configuration with different model assumptions

Table E.9 Results of sensitivity case with small, dissolved glass mass $\ldots \ldots \ldots \ldots \ldots$

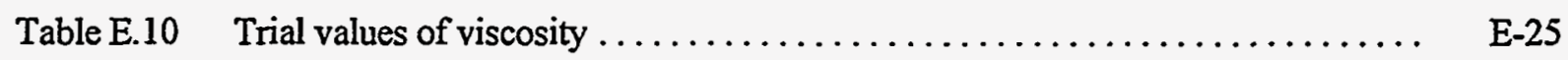

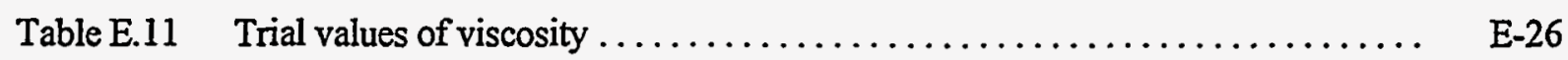

Table E.12 Assumed properties of core debris $\ldots \ldots \ldots \ldots \ldots \ldots \ldots \ldots \ldots \ldots \ldots \ldots \ldots \ldots \ldots \ldots$

Table E.13 Properties assumed for glass in nonmixed calculations . . . . . . . . . . . E E-29

Table E.14 Summary of results of calculations during mixing phase $\ldots \ldots \ldots \ldots \ldots \ldots \ldots$ E-29

Table E.15 Results for well-mixed cases in alternate pool configurations .......... E-32

Table SE.1.1 Constants used in heat transfer correlations $\ldots \ldots \ldots \ldots \ldots \ldots \ldots \ldots \ldots$ SE.1-7

Table F.1 Basis and assumptions for use in mass transfer rate estimates . . . . . . . F $\quad$ F-5

Table F.2 Composition and molecular weight for $2: 1$ lead borate glass ........... F-6

Table F.3 Core debris composition and molar volume $\ldots \ldots \ldots \ldots \ldots \ldots \ldots \ldots \ldots$ F-7

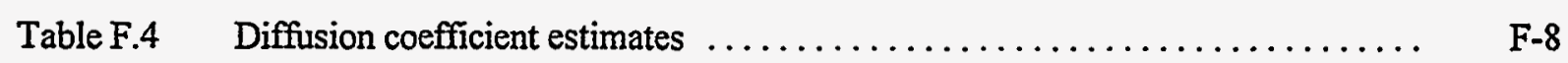

Table F.5 Measured diffusion coefficients for some common solutes in water near $300^{\circ} \mathrm{K}$. F-8

Table F.6 Solution concentration near the surface $\ldots \ldots \ldots \ldots \ldots \ldots \ldots \ldots \ldots \ldots \ldots$

Table F.7 Mass transfer rate estimates for core debris $\ldots \ldots \ldots \ldots \ldots \ldots \ldots \ldots \ldots \ldots \ldots$

Table F.8 Example corium mass composition ..................... F.10 


\section{ACRONYMS}

$\begin{array}{ll}\text { ALWR } & \text { advanced light-water reactor } \\ \text { COMSORS } & \text { COre-Melt SOurce Reduction System } \\ \text { CRD } & \text { control rod drive } \\ \text { GE } & \text { General Electric } \\ \text { GMODS } & \text { Glass Material Oxidation and Dissolution System } \\ \text { HLW } & \text { high-level waste } \\ \text { LWR } & \text { light-water reactor } \\ \text { ORNL } & \text { Oak Ridge National Laboratory } \\ \text { PCRV } & \text { prestressed concrete reactor vessel } \\ \text { RPM } & \text { revolutions per minute } \\ \text { SBWR } & \text { Simplified Boiling Water Reactor } \\ \text { SRS } & \text { Savannah River Site }\end{array}$




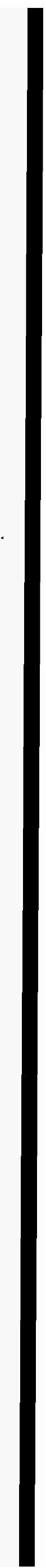




\section{EXECUTIVE SUMMMARY}

The Core-Melt Source Reduction System (COMSORS) is a new approach to terminate light-water reactor core-melt accidents and ensure containment integrity. A special dissolution glass made of lead oxide $(\mathrm{PbO})$ and boron oxide $\left(\mathrm{B}_{2} \mathrm{O}_{3}\right)$ is placed under the reactor vessel. If molten core debris is released onto the glass, the following sequence happens: (1) the glass absorbs decay heat as its temperature increases and the glass softens; (2) the core debris dissolves into the molten glass; (3) molten glass convective currents create a homogeneous, high-level waste glass; (4) the molten glass spreads into a wide pool, distributing the heat for removal by radiation to the reactor cavity above or transfer to water on top of the molten glass; and (5) the glass solidifies as increased surface cooling area (including cracking of glass) and decreasing radioactive decay heat generation allows heat removal to exceed heat generation.

COMSORS is designed to convert core debris of unknown composition and geometry (which may be uncoolable) into a relatively uniform glass composition with known properties in a coolable geometry. It is a chemical core catcher in which the glass composition is used to adjust the physical and chemical properties of the core debris. The debris, which is dissolved into the glass, is transformed to glass with properties that are favorable for termination of a core-melt accident. The glass does not chemically react with water (no zirconium reaction), has a low softening temperature, and has a low viscosity when molten.

Traditional glasses readily dissolve oxides-but do not dissolve metals. The $\mathrm{PbO}$ in this dissolution glass reacts with metals (Zircaloy, stainless steel, etc.) in core debris, thus producing (a) metal oxides that dissolve into the glass and (b) a lead-metal reaction product. This reaction creates a homogeneous glass with the fission products and prevents reactive metals (e.g., zirconium) from reacting with water and generating hydrogen. The reaction product-lead metal - sinks to the bottom of the molten glass. Core debris is less dense than lead and floats at the lead-glass interface during the dissolution process and thus is precluded from rapidly penetrating the glass before the debris is fully dissolved.

Laboratory experiments demonstrated the dissolution of $\mathrm{UO}_{2}, \mathrm{ZrO}_{2}, \mathrm{Al}_{2} \mathrm{O}_{3}, \mathrm{Ce}_{2} \mathrm{O}_{3}, \mathrm{MgO}$, and other oxides into the glass. Oxidation-dissolution tests demonstrated the oxidation of the following metals and alloys (followed by the dissolution of their oxides into the melt): Zircaloy-2, stainless steel, aluminum, uranium, cerium, and other metals.

A series of models were developed to analyze the performance of COMSORS. The models, which used the physical properties measured in the laboratory, were applied to a representative core-melt accident in the proposed General Electric Company Simplified Boiling Water Reactor. These results indicate that the molten glass, after core-debris dissolution, reaches a maximum temperature of $\sim 600^{\circ} \mathrm{C}$. Convective glass currents 
efficiently transferred heat to the water layer above the molten glass. The upward heat flux to the water in the reference design was calculated to be $130 \mathrm{~kW} / \mathrm{m}^{2}$, whereas the downward heat flux to the containment was calculated to be about $0.4 \mathrm{~kW} / \mathrm{m}^{2}$. The low glass temperatures and low downward heat fluxes ensure that containment failure will not occur.

Experiments, theoretical analysis, and numerical modeling have been applied to study the operation of COMSORS. These findings are reported herein. However, additional work is required to demonstrate a technology that can adequately address all core-melt scenarios. 


\begin{abstract}
The Core-Melt Source Reduction System (COMSORS) is a new approach to terminate light-water reactor core melt accidents and ensure containment integrity. A special dissolution glass is placed under the reactor vessel. If core debris is released onto the glass, the glass melts and the debris dissolves into the molten glass, thus creating a homogeneous molten glass. The molten glass, with dissolved core debris, spreads into a wide pool, distributing the heat for removal by radiation to the reactor cavity above or by transfer to water on top of the molten glass. Expected equilibrium glass temperatures are $\sim 600^{\circ} \mathrm{C}$. The creation of a low-temperature, homogeneous molten glass with known geometry permits cooling of the glass without threatening containment integrity. This report describes the technology, initial experiments to measure key glass properties, and modeling of COMSORS operations.
\end{abstract}




\section{INTRODUCTION}

Reactor vendors in the United States and elsewhere are developing the next generation of light-water reactors (LWRs). These advanced designs include improved containment systems to prevent the release of radioactivity in the event of a core-melt accident. Currently, one of the major unresolved design, safety, and licensing issues is how best to terminate a reactor core-melt accident that results in the release of core debris from the reactor vessel onto the concrete containment floor. Termination of the accident sequence is required to ensure that no reactor containment failure occurs. The safety concerns are that the molten core material will attack the concrete and penetrate the containment basemat or generate sufficient noncondensable gases to pressurize the containment to the point that its integrity is threatened.

At Oak Ridge National Laboratory (ORNL), a new technology to terminate core-melt accidents has been invented (Forsberg et al., 1992), the Core-Melt Source Reduction System (COMSORS). This report provides an initial description of this technology, describes what is known, and indicates what the major uncertainties are. The initial studies used the proposed General Electric (GE) Company Simplified Boiling Water Reactor (SBWR) as a basis for design calculations. COMSORS is applicable to any LWR.

The body of the report describes the technology, while the appendixes describe the experimental work, models, and detailed assumptions. 



\section{PROBLEM DESCRIPTION}

\subsection{REQUIREMENTS FOR CONTAINMENT INTEGRITY: WHAT COMSORS MUST ACCOMPLISH}

To protect the public and the environment in the event of a major accident, LWRs are built inside containment buildings. The major safety concern is a reactor core meltdown, such as the one that occurred at Three Mile Island, at which water cooling was restored after the reactor core partially melted, but before the reactor core material penetrated the bottom of the steel reactor vessel. If the progression of the accident had continued, the pressure vessel would have failed, and molten core debris-a mixture of uranium oxide $\left(\mathrm{UO}_{2}\right)$, zirconium metal $(\mathrm{Zr})$, zirconium oxide $\left(\mathrm{ZrO}_{2}\right)$, fission products, and other materials-would have fallen onto the containment floor.

To ensure the integrity of the containment building and prevent release of radionuclides to the environment in the event of an accident, core debris must be cooled after it leaves the reactor vessel. Core debris can threaten containment integrity and cause release of radioactivity to the environment in three ways:

- Excess temperature. The core debris $\left(>2000^{\circ} \mathrm{C}\right)$ can "ablate" a hole through the containment basement or side walls. This process involves decomposition of the concrete $\left(>1300^{\circ} \mathrm{C}\right)$, followed by melting of the concrete residue. The concrete can also become dehydrated and, thus, weakened at lower temperatures.

- Overpressurization. Chemical and thermal reactions between the core debris and the concrete can generate noncondensable gases that overpressurize the containment and cause the containment to fail. At high debris temperatures, the concrete decomposes to yield water $\left(\mathrm{H}_{2} \mathrm{O}\right)$ and, in many cases, carbon dioxide $\left(\mathrm{CO}_{2}\right)$. Furthermore, these gases, in turn, can react with zirconium in the core-melt debris to create potentially noncondensable and burnable gases by the following reactions:

$$
\begin{aligned}
& \mathrm{Zr}+2 \mathrm{H}_{2} \mathrm{O} \rightarrow \mathrm{ZrO}_{2}+2 \mathrm{H}_{2} \\
& \mathrm{Zr}+2 \mathrm{CO}_{2} \rightarrow \mathrm{ZrO}_{2}+2 \mathrm{CO}
\end{aligned}
$$

- High radioactivity. The high temperatures vaporize many radioactive materials and may create radioactive aerosols. Generation of these materials increases the consequences of any containment leakage.

An understanding of potential containment failure mechanisms in an uncontrolled core-melt accident provides a basis for understanding COMSORS and other core catchers. The high energy (decay heat) release rate of core debris by itself is not the problem. The problem is that the high energy release rate (unavoidable) 
combines with inefficient heat transfer mechanisms to dump the heat. The poor heat transfer results in extremely high core debris temperatures which can destroy concrete. There are two reasons for poor heat transfer.

- Geometry. In some accident scenarios, the core debris may pile up in a particular location and create very high local temperatures.

- Materials properties. The debris primarily consists of high-temperature ceramic materials which act as insulators. With a pile of core debris, outer layers provide insulation which does not melt and drain away. The bottoms of such piles may burn holes through the concrete even if the top of the core debris is cold and flooded with water. The "turtle" effect (hard shell on top with core debrisconcrete reactions below) implies that flooding of the floor of the containment by itself may not necessarily stop a core-melt accident.

The above potential interactions between core debris and the containment structure define five objectives for COMSORS.

- Stop core-melt progression to prevent containment failure by ablation through bottom or side of containment.

- Stop noncondensable gas generation-including formation of combustible gases such as hydrogen and carbon monoxide - to prevent overpressurization and subsequent failure of containment.

- Provide a heat sink which will minimize thermal loads and containment overpressurization until active or passive cooling systems become operational.

- Trap radionuclides within a solidified matrix.

- Terminate accident progression with debris placed in a long-term, stable state.

\subsection{REPRESENTATIVE ACCIDENT SCENARIO}

To develop COMSORS, an initial core-melt accident scenario is required to identify concerns and create conceptual designs. For this purpose, a representative core-melt scenario of the proposed SBWR was chosen (Table 1).

Several characteristics of core-melt accidents are important to understand when considering methods to control debris. First, it is expected to take several hours after an accident initiation begins before the pressure vessel fails and releases debris onto the containment floor. A significant fraction of the more volatile radioactive materials (e.g., cesium) would boil out of the molten core debris, thus somewhat reducing decay heat levels and altering the elemental composition of the core debris. Time also reduces the decay heat load through the decay of short-lived fission products. Second, typical core debris is primarily a mixture of ceramics $\left(\mathrm{UO}_{2}\right.$ and $\left.\mathrm{ZrO}_{2}\right)$ and metals (zirconium and iron) released together or separately with ill-defined properties. Last, the zirconium, if it reacts with steam, can generate significant quantities of heat from chemical oxidation reactions. For short durations (while zirconium remains), these chemical heat release rates can exceed the radioactive decay heat release rates. 
Table 1. SBWR design parameters and COMSORS design parameters

Reactor design parameters

Type: SBWR

Reactor power level: $2000 \mathrm{MW}(\mathrm{t})$

Reactor cavity floor diameter: $7.58 \mathrm{~m}$

Reactor cavity floor area per reactor power rating: $0.02 \mathrm{~m}^{2} / \mathrm{MW}$

COMSORS design parameters

Glass volume: $105 \mathrm{~m}^{3}$

Glass mass: $810 \mathrm{t}$

Initial glass molar composition: $3 \mathrm{PbO}: 1 \mathrm{~B}_{2} \mathrm{O}_{3}$

Initial glass density: $7.7 \mathrm{~g} / \mathrm{cm}^{3}$

Reference chemical compositions before and after interaction of core debris ( $\mathrm{kg}$ )

\section{Compound}

Before

After

Glass

$\mathrm{PbO}$

733,000

587,000

$\mathrm{B}_{2} \mathrm{O}_{3}$

77,000

77,000

$\mathrm{Pb}$

135,000

Core debris

$\mathrm{UO}_{2}$

81,000

$\mathrm{U}_{3} \mathrm{O}_{8}$

84,200

$\mathrm{Zr}$

10,000

$\mathrm{ZrO}_{2}$

30,000

43,500

$\mathrm{Fe}$

10,000

$\mathrm{Fe}_{3} \mathrm{O}_{4}$

13,800

Postaccident "equilibrium" calculated conditions

after debris dissolution in glass (Stage 2)

Water over core debris

Bulk glass temperature: $547^{\circ} \mathrm{C}$

Downward heat flux: $0.4 \mathrm{~kW} / \mathrm{m}^{2}$

Upward heat flux: $130 \mathrm{~kW} / \mathrm{m}^{2}$ 


\subsection{ALTERNATIVE APPROACHES TO TERMINATE A CORE-MELT ACCIDENT}

There are three approaches (Fig. 1) to terminate a core-melt accident after molten material has exited the reactor pressure vessel and begun to attack the containment floor (Castle, 1984).

- Coolable molten core material. The approach to prevent containment failure is (1) to ensure that, in the event of a core-melt accident, molten core material is spread under the reactor vessel and (2) to freeze the core-melt material by flooding the under reactor cavity with water. The current requirement is that "the containment shall be arranged so core debris can spread over an area not less than $0.02 \mathrm{~m}^{2} / \mathrm{MW}$ rated thermal power" (Electric Power Research Institute 1990; Sehgal and Spencer 1992) to attempt to ensure cooling by water. This is the current mainline approach for the advanced LWR (ALWR) program in the United States.

- Conventional high-temperature core catcher. This consists of a high-temperature barrier [usually magnesium oxide $(\mathrm{MgO})]$ to prevent penetration of the containment floor by core materials. Implicit in its operation is the generation of significant quantities of aerosols because of the high operating temperatures. This option has been investigated for both LWRs and liquid-metal fast breeder reactors.

- Chemical core catcher. In a chemical core catcher, the core debris reacts with and dissolves into some other material. The resultant molten solution has physical and chemical properties that promote retention of fission products and allow coolability of the final material. The COMSORS concept is a chemical core catcher.

It is noted that for some reactor types, methods are being developed for invessel retention of core debris. The feasibility of this approach depends upon the reactor power level and pressure vessel design. 
ORNL DWG 96C-159R2
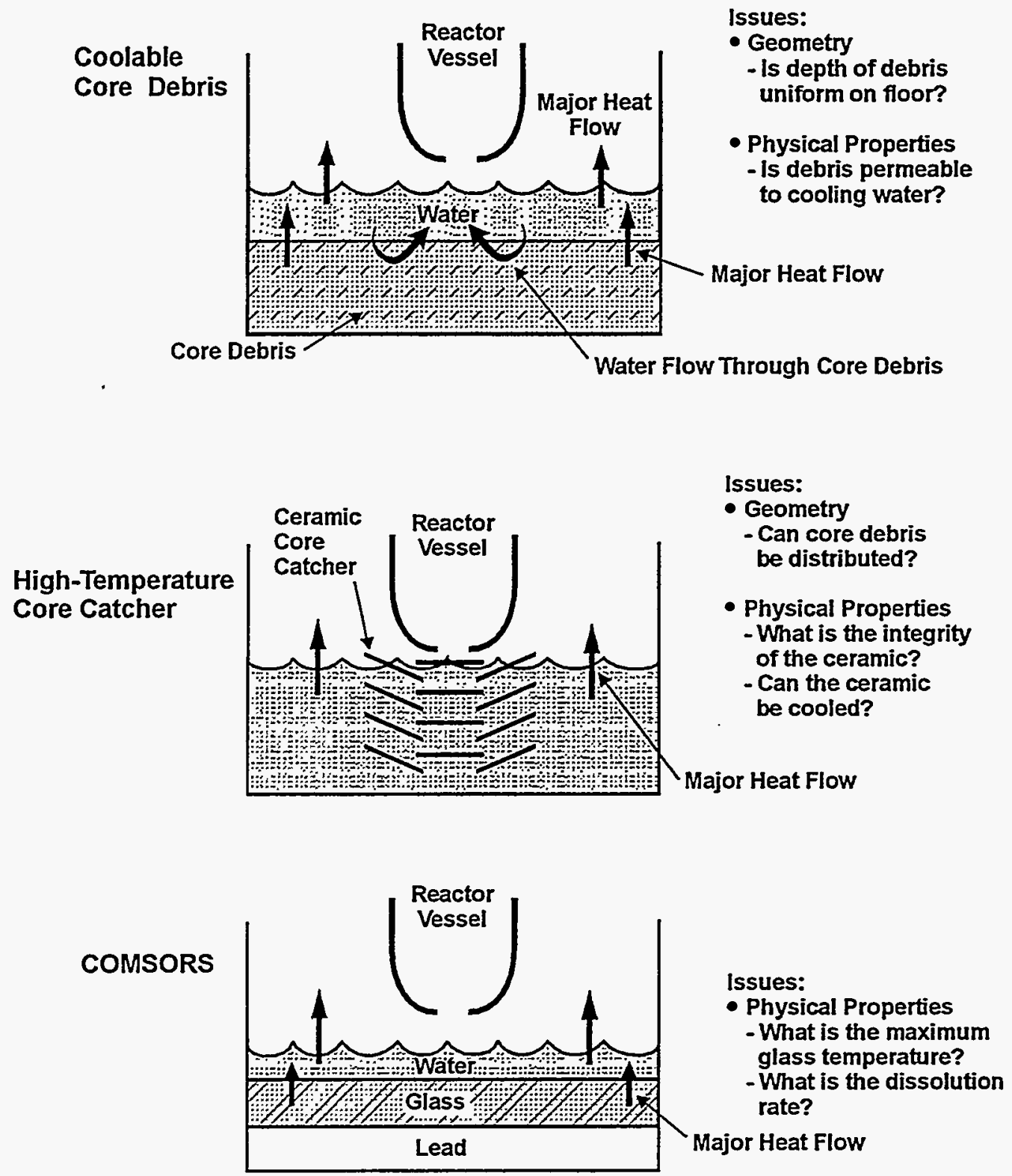

Fig. 1. Alternative core-catcher concepts. 



\section{DESCRIPTION OF COMSORS}

\subsection{GENERAL DESCRIPTION}

The basic concept of COMSORS is to place glass or glass formers under the reactor vessel (Fig. 2, Table 1). In an accident, the system evolves through three stages (Fig. 3).

In the first stage of an accident, the molten core material drops onto COMSORS. The following sequence of events happen:

1. Glass absorbs heat for hours as the glass heats up and becomes a flowable liquid, while the total power generated by the debris decreases.

2. As the melting process progresses, the uranium and fission products react with and dissolve into the glass, creating a high-level waste (HLW) glass with relatively uniform properties due to convective currents and lead metal from chemical reactions in the glass. The high-density, molten lead metal separates from the molten glass and sinks to the bottom of the system.

3. The molten HLW glass spreads into a wide pool, thereby uniformly distributing the heat for removal by radiation to the reactor cavity above or transfer to water that spills on top of the glass from containment.

The water is supplied by pipes connected to the suppression pool positioned above COMSORS. Water is released via pipes with fusible plugs that melt at high temperatures. (This is the same technique used by sprinkler systems in commercial buildings.) Cooling of the glass after core dissolution would occur primarily by flooding COMSORS with water and boiloff of water from the glass surface. In the longer term, water from steam that has condensed in the containment above will flow down onto COMSORS.

In the second stage of the accident, there are semiequilibrium conditions. The core debris is dissolved into the molten glass that floats on top of a layer of molten lead metal. The radioactive decay heat slowly decreases. Early in an accident, the glass would be molten with rapid water boiling and a thin, solid-glass layer between water and molten glass. The efficient convective heat transfer within the molten glass limits temperatures to $<700^{\circ} \mathrm{C}$. At these temperatures, insulation can limit the heat fluxes to the underlying concrete to manageable values.

In the third stage of the accident, the glass with dissolved core debris begins to solidify as an increased surface cooling area results in more rapid removal of heat than generation by radioactive decay heating. As the core debris cools, the glass would probably fracture allowing water circulation through the glass-rubble bed. 


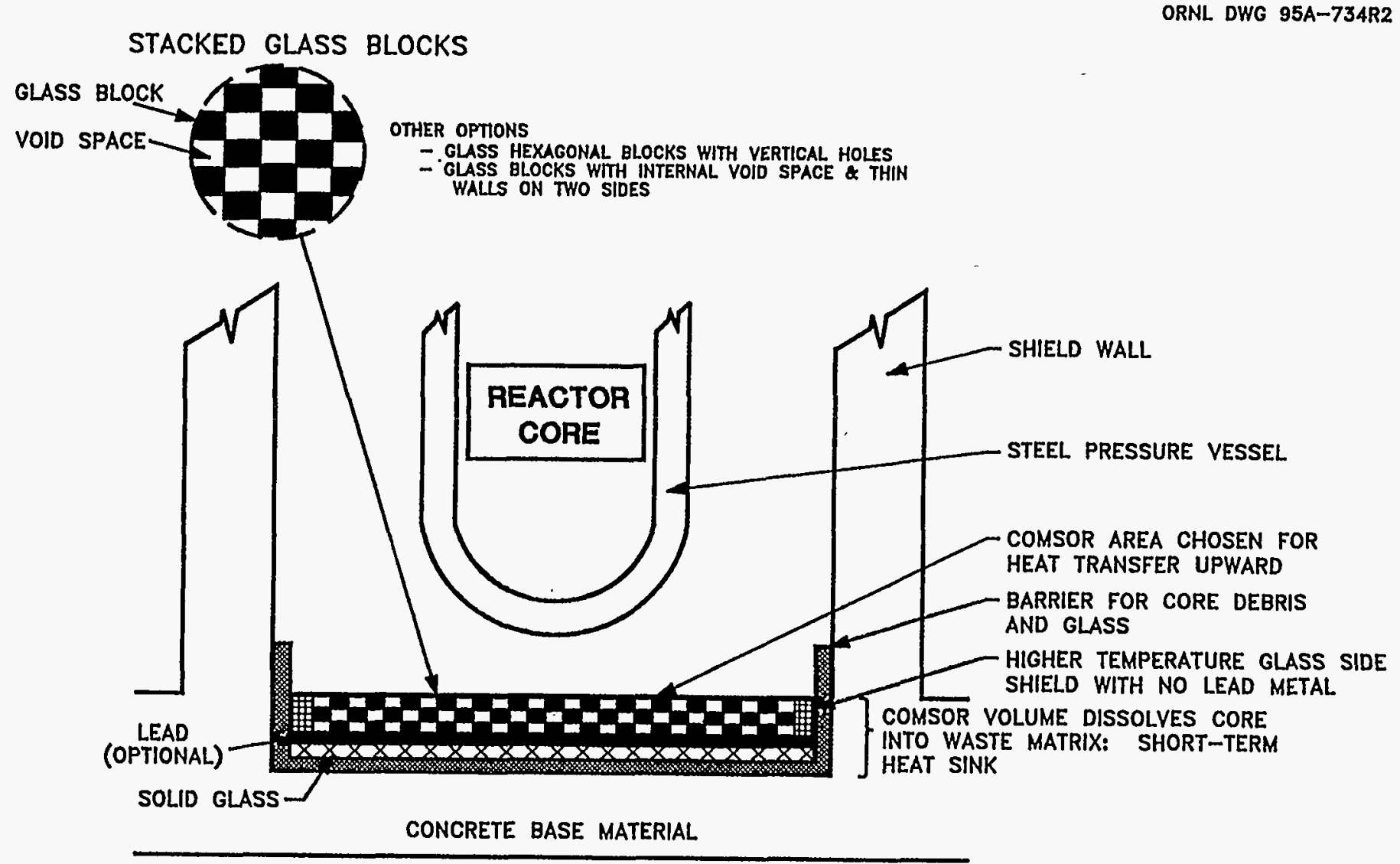

Fig. 2. Schematic of COMSORS. 


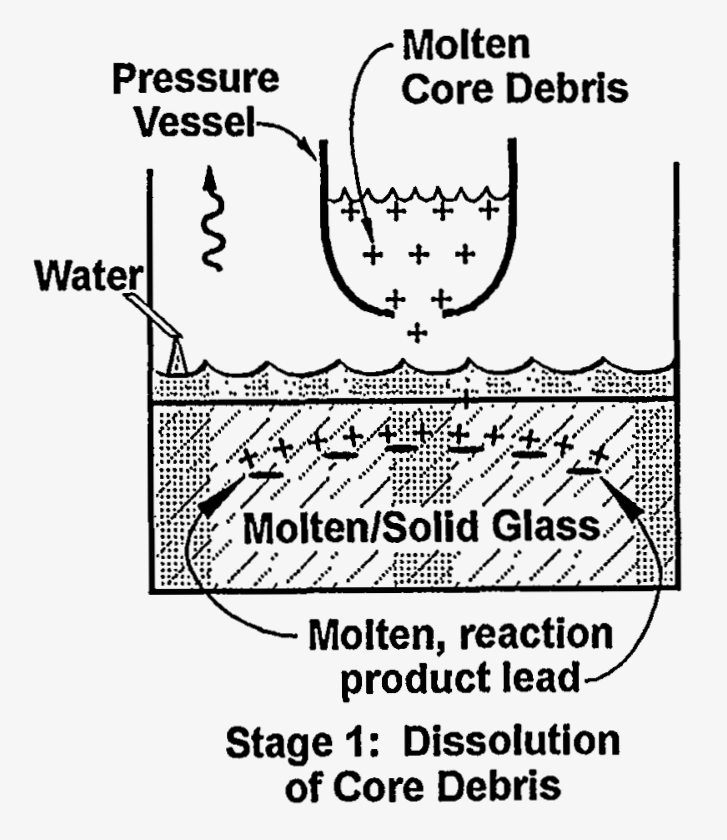

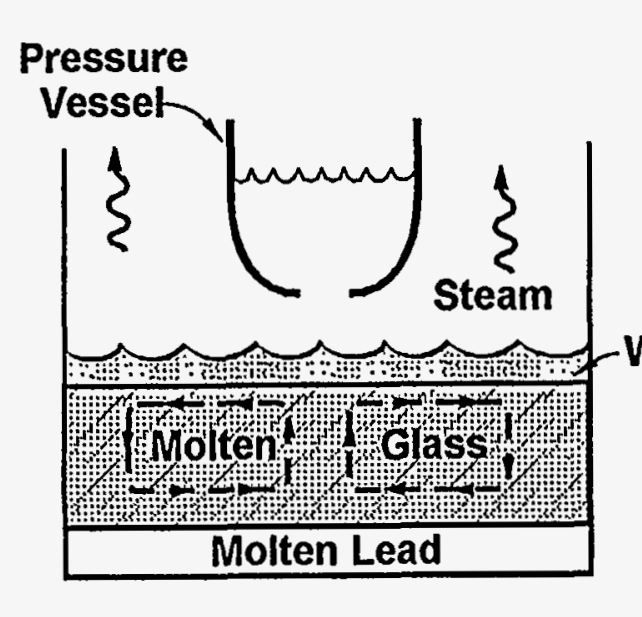

Stage 2: Homogeneous Molten Glass
ORNL DWG 96C-160R

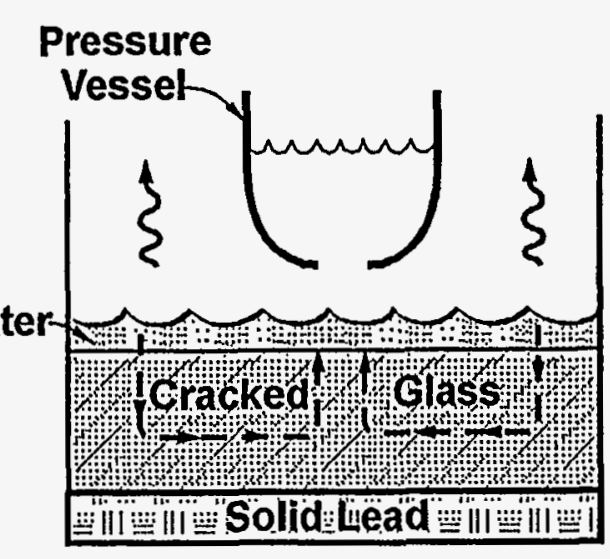

Stage 2: Cool Down

Fig. 3. Operation of COMSORS. 


\subsection{DETAILED DESCRIPTION}

The primary task of COMSORS is to stop core-melt progression to prevent containment melt-through and failure. This task is accomplished by limiting the temperature of the concrete. COMSORS lowers maximum core debris temperatures by improving heat transfer. With these lower temperatures $\left(<700^{\circ} \mathrm{C}\right.$ vs $2000^{\circ} \mathrm{C}$ ), insulation and passive cooling techniques can successfully limit concrete temperatures.

COMSORS improves heat transfer by the following two mechanisms:

- Geometry. In COMSORS, core debris melts the glass and dissolves into the glass. The radioactive heat source in an unknown geometry somewhere on the containment floor is converted into a uniform heat source of known geometry in the form of a molten pool of glass. This distribution of the heat source provides a glass pool of known surface area that can efficiently transfer heat to water above the glass via highly efficient molten glass convective currents.

- Composition. The dissolution process creates a glass with well-defined chemical and physical properties that can dissolve almost all materials at relatively low temperatures. The glass withstands high radiation fields and remains liquid over wide temperature ranges, and its properties can be controlled. In effect, the designer chooses acceptable properties for efficient heat transfer by the selection of the glass composition to match performance requirements.

Because the performance of COMSORS depends upon the properties of the glass, several requirements must be imposed on the selection of a glass. The glass must become molten at low temperatures to avoid overheating the containment. The glass must have low viscosity and a high thermal expansion coefficient to create powerful convective mixing currents for rapid dissolution of core debris and transport of heat to water above the glass. The glass must be able to dissolve all of the core debris.

To dissolve core debris fully, a special lead borate glass has been developed which contains at least 2 mol lead oxide $(\mathrm{PbO})$ per mole of boron oxide $\left(\mathrm{B}_{2} \mathrm{O}_{3}\right)$. Each component of the glass accomplishes specific tasks. Boron oxide ensures the rapid dissolution of oxides in the core debris. Boron oxide is used in welding fluxes and other applications for which fast dissolution of oxides is required. Lead oxide ensures the rapid oxidation and dissolution of the metals within the core debris into the glass.

Traditional glasses are oxide mixtures that will dissolve oxides-but not metals. To eliminate reactive metals in core debris, a sacrificial metal oxide is incorporated into the glass- $\mathrm{PbO}$. The $\mathrm{PbO}$ oxidizes the reactive metals, generating metal oxides and by-product lead. The oxidized products of reactive metals, such as zirconium oxide, dissolve into the glass. Typical chemical reactions include:

$$
\mathrm{Zr}+2 \mathrm{PbO} \rightarrow \mathrm{ZrO}_{2}+2 \mathrm{~Pb} \downarrow
$$


and

$$
3 \mathrm{Fe}+4 \mathrm{PbO}=\mathrm{Fe}_{3} \mathrm{O}_{4}+4 \mathrm{~Pb} \downarrow
$$

Several possible sacrificial oxides exist. From these, lead oxide $(\mathrm{PbO})$ was chosen as the preferred sacrificial oxide for several reasons:

- Low chemical reactivity. Lead metal does not further react with water or other materials in containment. It is chemically inert in the expected environment.

- Core catcher. Reaction-product lead helps COMSORS operation by preventing rapid core debris penetration of glass (see below).

- Low energy release. There is limited energy release. If cold glass and stoichiometric quantities of molten zirconium metal $\left(1852^{\circ} \mathrm{C}\right)$ chemically react, the reaction yields a glass with final product temperature of $\sim 800^{\circ} \mathrm{C}$.

- Uniform heat transfer. Lead is a liquid at temperatures between 350 and $1753^{\circ} \mathrm{C}$. This ensures uniform heat distribution under the glass by convective lead currents over a wide range of temperatures.

Synergetic effects occur between the $\mathrm{PbO}$ and the $\mathrm{B}_{2} \mathrm{O}_{3}$. For example, many metals form protective oxides. With this specific mixture, the $\mathrm{PbO}$ oxidizes metals, while the $\mathrm{B}_{2} \mathrm{O}_{3}$ rapidly removes any protective oxides that form.

\subsubsection{Prevention of Penetration of the Core Debris Into the Containment}

Several issues must be addressed to ensure that COMSORS performs as expected. COMSORS has several special features to prevent agglomerations of high-density $\left(8.5 \mathrm{~g} / \mathrm{cm}^{3}\right)$ core debris (Parker, 1990) from melting holes in the glass $\left(6+\mathrm{g} / \mathrm{cm}^{3}\right)$ in a few locations and attacking the containment floor. Time must be provided for core dissolution and melting of the bulk glass. In most accident scenarios, the core debris is initially expected to be relatively uniformly distributed, which should assist dissolution into the glass. However, the design is controlled by the reasonable worst-case accident scenario. The scenario of concern is, that for unforeseen reasons, the core debris begins to melt preferentially through the glass at a specific location before dissolving into the glass. Several mechanisms may be used to prevent such a scenario.

- Glass Geometry. The core catcher primarily consists of glass with internal channels (Fig. 2, Appendix A) arranged in a pattern. The top of the glass structure is covered with a steel work floor. In a core-melt accident, the core debris melts through the steel and enters the glass structure. The liquid core debris flows down into the glass structure and is dispersed into multiple channels. Much of the liquid against the cold glass freezes. The dispersed core debris material is intermixed with the glass and rapidly dissolves as the core debris remelts, melts the glass, and dissolves into the glass. The high surface area ensures rapid chemical reactions and debris dissolution. 
The channels can be formed by several mechanisms. The blocks can be layered in a pattern with interconnecting space between blocks. Alternatively, the blocks can have channels molded in the glass (similar to glass wall construction blocks).

- Lead Properties. Chemical reactions generate lead metal during COMSORS operations. The lead provides several mechanisms to slow core debris penetration and provide the time for core debris dissolution into the glass. Lead has a density of $\sim 11.5 \mathrm{~g} / \mathrm{cm}^{3}$, which is higher than that of the mixture generally characterized as "core debris." The lead gathers in low spots where the glass is molten and floats the core debris off the underlying solid glass. Lead has a relatively low melting point $\left(350^{\circ} \mathrm{C}\right)$ and a high boiling point $\left(1620^{\circ} \mathrm{C}\right)$, qualities which make it a good fluid for this application. The lead then acts as a thermal and chemical barrier to the downward heat flux. This in turn reduces melting of glass below the core debris. Simultaneously, lead-convective currents transfer heat upward to molten glass and sideways to solid glass. This convective heat transfer preferentially melts glass in a horizontal plane and distribute heat uniformly across the system. The melting glass absorbs heat and provides fresh glass to dissolve additional core debris. The lead is a self-healing mechanism to prevent penetration of core debris through the glass to the containment floor. Figure 4 schematically shows a single pile of core debris and the interaction with COMSORS at different times. Furthermore, the option exists to add lead metal layers between glass layers.

\subsubsection{Control of Reactive Metals and Avoidance of Generation of Combustible Gases}

The second task of COMSORS is to eliminate chemically reactive hot metals which (1) generate burnable gases from reaction with containment materials, (2) cause other undesirable chemical reactions, and (3) will not dissolve in the glass. The primary concern is hot zirconium metal, which is a very powerful reducing agent capable of reacting with most materials in containment. The use of a sacrificial oxide, such as $\mathrm{PbO}$, eliminates the formation of reactive metals such as liquid zircaloy. This minimizes the production of hydrogen in the containment.

\subsubsection{Control of Accident Temperatures}

The third COMSORS task is to minimize heat rejection to the containment early in the accident. Excess heat can raise gas temperatures and, thus, raise gas pressure. Excess heat can damage structures. While the very high heat fluxes early in the accident are difficult to manage, they decrease as the radioactive decay heat decreases. In COMSORS, the lead borate glass has a high volumetric heat capacity. Assuming adiabatic conditions, it will take hours for core debris to raise the glass temperature to its softening point. This large heat capacity offers the time needed to dissolve debris and for various heat transfer mechanisms to become fully operational. In practice, with the expected cooling with water on top of COMSORS early in the accident sequence, it may take days to melt the glass. 


\section{EARLY MELT PROGRESSION}

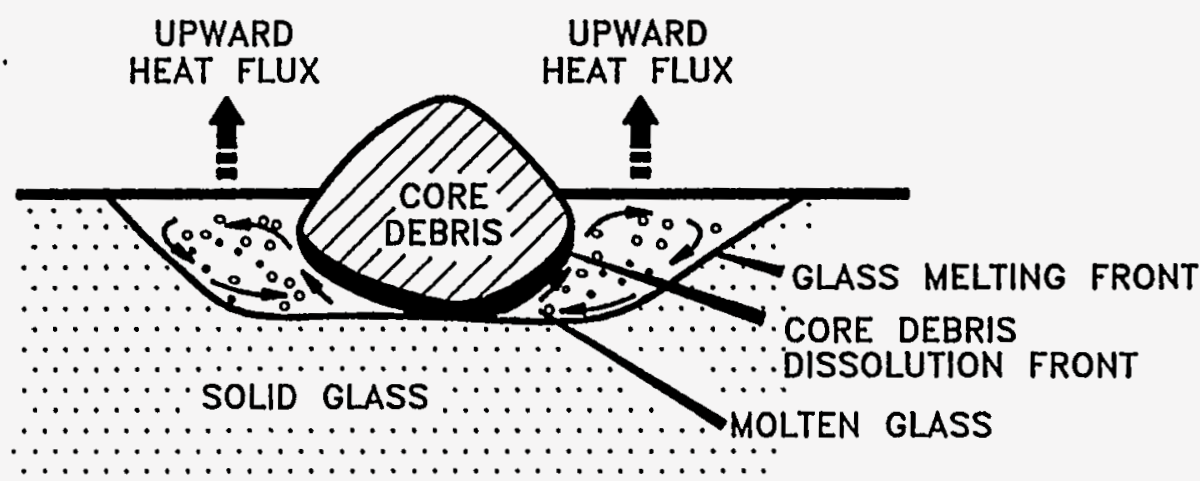

\section{LATE MELT PROGRESSION}

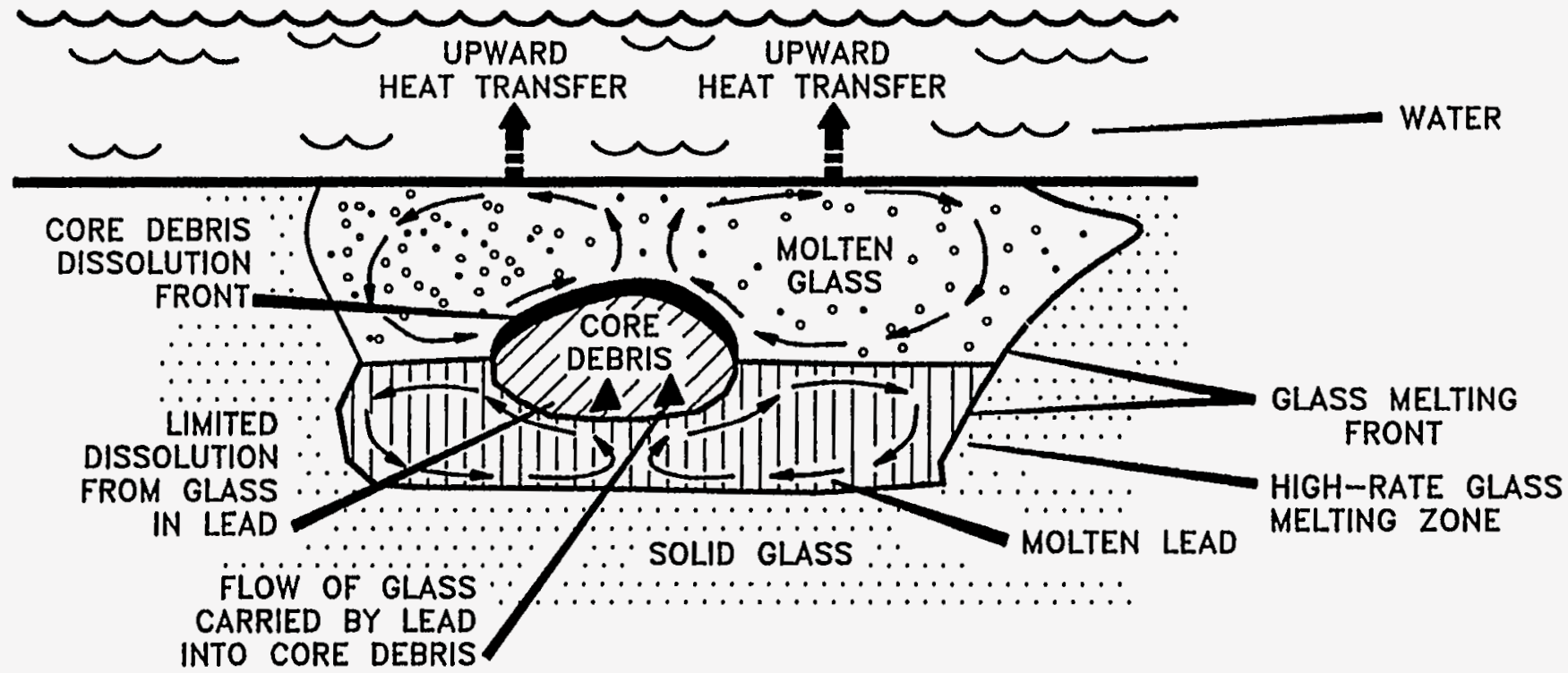

Fig. 4. Penetration of core debris into glass. 


\subsubsection{Control of Radioactivity}

The fourth COMSORS task is to trap radionuclides. Glass has been recognized historically as the material that most readily incorporates most fission products in its structure. The low temperature of COMSORS glass with dissolved core debris, as compared with that of core debris, further minimizes volatilization of fission products and generation of aerosols. The only major fission products expected to separate from the molten glass would be inert gas ( $\mathrm{Kr}$ and Xe) and halogens $\left(\mathrm{I}_{2}, \mathrm{Cl}_{2}\right)$. The halogens would be expected to dissolve in the water above the glass.

\subsubsection{Long-Term Cooling}

The fifth task of COMSORS is to end the accident sequence in a long-term, stable state (Fig. 5). COMSORS can operate for extended periods of time with molten glass. Ultimately, the glass will slowly cool and crack, and water will enter the glass bed for long-term cooling.

Most of the heat is removed by transfer to the water above with only small downward heat fluxes $\left(\sim 400 \mathrm{~W} / \mathrm{m}^{2}\right)$. However, over long time periods (weeks), bottom containment temperatures would match molten glass temperatures $\left(-600^{\circ} \mathrm{C}\right)$. These temperatures would result in degradation of the concrete. However, there are two options to prevent this degradation:

- Vents can be placed into the concrete to allow steam that escapes from the concrete to enter the containment area. However, a disadvantage to this option is that degradation of the concrete may weaken the containment.

- Heat removal systems (heat pipes, natural circulation water loops, etc.) can be installed in the liner of COMSORS to remove the downward heat flux. Because of the very low heat flux, very simple passive heat removal systems with limited capabilities can handle the heat flux. In this context, the molten lead can be cooled below the solification point of the glass. Furthermore, cooling molten lead anywhere provides cooling everywhere under COMSORS due to convective lead currents. 


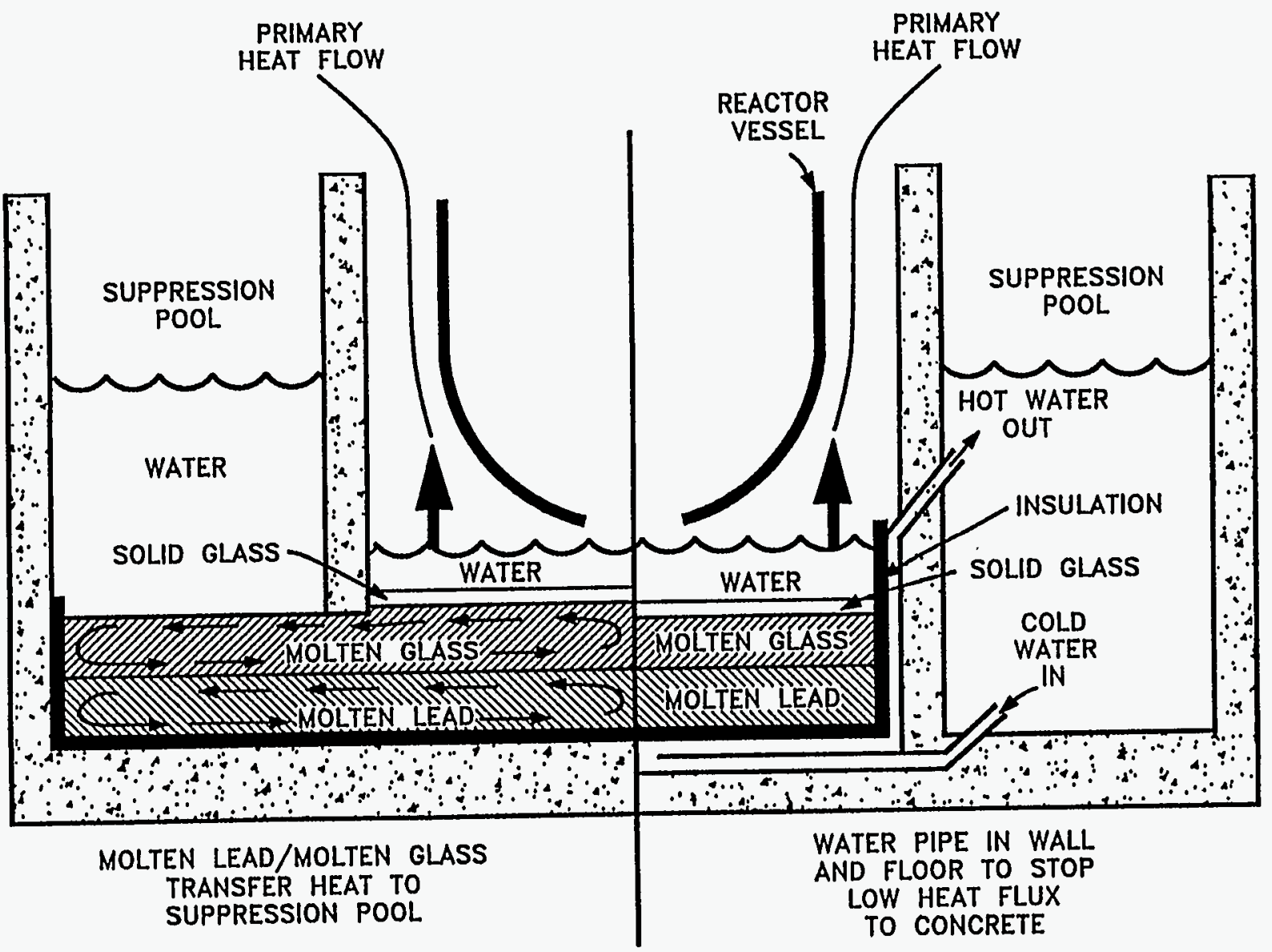

Fig. 5. COMSORS cooling options. 
. 


\section{THERMODYNAMIC AND EXPERIMENTAL RESULTS}

COMSORS requires a special glass. Theoretical considerations were used to identify potential glass compositions and estimate some physical properties. Experiments were used to measure other key physical and chemical parameters for which theoretical methods can not provide reasonable estimates of system properties. Experiments also demonstrated the key chemistry of the system. Many of the experiments were scoping experiments to bound the properties of the glass or system performance.

\subsection{THERMODYNAMICS}

A preliminary thermodynamic study was conducted (Appendix $\mathrm{C}$ ). The $\mathrm{PbO}-\mathrm{B}_{2} \mathrm{O}_{3}$ glass system is the basis of COMSORS. The capabilities to oxidize metals and to dissolve metal oxides are directly related to the thermochemical activity of $\mathrm{PbO}$ and $\mathrm{B}_{2} \mathrm{O}_{3}$. This system was previously assessed by Slough and Jones (1974), who used the Gibbs energy values reported by Kapoor and Frohberg (1973). Herein, we also have used the data of the latter.

The processing of metals in COMSORS involves oxidation and dissolution in a $\mathrm{PbO}-\mathrm{B}_{2} \mathrm{O}_{3}$ glass. The overall free-energy change for the process includes the free-energy change for the oxidation and the freeenergy change for the dissolution. The final dissolution product will be at least a ternary system involving $\mathrm{PbO}-\mathrm{B}_{2} \mathrm{O}_{3}$-metal oxide. No data are available about such systems on which to base a calculation of the distribution of species for the entire process. It may be possible to perform calculations of ternary and higher systems using thermodynamic solution models. Until that work is done, the best guide to the oxidation and dissolution of core debris by COMSORS is the oxidation of the metal using $\mathrm{PbO}$.

The best way to compare the relative ease of oxidizing a given metal is to use oxygen potentials which are described in units of energy and are defined as $R T \ln \mathrm{P}_{\mathrm{O}_{2}}$, where $\mathrm{R}$ is the gas constant, $\mathrm{T}$ is the absolute temperature, and $\mathrm{P}_{\mathrm{O}_{2}}$ is the partial pressure of oxygen. Figure 6 shows plots of oxygen potentials for forming a number of metal oxides. This figure shows the important feature that any metal oxide that is higher than another can oxidize the metal in the lower position. Here, we are concerned about the ability of $\mathrm{PbO}$ to oxidize metals. Figure 6 shows that any metal $(\mathrm{U}, \mathrm{Zn}, \mathrm{Cr}, \mathrm{Pu}, \mathrm{Al}, \mathrm{Si}, \mathrm{B}$, etc.) that lies below the $\mathrm{PbO}: \mathrm{aPbO}=0.1$ line will be oxidized when the activity of $\mathrm{PbO}$ is 0.1 , where $\mathrm{a}$ is the activity coefficient. In this figure, only $\mathrm{Cu}_{2} \mathrm{O}$ lies above the $\mathrm{PbO}$ lines. However, Zhou et al. (1993) have shown that copper in the +2 oxidation state, as in $\mathrm{CuO}$, is stable in $2 \mathrm{PbO}-\mathrm{B}_{2} \mathrm{O}_{3}$ glass. The stability of oxidized copper in this glass must result from the combination of oxidation and dissolution-not from oxidation alone. Other metals (Ag, $\mathrm{Au}, \mathrm{Pt}$, and $\mathrm{Pd}$ ) more noble than copper, do not form oxides that are stable at high temperatures; therefore, they are not included here. These noble metals would ultimately dissolve into the lead at the bottom of COMSORS. The oxygen potentials for the formation of $\mathrm{ZrO}_{2}$ are similar to those of $\mathrm{Al}_{2} \mathrm{O}_{3}$. 


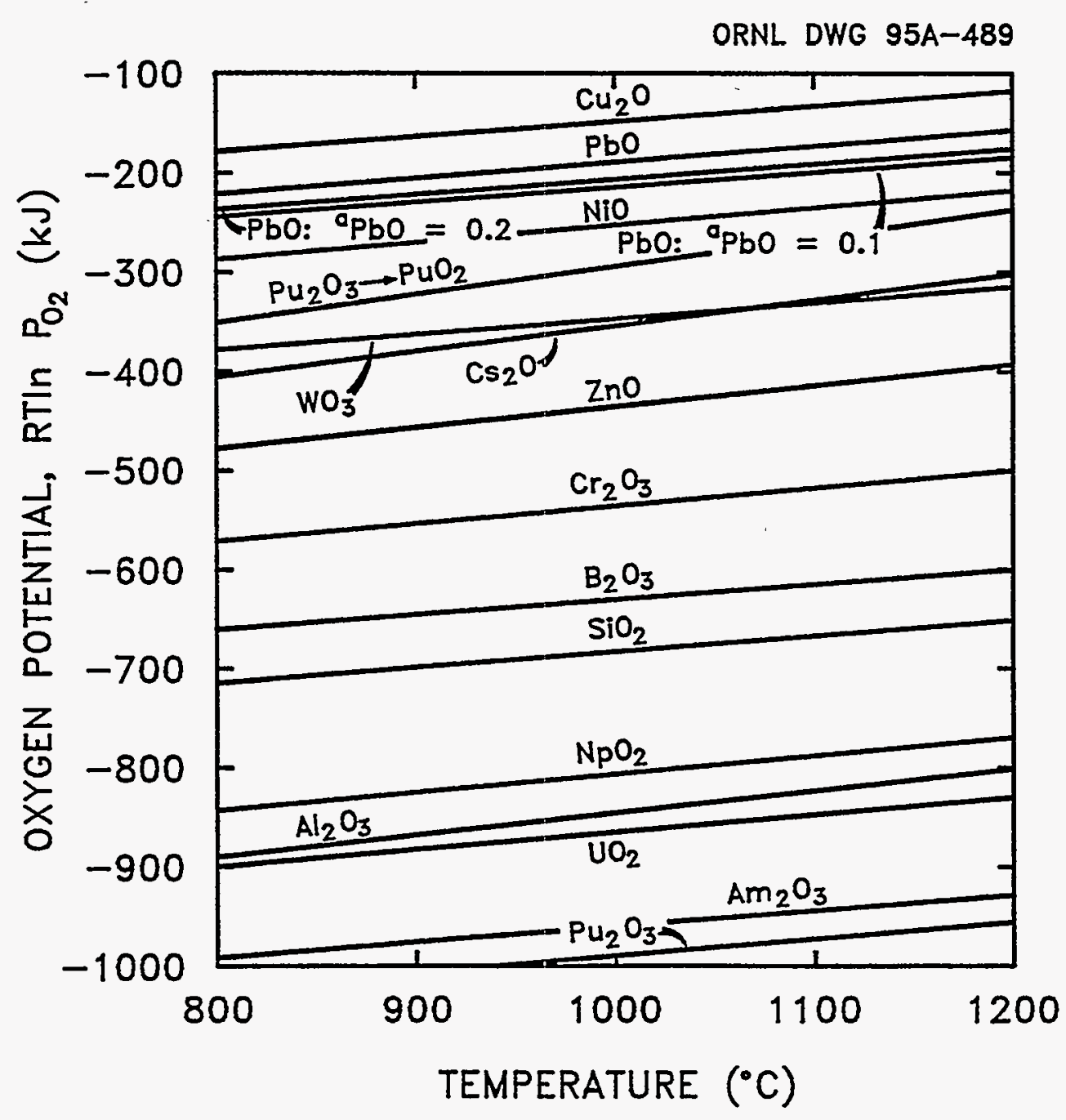

Fig. 6. Oxygen potential in the lead-borate glass system. 
Some metals, such as uranium $(U)$ and plutonium $(\mathrm{Pu})$, can form more than one oxide. The highest oxides are thermodynamically stable as far as oxidation is concerned. However, the overall oxidation and dissolution may result in a lower oxide in the borate glass. Tests of uranium oxide oxidation and dissolution resulted in a black product that most likely contains triuranium octoxide $\left(\mathrm{U}_{3} \mathrm{O}_{8}\right)$.

The vapor pressures of the major glass components were estimated as a function of temperature. As shown in Table 2, over the expected range of activity coefficients (and corresponding ratios of $\mathrm{PbO}$ to $\mathrm{B}_{2} \mathrm{O}_{3}$ in the glass), volatilization of lead oxide is not a concern. The partial pressures of $\mathrm{B}_{2} \mathrm{O}_{3}$ will be several orders of magnitude lower than those of $\mathrm{PbO}$. These low vapor pressures indicate that there is no significant concern about volatilization of glass components into the containment during COMSORS operation.

Table 2. Vapor pressure of $\mathrm{PbO}$ in the $\mathrm{PbO}-\mathrm{B}_{2} \mathrm{O}_{3}$ system

\begin{tabular}{ccc}
\hline & \multicolumn{2}{c}{$\mathrm{P}_{\mathrm{PbO}}(\mathrm{atm})$} \\
\cline { 2 - 3 } Temperature & & \\
${ }^{\circ} \mathrm{C}$ & At $\mathrm{a}_{\mathrm{PbO}}=0.1$ & At ${ }_{\mathrm{PbO}}=0.2$ \\
\hline 800 & $2.9 \times 10^{-7}$ & $5.9 \times 10^{-7}$ \\
900 & $3.9 \times 10^{-6}$ & $7.8 \times 10^{-6}$ \\
1000 & $2.8 \times 10^{-5}$ & $5.6 \times 10^{-5}$ \\
1100 & $1.5 \times 10^{-4}$ & $3.0 \times 10^{-4}$ \\
1200 & $6.3 \times 10^{-4}$ & $1.3 \times 10^{-3}$ \\
\hline
\end{tabular}

\subsection{EXPERIMENTAL INVESTIGATIONS}

Experimental investigations were initiated to understand glass performance under simulated accident conditions (with presence of debris). Laboratory experiments were conducted in platinum and high-fired aluminum oxide crucibles within vertical tube furnaces. Platinum was used for experiments that did not involve lead (lead dissolves into platinum at high temperatures). Various ceramic crucible materials were investigated for use in oxidation process experiments. While the dissolution glass dissolves oxides, the rate of attack on the Coors ${ }^{\mathrm{TM}}$ high-fired aluminum oxide crucible is sufficiently low for short-time experiments. A typical experiment involved several hundred grams of material. 


\subsubsection{Chemical Reactions Between Core Debris Components and Glass}

Tests demonstrated that $\mathrm{UO}_{2}, \mathrm{ZrO}_{2}, \mathrm{Al}_{2} \mathrm{O}_{3}, \mathrm{Ce}_{2} \mathrm{O}_{3}, \mathrm{MgO}$, and other oxides dissolve in the glass. The glasses were examined by a variety of methods to ensure complete dissolution. As expected, the glass melt with high concentrations of $\mathrm{B}_{2} \mathrm{O}_{3}$ had good dissolution capabilities for oxides. In analytical chemistry, $\mathrm{B}_{2} \mathrm{O}_{3}$ is the standard chemical reagent for fusion dissolution of unknown oxides because of its capability to dissolve such materials.

Oxidation-dissolution tests demonstrated the oxidation of the following metals and alloys (followed by the dissolution of their oxides into the melt): Zircaloy-2, stainless steel, $\mathrm{Al}, \mathrm{U}, \mathrm{Ce}$, and other metals. Figure 7 shows the partial dissolution of zircaloy clad. In this test, zircaloy clad was added to the glass, the glass was heated for a short time, and the test was terminated. The crucible was sealed in epoxy and cut in two to show the chemical reactions at the half-way point. The reaction by-product lead can clearly be seen. Oxidationdissolution tests also demonstrated the oxidation of carbon and graphite, with production of $\mathrm{CO}_{2}$.

\subsubsection{Physical Property Measurements}

For convective, fluid heat-transfer systems, there are three key physical inputs to the model: glass viscosity, glass thermal expansion coefficient, and thermal conductivity. In each case, the parameters must be known as a function of temperature and chemical composition. Viscosity and thermal expansion (Table 3) coefficients were experimentally measured. Literature values for thermal conductivity were used. Other data are presented in Appendix D.

\subsubsection{Solubility Limits of Core Debris in Glass}

Different glasses were experimentally evaluated to determine the glass chemical composition that maximizes the solubility of core debris material. Glass compositions from $4 \mathrm{PbO}: \mathrm{B}_{2} \mathrm{O}_{3}$ to $\mathrm{PbO}: \mathrm{B}_{2} \mathrm{O}_{3}$ were evaluated. The glass composition $2 \mathrm{PbO}: \mathrm{B}_{2} \mathrm{O}_{3}$ had the highest solubility for $\mathrm{UO}_{2}$. With this glass composition, more than $30 \mathrm{wt} \% \mathrm{UO}_{2}$ or $30 \mathrm{wt} \% \mathrm{ZrO}_{2}$ was soluble in the glass at $\sim 1000^{\circ} \mathrm{C}$. It was also observed that $20 \mathrm{wt} \% \mathrm{UO}_{2}$ with $20 \mathrm{wt} \% \mathrm{ZrO}_{2}$ could be dissolved in this glass at $1000^{\circ} \mathrm{C}$. At higher temperatures, the solubilities in the glass are expected to be greater. In contrast, a glass of $\mathrm{PbO} \cdot \mathrm{B}_{2} \mathrm{O}_{3}$ dissolved $>30 \mathrm{wt} \% \mathrm{UO}_{2}$ but $<10 \mathrm{wt} \% \mathrm{ZrO}_{2}$. A glass of $3 \mathrm{PbO} \cdot \mathrm{B}_{2} \mathrm{O}_{3}$ was not able to dissolve the combination of $20 \mathrm{wt} \% \mathrm{ZrO}_{2}$ and $20 \mathrm{wt} \% \mathrm{UO}_{2}$ as had the $2 \mathrm{PbO} \cdot \mathrm{B}_{2} \mathrm{O}_{3}$ glass.

The high solubility, in part, results from the uranium. Some components of core debris (e.g., $\mathrm{ZrO}_{2}$ ) normally have low solubility in glass. The addition of uranium oxides to the glass increases the solubility of the $\mathrm{ZrO}_{2}$ and other normally low-soluble components in molten glass systems. 


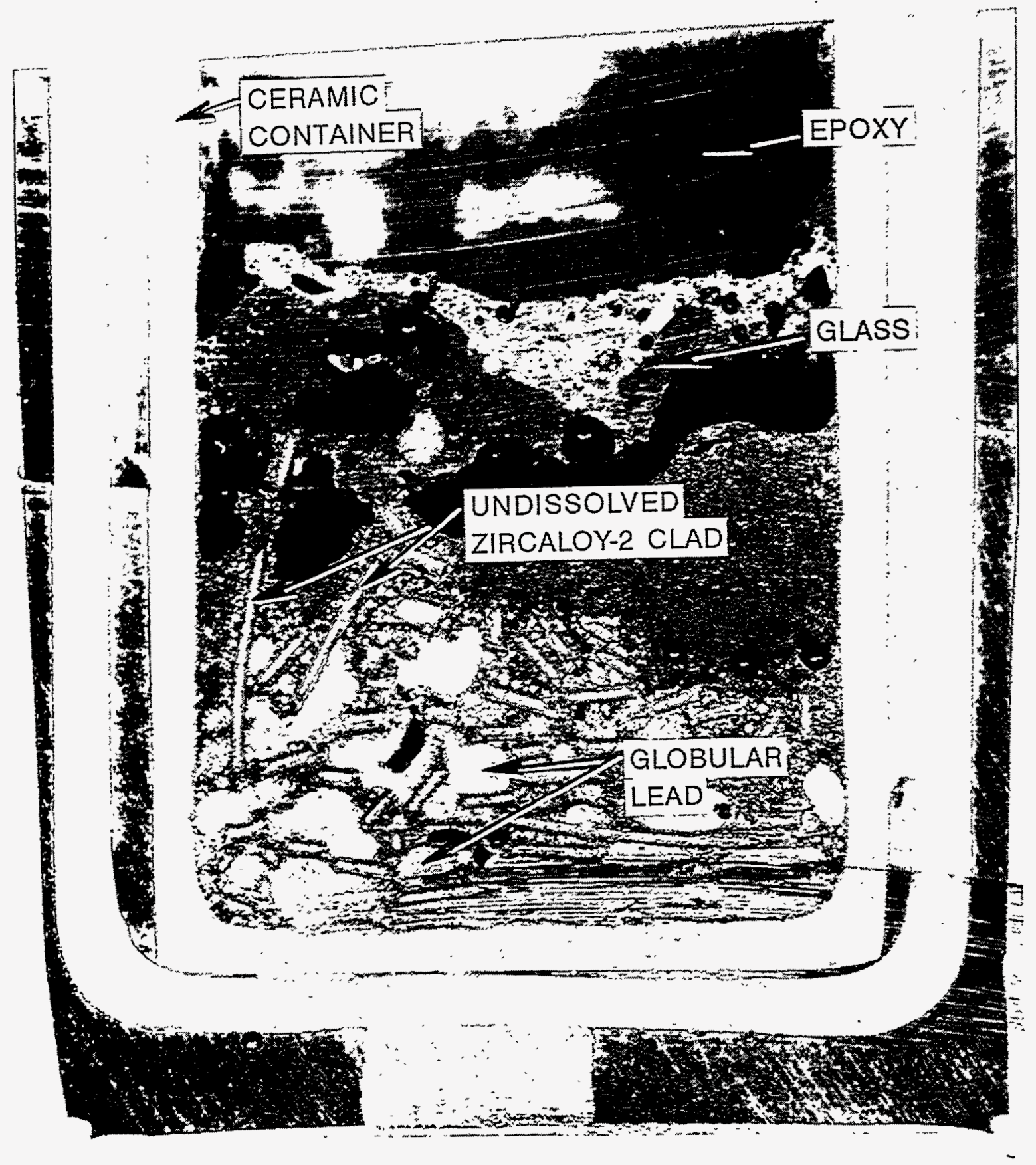

Fig. 7. Dissolution of Zircaloy. 
Table 3. Temperature $\left({ }^{\circ} \mathrm{C}\right)$ and viscosity [centipoise (cp)] for different molar ratios of lead borate glass and wt \% uranium oxide in glass ${ }^{a}$

\begin{tabular}{ccccc}
\hline $\begin{array}{c}\mathrm{PbO}: \mathrm{B}_{2} \mathrm{O}_{3} \\
(\mathrm{U}=\mathbf{0} \mathrm{wt} \%)\end{array}$ & $\begin{array}{c}2 \mathrm{PbO}: \mathrm{B}_{2} \mathrm{O}_{3} \\
(\mathrm{U}=\mathbf{0 w t} \%)\end{array}$ & $\begin{array}{c}3 \mathrm{PbO}: \mathrm{B}_{2} \mathrm{O}_{3} \\
(\mathrm{U}=0 \mathrm{wt} \%)\end{array}$ & $\begin{array}{c}4 \mathrm{4POO}: \mathrm{B}_{2} \mathrm{O}_{3} \\
(\mathrm{U}=\mathbf{0 w t} \%)\end{array}$ & $\begin{array}{c}2 \mathrm{PbO}: \mathrm{B}_{2} \mathrm{O}_{3} \\
(\mathrm{U}=20 \mathrm{wt} \%)\end{array}$ \\
\hline $706^{\circ} \mathrm{C}: 263 \mathrm{cp}$ & $620^{\circ} \mathrm{C}: 200 \mathrm{cp}$ & $603^{\circ} \mathrm{C}: 104 \mathrm{cp}$ & $615^{\circ} \mathrm{C}: 75.9 \mathrm{cp}$ & $626^{\circ} \mathrm{C}: 1970 \mathrm{cp}$ \\
$750^{\circ} \mathrm{C}: 101 \mathrm{cp}$ & $710^{\circ} \mathrm{C}: 47.4 \mathrm{cp}$ & $665^{\circ} \mathrm{C}: 59.1 \mathrm{cp}$ & $705^{\circ} \mathrm{C}: 57.5 \mathrm{cp}$ & $768^{\circ} \mathrm{C}: 116 \mathrm{cp}$ \\
$810^{\circ} \mathrm{C}: 51.6 \mathrm{cp}$ & $820^{\circ} \mathrm{C}: 21.8 \mathrm{cp}$ & $713^{\circ} \mathrm{C}: 42.3 \mathrm{cp}$ & $822^{\circ} \mathrm{C}: 21.3 \mathrm{cp}$ & $905^{\circ} \mathrm{C}: 22.2 \mathrm{cp}$ \\
& & & &
\end{tabular}

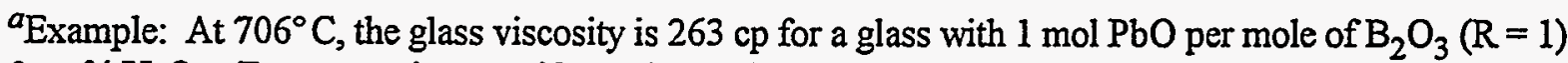
and $0 \mathrm{wt} \% \mathrm{U}_{3} \mathrm{O}_{8}$. For comparison, antifreeze has a viscosity of $20 \mathrm{cp}$, while light machine oil has a viscosity of $110 \mathrm{cp}$.

\subsubsection{Chemical Reaction Rates}

A limited number of reaction rate experiments were conducted. Reaction rates were determined to be $\sim 0.1 \mathrm{~g} / \mathrm{cm}^{2} \mathrm{~h}$ for carbon and metals. This is approximately the same as calculated from theory (see following). 


\section{DESIGN ENVELOPE AND MODELING}

The basic chemistry ensures the intended COMSORS operation if there is sufficient glass. Practical designs require limiting the quantities of glass; thus, it is important to understand what controls the volumes of glass that are required for a practical design. Four design limits have been identified: excess molten-glass temperature, excess lead temperature, hot core-debris penetration of COMSORS, and core-debris jet penetration of COMSORS. The first two limits were investigated using models and experimental data. For this analysis, a representative core melt accident in the SBWR design was used (Table 1).

\subsection{EXCESS MOLTEN-GLASS TEMPERATURES}

Excess molten-glass temperatures can cause containment failure during Stage 2 of the accident sequence. After debris dissolution occurs, the system is characterized by two natural circulation systems: molten glass and molten lead (Fig. 8). The properties of the glass and the geometry of the system determine maximum glass temperatures. If the temperatures are too high, the containment could fail.

A thermohydraulic model (Appendix E) of COMSORS was developed to understand quasi-steady-state operation during Stage 2 operation. A combination of experimental measurements and literature-derived properties were used to provide the values of key physical properties.

The model calculates the steady-state temperature distribution in a pool composed of COMSORS glass with dissolved core debris, and metallic lead with user-input definitions for the configuration of the pool boundaries. Temperatures are calculated using standard correlations for convective heat transfer, many of which were originally developed to study the cooling of core debris in the lower head of reactor vessels. Conduction through frozen glass-debris crusts (when these can form) and through structural members are modeled using conventional techniques.

One aim of the model is to investigate the sensitivity of the long-term (Stage 2) behavior of the pool to uncertainties in material properties and heat transfer correlations. This is important in determining the sensitivity of the system to different accident scenarios with different starting conditions. Another use of the model is to investigate the impact of different boundary conditions, that is, the properties input for the lower insulation layer and side wall.

The thermohydraulic model coupled with hand calculations was also used to gain insights into the conditions that would prevail during the mixing process (Stage 1). These calculations, which are documented in Appendix E, were performed for an earlier design in which the fuel debris was allowed to pour into a "pit" formed in the glass, rather than into channels. The results suggested that mixing would occur at relatively low temperatures, leading to relatively slow dissolution rates. These results led to the revised glass configuration described previously, that is meant to ensure more rapid dissolution rates. 


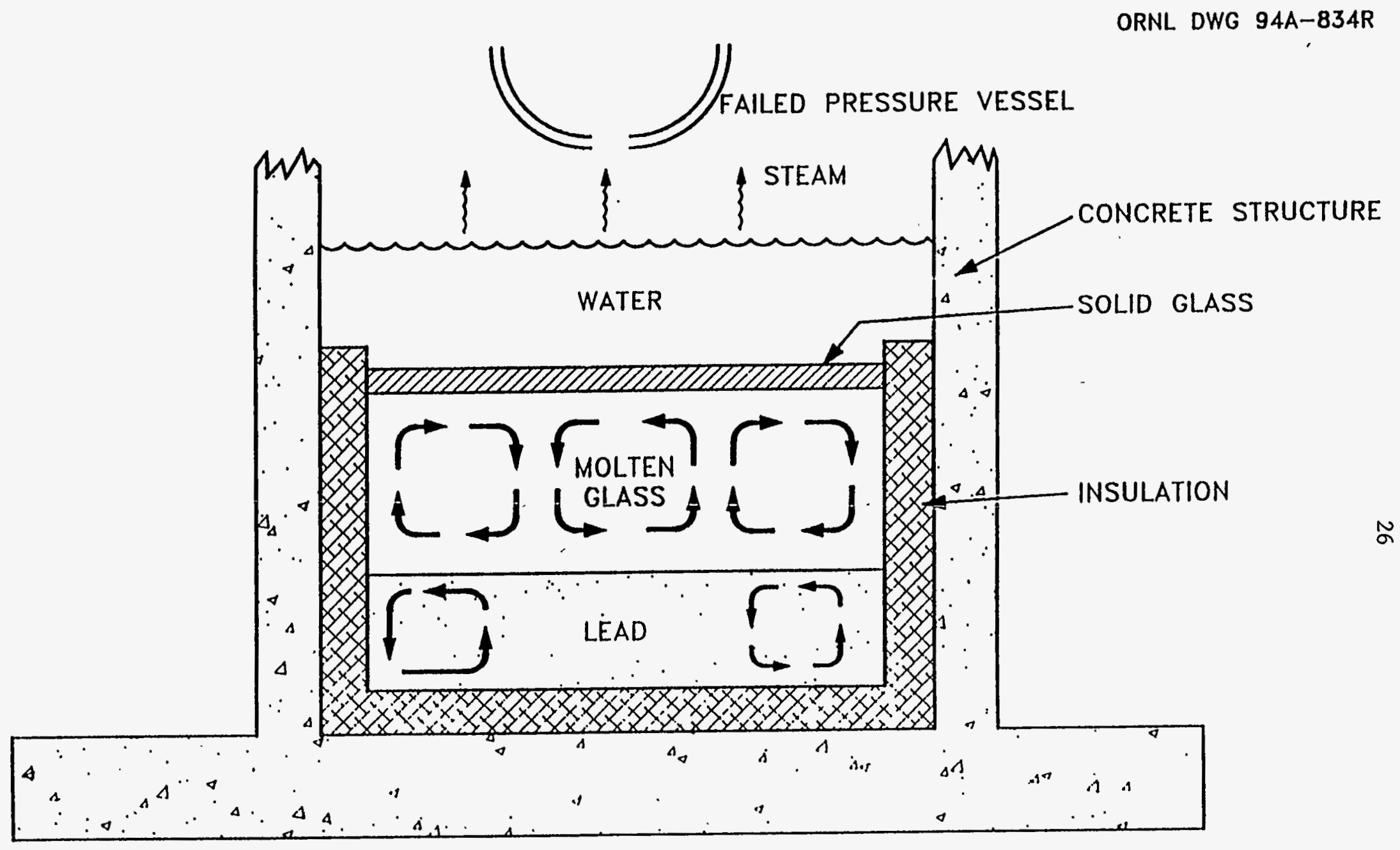

Fig. 8. COMSORS Stage 2 operation with molten glass and molten lead. 
There is one unique aspect of modeling a natural circulation system with glass compared to conventional fluids: the thermal conductivity. Glass systems are optically transparent fluids at high temperatures. This transparency allows significant radiative heat transfer when temperatures exceed several hundred degrees Celsius. It also provides an efficient heat transfer mechanism to heat surfaces of undissolved core debris within the glass. This effect implies that at system operating temperature, the effective thermal conductivity of glass is comparable to that of metals and that there is a very strong temperature coefficient (Gardon, 1961).

$$
k=\frac{16}{3} n^{2} \sigma \lambda T^{3}
$$

where

$$
\begin{aligned}
& \mathrm{n}=\text { index of refraction, } \\
& \lambda=\text { weighted photon wave length, } \\
& \sigma=\text { Stephan-Boltzman constant, and } \\
& \mathrm{T}=\text { absolute temperature. }
\end{aligned}
$$

For the specific SBWR that was analyzed, the equilibrium glass temperature was $<600^{\circ} \mathrm{C}$. Convective and radiative heat transfer efficiently transfer decay heat from the molten glass to the water above. The results are not strongly sensitive to the measured physical properties of the glass. Glass viscosity drops very rapidly with increasing temperature. Glass thermal conductivity increases rapidly with temperature. These system characteristics suggest that a small increase in temperature compensates for uncertainties in physical properties or higher heat generation rates. This phenomenon was seen in the model results when the physical properties were varied to determine the sensitivity of the results to input data:

- Increasing the glass viscosity by a factor of 5 increases bulk pool temperature $24^{\circ} \mathrm{K}$. Reducing the glass viscosity has a similar, but opposite, effect.

- Reducing the thermal conductivity of the molten glass by 50 and $90 \%$ increases pool temperature by 21 and $120^{\circ} \mathrm{K}$, respectively.

- Increasing the assumed effective melting temperature of the glass by $\sim 100^{\circ} \mathrm{K}$ causes a similar rise in pool temperature.

The downward heat flux to the containment floor is $0.4 \mathrm{~kW} / \mathrm{m}^{2}$. This low downward heat flux is a result of a layer of insulation provided below the glass in the reference design (Appendix $E$ ). With such a very low heat flux, minimal cooling prevents damage to the containment structure. By comparison, the upward heat flux was $130 \mathrm{~kW} / \mathrm{m}^{2}$. 


\subsection{EXCESS LEAD TEMPERATURES}

Excess lead temperatures can cause containment failures. Excess lead temperatures may occur if sufficient core debris (1) fails to dissolve or (2) fails to dissolve sufficiently fast into the glass (Fig. 9). In either case, core debris will form a solid floating layer between the molten glass and molten lead because the core debris has a density intermediate between that of molten glass and molten lead. If a thick layer of insulative, undissolved, heat-generating debris totally covers this interface, it can heat the lead and, hence, the concrete to excessive temperatures. The lead will overheat until it reaches its boiling point of $1620^{\circ} \mathrm{C}$. However, containment failure caused by the hot, corrosive lead is likely to occur before this temperature is reached.

If there is a sufficient glass-lead interface area for heat transfer, the existence of floating, undissolved materials does not (1) impact heat removal by glass to the water above or (2) significantly raise glass or lead temperatures. The requirement (for failure) is for a core-debris layer that is both thick and that fully covers the interface.

\subsubsection{Solubility Limits of Core Debris in Glass}

If the solubility limits of core-debris components in glass are exceeded, a layer of core debris will form. Experimental measurements of core debris (Sect. 4 and Appendix D) defined the maximum loading in the glass before this limit is exceeded.

\subsubsection{Dissolution Rate Limits of Core Debris in Glass}

COMSORS requires reasonable dissolution kinetics of core debris into glass to avoid high lead temperatures and subsequent high concrete temperatures. The avoidance of the formation of a layer of core debris between the molten glass and molten lead with ensuing overheating of the lead can be viewed as a race between (a) the dissolution of the core debris and (b) the rate of lead temperature heatup.

- Dissolution rate. The rate of dissolution depends upon the (1) chemical reaction rates and (2) surface area between the glass and core debris. Chemical reaction rates depend upon temperature and chemical composition. The surface area depends upon the geometric design of COMSORS.

- Cooling rate. The rate of lead heatup is dependent upon multiple factors. Adiabatic heatup requires hours. Heat losses to the water on top of the core debris and any cooling of the lead increase this time.

\subsubsection{Expected Operation}

Because experiments have not yet been conducted to provide high assurance that excess lead temperatures will not occur, a nominal design was chosen that uses engineering solutions to ensure rapid core debris dissolution. Whether such engineering solutions are needed is unknown, at this time. 


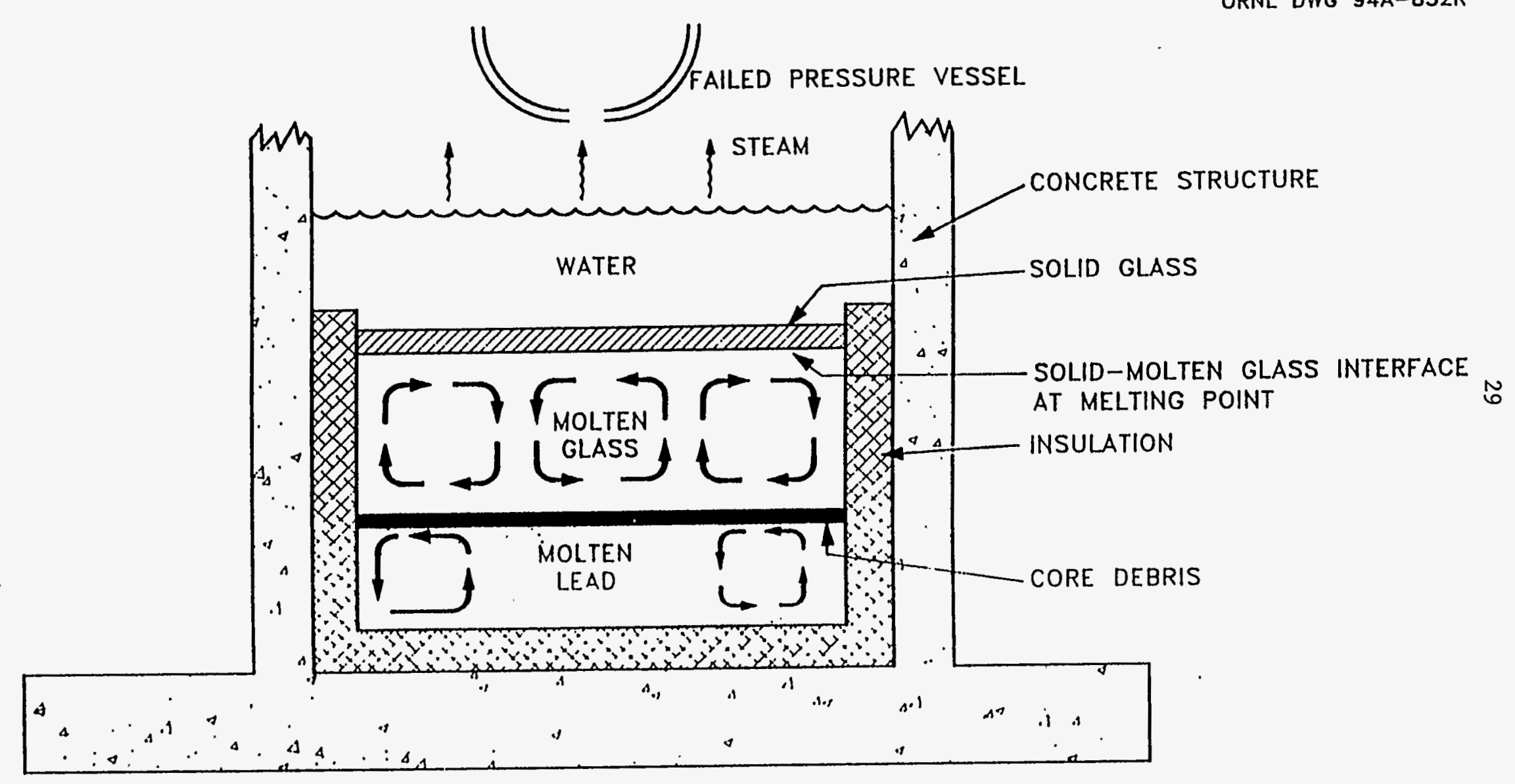

Fig. 9. COMSORS worst-case analysis with core debris between molten glass and molten lead. 
The rate of core-debris dissolution depends on the surface area between the core-debris and the molten glass. The use of a high surface area core catcher (see the following) ensures a rapid dissolution of the hot, liquid core debris.

It is also likely, but undemonstrated, that COMSORS would work effectively and safely with a small surface area and a monolithic glass below the reactor core. The probable Stage 1 operation for COMSORS (assuming a monolithic glass below the reactor) is (1) core debris flowing onto the glass; (2) core debris partially reacting with the glass, thus creating molten lead; and (3) formation of a core-debris layer floating on the reaction product lead. Water would be on top of the core debris, and solid unreacted glass would be below the lead. Shortly after a debris release from the reactor vessel, from top to bottom, there would be layers of boiling water, core debris in molten glass, molten lead, and solid glass.

In such a scenario, the lead would begin to heat up. As it heats up, the low-softening-temperature glass below the lead would begin to "melt." The lower density glass would form molten glass drops that would float upward through the molten lead to the bottom of the core debris. These glass droplets would dissolve into the core debris, thus lowering its density and viscosity. Because the molten glass has a lower density than the debris, these beads would tend to bore into the core debris. Higher local temperatures accelerate the process. The process would continue until a uniform glass mixture was created.

There is also a temperature at which there will be very rapid dissolution of the molten core debris. Experiments with other boron glass systems (Dalle-Donne, 1978) show that as the temperature rises, dissolution rates rapidly increase. This increase appears to be a result of boron oxide diffusion into the core debris; thereby lowering the melting point of the core debris by forming a borate glass and rapidly dissolving and breaking up of the debris. Experiments have not yet been conducted to quantify this phenomenon as a function of temperature in the lead borate glass system.

\subsubsection{Engineering Solutions To Accelerate Debris Dissolution}

The dissolution rate between core debris and molten glass depends upon the surface area, dissolution mechanism, temperature, glass viscosity, and many other parameters that are discussed herein. For this analysis, it is assumed that the process can be modeled as dissolution. This is a conservative assumption on which to base the initial design.

The problem of determining the dissolution rate of core debris into the molten glass reservoir of COMSORS is essentially that of diffusion through a liquid (lead borate glass) at a solid boundary (core debris), at which the liquid is undergoing natural convection because of thermal driving forces. This problem has been examined previously, with results that are well known for simple geometries (Welty, Wicks, and 
Wilson, 1969; Sherwood, Pigford, and Wilke, 1975). An estimation of the dissolution rate of core debris in molten glass requires the following steps: (1) determination of properties of the glass, including composition; (2) determination of properties of the core debris, including composition; (3) estimation of diffusion coefficient for core debris in glass; (4) determination of the concentration near the surface; and (5) calculation of the mass transfer rate. Some information required for the estimate was assumed. Some assumptions are based on calculations which analyzed the thermal hydraulic behavior of a reference COMSORS system during Stage 2 operation (Appendix E).

Using standard mass transfer correlations and the reference system (Appendix F), the rate of core debris dissolution can be represented by:

$$
\mathrm{w}_{\mathrm{AB}}=\frac{1.77 \times 10^{-7} \mathrm{~L}^{1.5} \mathrm{~T} \Delta \mathrm{C}_{\mathrm{A}}\left(\phi v \mathrm{M}_{\mathrm{B}}\right)^{0.5} \rho_{\mathrm{B}}^{0.167}}{\mu_{\mathrm{B}}^{0.83} \mathrm{~V}_{\mathrm{A}}^{0.6}}
$$

where

$$
\Delta \mathrm{C}_{\mathrm{A}}=\mathrm{C}_{\mathrm{As}}-\mathrm{C}_{\mathrm{A \infty}},
$$

where

$$
\begin{aligned}
& \mathrm{w}_{\mathrm{AB}}=\text { mass transfer rate, } \mathrm{kg} / \mathrm{h} \text {; } \\
& \mathrm{L} \quad=\text { system length, } \mathrm{cm} \text {; } \\
& \mathrm{T}=\text { absolute temperature, } \mathrm{K} \text {; } \\
& \mathrm{C}_{\mathrm{A \omega}}=\text { concentration of solute } \mathrm{A} \text { far from the surface, in } \mathrm{gmol} / \mathrm{cm}^{3} \text {; } \\
& \mathrm{C}_{\mathrm{As}}=\text { concentration of solute } \mathrm{A} \text { (at saturation) near the surface, in } \mathrm{gmol} / \mathrm{cm}^{3} \text {; } \\
& \phi \quad=\text { association parameter of solvent } \mathrm{B} \text { (molten glass); } \\
& \mathrm{v}=\text { bulk velocity of solvent (liquid) } \mathrm{B} \text {, in } \mathrm{cm} / \mathrm{s} \text {; } \\
& \mathrm{M}_{\mathrm{B}} \text { = molecular weight of solvent } \mathrm{B} \text {; } \\
& \rho_{\mathrm{B}}=\text { density of solvent } \mathrm{B} \text {, in } \mathrm{g} / \mathrm{cm}^{3} \text {; } \\
& \mu_{B}=\text { viscosity of solvent } B \text {, in } g /(\mathrm{cm}-\mathrm{s}) \text {; and } \\
& \mathrm{V}_{\mathrm{A}}=\text { mole volume of the solute at its normal boiling point, in } \mathrm{cm}^{3} / \mathrm{g} \text {. }
\end{aligned}
$$

From this equation, the impact of various physical properties and some design parameters can be analyzed: 
- Effect of velocity on mass transfer rate. A design parameter is the bulk velocity of the molten glass. This velocity arises because of natural convection caused by thermal driving forces. Mass transfer is dependent on bulk velocity to only one-half power; therefore, this is not a strong influence on the total mass transfer rate.

- Effect of viscosity on mass transfer rate. The glass melt viscosity has a greater influence on mass transfer rate than does bulk velocity, but with an inverse effect.

- Effect of temperature on mass transfer rate. The temperature of the glass melt has a somewhat greater influence on mass transfer rate than viscosity with a linear relationship. Yet the temperature also directly affects the viscosity. Because of the inverse relationship of viscosity to temperature and mass transfer rate, an increase in $\mathrm{T}$ will cause an additional increase in $\mathrm{w}_{\mathrm{AB}}$ as the viscosity decreases. Increasing temperatures also increase natural convection, giving rise to an added increase in $w_{A B}$ as the bulk velocity increases with $T$. The effect of $T$ on core debris density and glass melt molar volume is probably not important by comparison.

The total impact of these parameters is that the hottest core debris dissolves first (Fig. 10). Temperatures near the core debris will rise unless decay heat is transported away. Until the core debris is dispersed, the nearby glass will tend to be at elevated temperatures, which will lower glass viscosities, increase natural circulation rates by the core debris and increases the solubility of core debris in glass. Hence, poor mass transfer conditions would seem to be somewhat self-correcting.

Equation (2) assumes that COMSORS is a monolithic glass cylinder with diameter L. However, other initial configurations may be used also to present a greater amount of surface area for mass transfer and proportionally increase the dissolution rate of core debris. Several other simple geometries were investigated that can increase the surface area by three orders of magnitude. More sophisticated geometries could increase the surface area by another order of magnitude. As an example, conversion of the same quantity of glass in the reference design to the equivalent of vertical slabs $5 \mathrm{~cm}$ in width and separated by $5 \mathrm{~cm}$ of empty space increases the surface area by a factor of 400 . Such geometries reduce the dissolution times far below the times required to heat the glass to the melting point under adiabatic conditions.

Many geometries are possible. One example is a stack of bricks. Stacked bricks are used in the steel and chemical industries for heat recovery from high-temperature operations. As off-gases are blown through stacked bricks, the bricks absorb heat. Air is then blown through the hot brick pile to preheat incoming air to the furnaces. Such designs have been used for decades; thus, methods for creating very robust brick stacks exist. An alternative geometry is hexagonal blocks with vertical holes. Such blocks would be geometrically similar to high-temperature, gas-cooled reactor fuel assemblies. This geometry, as a reactor fuel, has been designed to be very rugged and to have a high surface area for heat transfer. This rugged geometry would be applicable to COMSORS. A typical design of hexagonal block might have vertical holes 3 to $5 \mathrm{~cm}$ in diameter on a triangular spacing of 10 to $15 \mathrm{~cm}$. In all of these geometries, the core debris would initially freeze in the channels, reheat, and dissolve into the glass as the glass melted. Testing will be required to assure mixing and avoidance of softening before glass-core debris mixing. 


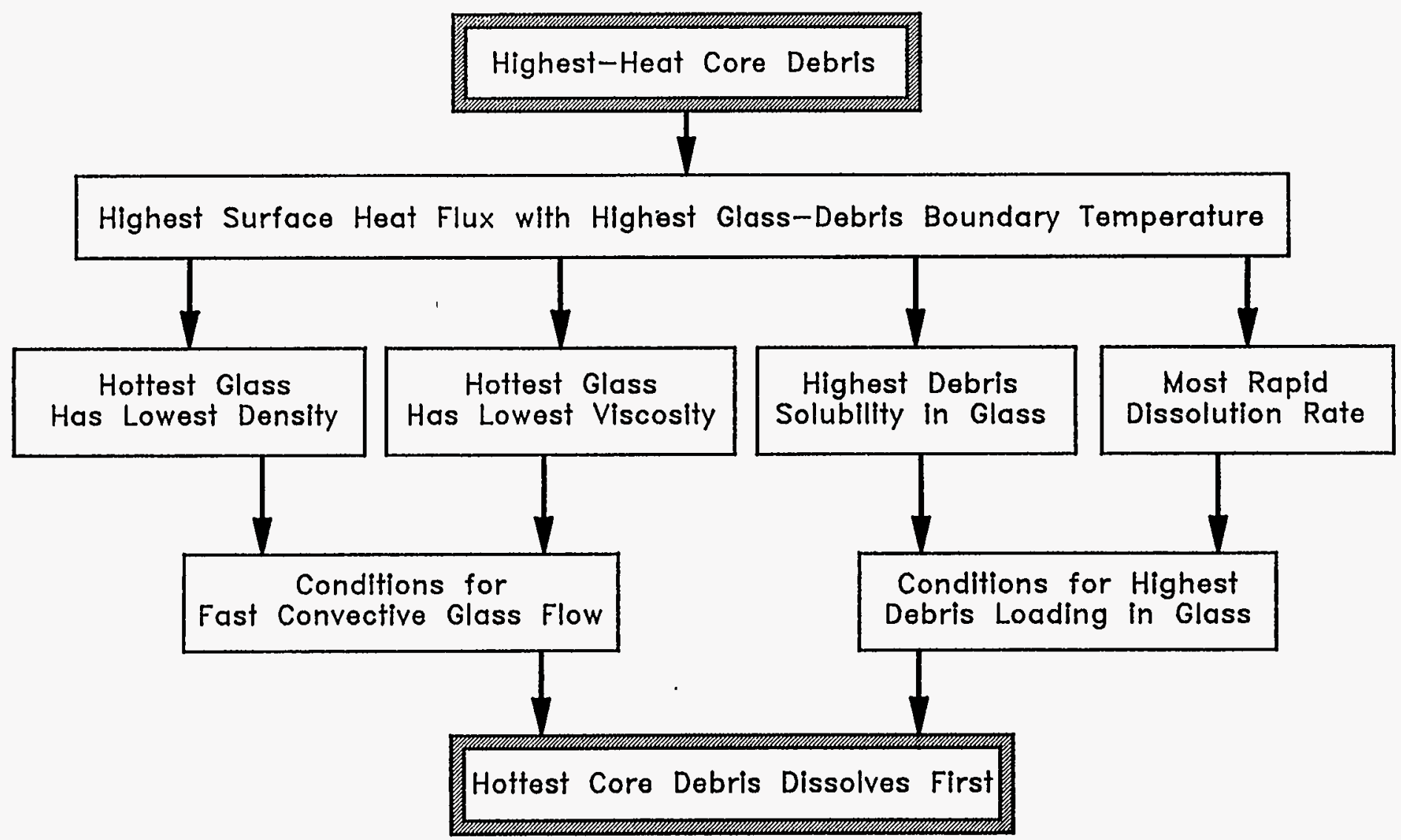

Fig. 10. Dissolution-of-core-debris logic. 
The disadvantage of these approaches is that the space requirements below the reactor vessel are increased.

\subsubsection{Engineering Solutions To Cool Lead}

The lead can also be cooled to provide more time for dissolution of the core debris. Cooling pipes from the containment suppression pools or a cooling annulus could cool the lead lying under the core debris. This type of cooling does not eliminate the threat of long-term core debris damage to the containment if the debris does not dissolve, but it does buy time (Appendix E). 


\section{OTHER CONSIDERATIONS}

\subsection{GLASS ISSUES}

The glass will have to be protected from water during normal operations. Leaching experiments in water have been conducted. During normal operations, the bottom of a containment may occasionally be exposed to spilled water. The $2 \mathrm{PbO}: \mathrm{B}_{2} \mathrm{O}_{3}$ glass slowly decomposed in water at a rate of $\sim 35 \mathrm{mg} \mathrm{cm} \mathrm{cm}^{-2} \cdot \mathrm{h}^{-1}$ based on 1- and 2-h tests. The decomposition products appeared to be soluble $\mathrm{B}_{2} \mathrm{O}_{3}$ and insoluble hydrated lead oxide. In contrast, the glass loaded with $\mathrm{UO}_{2}$ and $\mathrm{ZrO}_{2}$ appeared to be very insoluble in water. Such experiments suggest (a) that COMSORS glass will need to be sealed by a floor covering (steel plate) to avoid selective leaching (over a period of decades) of the $\mathrm{B}_{2} \mathrm{O}_{3}$ from the glass or (b) that the glass composition will need to be modified to reduce solubility. If the glass remains uncontaminated, it can be recycled for feedstock in the glass or battery industries.

\subsection{INSULATION}

COMSORS requires insulation between the concrete and the glass. Given sufficient time, all ceramics will dissolve into the glass. Very high-fired alumina ceramics have low dissolution rates. The bottom is protected by the lead. If passive cooling is used in the walls, wall corrosion is prevented by the frozen layer of glass that is formed or by the very low corrosion rates at low temperatures.

\subsection{RELATED TECHNOLOGIES}

COMSORS is a new technology, but there are related technologies that are, to various degrees, well developed. These provide some of the technology and understanding required for development of COMSORS (Appendix G). For example:

- Borax core catcher. Developmental work was performed on a borax core-catcher for 1000-MW(e) [2700-MW(th)] gas-cooled fast reactors in Germany (Dalle-Donne, 1978) in the 1970s. This was a chemical core catcher. Borax $\left(\mathrm{Na}_{2} \mathrm{~B}_{4} \mathrm{O}_{9}\right)$ was placed under the reactor vessel. In a core melt accident, the core debris reacted with the borax. The oxides dissolved into the borax, and a separate molten layer of metal was formed under the molten borax. Some integral experiments were performed. This system was designed for stainless steel clad fuel.

- HLW vitrification. In the last 20 years, more than a billion dollars have been spent to develop glass melters to solidify radioactive HLW. Many of these melters dissolve fission products into molten glass with the HLW feed as an aqueous slurry to the melter. The glass is heated internally by passing electricity through it. This process results in a configuration similar to COMSORS: water on top of molten glass with an internally generated heat source. Heat transfer correlations and other integral data are applicable to COMSORS. 
Much of the HLW vitrification technology is directly applicable to COMSORS. Tests in glass melters have shown that up to $600 \mathrm{~kW} / \mathrm{m}^{2}$ can be transferred from molten glass to water (Mahoney, 1986). This is about five times the maximum heat flux from glass to water for the reference COMSORS design. Other experimental and analytical programs (Hutchenson, 1983) have evaluated the potential for steam explosions and other highly energetic events and have indicated that this is not a major concern for water-glass systems.

- Chernobyl. During the Chernobyl nuclear power accident, large quantities of sand, borax, and lead were dropped from the air onto the top of the burning reactor to help contain the accident. The materials are similar to those proposed for COMSORS. Recent investigations at Chernobyl indicate that much of the material was converted to a glassy waste form and flowed from the reactor cavity to lower levels in the plant where it solidified.

- Glass Material Oxidation and Dissolution System (GMODS). The basic chemistry of COMSORS is the basis for a new radioactive and hazardous chemical waste treatment process to convert complex waste mixtures to glass for safe disposal. The treatment process is called GMODS. It is designed to (1) convert metals, ceramics, and amorphous solids to borosilicate glass; (2) convert halogens to a low-halogen borosilicate glass and a secondary clean sodium-halide stream; and (3) oxidize organics with the residue converted to borosilicate glass. Development work on GMODS provides additional data on chemical reaction rates that are applicable to COMSORS.

\subsection{NUCLEAR CRITICALITY}

In some core melt accident scenarios, nuclear criticality is a concern. COMSORS eliminates these concerns by dissolving the core debris into a borate glass. Boron has a very high neutron cross section and will prevent nuclear criticality.

\subsection{ECONOMICS}

No detailed economic analysis has been done. Costs are strongly dependent upon the general containment design. The raw material costs for COMSORS are low. Lead metal costs $\sim \$ 1000 /$ ton. Boron oxide is less expensive than lead.

\subsection{POST ACCIDENT RECOVERY}

COMSORS creates a glass that should simplify any post-accident cleanup operations. The material would be expected to be convertible to a quality HLW glass. 


\section{STATUS OF DEVELOPMENT}

COMSORS is a new system. Some characteristics of the system have been demonstrated. However, uncertainties exist concerning other aspects of performance. The COMSORS chemistry is proven. Thermodynamic calculations, literature data, and experiments show (1) oxides in core debris will dissolve into the glass and (2) metals will be oxidized and then dissolved into the glass.

There is reasonable confidence in the steady-state performance (Stage 2) of COMSORS. During quasisteady-state operation, the core debris is dissolved in the molten glass, the molten glass floats on the molten lead, and the molten glass is cooled by the overlying water. Performance is measured by the maximum temperature of the glass. The glass temperature is calculated to be $<600^{\circ} \mathrm{C}$ with $<1 \mathrm{~kW} / \mathrm{m}^{2}$ downward heat flux to the containment floor. Under these conditions, containment integrity can be assured. It is noted that with current insulation materials, glass temperatures as high as $1000^{\circ} \mathrm{C}$ could be tolerated.

However, uncertainties are associated with these calculations. Many physical properties were derived from limited experimental measurements, and several physical properties (thermal conductivity) were estimated based on extrapolation of physical properties from related systems. The compensating factor is that in this system, there are very strong temperature feedback mechanisms (thermal conductivity, heat transfer by natural convection of molten glass) that imply large uncertainties in physical property values translate into only small increases in the maximum molten glass temperature. Additional experimental physical property measurements would provide higher confidence in the results.

Reasonable confidence exists in the initial (Stage 1) performance of COMSORS for some accident scenarios, but insufficient data exist to have confidence in COMSORS' performance for other accident scenarios. If there were a hot, rapid discharge of core debris onto COMSORS, the debris would (a) be dispersed between the glass blocks, (b) oxidize and dissolve rapidly into the glass, and (c) proceed to a steady-state system. There are, however, many possible core melt scenarios. The question is: Will the system prevent containment damage for all likely scenarios? To address these questions, the following additional work is required:

- A full range of core melt scenarios must be developed.

- Chemical reaction rates must be measured for a wide variety of chemical compositions and temperatures to better estimate debris dissolution times. A particular need exists to measure oxide dissolution rates as a function of temperature. Indications (but not proof) are that the dissolution rate accelerates rapidly as temperatures rise. These rates may be sufficiently fast such as to eliminate many uncertainties. 
- Models of COMSORS performance vs design details (internal brick surface area, added lead between blocks, depth of glass) must be developed.

- Small pourings of simulated core debris into glass blocks are required to confirm dissolution behavior in integral tests.

The work, to date, provides confidence in the feasibility of COMSORS. The uncertainties, however, require that significantly more glass would be required for its construction than may actually be necessary. There is one desirable characteristic of these uncertainties. They may be resolved with small laboratory experiments and models. In this context, COMSORS is fundamentally different from other core catcher concepts. This is a direct result of the fact that it is a chemical process rather than a mechanical device. Chemical processes can be scaled from small experiments to large systems, while most mechanical systems are not amenable to such scaling. 


\section{CONCLUSIONS}

COMSORS is a new concept to terminate core-melt accidents in ALWRs. Initial small-scale scoping experiments, preliminary analysis, and experimental data from other sources (HLW glass melters, Chernobyl, etc.) support its feasibility. COMSORS uses an alternative approach to terminate a core-melt accident: dissolve the core debris into glass to create a coolable mass of material with known geometry and physical properties. The initial work indicates that the concept is feasible, but there are significant uncertainties. Added analytical and experimental work is required to provide high confidence in the concept, to optimize the design, and to address engineering issues. 



\section{REFERENCES}

Castle, J. N., I. Catton, J. L. Dooley, W. E. Kastenberg, and E. Swanson, 1984. Survey of the State of the Art in Mitigation Systems, NUREG/CR-3908, U.S. Nuclear Regulatory Commission, Washington, D.C.

Dalle-Donne, M. D., S. Dorner, and G. Schumacher, 1978, "Development Work for a Borax Internal CoreCatcher for Gas-Cooled Fast Reactor," Nucl. Tech. 39,138.

Electric Power Research Institute, 1990, Advanced Light-Water Reactor Requirements Documents:

Vol. III-Utility Requirements for Passive Plants, Electric Power Research Institute, Palo Alto, California.

Forsberg, C. W., E. C. Beahm, and G. W. Parker, April 25, 1995. "Reactor Accident Meltdown Limit and Control System,"U.S. Patent 5,410,577.

Gardon, R., 1961. “A Review of Radiant Heat Transfer in Glass,” J. Am. Ceramic Soc., 44:305-12.

Hutcherson, M. N., H. K. Fanske, R. E. Henry, and T. J. Marciniak, 1983, Assessment of the Potential and Consequences of a Hypothetical Steam Explosion in the Defense Waste Processing Facility Glass Melter, FAI/83-8, Fauske \& Associates, Inc., Burr Ridge, Illinois.

Mahoney, L. J., 1986, "Pilot Plant Demonstration of the Defense Waste Processing Facility (DWPF) Melter Concepts," Spectrum, pp. 746, American Nuclear Society, La Grange Park, Illinois.

Parker, G. W., L. J. Ott, and S. A. Hodge, 1990. "Small-Scale BWR Core Debris Eutectics Formation and Melting Experiment,"Nuclear Engineering Design, 121,341.

Sehgal, B. R. and B. W. Spencer, 1992. "ACE Program Phase D: Melt Attack and Coolability Experiments (MACE) Program," presented at the CSARP Meeting, Washington, D.C.

Sherwood, T. K., R. L. Pigford, and C. R. Wilke, 1975. Chapters 2 and 3 in Mass Transfer, McGraw-Hill, New York.

Welty, J. R. C. E. Wicks, and R. E. Wilson, 1969. Chapters 24, 28, and 30 in Fundamentals of Momentum, Heat, and Mass Transfer, John Wiley \& Sons, Inc., New York.

Wilke, C. R. and P. Chang, 1995. AIChE J., 1,264. 

Appendix A:

DESIGN OPTIONS 

Many design options for COMSORS are possible, but only a few have been examined. Several of these are discussed in the following.

\section{A.1 DEBRIS DISSOLUTION RATES AND BRICK PATTERNS}

COMSORS can be built from glass bricks with the surface protected from water. The design of the bricks and their layout will determine the surface area for debris dissolution. Previous chemical and mechanical engineering experience can guide those designing the facility.

In the steel industry, brick recouperators are used to recover heat during steel-making operations. Hot furnace gasses are sent through the large brick piles. The bricks absorb the heat. When the brick becomes hot, air is sent through the bricks in the opposite direction to be preheated before being fed to the blast furnaces. In this application, the bricks must withstand thermal and mechanical stresses while efficiently recovering heat. The experience base since the mid-1800s provides an empirical knowledge on brick patterns that are mechanically robust.

In the chemical industry, similar brick systems are used to recover heat from hazardous off-gases while the gasses chemically react on the catalytic surfaces of the brick. The brick patterns must be designed for efficient chemical reactions and heat transfer.

Glass block designs can also include flow channels inside sealed glass blocks. In such cases, hot core debris would melt the thin walls in the glass blocks and flow through the brick structure. Such designs may assure surface area within the blocks is reserved only for dissolution of hot core debris and does not fill with other debris.

\section{A.2 PREVENTION OF CORE DEBRIS INTO GLASS AND LEAD}

The option exists to include lead metal in the COMSORS design. Lead provides additional barriers to the penetration of COMSORS by hot core debris early in an accident. No detailed investigations of this option have been performed.

\section{A.3 COOLING OF CONTAINMENT FLOOR}

The containment floor can be cooled with a variety of passive cooling systems because of the very low downward heat flux. There is also the option to cool the molten lead with natural circulation water flow from the suppression pool to the lead and back to the suppression pool. The layer of molten lead provides a mechanism to remove heat from across the bottom of the entire containment above the floor level. 

Appendix: B

PHYSICAL AND CHEMICAL PROPERTIES 



\section{B.1 LITERATURE DATA}

Limited information exists within the technical literature on the lead borate system and related systems. Phase diagrams and other relevant information (Figs. B.1-B.3) are included herein. The following references includes other articles that discuss the lead borate and related systems.

Khalifa, F. A., Z. A. El-Hadi, F. A. Moustaffa, and N. A. Hassan, June 1989. Indian Journal of Applied Physics, 27,279.

Geller, R. F. and E. M. Bunting, 1937. J. Research National Bureau of Standards 18(5),585. 


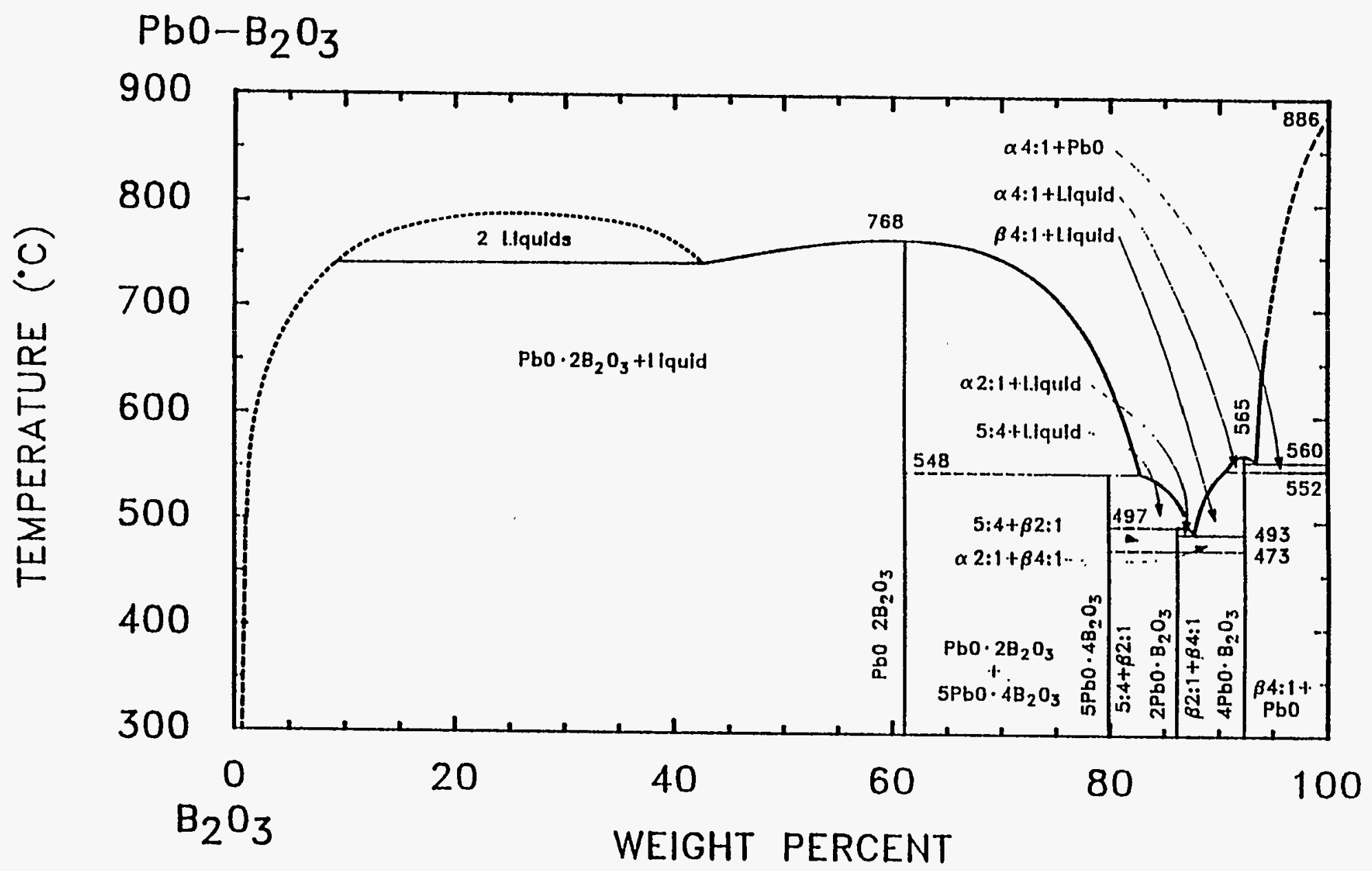

Fig. B.1. Boron oxide-lead oxide phase diagram. 


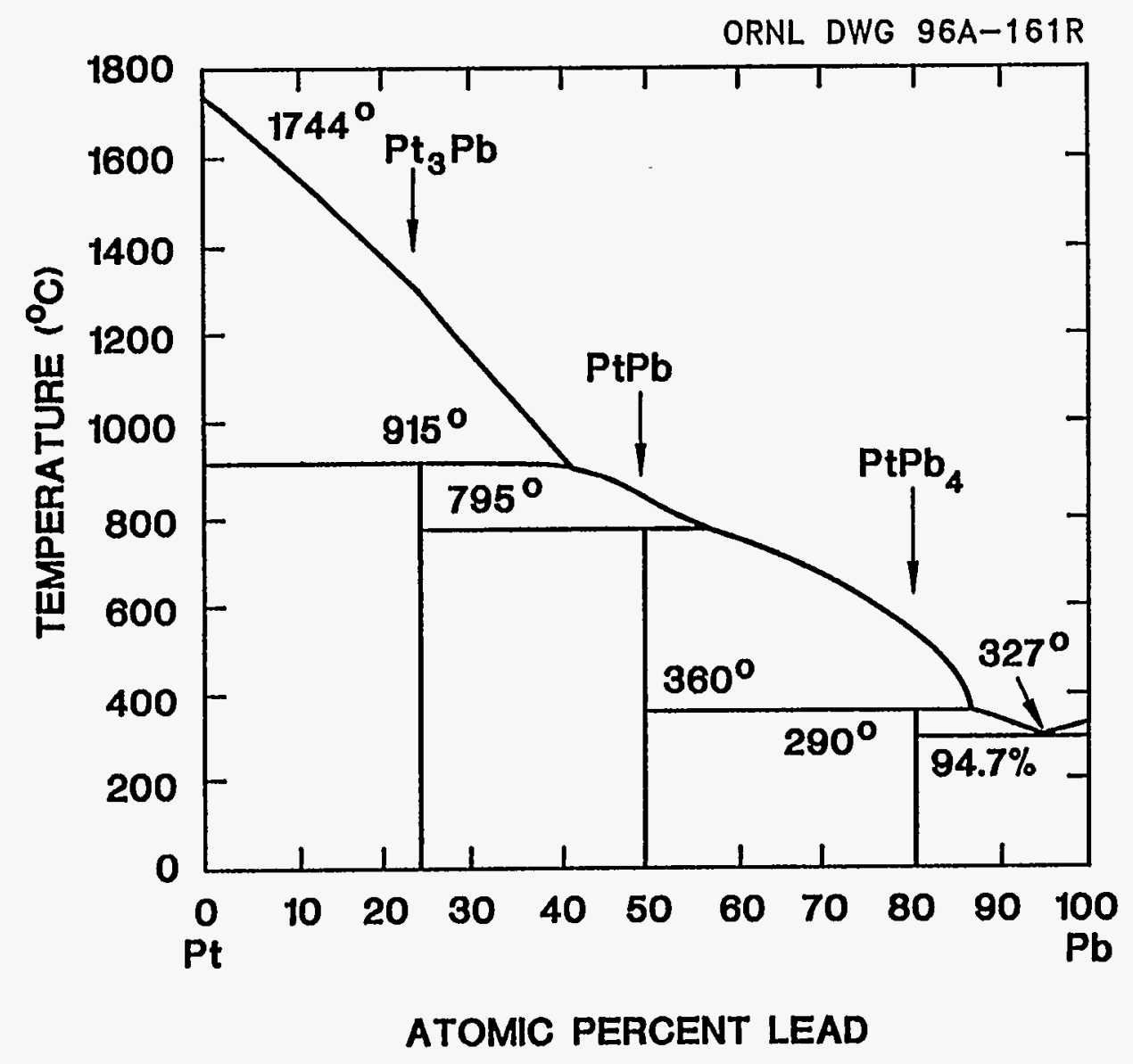

Fig. B.2. Platinum-lead phase diagram. 


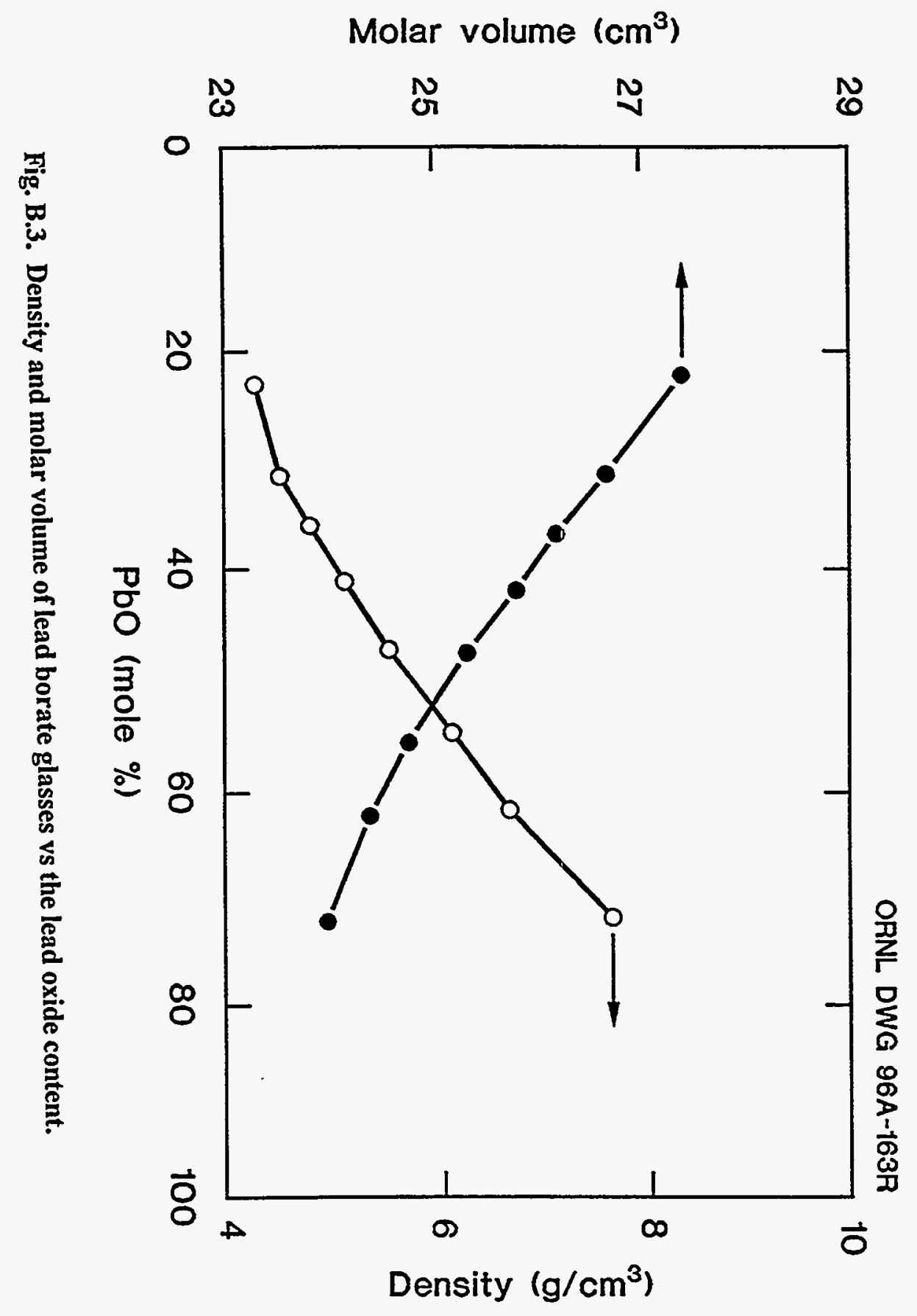


Appendix C:

THERMODYNAMICS 


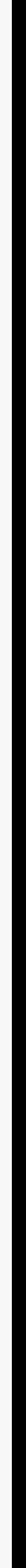




\section{C.1 THE PbO- $\mathrm{B}_{2} \mathrm{O}_{3}$ SYSTEM}

The thermochemical properties of the $\mathrm{PbO}-\mathrm{B}_{2} \mathrm{O}_{3}$ system are the basis for COMSORS. The capabilities to oxidize metals and to dissolve metal oxides are directly related to the thermochemical activity of $\mathrm{PbO}$ and $\mathrm{B}_{2} \mathrm{O}_{3}$. This system was assessed by Slough and Jones (August 1974). These authors used the Gibbs energy values reported by Kapoor and Frohberg (1973). In this work, we also have used the data of the latter authors.

This system shows negative deviation from ideality. In other words, the thermodynamic activities of $\mathrm{PbO}$ and $\mathrm{B}_{2} \mathrm{O}_{3}$ will be less than those in an ideal system. This means that $\mathrm{PbO}$ and $\mathrm{B}_{2} \mathrm{O}_{3}$ interact probably in an acid $\left(\mathrm{B}_{2} \mathrm{O}_{3}\right)$ and base $(\mathrm{PbO})$ reaction (Kapoor and Frohberg, 1974):

$$
-B-O-B+O^{-2} \neq 2\left[-B-O^{-}\right] .
$$

In this reaction, $\mathrm{O}^{-2}$ from the $\mathrm{PbO}$ is the "Lux-Flood" base, and the boron group is the acid.

The thermodynamic activity of $\mathrm{PbO}$ is the key parameter in determining whether a metal will be oxidized in COMSORS. Kapoor and Frohberg (1974) expressed the activity of $\mathrm{PbO}$ at $1000^{\circ} \mathrm{C}$ by the following equations:

$$
a_{\mathrm{PbO}}=\mathrm{N}_{\mathrm{PbO}}\left(1+2 \mathrm{~N}_{\mathrm{B}_{2} \mathrm{O}_{3}}\right) \frac{\left[1+\frac{\mathrm{F}-2}{\mathrm{~F}-1} \mathrm{~N}_{\mathrm{B}_{2} \mathrm{O}_{3}}\right]^{\mathrm{F}-1}}{\left(1+\mathrm{N}_{\mathrm{B}_{2} \mathrm{O}_{3}}\right)^{\mathrm{F}+1}} \text {, }
$$

and

$$
\mathrm{F}=1.0005\left(\frac{1+2 \mathrm{~N}_{\mathrm{B}_{2} \mathrm{O}_{3}}}{1+\mathrm{N}_{\mathrm{B}_{2} \mathrm{O}_{3}}}\right) \text {, }
$$

where $\mathrm{a}_{\mathrm{PbO}}$ is the activity of $\mathrm{PbO} ; \mathrm{N}_{\mathrm{PbO}}$, and $\mathrm{N}_{\mathrm{B}_{2} \mathrm{O}_{3}}$ are the mole fractions of $\mathrm{PbO}$ and $\mathrm{B}_{2} \mathrm{O}_{3}$, respectively. The $\mathrm{F}$ in these equations is the ratio of anionic to cationic sites in the structure. Table $\mathrm{C} .1$ lists activities for some $\mathrm{PbO}-\mathrm{B}_{2} \mathrm{O}_{3}$ compositions that were calculated from these equations, and Fig. $\mathrm{C} .1$ is reproduced from Kapoor and Frohberg (1974). 
Table C.1. Calculated $\mathrm{PbO}$ activities at $1000^{\circ} \mathrm{C}$

\begin{tabular}{cc}
\hline Composition & $a_{\mathrm{PbO}}$ \\
\hline $\mathrm{N}_{\mathrm{B}_{2} \mathrm{O}_{3}}=0.762$ & $1.2 \times 10^{-2}$ \\
$\mathrm{~N}_{\mathrm{PbO}}=0.238$ & \\
$(50$ wt $\%)$ & \\
$\mathrm{N}_{\mathrm{B}_{2} \mathrm{O}_{3}}=0.500$ & $5.6 \times 10^{-2}$ \\
$\mathrm{~N}_{\mathrm{PbO}}=0.500$ & \\
$\mathrm{~N}_{\mathrm{B}_{2} \mathrm{O}_{3}}=0.33$ & \\
$\mathrm{~N}_{\mathrm{PbO}}=0.67$ & \\
& \\
$\mathrm{~N}_{\mathrm{B}_{2} \mathrm{O}_{3}}=0.25$ & $2.4 \times 10^{-1}$ \\
$\mathrm{~N}_{\mathrm{PbO}}=0.75$ & \\
\hline
\end{tabular}

It is likely that COMSORS would be operated in the composition region where the activity of $\mathrm{PbO}$ would be $\sim 0.1$ to 0.2. At a composition of $\mathrm{N}_{\mathrm{PbO}} \approx 0.64$ and $\mathrm{N}_{\mathrm{B}_{2} \mathrm{O}_{3}} \approx 0.36, \mathrm{a}_{\mathrm{PbO}}=\mathrm{a}_{\mathrm{B}_{2} \mathrm{O}_{3}}=0.12$. The composition can be adjusted to suit the type of core debris [pressurized-water reactor (PWR) or boiling-water reactor]. In general, higher values of $\mathrm{a}_{\mathrm{PbO}}$ would enhance the oxidation process, and higher values of $\mathrm{a}_{\mathrm{B}_{2} \mathrm{O}_{3}}$ would enhance the formation of borates.

Table C. 2 lists calculated $\mathrm{PbO}$ partial pressures when $\mathrm{a}_{\mathrm{PbO}}=0.1$ and 0.2 , respectively. The partial pressures of $\mathrm{B}_{2} \mathrm{O}_{3}$ will be several orders of magnitude lower than those of $\mathrm{PbO}$.

\section{C.2 OXIDATION OF METALS BY PbO}

The processing of metals in COMSORS involves both oxidation and dissolution into a $\mathrm{PbO}-\mathrm{B}_{2} \mathrm{O}_{3}$ glass. The overall free energy change for the process will include the free energy change for the oxidation plus the free energy change for the dissolution. The final dissolution product will be at least a ternary system involving $\mathrm{PbO}-\mathrm{B}_{2} \mathrm{O}_{3}$-metal oxide. No data are available about such systems on which to base a calculation on the distribution of species for the entire process. It may be possible to perform calculations on ternary and higher systems using thermodymamic solution models. Until that work is done, the best guide to treatability of a material by COMSORS is the oxidation of the metal by $\mathrm{PbO}$. 
ORNL DWG 94A-657

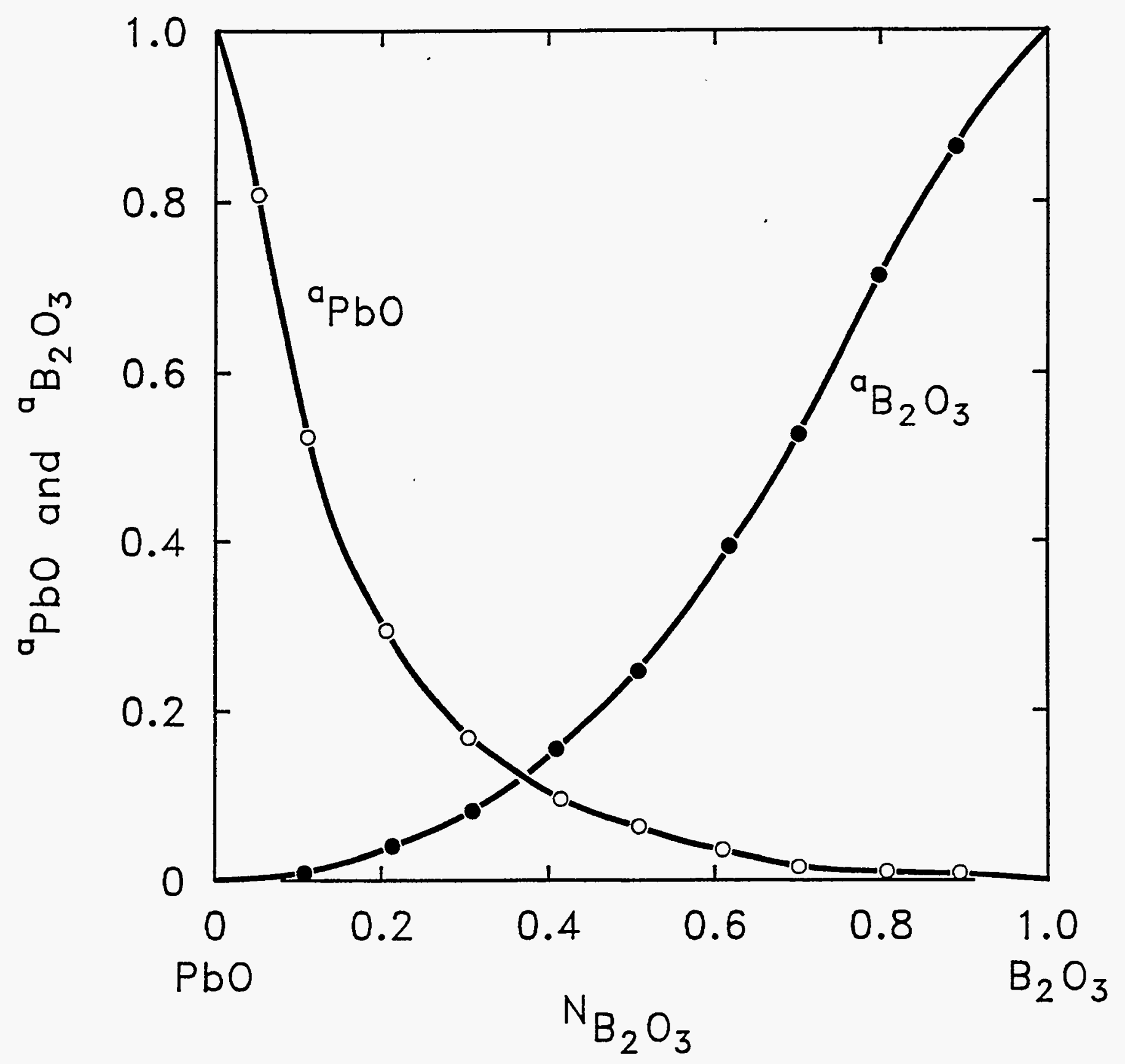

Fig. C.1. Activity coefficients of $\mathrm{PbO}$ and $\mathrm{B}_{2} \mathrm{O}_{3}$ vs mole fraction. 
Table C.2. Vapor pressure of $\mathrm{PbO}$ in $\mathrm{PbO}-\mathrm{B}_{2} \mathrm{O}_{3}$ system $^{2}$

\begin{tabular}{ccc}
\hline & \multicolumn{2}{c}{$\mathbf{P}_{\mathbf{P b O}}(\mathrm{atm})$} \\
\cline { 2 - 3 } Temperature & & \\
$\left(^{\circ} \mathrm{C}\right)$ & ${\text { At } \mathbf{a}_{\mathbf{P b O}}=\mathbf{0 . 1}}$ & At $\mathbf{a}_{\mathbf{P b O}}=\mathbf{0 . 2}$ \\
\hline 800 & $2.9 \times 10^{-7}$ & $5.9 \times 10^{-7}$ \\
900 & $3.9 \times 10^{-6}$ & $7.8 \times 10^{-6}$ \\
1000 & $2.8 \times 10^{-5}$ & $5.6 \times 10^{-5}$ \\
1100 & $1.5 \times 10^{-4}$ & $3.0 \times 10^{-4}$ \\
1200 & $6.3 \times 10^{-4}$ & $1.3 \times 10^{-3}$ \\
\hline
\end{tabular}

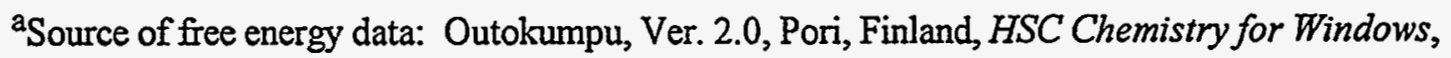
May 1994.

Oxidation of metals will result in oxides that have different metal:oxygen ratios (i.e., $2: 3$ in $\mathrm{Al}_{2} \mathrm{O}_{3}, 1: 2$ in $\mathrm{PuO}_{2}$ ). The best way to compare the relative ease of oxidizing a given metal is to use oxygen potentials. Oxygen potential has a unit of energy and is defined as $\mathrm{RT} \ln \mathrm{P}_{2}$. A single example will show what is meant by oxygen potential and how they are used. Consider the oxidation of $\mathrm{Al}$ :

$$
2 \mathrm{Al}+3 / 2 \mathrm{O}_{2}=\mathrm{Al}_{2} \mathrm{O}_{3}
$$

The overall free energy change for this reaction, $\Delta \mathrm{G}_{\mathrm{T}}^{\circ}$, can be written as:

$$
\Delta \mathrm{G}_{\mathrm{T}}^{0}=-\mathrm{RT} \ln \frac{1}{\mathrm{P}_{\mathrm{O}_{2}^{3 / 2}}}=3 / 2 \mathrm{RT} \ln \mathrm{P}_{\mathrm{O}_{2}}
$$

or

$$
\mathrm{RT} \ln \mathrm{P}_{\mathrm{O}_{2}}=2 / 3 \Delta \mathrm{G}_{\mathrm{T}}^{\circ}
$$


Note that the stoichiometric factor for $\mathrm{O}_{2}$ is accounted for in calculating $\mathrm{RT} \ln \mathrm{P}_{2}$, the oxygen potential. Figure C.2 shows plots of oxygen potentials for forming a number of metal oxides. This type of figure has the important feature that any metal oxide that is higher than another can oxidize the metal in a lower position. Here, we are concerned about the ability of $\mathrm{PbO}$ to oxidize metals. Figure $\mathrm{C} .2$ shows that any metal, $\mathrm{Zn}, \mathrm{Cr}, \mathrm{U}, \mathrm{Pu}, \mathrm{Al}$, etc., that lies below the $\mathrm{PbO}: \mathrm{a}_{\mathrm{PbO}}=0.1$ line will be oxidized when the activity of $\mathrm{PbO}$ is 0.1 . In this figure, only $\mathrm{Cu}_{2} \mathrm{O}$ lies above the $\mathrm{PbO}$ lines. However, $\mathrm{Zhou}$ et al. (1993) have shown that copper in the +2 oxidation state, as in $\mathrm{CuO}$, is stable in $2 \mathrm{PbO}^{-} \mathrm{B}_{2} \mathrm{O}_{3}$ glass. The stability of oxidized copper in this glass must be due to the combination of oxidation and dissolution and not oxidation alone. Other metals, such as $\mathrm{Ag}, \mathrm{Au}, \mathrm{Pt}$, and $\mathrm{Pd}$, do not form oxides that are stable at high temperatures and they are not included here. Ruthenium will not be oxidized by $\mathrm{PbO}$, thus avoiding the volatile $\mathrm{RuO}_{4}$. The oxygen potentials for the formation of $\mathrm{ZrO}_{2}$ are similar to those of $\mathrm{Al}_{2} \mathrm{O}_{3}$.

Some metals, such as $\mathrm{U}$ and $\mathrm{Pu}$, have more than one oxide that may form. The highest oxide of $\mathrm{Pu}$, $\mathrm{PuO}_{2}$, is thermodynamically stable as far as oxidation is concerned. However, the overall oxidation and dissolution may result in a lower oxide in the borate glass.

\section{C.3 DISSOLUTION OF METALS IN Pb}

In a COMSORS-core melt event, metals may dissolve in molten $\mathrm{Pb}$. Figure C.3 shows the platinum-lead $(\mathrm{Pt}-\mathrm{Pb}$ ) phase diagram. At temperatures expected in COMSORS, there is an extensive $\mathrm{Pt}$ solubility in $\mathrm{Pb}$ in a liquid phase (Hansen and Anderko, 1958). However, other metals have very limited solubilities in $\mathrm{Pb}$.

Molybdenum solubility in lead is only $\sim 10^{-5}$ at. \% at $1000^{\circ} \mathrm{C}$ (Brewer, 1980); and iron, $8.5 \times 10^{-4}$ at. \% at $600^{\circ} \mathrm{C}$ (Weeks, 1963). The solubility of zirconium in lead has not been studied, but on the zirconium-rich side of this system, lead dissolves to at least 14.5 at. \%, and zirconium and lead form intermetallic compounds (Alcock, 1976).

\section{C.4 HEAT CAPACITY}

Heat capacity can be estimated from thermodynamic data already available. An estimate for heat capacity of $2: 1 \mathrm{PbO}: \mathrm{B}_{2} \mathrm{O}_{3}$ at $1000^{\circ} \mathrm{C}$ is:

$$
65.25 \pm 4.5 \mathrm{cal} / \mathrm{K} \cdot \mathrm{mol}
$$

This same estimating scheme could be made over a larger temperature range, if necessary. 
ORNL DWG 95A-489

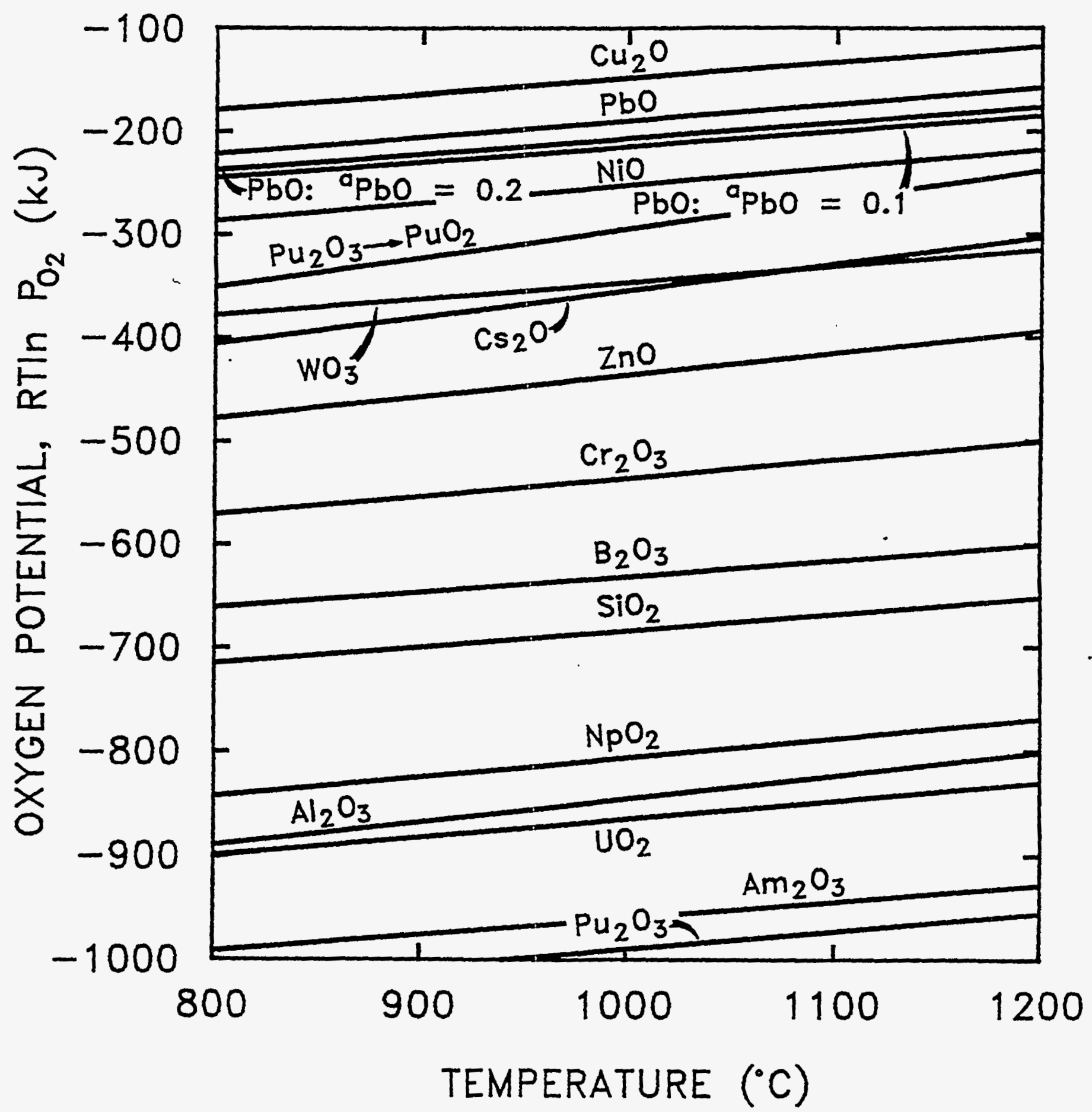

Fig. C.2. Oxygen-potential diagram. 


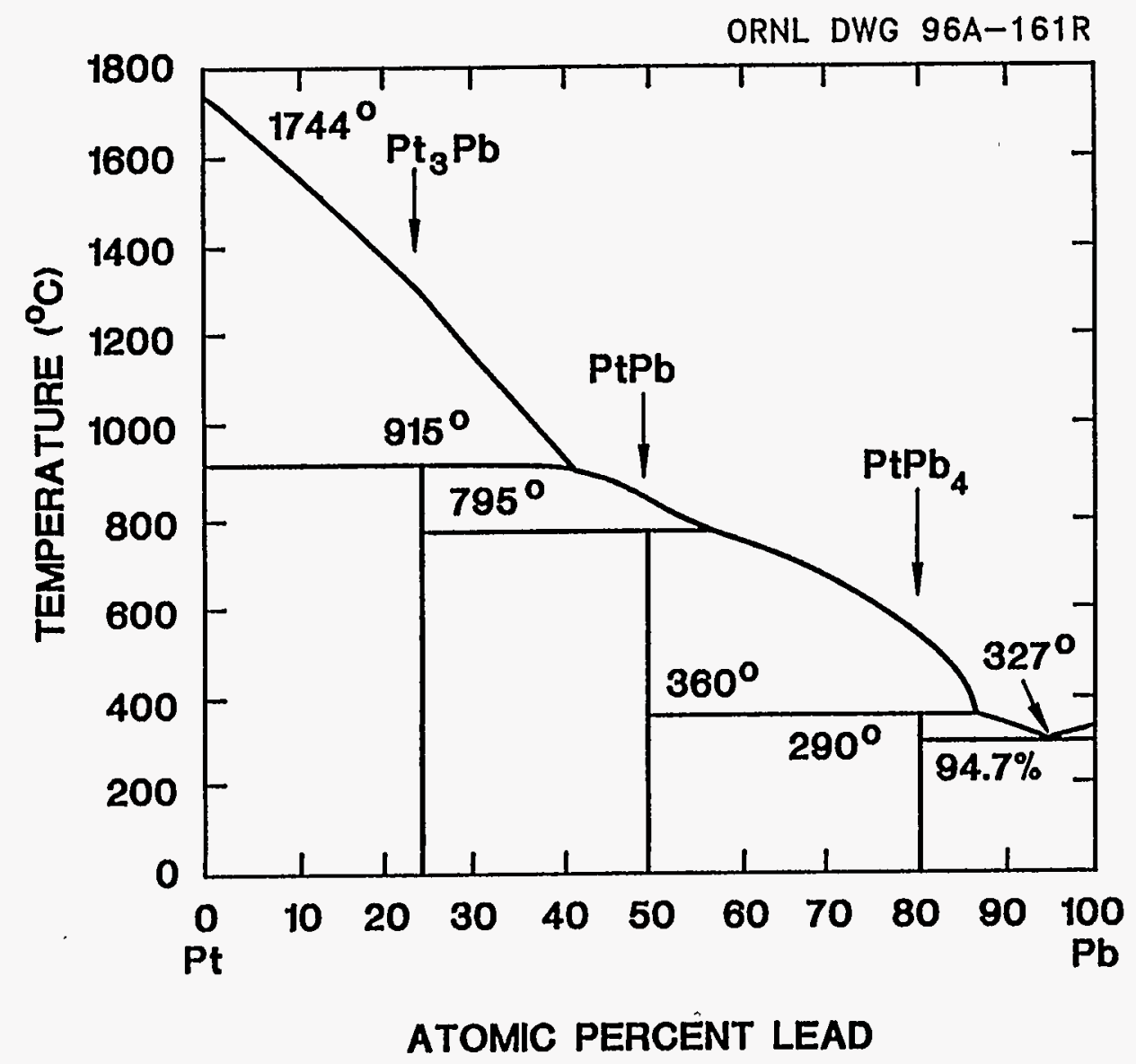

Fig. C.3. Platinum-lead phase diagram (Hansen, 1958). 


\section{C.5 REFERENCES}

Alcock, C. B., et al., 1976. Atomic Energy Review, Special Issue No. 6 (Zirconium: Physico-Chemical Properties of Its Compounds and Alloys), International Atomic Energy Agency, Vienna.

Brewer, L. and R. H. Lamoreaux, 1980. Atomic Energy Review, Special Issue No. 7 (Molybdenum:

Physico-Chemical Properties of Its Compounds and Alloys), International Atomic Energy Agency, Vienna.

Hansen, M. and K. Anderko, 1958. Constitution of Binary Alloys, McGraw-Hill, New York.

Kapoor, M. L., and M. G. Frohberg, 1973. "Thermodynamic Properties of the System $\mathrm{PbO}-\mathrm{B}_{2} \mathrm{O}_{3}$," Can. Met. Quarterly, 12(2), 137.

Outokumpu, May 1994. HSC Chemistry for Windows, Version 2.0, Pori, Finland.

Slough, W., and G. P. Jones, August 1974. "A Compilation of Thermodynamic Data for Borate Systems," Chem. 31.

Weeks, J. R, 1963. NASA Special Publication, NASA-5P-41, Washington, D.C.

Wood, D. H., E. M. Cramer, P. L. Wallace, and W. J. Ramsey, 1969. "Phase Relations in the PlutoniumLead System," J. Nucl. Mater. 32, 193.

Zhou, Z., A. Navrotsky, and D. S. McClure, "Oxidation States of Copper in Lead Borate Glass," Phys. Chem. Glasses, 34(6), 251 (1993). 
Appendix D:

EXPERIMENTAL DATA 



\section{D.1 INTRODUCTION}

This appendix presents a summary of the experimental data collected on the lead borate system that are applicable to COMSORS. These include information collected for the COMSORS program and information generated for other programs.

The COMSORS experiments are designed to answer the questions presented herein. Note that the characteristics of lead borosilicate glass (fine dinner crystal) and borosilicate glass (laboratory glassware and HLW glass) are reasonably well known over wide ranges of chemical compositions. This knowledge provides a basis for understanding the lead borate system. The experimental questions are:

- What are the solubilities of different oxides in lead borate glass as a function of chemical composition and temperature?

- Higher solubilities minimize glass requirements for COMSORS. Reasonable oxide solubilities are required for practical systems.

- Under what conditions (temperature and composition) will metals react and dissolve into lead borate glasses?

- Thermodynamics studies clearly show that most metals (except noble metals) will react with a lead borate glass. Practical dissolution systems require reasonably fast kinetics that, in turn, require the avoidance of formation of passivating oxide layers on the metal surfaces in the glass. Dissolution depends upon chemical composition.

- What are the viscosities of lead borate systems as a function of temperature and chemical compositions?

- Low glass viscosities are required for good heat transfer within COMSORS. Maximum loading of core debris in the glass is desired. Higher core debris loadings increase system viscosities; thus, there is a trade-off between waste loading and low viscosities.

- What are the reaction rates for each chemical reaction?

- Chemical reaction rates may be limited by local kinetics or mass transfer. With high-temperature systems, mass transfer (mixing) is usually limiting, but this must be shown. Rapid kinetics ensures rapid core debris dissolution and avoidance of high temperature lead.

These questions have been addressed in proof-of-principle experiments over a limited range of conditions. More complete answers will require experimental measurements over a wider range of chemical compositions and temperatures. The order of performing the experiments depended partly upon the sequence of key questions listed above and the available experimental apparatus. In some cases, certain sets of experiments were performed together because the same equipment could be used to obtain multiple sets of information. 


\section{D.2 EXPERIMENTAL METHODS}

The methods used are typical of those used by glass-industry experimentalists in that most of the work required the use of platinum ware in place of ceramics. Weighed amounts of powder mixes of $\mathrm{PbO}$ and boric oxide $\left(\mathrm{B}_{2} \mathrm{O}_{3}\right)$ in the whole-number ratios of $1: 2$ up to $4: 1$ gmol of $\mathrm{PbO}: \mathrm{B}_{2} \mathrm{O}_{3}$ are mixed and poured into a standard 3-in. high by 2.75 -in. wide crucible, the crucible, which is placed in a vertical quartz thimble being heated in an open-top nichrome furnace with standard chromal thermocouple controls (Fig. D.1). A platinum-rhodium thermocouple is used inside the crucible to follow the temperature of the melt. Through the open top, the melt is stirred frequently with an extended platinum rod, which is then withdrawn from the furnace to avoid the oxidation of the extension material above the platinum. An open-top furnace thimble is normally used for all oxide melts; however, a closed system is available for oxidizable compositions such as added metals. When the melt is judged completely homogeneously melted, the crucible is retrieved with surgical tongs and is tilted, and the melt is poured into a platinum dish (Fig. D.2). This procedure is duplicated when solubility studies are made with added oxides, such as those of alumina, zirconia, ceria, magnesia, and uranium.

After the vitrified products are cooled, they are examined for complete dissolution of all components. A clear sample is then removed (made easy by the spontaneous cracking of the glass melt as it cools) and weighed in air and then under toluene to measure the glass density.

\section{D.3 MATERIALS USED}

Table $\mathrm{D} .1$ lists the amount of material used in the formation of $2: 1 \mathrm{PbO}: \mathrm{B}_{2} \mathrm{O}_{3}$ base glass and the amount of oxides used for solubility experiments. The only difference in preparing glasses of differing ratios is the amount of $\mathrm{PbO}$ used. 


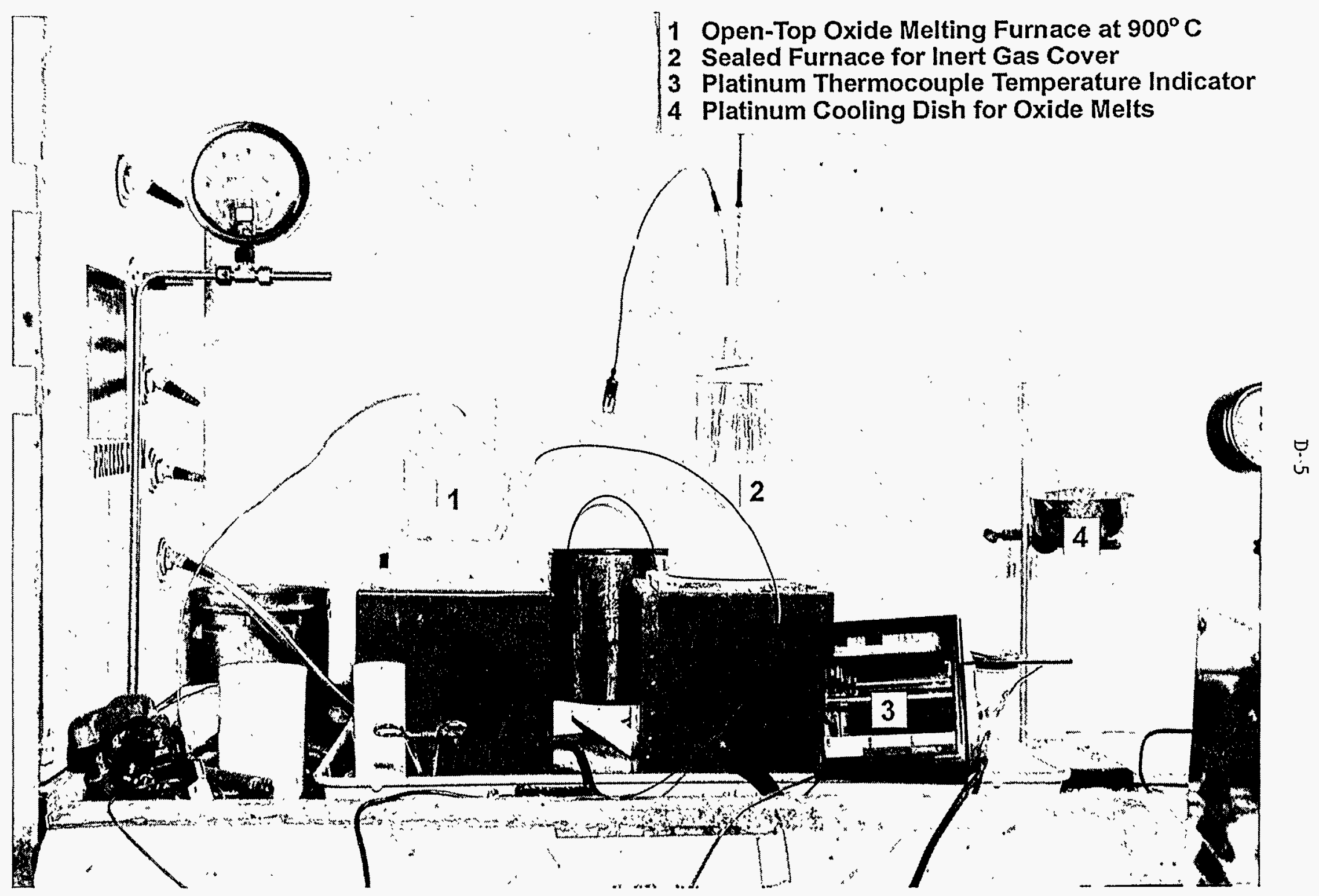

Fig. D.1. Lead-borate glass-melting furnaces for COMSORS. 

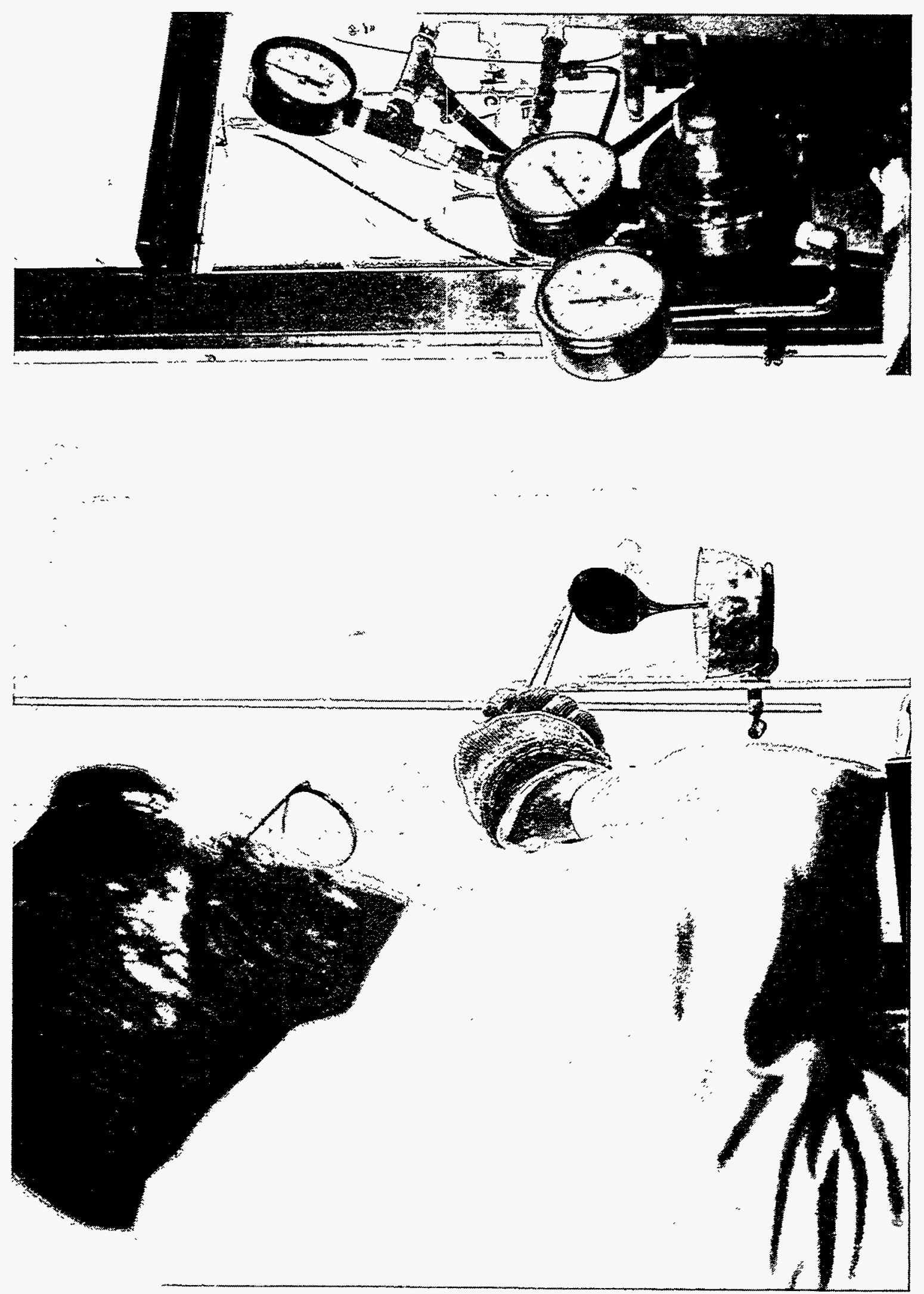

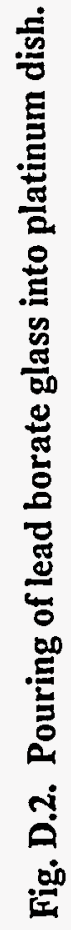


D-7

Table D.1. Lead borate mix for the 2:1 type solvent glass

\begin{tabular}{lc}
\multicolumn{1}{c}{ Experimental inputs } & Weight \\
\hline Lead oxide $(\mathrm{PbO}), 2$ gmol & 446.0 \\
Boric oxide anhydride $\left(\mathrm{B}_{2} \mathrm{O}_{3}\right), 1$ gmol & 69.6 \\
Total weight & 515.6 \\
Oxide to mix at $10 \mathrm{wt} \%$ of $\mathrm{Al}_{2} \mathrm{O}_{3}, \mathrm{ZrO}_{2}, \mathrm{CeO}_{2}$ & 51.6 \\
$\mathrm{U}_{3} \mathrm{O}_{8}$ to mix at $20 \mathrm{wt} \%$ & 103.2 \\
\hline
\end{tabular}

\section{D.4 SCOPING EXPERIMENTS}

Scoping experiments are proof-of-principle tests designed to demonstrate occurrence of expected phenomena. By definition, tests are conducted with the minimum equipment and measurements to confirm or disprove a particular hypothesis. The experiments are not designed to obtain detailed design information.

Bench-scale tests $(\sim 500-600 \mathrm{~g})$ with lead borate glasses were used to evaluate four important characteristics: (1) solubility of $\mathrm{UO}_{2}, \mathrm{ZrO}_{2}$, and $\mathrm{Al}_{2} \mathrm{O}_{3}$ in the glass; (2) oxidation of $\mathrm{Zr}$ or $\mathrm{Al}$ and then dissolution in the glass; (3) cracking of the glass on cooling; and (4) disintegration of the glass in water.

\section{D.4.1 Solubility of Selected Oxides in Lead Borate Glasses}

These tests were run at $\sim 1020^{\circ} \mathrm{C}$. Several tests were run to determine the solubility of $\mathrm{UO}_{2}, \mathrm{Al}_{2} \mathrm{O}_{3}$, or $\mathrm{ZrO}_{2}$ in a glass with the initial composition $1 \mathrm{PbO} \cdot \mathrm{BB}_{2} \mathrm{O}_{3}$. Both the $\mathrm{UO}_{2}$ and $\mathrm{Al}_{2} \mathrm{O}_{3}$ readily dissolved in this glass. The limit of solubility for $\mathrm{UO}_{2}$ was $>30 \mathrm{wt} \%$, and for $\mathrm{Al}_{2} \mathrm{O}_{3}$, it was $20 \mathrm{wt} \%$. The dissolution of $30 \mathrm{wt} \% \mathrm{Al}_{2} \mathrm{O}_{3}$ was hampered by the very high viscosity of the melt rather than by a solubility limit.

An attempt to dissolve $10 \mathrm{wt} \% \mathrm{ZrO}_{2}$ was not successful. However, with a glass composition of $2 \mathrm{PbO}: 1 \mathrm{~B}_{2} \mathrm{O}_{3}, 20 \mathrm{wt} \% \mathrm{ZrO}_{2}$, and $20 \mathrm{wt} \% \mathrm{UO}_{2}$ were dissolved. The results of the solubility studies are listed in Table D.2.

A material containing $\mathrm{Al}_{2} \mathrm{O}_{3}: 2 \mathrm{~B}_{2} \mathrm{O}_{3}$ with $10 \mathrm{wt} \% \mathrm{UO}_{2}$ was prepared and heated to $1020^{\circ} \mathrm{C}$. The product contained both a solid and a liquid. When the $\mathrm{B}_{2} \mathrm{O}_{3}$ content was increased to $\mathrm{Al}_{2} \mathrm{O}_{3}: 4 \mathrm{~B}_{2} \mathrm{O}_{3}$, there were still some solids. Significantly, the only way that this material could be removed from the platinum crucible was first to add $\mathrm{PbO}$. 
Table D.2. Solubility of $\mathrm{UO}_{2}, \mathrm{Al}_{2} \mathrm{O}_{3}$, and $\mathrm{ZrO}_{2}$ in lead borate glasses

\begin{tabular}{cl}
\hline Glass composition & \multicolumn{1}{c}{ Solubility at $1020^{\circ} \mathrm{C}$} \\
\hline $1 \mathrm{PbO}: 1 \mathrm{~B}_{2} \mathrm{O}_{3}$ & $>30 \mathrm{wt} \% \mathrm{UO}_{2}$ \\
& $<10 \mathrm{wt} \% \mathrm{ZrO}_{2}$ \\
& $>20 \mathrm{wt} \% \mathrm{Al}_{2} \mathrm{O}_{3}$ \\
$1 \mathrm{PbO}: 1 \mathrm{~B}_{2} \mathrm{O}_{3}$ & $20 \mathrm{wt} \% \mathrm{UO}_{2}$ plus $20 \mathrm{wt} \% \mathrm{ZrO}_{2}$ \\
$2 \mathrm{PbO}: 1 \mathrm{~B}_{2} \mathrm{O}_{3}$ & Incomplete dissolution of $20 \mathrm{wt} \% \mathrm{UO}_{2}$ plus $20 \mathrm{wt} \% \mathrm{ZrO}_{2}$ \\
$3 \mathrm{PbO}: 1 \mathrm{~B}_{2} \mathrm{O}_{3}$ &
\end{tabular}

From these studies, it is clear that $\mathrm{PbO}$ enhances the solubility of oxides in these borate glasses. The optimum composition for dissolution of $\mathrm{UO}_{2}$ together with $\mathrm{ZrO}_{2}$ is $2 \mathrm{PbO} \cdot 1 \mathrm{~B}_{2} \mathrm{O}_{3}$.

\section{D.4.2 Oxidation of Nuclear Metals and Carbon by Lead Borate Glass}

A central feature of $C O M S O R S$ is that the glass will contain a sacrificial oxide, $\mathrm{PbO}$, which can react with metals. For example, the reaction with metallic zirconium to form $\mathrm{ZrO}_{2}$ and $\mathrm{Pb}$ is:

$$
\mathrm{Zr}+\mathrm{PbO} \text { (in glass) } \neq \mathrm{ZrO}_{2} \text { (dissolved in glass) }+2 \mathrm{~Pb} \downarrow
$$

This reaction would result in the zirconium's being dissolved in the glass as $\mathrm{ZrO}_{2}$.

All tests with metals and carbon were performed in high-fired ceramic alumina because the lead product of this reaction readily forms alloys with platinum metals. This is satisfactory provided the melt is not allowed to solidify and then be reheated. Pouring the melt into an open silica dish is the most satisfactory way of recovering the sample and examining it for the lead product. All experiments were performed under argon gas without stirring to prevent oxidation from air. Tests were run at $1000^{\circ} \mathrm{C}$ with an initial glass composition of $4 \mathrm{PbO} \cdot 1 \mathrm{~B}_{2} \mathrm{O}_{3}$ to provide ample $\mathrm{PbO}$ for the oxidation of $\mathrm{Zr}$ or $\mathrm{Al}$ and to give a resultant $\mathrm{PbO} \cdot \mathrm{B}_{2} \mathrm{O}_{3}$ ratio of $2 \mathrm{PbO} \cdot 1 \mathrm{~B}_{2} \mathrm{O}_{3}$ after reaction.

This reaction has been investigated qualitatively with powdered zirconium, strips of aluminum, Zircaloy, cerium chunks, and a solid-carbon rod. The reaction with powdered zirconium metal was very rapid; the energy released resulted in a flash of light, an audible report, and a broken crucible and quartz sleeve. Further experiments used 1/8-in. to 1/16-in. strips of metal without further difficulty. Figure D.3 shows the partial dissolution of Zircaloy-2 at the half-way point. At the start of the experiment, the crucible contained no lead. 


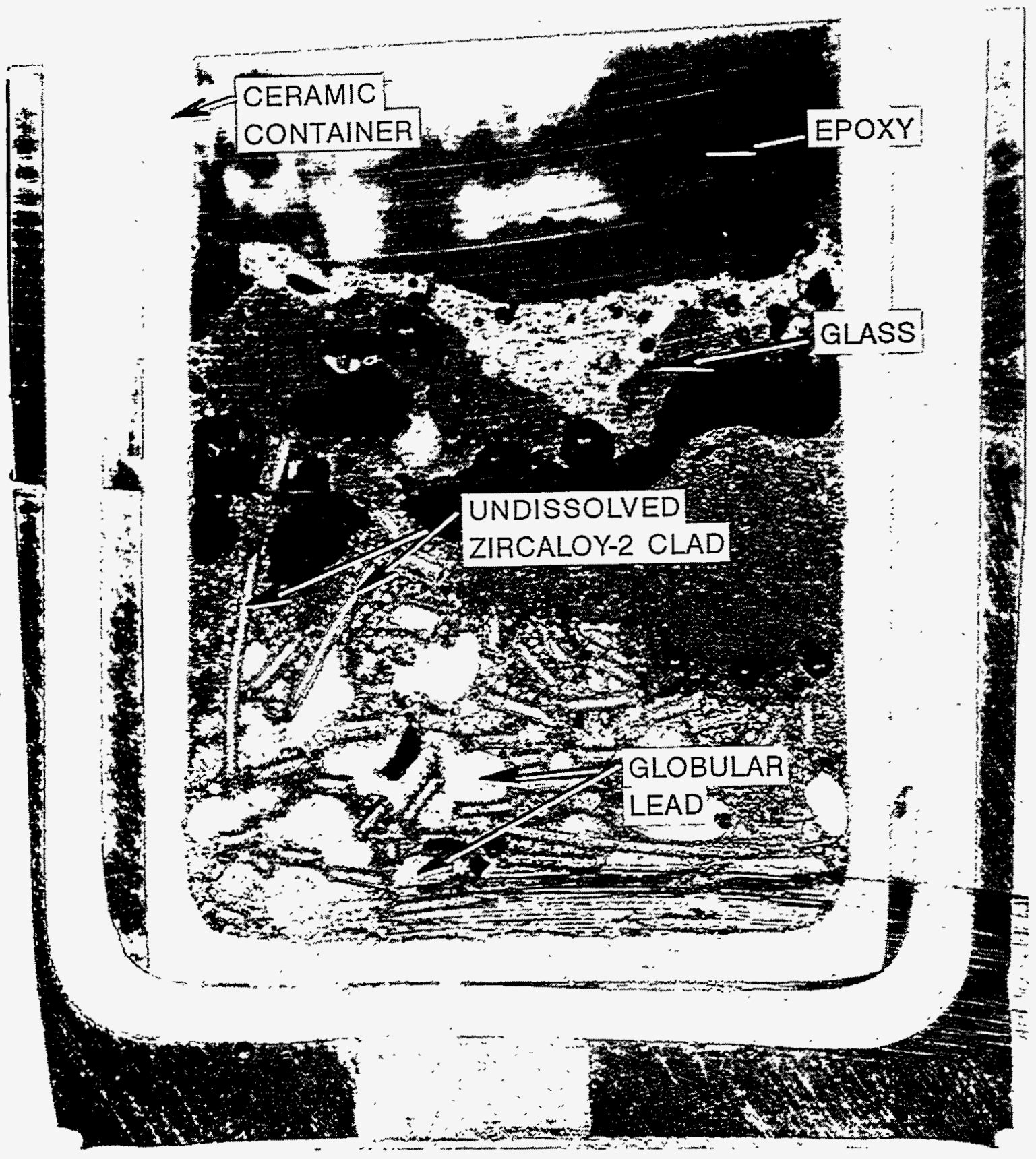

\section{CENTIMETERS}

Fig. D.3. Dissolution of Zircaloy-2 in lead borate glass at half-way point. 
Stainless steel was discovered to be rapidly attacked when a standard stainless-steel-clad thermocouple was inserted into the melt and soon thereafter was found to be shortened because of the complete dissolution of the immersed portion. Examination showed that these metals readily reacted with the lead borate glass to form lead and to dissolve the newly formed metal oxide. Lead globules were seen in the sample specimens after they were cooled.

\section{D.4.3 Cracking of Glass}

Tests with a $2 \mathrm{PbO}: 1 \mathrm{~B}_{2} \mathrm{O}_{3}$ glass and a similar glass loaded with $20 \mathrm{wt} \% \mathrm{UO}_{2}$ and $20 \mathrm{wt} \% \mathrm{ZrO}_{2}$ resulted in significant cracking during air cooling from $1020^{\circ} \mathrm{C}$ to room temperature. This suggests a significant coefficient of thermal expansion of glass.

\section{D.4.4 Leach Test of $2 \mathrm{PbO}: \mathrm{B}_{2} \mathrm{O}_{3}$ with Boiling Water}

Lead borate glasses dissolve incongruently in water; that is, they break down into soluble $\mathrm{B}_{2} \mathrm{O}_{3}$ and insoluble hydrated $\mathrm{PbO}$. Tests with the glass $2 \mathrm{PbO} \cdot 1 \mathrm{~B}_{2} \mathrm{O}_{3}$ found that the rate of loss of glass in boiling water was $35 \mathrm{mg} / \mathrm{cm}^{2} \cdot \mathrm{h}$.

\section{D.4.5 Scoping Experiment Conclusions}

The optimal glass composition of $2 \mathrm{PbO}: \mathrm{IB}_{2} \mathrm{O}_{3}$ was found for dissolution of materials $\mathrm{UO}_{2}$ and $\mathrm{ZrO}_{2}$. The oxidation and dissolution of $\mathrm{Zr}, \mathrm{Al}$, and $\mathrm{Ce}$ by the sacrificial oxide $\mathrm{PbO}$ in the glass were demonstrated. In addition, the glasses readily cracked during cooling.

\section{D.5 DENSITY MEASUREMENTS OF SOLID GLASS}

Small-scale experiments were conducted with the proposed COMSORS glass system to measure density of the mixtures over the range of potential system compositions (Table D.3). The range of compositions of the proposed COMSORS dissolution mixture is between the mole ratios of $1: 1$ up to $4: 1 \mathrm{PbO}$ to $\mathrm{B}_{2} \mathrm{O}_{3}$. Over this range, a fairly uniform vitrified glass is obtained, and the measurement of freezing-temperature, ambient glass density has been partially completed and is summarized herein.

It has been found that density of the solid glass closely follows the empirical calculated range of densities (Table D.4) based on simple mole ratio average from 1:1 up to 4:1 $\mathrm{PbO}$ to $\mathrm{B}_{2} \mathrm{O}_{3}$. The high-ratio 4:1 mix always crystallizes on solidification and appears to expand, thus leaving voids in the solid-hence a lower density. The $3: 1 \mathrm{mix}$ is variable, that is, mostly a clear vitrified phase with crystalline inclusions-hence, a variable density. 
D-11

Table D.3. Measured lead borate densities

\begin{tabular}{ccc}
\hline $\begin{array}{c}\mathrm{PbO}: \mathrm{B}_{2} \mathrm{O}_{3} \\
\mathrm{Mix}\end{array}$ & $\begin{array}{c}\text { Observed freezing temperature } \\
\left({ }^{\circ} \mathrm{C}\right)\end{array}$ & $\begin{array}{c}\text { Density } \\
\left(\mathrm{g} / \mathrm{cm}^{3}\right)\end{array}$ \\
\hline $1: 1$ & 500 & 6.35 \\
$1.5: 1$ & 440 & 6.82 \\
$2: 1$ & 480 & 7.63 \\
$2.5: 1$ & 500 & 7.60 \\
$3: 1$ & 530 & $7.22-7.70^{a}$ \\
$4: 1$ & 550 & $6.57^{b}$ \\
\hline
\end{tabular}

${ }^{a}$ Clear, vitrified phase.

${ }^{b}$ Solid phase (mostly crystalline).

Table D.4. Calculated vitrified lead borate densities

\begin{tabular}{ccc}
\hline PbO: $\mathrm{B}_{2} \mathbf{O}_{3} \mathrm{mix}$ & $\begin{array}{c}\text { Sum of mole weights } \times \text { density } \\
(\text { No. moles })\end{array}$ & $\begin{array}{c}\text { Calculated density } \\
\left(\mathrm{g} / \mathrm{cm}^{3}\right)\end{array}$ \\
\hline $1: 1$ & $11.34(2)$ & 5.67 \\
$1.5: 1$ & $16.10(2.5)$ & 6.44 \\
$2: 1$ & $20.87(3)$ & 6.95 \\
$2.5: 1$ & $25.63(3.5)$ & 7.32 \\
$3: 1$ & $30.4(4)$ & 7.60 \\
$4: 1$ & $39.93(5)$ & 7.98 \\
\hline
\end{tabular}




\section{D.6 SOLIDIFICATION TEMPERATURE MEASUREMENTS}

Measurements were made of the softening temperature of several glass mixtures containing uranium, zirconium, aluminum, and cerium oxide. Cerium oxide is the chemical substitute for plutonium. Initial results are shown in Table D.5.

Table D.5. Physical property measurements of various materials in lead borate glass with molar ratio 2:1 $\mathrm{PbO}: \mathrm{B}_{2} \mathrm{O}_{3}$

\begin{tabular}{cccccc}
\hline & & \multicolumn{2}{c}{ Temperature } & & \\
\cline { 3 - 4 } Compound & $\begin{array}{c}\text { Concentration } \\
\text { (wt \%) }\end{array}$ & Maximum $^{b}$ & Freezing & $\begin{array}{c}\text { Solid density } \\
\left(\mathrm{g} / \mathrm{cm}^{3}\right)\end{array}$ & $\begin{array}{c}\text { Relative } \\
\text { viscosity }\end{array}$ \\
\hline $\mathrm{U}_{3} \mathrm{O}_{8}$ & 20 & 1000 & 475 & 8.14 & Fluid at $550^{\circ} \mathrm{C}$ \\
$\mathrm{ZrO}_{2}$ & 10 & 950 & 500 & 6.97 & Viscous at $550^{\circ} \mathrm{C}$ \\
$\mathrm{Al}_{2} \mathrm{O}_{3}$ & 10 & 1000 & 500 & 6.50 & Very Viscous at $550^{\circ} \mathrm{C}$ \\
$\mathrm{CeO}_{2}$ & 10 & 1000 & 450 & 6.99 & Viscous at $550^{\circ} \mathrm{C}$ \\
\hline
\end{tabular}

${ }^{a}$ Weight percent of combined $2 \mathrm{PbO}+\mathrm{B}_{2} \mathrm{O}_{3}$.

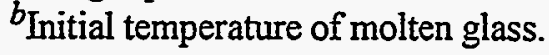

\section{D.7 VISCOSITY MEASUREMENTS}

\section{D.7.1 Description of Apparatus for Viscosity Measurements of Lead Borate Glasses}

One important physical characteristic of the starting material and the final mixture is the fluid viscosity. Viscosity is important in determining fluid flow, chemical reactor mixing characteristics, and heat-transfer information.

A standard Brookfield (Model RVDV III) ${ }^{\mathrm{TM}}$ rheometer is the central component of the experimental setup (Fig. D.4). The principle of operation is relatively simple: a spindle is attached to a motor and is then immersed into the liquid to a specified depth. The motor is started and set at a constant speed [in revolutions per minute (RPM)]. The rotation induces a torque on the spindle which is measured. The viscosity is directly related to the torque and inversely related to the speed. A constant based on the system geometry (determined by using standardized Newtonian fluids) is used to convert these readings to a viscosity in centipoise. 


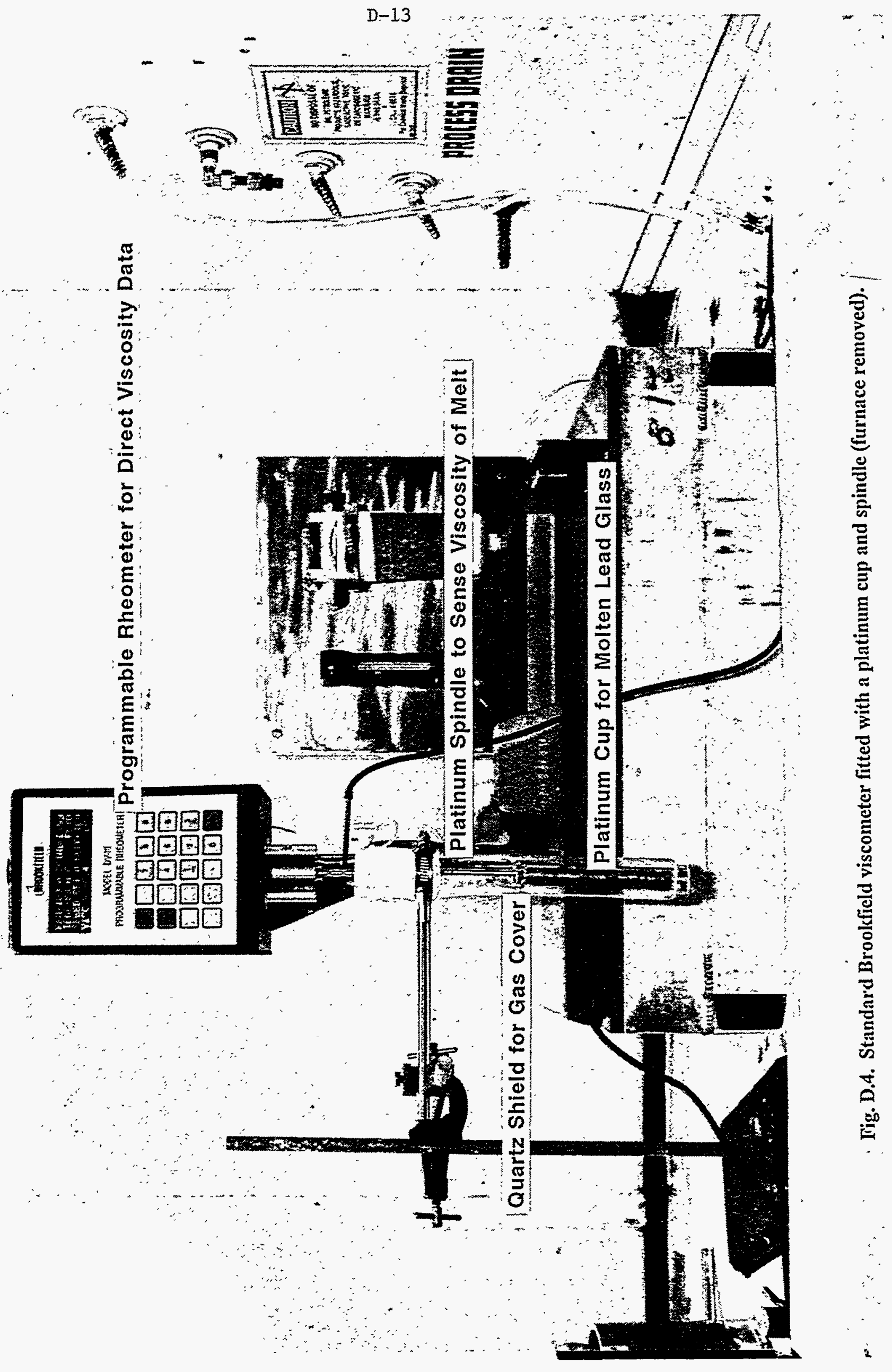


The standard spindles which accompany the rheometer will not withstand the extreme oxidizing conditions present in the molten glass. A platinum spindle (0.375-in. diam at the measuring point) and a platinum cup ( 0.75 -in. diam and 5 in. high) were therefore constructed. The cup and the spindle were enclosed in a quartz shield to capture the gases emitted when the glass is heated. The apparatus was covered with a Teflon ${ }^{\mathrm{TM}}$ lid, which has a central hole large enough such as to allow the spindle to rotate freely. The lid also has a second opening from which a suction is drawn to remove the gases.

The quartz tube is placed into a platinum furnace (not shown in the figure). The temperature of the molten glass is taken with a platinum thermocouple until the temperature stabilizes. The thermocouple is then removed, and the rheometer is started. Viscosity measurements can then be recorded over a range of speeds.

\section{D.7.2 Calibration of Brookfield Rheometer}

To calibrate the rheometer, some standardized fluids (silicone oils) were purchased from Brookfield and were first tested with standard stainless steel spindles. Calibrations with these spindles indicated that the rheometer was out of tolerance. Although this was unfortunate, tolerance was achieved by using a calibration curve. Eventually the rheometer will need to be returned to Brookfield for recalibration.

After checking the accuracy of the rheometer, the platinum spindle and cup were tested with standard fluids to determine the constant which is specific to the geometry of the experimental apparatus (i.e., diameter of container, diameter of spindle, and depth of immersion). This calibration was reproducible to within $5 \%$ error. Table D. 6 provides viscosities of some standard substances to compare with the data on the glass systems to come:

Table D.6. Viscosities of common substances

\begin{tabular}{lcc}
\hline Substance & $\begin{array}{c}\text { Temperature } \\
\left({ }^{\circ} \mathrm{C}\right)\end{array}$ & $\begin{array}{c}\text { Viscosity } \\
(\text { cp })\end{array}$ \\
\hline Castor oil & 25 & 986 \\
Glycerin & 25 & 954 \\
Machine oil, heavy & 15.6 & 660.6 \\
Machine oil, light & 15.6 & 113.8 \\
Olive oil & 20 & 84 \\
Antifreeze & 20 & 19.9 \\
\hline
\end{tabular}




\section{D-15}

\section{D.7.3 Viscosity Measurements of Initial Glass Compositions}

Viscosity measurements of $1: 1,2: 1,3: 1$, and 4:1 $\mathrm{PbO}: \mathrm{B}_{2} \mathrm{O}_{3}$ were taken (Table D.7 and Table D.8) from a range of $603-822^{\circ} \mathrm{C}$. The sample sizes measured were between $100-150 \mathrm{~g}$. The measurements taken were at the low end of the viscosity range for this particular geometry (the circumference of the spindle is small; therefore, it does not produce much torque in low-viscosity fluids). This procedure gives a relatively large degree of error.. However, these data show that at temperatures considerably lower than the expected temperature in this system, $600-820^{\circ} \mathrm{C}$ compared to $1000-1100^{\circ} \mathrm{C}$, the glass viscosity is very low $-\leq 100 \mathrm{cp}$ at $750^{\circ} \mathrm{C}$, or less viscous than light machine oil. The data also show Newtonian fluid behavior (constant viscosity with increasing shear rate). A correlation could be obtained to predict the change in viscosity with the change in temperature. However, this correlation would require more accurate low viscosity readings which are not considered necessary at this time because the final glass composition is predicted to have a much higher viscosity which will be a much more limiting condition for the process.

\section{D.7.4 Viscosity Measurements of $20 \% \mathrm{U}_{3} \mathrm{O}_{8}$ in $2: 1 \mathrm{PbO}: \mathrm{B}_{2} \mathrm{O}_{3}$}

Uranium oxide was expected to raise the viscosity of the glass greatly, thereby causing heat and mass transfer in the liquid to decrease substantially; however, this did not occur (Table D.9). While the mixture is very viscous near its melting point $\left(\approx 600^{\circ} \mathrm{C}\right)$, it drops quickly over the range $600-900^{\circ} \mathrm{C}$ to a viscosity approximately equivalent to antifreeze.

\section{D.7.5 Viscosity Measurements of $10 \% \mathrm{ZrO}_{2}$ in $2: 1 \mathrm{PbO}: \mathrm{B}_{2} \mathrm{O}_{3}$}

A solution of $10 \% \mathrm{ZrO}_{2}$ showed high viscosities (Table D.10), relative to $20 \% \mathrm{U}_{3} \mathrm{O}_{8}$. The viscosity is very well defined by the Bingham model ${ }^{2}$. The Bingham model is used to model "viscoplastic" materials,

${ }^{1}$ More accurate data could be obtained in a larger experimental setup, but because platinum equipment is required, it may become rather expensive. Also, because the viscosity of the glass is expected to increase significantly with the addition of other oxides, it was decided to maintain our present configuration.

${ }^{2}$ The Bingham model is described by the equation:

$$
\mu=\mu_{0}+\frac{\tau_{0}}{\gamma}
$$

with $\mu=$ viscosity, $\mu_{0}=$ viscosity at infinite shear, $\tau_{0}=$ yield stress, and $\gamma=$ shear rate. 
D-16

Table D.7. Viscosity (in $\mathrm{cp}$ ) of 1:1 and 2:1 $\mathrm{PbO}: \mathrm{B}_{2} \mathrm{O}_{3}$ glass at low temperatures

\begin{tabular}{|c|c|c|c|c|c|c|c|c|}
\hline \multirow{3}{*}{$\begin{array}{c}\text { Spindle } \\
\text { (rpm) }\end{array}$} & \multirow{3}{*}{$\begin{array}{c}\text { Shear } \\
\text { rate } \\
(1 / s)\end{array}$} & \multicolumn{6}{|c|}{ Temperature $\left( \pm 10^{\circ} \mathrm{C}\right)$} & \multirow{3}{*}{$\begin{array}{c}\text { Viscosity } \\
\text { error } \\
\text { (cp) }\end{array}$} \\
\hline & & \multicolumn{3}{|c|}{ 1:1 $\mathrm{PbO}: \mathrm{B}_{2} \mathrm{O}_{3}$} & \multicolumn{3}{|c|}{ 2:1 $\mathrm{PbO}: \mathrm{B}_{2} \mathrm{O}_{3}$} & \\
\hline & & 706 & 750 & 810 & 620 & 710 & 820 & \\
\hline 100 & 27.5 & 261 & & & 205 & & & \pm 58 \\
\hline 125 & 34.4 & 262 & 102 & 47 & 201 & 52.6 & & \pm 48 \\
\hline 150 & 41.3 & 265 & 99 & 49 & 200 & 48.3 & 23 & \pm 40 \\
\hline 175 & 48.1 & 267 & 103 & 55 & 202 & 50 & 19 & \pm 35 \\
\hline 200 & 55 & 262 & 100 & 54 & 199 & 44.8 & 18 & \pm 30 \\
\hline 225 & 61.9 & 262 & 101 & 50 & 197 & 42.6 & 21 & \pm 27 \\
\hline 250 & 68.8 & 264 & 100 & 55 & 197 & 45.9 & 29 & \pm 24 \\
\hline Average & & 263 & 101 & 52 & 200 & 47.4 & 22 & \\
\hline
\end{tabular}

Table D.8. Viscosity (in $\mathrm{cp}$ ) of 3:1 and 4:1 $\mathrm{PbO}: \mathrm{B}_{2} \mathrm{O}_{3}$ glass at low temperatures

\begin{tabular}{|c|c|c|c|c|c|c|c|c|c|}
\hline \multirow{3}{*}{$\begin{array}{c}\text { Spindle } \\
\text { (rpm) }\end{array}$} & \multirow{3}{*}{$\begin{array}{c}\text { Shear } \\
\text { rate } \\
(1 / s)\end{array}$} & \multicolumn{7}{|c|}{ Temperature $\left( \pm 10^{\circ} \mathrm{C}\right)$} & \multirow{3}{*}{$\begin{array}{c}\text { Viscosity } \\
\text { error } \\
\text { (cp) }\end{array}$} \\
\hline & & \multicolumn{4}{|c|}{ 3:1 $\mathrm{PbO}: \mathrm{B}_{2} \mathrm{O}_{3}$} & \multicolumn{3}{|c|}{ 4:1 $\mathrm{PbO}: \mathrm{B}_{2} \mathrm{O}_{3}$} & \\
\hline & & 603 & 665 & 713 & 803 & 615 & 705 & 822 & \\
\hline 125 & 34.4 & 107 & 60 & & & 76 & 65 & & \pm 48 \\
\hline 150 & 41.3 & 104 & 62 & 47 & 22 & 75 & 63 & 21 & \pm 40 \\
\hline 175 & 48.1 & 105 & 60 & 39 & 27 & 76 & 53 & 19 & \pm 35 \\
\hline 200 & 55 & 105 & 60 & 41 & 32 & 77 & 55 & 16 & \pm 30 \\
\hline 225 & 61.9 & 101 & 57 & 43 & 31 & 76 & 56 & 23 & \pm 27 \\
\hline 250 & 68.8 & 101 & 55 & 42 & 30 & 76 & 53 & 28 & \pm 24 \\
\hline Average & & 104 & 59 & 42 & 29 & 76 & 58 & 21 & \\
\hline
\end{tabular}




\section{D-17}

Table D.9. Viscosity (in cp) of 20 wt $\% \mathrm{U}_{3} \mathrm{O}_{8}$ in 2:1 $\mathrm{PbO}: \mathrm{B}_{2} \mathrm{O}_{3}$ glass at low temperatures

\begin{tabular}{|c|c|c|c|c|c|}
\hline \multirow[b]{2}{*}{$\begin{array}{c}\text { Spindle } \\
\text { (rpm) }\end{array}$} & \multirow{2}{*}{$\begin{array}{c}\text { Shear } \\
\text { rate } \\
(1 / s)\end{array}$} & \multicolumn{3}{|c|}{ Temperature $\left( \pm 10^{\circ} \mathrm{C}\right)$} & \multirow{2}{*}{$\begin{array}{c}\text { Viscosity } \\
\text { error } \\
\text { (cp) }\end{array}$} \\
\hline & & $626^{a}$ & 768 & 905 & \\
\hline 150 & 41.3 & $2070^{a}$ & 121 & 19.3 & \pm 40 \\
\hline 175 & 48.1 & $2040^{a}$ & 116 & 20.8 & \pm 35 \\
\hline 200 & 55 & $1980^{a}$ & 113 & 24.2 & \pm 30 \\
\hline 225 & 61.9 & $1940^{a}$ & 109 & 24.4 & \pm 27 \\
\hline 250 & 68.8 & $1825^{a}$ & 110 & 22.4 & \pm 24 \\
\hline Average & & 1970 & 116 & 22.2 & \\
\hline
\end{tabular}

${ }^{a_{T}}$ These viscosity measurements have a greater error $( \pm 200 \mathrm{cp})$ than indicated in the far right column because of difficulty with the experimental measurement at high viscosities.

Table D.10. Viscosity (in cp) of 10 wt $\% \mathrm{ZrO}_{2}$ in 2:1 $\mathrm{PbO}: \mathrm{B}_{2} \mathrm{O}_{3}$ glass

\begin{tabular}{|c|c|c|c|c|c|}
\hline \multirow[b]{2}{*}{$\begin{array}{c}\text { Spindle } \\
\text { (rpm) }\end{array}$} & \multirow[b]{2}{*}{$\begin{array}{c}\text { Shear rate } \\
(1 / \mathrm{s})\end{array}$} & \multicolumn{3}{|c|}{ Temperature $\left( \pm 10^{\circ} \mathrm{C}\right)$} & \multirow{2}{*}{$\begin{array}{c}\text { Viscosity } \\
\text { error } \\
\text { (cp) }\end{array}$} \\
\hline & & 810 & 1000 & 1100 & \\
\hline 150 & 41.3 & 651 & $\cdots$ & 246 & \pm 40 \\
\hline 175 & 48.1 & 600 & 450 & 221 & \pm 35 \\
\hline 200 & 55 & 553 & 406 & 202 & \pm 30 \\
\hline 225 & 61.9 & 511 & 370 & 181 & \pm 27 \\
\hline 250 & 68.8 & 484 & 346 & 174 & $\begin{array}{l} \pm 24 \\
\pm 24\end{array}$ \\
\hline \multicolumn{2}{|c|}{ Average } & $560^{\mathrm{a}}$ & $393^{a}$ & $205^{\mathrm{a}}$ & \\
\hline
\end{tabular}

${ }^{a}$ Glasses at these conditions behaved as Bingham fluids which is common in fluids with suspended solids. 
meaning, materials that have an infinite viscosity (no flow) until their yield stress is reached. This behavior is typical of thick slurries and is a likely indication of incomplete dissolution of $\mathrm{ZrO}_{2}$. If a material conforms to the Bingham model, one would expect to observe high viscosities when the viscometer is started, but the yield stress for the $\mathrm{ZrO}_{2}$ is low enough that the decrease in viscosity is too rapid to note. This phenomenon is observed in the $10 \mathrm{wt} \% \mathrm{U}_{3} \mathrm{O}_{8}-10 \% \mathrm{ZrO}_{2}$ described in Sect. D.7.6.

\section{D.7.6 Viscosity Measurements of $\mathrm{U}_{3} \mathrm{O}_{8}-\mathrm{ZrO}_{2}$ Mixtures in 2:1 $\mathrm{PbO}: \mathrm{B}_{2} \mathrm{O}_{3}$}

Replacing $10 \%$ of the $\mathrm{U}_{3} \mathrm{O}_{8}$ with $\mathrm{ZrO}_{2}$ caused the viscosity to increase sharply at lower temperatures. The glass appears to act as a Bingham fluid up to at least $960^{\circ} \mathrm{C}$. The viscosity starts off very high $\left(7000-8000 \mathrm{cp}\right.$ at $850^{\circ} \mathrm{C}, 3000-3500$ at $\left.960^{\circ} \mathrm{C}\right)$ and then decreases quickly with mixing. The steady-state values are shown in Table D.11. The glass is also shear thinning, as the Bingham model predicts, which again suggests incomplete dissolution. There is a relatively large degree of error resulting from spindle slippage. When the temperature was raised to $1160^{\circ} \mathrm{C}$, the glass no longer behaved as a Bingham fluid. Normal Newtonian behavior was observed. This observation shows that complete dissolution has probably occurred. Whether the glass will remain homogeneous as the temperature is lowered is not clear. One should note that while the $10 \% \mathrm{U}_{3} \mathrm{O}_{8}-10 \% \mathrm{ZrO}_{2}$ mixture is relatively viscous at low temperatures, this is an extreme condition. More than likely, the ratio of $\mathrm{U}_{3} \mathrm{O}_{8}-\mathrm{ZrO}_{2}$ will be $2: 1$ or 3:1 or greater.

Viscosities for the $13.3 \mathrm{wt} \% \mathrm{U}_{3} \mathrm{O}_{8}-6.7 \mathrm{wt} \% \mathrm{ZrO}_{2}$ mixture were much lower even though overall weight loading is equivalent. This is due to the much greater fluidity of $\mathrm{U}_{3} \mathrm{O}_{8}$. However, the high initial viscosities are still noted at temperatures under $1000^{\circ} \mathrm{C}$. The non-Newtonian behavior is still observed in this glass even at $1100^{\circ} \mathrm{C}$, but is a very small effect. Another interesting fact is that the viscosities were lower as the temperature was ramped down, than they were as the temperature was increased. This would indicate that the oxide dissolved at higher temperatures stays in solution as the glass is cooled down. Viscosity data (Table D.12) is given in the order the measurements were taken.

\section{D.7.7 Literature Values for Viscosity of $1: 1 \mathrm{PbO}: \mathrm{B}_{2} \mathrm{O}_{3}$}

Table D.13 shows measurements of up to $50 \mathrm{~mol} \% \mathrm{PbO}$ in lead borate.

As shown, it correlates relatively well with our experimental results. The data were taken off a log plot which is the reason for the range in values. In addition, Eagan shows values for lower concentrations of $\mathrm{PbO}$, and there is a large decrease in viscosity as $\mathrm{PbO}$ content increases. This is the same trend we find until approximately the eutectic point of the $\mathrm{PbO}: \mathrm{B}_{2} \mathrm{O}_{3}$. From the eutectic point up to $80 \mathrm{~mol} \%$ lead, the viscosity levels off. A summary of glass viscosity data is shown in Table D.14. 
D-19

Table D.11. Viscosity (in cp) of 10 wt $\% \mathrm{U}_{3} \mathrm{O}_{8}-10$ wt $\% \mathrm{ZrO}_{2}$ in 2:1 $\mathrm{PbO}: \mathrm{B}_{2} \mathrm{O}_{3}$ glass

\begin{tabular}{|c|c|c|c|c|c|}
\hline \multirow[b]{2}{*}{$\begin{array}{c}\text { Spindle } \\
\text { (rpm) }\end{array}$} & \multirow[b]{2}{*}{$\begin{array}{c}\text { Shear rate } \\
(1 / s)\end{array}$} & \multicolumn{3}{|c|}{ Temperature $\left( \pm 20^{\circ} \mathrm{C}\right)$} & \multirow{2}{*}{$\begin{array}{c}\text { Viscosity } \\
\text { error } \\
\text { (cp) }\end{array}$} \\
\hline & & 850 & 960 & 1150 & \\
\hline 150 & 41.3 & $2100^{b}$ & $1300^{b}$ & 246 & \pm 40 \\
\hline 175 & 48.1 & 600 & ----- & 248 & \\
\hline 200 & 55 & $2000^{b}$ & $1110^{b}$ & 240 & \pm 30 \\
\hline 225 & 61.9 & 511 & 370 & 240 & \\
\hline 250 & 68.8 & $1800^{b}$ & $950^{\mathrm{b}}$ & 230 & \pm 24 \\
\hline \multicolumn{2}{|c|}{ Average } & $1970^{\mathrm{a}, \mathrm{b}}$ & $1120^{a, b}$ & 240 & \\
\hline
\end{tabular}
solids.

${ }^{a}$ Glasses at these conditions behaved as Bingham fluids which is common in fluids with suspended

${ }^{b}$ These viscosity measurements have a greater error $( \pm 200 \mathrm{cp})$ than indicated in the far right column. This was due to difficulty with the experimental equipment at high viscosities. When there is an opportunity to send the rheometer back for recalibration, this problem should be corrected.

Table D.12. Viscosity (in cp) of $13.3 \mathrm{wt} \% \mathrm{U}_{3} \mathrm{O}_{8}-6.7 \mathrm{wt} \% \mathrm{ZrO}_{2}$ in 2:1 $\mathrm{PbO}: \mathrm{B}_{2} \mathrm{O}_{3}$ glass

\begin{tabular}{|c|c|c|c|c|c|c|c|}
\hline \multirow{2}{*}{$\begin{array}{c}\text { Spindle } \\
\text { (rpm) }\end{array}$} & \multirow{2}{*}{$\begin{array}{c}\text { Shear rate } \\
(1 / s)\end{array}$} & \multicolumn{5}{|c|}{ Temperature $\left( \pm 20^{\circ} \mathrm{C}\right)$} & \multirow{2}{*}{$\begin{array}{c}\text { Viscosity } \\
\text { error } \\
\text { (cp) }\end{array}$} \\
\hline & & 955 & 1060 & 1100 & 895 & 790 & \\
\hline 150 & 41.3 & 545 & 188 & 107 & -- & $\cdots$ & \pm 40 \\
\hline 175 & 48.1 & 503 & 167 & 99 & 330 & 743 & \\
\hline 200 & 55 & 462 & 150 & 92 & 307 & 719 & \pm 30 \\
\hline 225 & 61.9 & 432 & 140 & 86 & 295 & 694 & \\
\hline 250 & 68.8 & 399 & 135 & 84 & 283 & 673 & \pm 24 \\
\hline \multicolumn{2}{|c|}{ Average } & 468 & 156 & $94^{\mathrm{a}}$ & 304 & 707 & \\
\hline
\end{tabular}
solids.

${ }^{a}$ Glasses at these conditions behaved as Bingham fluids which is common in fluids with suspended 
Table D.13. Comparison of literature and experimental viscosity data for $1: 1 \mathrm{PbO}: \mathrm{B}_{2} \mathrm{O}_{3}$

\begin{tabular}{ccccc}
\hline \multicolumn{2}{c}{ Eagan et al. } & & \multicolumn{2}{c}{ Experimental } \\
\cline { 2 - 2 } $\begin{array}{c}\text { Temperature } \\
\left({ }^{\circ} \mathrm{C}\right)\end{array}$ & $\begin{array}{c}\text { Viscosity } \\
(\mathrm{cp})\end{array}$ & & $\begin{array}{c}\text { Temperature } \\
\left({ }^{\circ} \mathrm{C}\right)\end{array}$ & $\begin{array}{c}\text { Viscosity } \\
(\mathbf{c p})\end{array}$ \\
\hline 780 & $20-100$ & & 810 & 52 \\
725 & $150-250$ & & 750 & 100 \\
680 & $500-700$ & & 706 & 263 \\
635 & $2000+-300$ & & & \\
600 & $8000+-1000$ & & & \\
560 & $40,000+-5000$ & & \\
\hline
\end{tabular}

\section{D.8 CHEMICAL REACTION RATE MEASUREMENTS}

Dissolution rates for lead borate glasses are being investigated systematically for all the candidate metals, including carbon. Quantitative data are incomplete; however, qualitative observations for Zircaloy, aluminum, stainless steel, and carbon confirm that satisfactory rates in the 2:1 $\mathrm{PbO}: \mathrm{B}_{2} \mathrm{O}_{3}$ can be expected. Of these, only carbon (using the rate of weight-loss from a cylindrical rod) has shown an estimated reaction rate of $0.1 \mathrm{~g} / \mathrm{cm}^{2} \cdot h$. By measuring the weight of the lead regulus that results from the reaction, similar rates are indicated for aluminum and Zircaloy. The surrogate metal, cerium, which simulates plutonium, also produced a similar amount of lead in the form of a lead pellet (Fig. D.5).

\section{D.9 THERMAL EXPANSION AND DENSITY MEASUREMENTS OF MOLTEN GLASS}

Two methods were used to determine thermal expansion coefficients for lead borate melts. The first method attempted was to measure the change in height of a glass melt using a level detector and a digital micrometer. This method proved to be too imprecise for fine measurements and could be used only to obtain order-of-magnitude estimates. The second method used the Archimedes's principle; the change in weight of a known mass submerged in a liquid is equal to the mass of the liquid displaced. This method proved to be much more precise and repeatable. Both methods and the results obtained are described in detail in the following. 
Table D.14 Summary of viscosity measurements (in $\mathrm{cp}$ ) vs temperature for several GMODS glasses

\begin{tabular}{|c|c|c|c|c|c|c|c|c|c|c|c|c|}
\hline \multirow[b]{2}{*}{ Ratio of $\mathrm{PbO}$ to $\mathrm{B}_{2} \mathrm{O}_{3}$} & \multicolumn{12}{|c|}{ Temperature $\left({ }^{\circ} \mathrm{C}\right)$} \\
\hline & 600 & 650 & 700 & 750 & 800 & 850 & 900 & 950 & 1000 & 1050 & 1100 & 1150 \\
\hline $1: 1$ & & & 260 & 100 & 55 & & & & & & & \\
\hline $2: 1$ & 200 & & 45 & & 30 & & & & & & & \\
\hline $3: 1$ & 105 & 65 & 45 & & 30 & & & & & & & \\
\hline $4: 1$ & 80 & & 60 & & 25 & & & & & & & \\
\hline $2: 1$ with $20 \mathrm{wt} \% \mathrm{U}_{3} \mathrm{O}_{8}$ & & $2000 *$ & & 125 & & & 22 & & & & & \\
\hline 2:1 with $10 \mathrm{wt} \% \mathrm{ZrO}_{2}$ & & & & & $560^{*}$ & & & & $390^{*}$ & & $200 *$ & \\
\hline 2:1 with $10 \mathrm{wt} \% \mathrm{ZrO}_{2}$ and $10 \mathrm{wt} \% \mathrm{U}_{3} \mathrm{O}_{8}$ & & & & & & $2000^{*}$ & & $1150 *$ & & & & 240 \\
\hline $2: 1$ with $6.7 \mathrm{wt} \% \mathrm{ZrO}_{2}$ and $13.3 \mathrm{wt} \% \mathrm{U}_{3} \mathrm{O}_{8}$ & & & & & $710^{*}$ & & $300 *$ & & & $150^{*}$ & $100^{*}$ & \\
\hline
\end{tabular}

"These viscosity measurements have a greater error $( \pm 200 \mathrm{cp})$ because of the difficulty with the experimental equipment at high viscosities. 


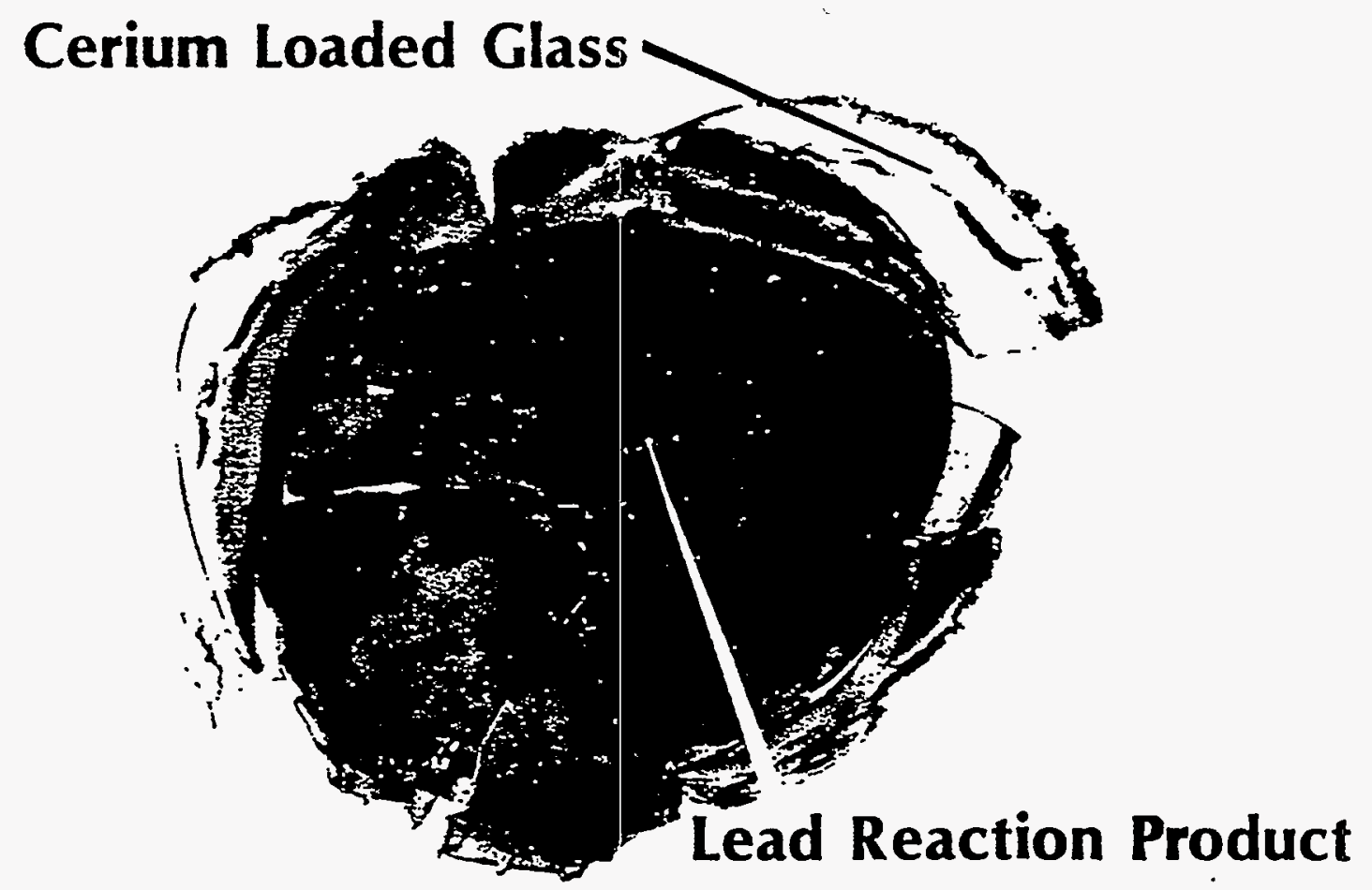

\section{Crucible Dissolution Test of Cerium Metal (Surrogate for Plutonium) In Lead Borate Glass}

Fig. D.5. Lead pellet formed by the reaction between cerium metal and lead borate. 


\section{D-23}

\section{D.9.1 Experimental Method (Differential Height Measurement)}

The platinum cup (Sect. D.7.1) is filled with a known mass of glass. The glass is melted, and the temperature then is taken by inserting a thermocouple in the liquid. The thermocouple is then removed. The platinum spindle (Sect. D.7.1) is then lowered into the cup until it touches the liquid surface. The $\mathrm{PbO}$ present in the liquid makes it a conductive medium. This enables one to detect the liquid level by setting up a circuit between the platinum spindle and cup. When the spindle contacts the liquid, the circuit is closed, and an indicator is tripped. A digimatic indicator, connected to the furnace and depressed by the head holding the spindle (Fig. D.6, digimatic indicator replaced vernier calipers), gives an indication of relative height. This test is done several times to attain a range of values. A gross density measurement (within $\pm 0.4 \mathrm{~g} / \mathrm{cm}^{3}$ ) is attained by measuring the length of the spindle which protrudes from the platinum cup. The temperature is then changed $\sim 100^{\circ} \mathrm{C}$, and then the measurement is repeated. The volume change [after the effects of the cup expansion (Sect. D.8.6) are added] gives the thermal expansion over this range.

\section{D.9.2 Difficulties With Method}

Several difficulties were encountered with this experimental procedure. The first was that the platinum cup was not firmly locked into position. When temperature measurements were taken (measurements had to be taken over the entire depth of fluid to observe the temperature variation), pressing the thermocouple against the bottom or sides of the cup would disturb it. The change was enough such that at the same temperature, the readings could be off by $1 \mathrm{~mm}$ or more. The amount of glass that wetted the thermocouple might have an effect, but it is likely to be small once the thermocouple is initially wetted. In addition, the spindle becomes wetted with the liquid, increasing the effective spindle length, which increases the measured height of the liquid. Attempting to measure a change of $<1 \mathrm{~mm}$ is a significant effect.

\section{D.9.3 Initial Measurements}

Only two repeatable results were obtained on the glasses tested and these are only valid as order of magnitude estimates.

\begin{tabular}{cc}
\hline Ratio: $\mathrm{PbO}: \mathrm{B}_{2} \mathrm{O}_{3}$ & $\begin{array}{c}\text { Thermal expansion coefficient } \\
\left(1 /{ }^{\circ} \mathrm{C}\right)\end{array}$ \\
\hline $2: 1$ & $1.3 \times 10^{-4}$ (order of magnitude estimate) \\
$3: 1$ & $1.8 \times 10^{-4}$ (order of magnitude estimate) \\
\hline
\end{tabular}


Also obtained at the beginning of each of the thermal expansion measurements were approximate glass densities.

\begin{tabular}{ccc}
\hline Ratio: $\mathrm{PbO}: \mathrm{B}_{2} \mathrm{O}_{3}$ & $\begin{array}{c}\text { Temperature } \\
\left({ }^{\circ} \mathrm{C}\right)\end{array}$ & $\begin{array}{l}\text { Density } \\
\left(\mathrm{g} / \mathrm{cm}^{3}\right)\end{array}$ \\
\hline $1: 1$ & $800 \pm 20$ & $5.5 \pm 0.4$ \\
$2: 1$ & $720 \pm 20$ & $6.1 \pm 0.4$ \\
$3: 1$ & $700 \pm 20$ & $6.6 \pm 0.4$ \\
\hline
\end{tabular}

\section{D.9.4 Literature Values}

Data from Drotning (1984) for $25-42 \mathrm{~mol} \% \mathrm{PbO}$ in $\mathrm{B}_{2} \mathrm{O}_{3}$ and a temperature range of $600-800^{\circ} \mathrm{C}$ are given in Table $\mathrm{D} .15$. The temperature dependence does seem to change as $\mathrm{PbO}$ concentration increases, however, a change of $1 \mathrm{E}-05 /{ }^{\circ} \mathrm{C}$ with composition is still very small.

Table D.15. Density and thermal expansion of $\mathrm{PbO}: \mathrm{B}_{2} \mathrm{O}_{3}$ glasses (Drotning 1984)

\begin{tabular}{|c|c|c|c|c|c|c|}
\hline \multirow[b]{3}{*}{$\begin{array}{c}\text { Temperature } \\
\left({ }^{\circ} \mathrm{C}\right) \\
\end{array}$} & \multicolumn{6}{|c|}{$\begin{array}{l}\text { Composition } \\
(\mathrm{mol} \% \mathrm{PbO})\end{array}$} \\
\hline & 27 & 33 & 42 & 27 & 33 & 42 \\
\hline & \multicolumn{3}{|c|}{$\begin{array}{l}\text { Density } \\
\left(\mathrm{g} / \mathrm{cm}^{3}\right)\end{array}$} & \multicolumn{3}{|c|}{$\begin{array}{l}\text { Expansion coefficient } \\
\left(11^{\circ} \mathrm{C} \times 10^{4}\right)\end{array}$} \\
\hline 600 & 3.64 & 4.10 & 4.73 & 3.47 & 3.07 & 2.72 \\
\hline 700 & 3.51 & 3.95 & 4.58 & 3.50 & 3.04 & 2.65 \\
\hline 800 & 3.38 & 3.82 & 4.46 & 3.52 & 2.98 & 2.57 \\
\hline 900 & 3.26 & 3.72 & 4.34 & & & \\
\hline
\end{tabular}




\section{D-25}

\section{D.8.5 Experimental Method (Differential Weight Measurement)}

This measurement of thermal expansion is based on the Archimedes principle: When a solid of known mass and volume is suspended in a liquid, the weight decreases by the mass of liquid displaced. The application of this principle to this experiment is as follows. The same platinum crucible described in Sect. D.7.1 is filled with glass and raised to temperature. Several platinum thermocouples are placed in contact with the sides of the crucible for accurate temperature measurements. A platinum cylinder of known mass and volume (at room temperature) is attached to a scale located directly above the glass melt (Fig. D.6). The cylinder is attached to the scale with 10-mil platinum wire and one of a series of different length hooks (used to ensure cylinder is completely submerged, but not touching the crucible bottom). The temperature of the melt is then taken by immersing a thermocouple directly into the melt and its value relative to the value of the remote thermocouples (those located on the sides of the crucible) is noted. The cylinder is then slowly lowered into the melt and then is observed to ensure complete submersion. Approximately $15 \mathrm{~min}$ is the time necessary for the cylinder to reach thermal equilibrium. An initial weight measurement is then taken. The temperature is then raised $100^{\circ} \mathrm{C}$, and a new weight reading is taken. This procedure is repeated until weight readings are taken at all desired temperatures. These weight readings are then used to calculate the density of the liquid at the various temperatures which also allows calculation of the thermal expansion coefficient. One should note that the thermal expansion of platinum cylinder is a correction that must be applied to these measurements.

\section{D.8.6 Density and Thermal Expansion Measurements of Lead Borate Melts}

The first step in calculating the densities and thermal expansion coefficients is to determine the correction factor for the platinum cylinder. The linear thermal expansion coefficient for platinum is given by the following relation ${ }^{11}$ :

$$
1_{\mathrm{t}}=1_{0}\left[1+8.87 \times 10^{-4} \times(\mathrm{T}-20)+1.32 \times 10^{-9} \times(\mathrm{T}-20)^{2}\right]
$$

where $\mathrm{l}_{\mathrm{t}}=$ length at the temperature of interest, $\mathrm{l}_{0}=$ length at $20^{\circ} \mathrm{C}$, and $\mathrm{T}=$ temperature in ${ }^{\circ} \mathrm{C}$.

The measured volume of the platinum cylinder at room temperature and calculated volumes (using the above linear expansion correlation) at elevated temperatures are given in the following: 


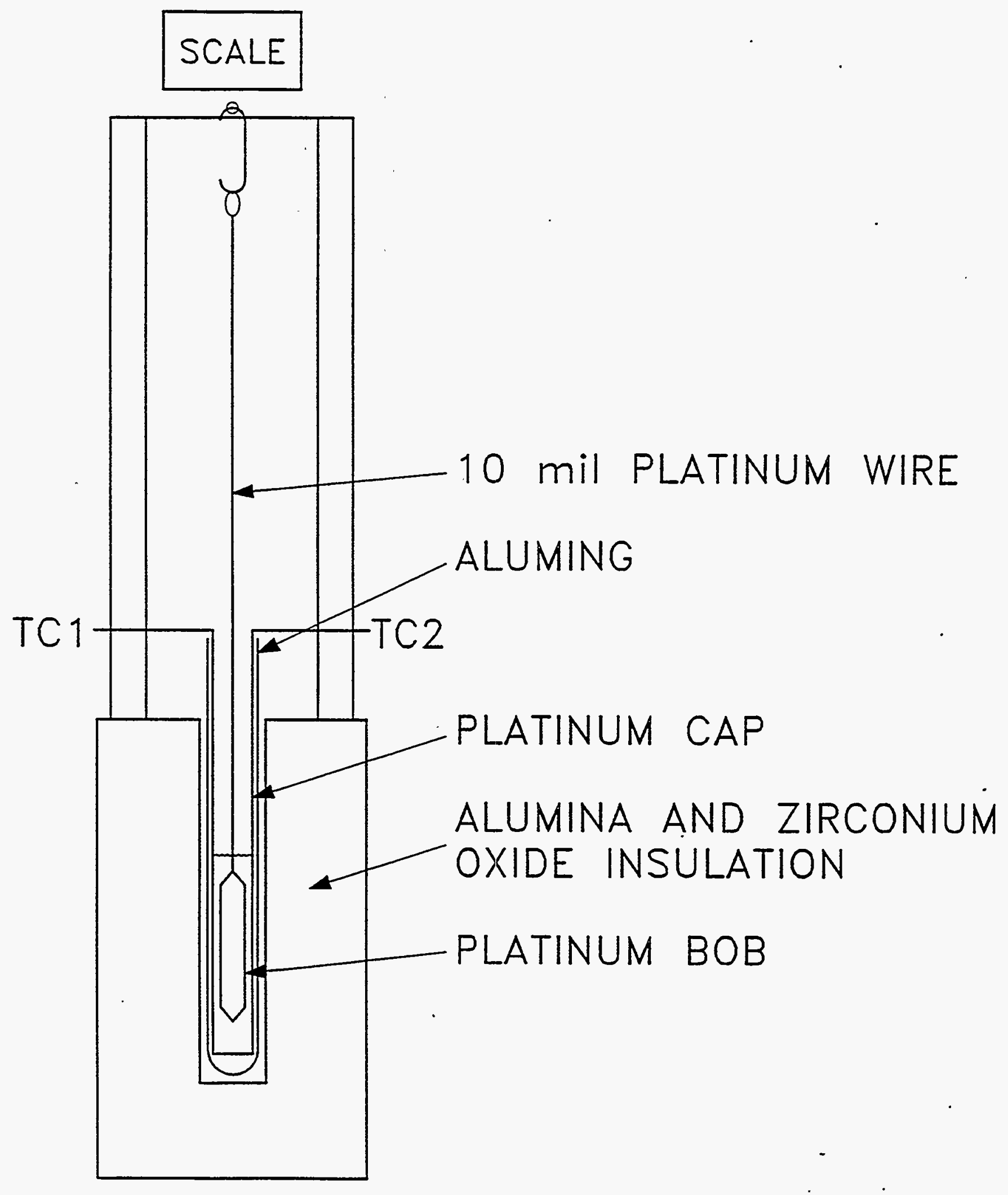

Fig. D.6. Experimental apparatus to measure thermal expansion coefficient of glass. 


\begin{tabular}{cc}
\hline $\begin{array}{c}\text { Temperature } \\
\left({ }^{\circ} \mathrm{C}\right)\end{array}$ & $\begin{array}{c}\text { Volume } \\
\left(\mathrm{cm}^{3}\right)\end{array}$ \\
\hline 20 & 4.166 \\
600 & 4.237 \\
700 & 4.250 \\
800 & 4.264 \\
900 & 4.278 \\
\hline
\end{tabular}

The mass measurements were taken over a composition range of 1:1 to $3: 1 \mathrm{PbO}: \mathrm{B}_{2} \mathrm{O}_{3}$ molar ratio. The mass of the platinum cylinder in air is $82.24 \mathrm{~g}$. Table D.16 gives the measured mass of the immersed cylinder and the calculated glass densities. Figures D.7 and D.8 show the effect of composition and temperature on the glass densities and compares it to that found in the literature. These data enable us to calculate the average thermal expansion over the $100^{\circ} \mathrm{C}$ temperature interval. As an estimate, this is denoted as the thermal expansion at the mean temperature between the two density measurements. It is obvious from the data that the expansion coefficient is not linear with temperature, but it is the best possible estimate from the available data. These coefficients are given in Table D.17. Figures D.9 and D.10 show the effect of composition and temperature on the expansion coefficients and compares it to that found in the literature.

\section{D.9 REFERENCES}

Drotning, W. D., 1984. Density and Thermal Expansion Measurements of Several Mixed Oxide Glasses in the Solid and Liquid Regions, SAND84-2006, Sandia National Laboratory, Albuquerque, New Mexico.

Eagan, R. J., et al. "Crystal Growth in the System PbO- $\mathrm{B}_{2} \mathrm{O}_{3}$ "” J. Amer. Ceramic Soc. 53(4),214. 
D-28

Table D.16. Density of lead borate glasses

\begin{tabular}{|c|c|c|c|c|c|c|}
\hline \multirow[b]{3}{*}{$\begin{array}{c}\text { Temperature } \\
\left({ }^{\circ} \mathrm{C}\right) \\
\end{array}$} & \multicolumn{6}{|c|}{$\mathrm{PbO}: \mathrm{B}_{2} \mathrm{O}_{3}$ molar ratio } \\
\hline & \multicolumn{2}{|c|}{ 1:1 } & \multicolumn{2}{|c|}{$2: 1$} & \multicolumn{2}{|c|}{$3: 1$} \\
\hline & $\begin{array}{c}\text { Cylinder } \\
\text { mass } \\
\text { (g) }\end{array}$ & $\begin{array}{l}\text { Density } \\
\left(\mathrm{g} / \mathrm{cm}^{3}\right)\end{array}$ & $\begin{array}{c}\text { Cylinder } \\
\text { mass } \\
(\mathrm{g})\end{array}$ & $\begin{array}{l}\text { Density } \\
\left(\mathrm{g} / \mathrm{cm}^{3}\right)\end{array}$ & $\begin{array}{c}\text { Cylinder } \\
\text { mass } \\
\text { (g) }\end{array}$ & $\begin{array}{l}\text { Density } \\
\left(\mathrm{g} / \mathrm{cm}^{3}\right)\end{array}$ \\
\hline 600 & 59.862 & 5.28 & & & & \\
\hline 615 & & & 55.921 & 6.27 & 54.076 & 6.64 \\
\hline 700 & 60.352 & 5.15 & & & & \\
\hline 715 & & & 56.24 & 6.12 & 54.346 & 6.56 \\
\hline 800 & 60.802 & 5.03 & & & & \\
\hline 815 & & & 56.528 & 6.03 & 54.586 & 6.48 \\
\hline 900 & 61.187 & 4.92 & & & & \\
\hline 915 & & & 56.8 & 5.94 & 54.827 & 6.41 \\
\hline
\end{tabular}

Table D.17. Thermal expansion coefficients $\left(1 /{ }^{\circ} \mathrm{C} \times 10^{4}\right)$ for lead borate glasses

$\mathrm{PbO}: \mathrm{B}_{2} \mathrm{O}_{3}$ molar ratio

\begin{tabular}{cccc}
$\begin{array}{c}\text { Temperature } \\
\left({ }^{\circ} \mathrm{C}\right)\end{array}$ & $1: 1$ & $2: 1$ & $3: 1$ \\
\hline 650 & 2.53 & & \\
665 & & 1.53 & \\
750 & 2.40 & & 1.27 \\
765 & & 1.47 & \\
850 & 2.15 & & 1.20 \\
865 & & 1.35 & \\
\hline
\end{tabular}




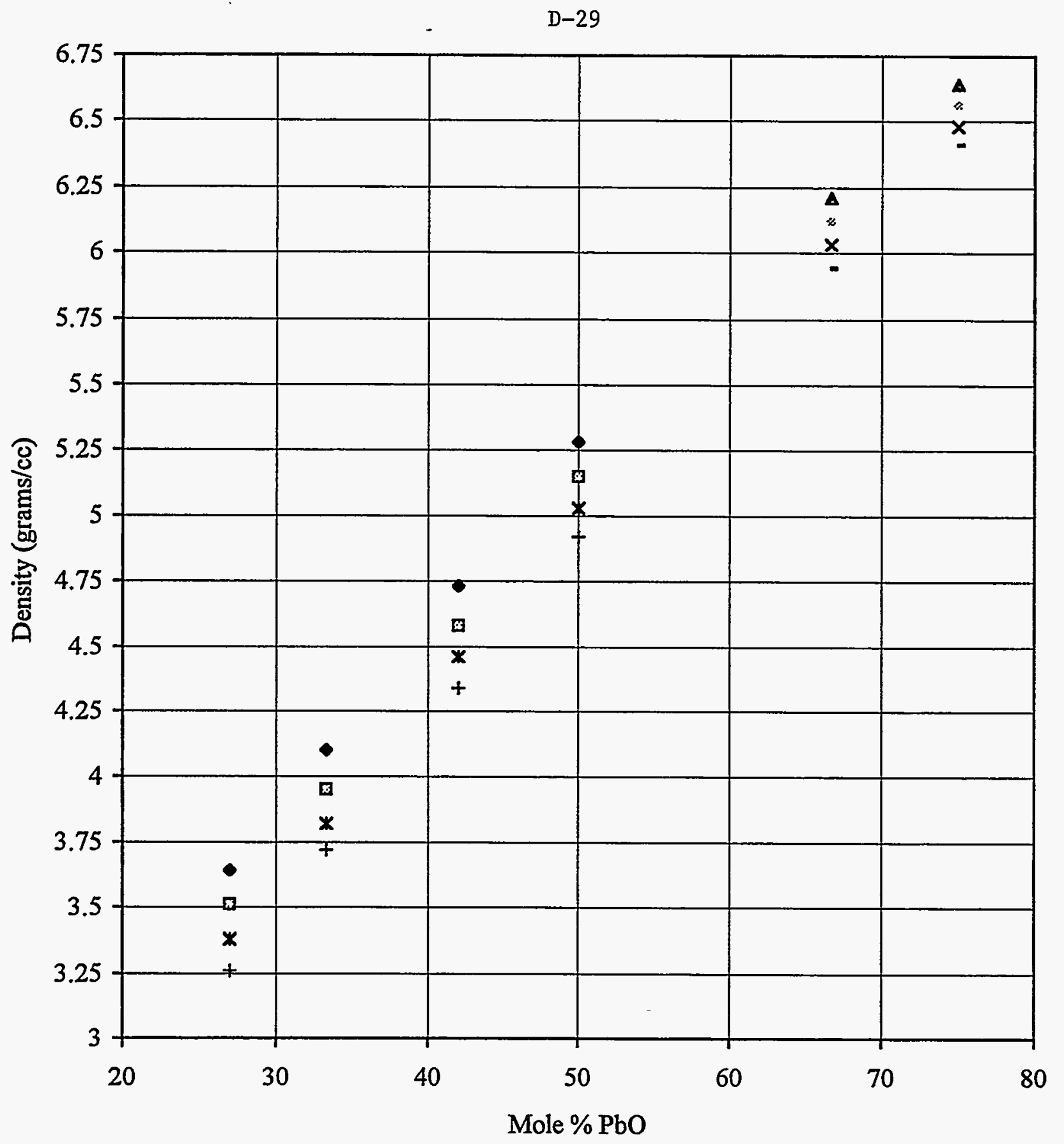

- $600 \Delta 615 \square 700 * 715 \times 800 \times 815+900-915$

Fig. D.7. Density vs mol \% $\mathrm{PbO}$ for borate glasses between 600 and $900^{\circ} \mathrm{C}$. 


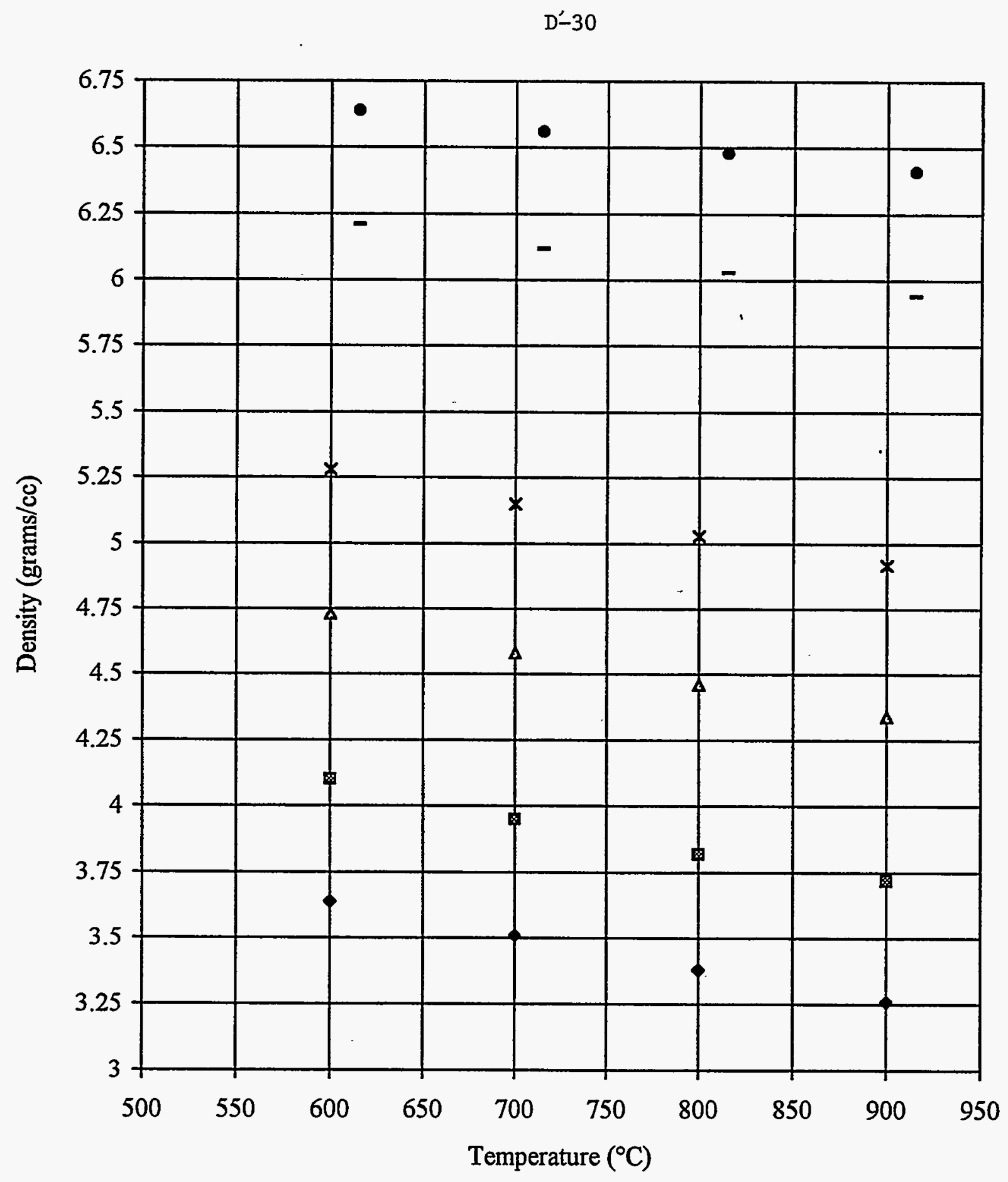

$\bullet 1: 2.7 \times 1: 2 \Delta 1: 1.4 \times 1: 1-2: 1 \bullet 3: 1$

Fig. D.8. Density vs temperature for $1: 2.7$ to $3: 1$ molar ratio $\mathrm{PbO}: \mathrm{B}_{2} \mathrm{O}_{3}$ glass melts. 


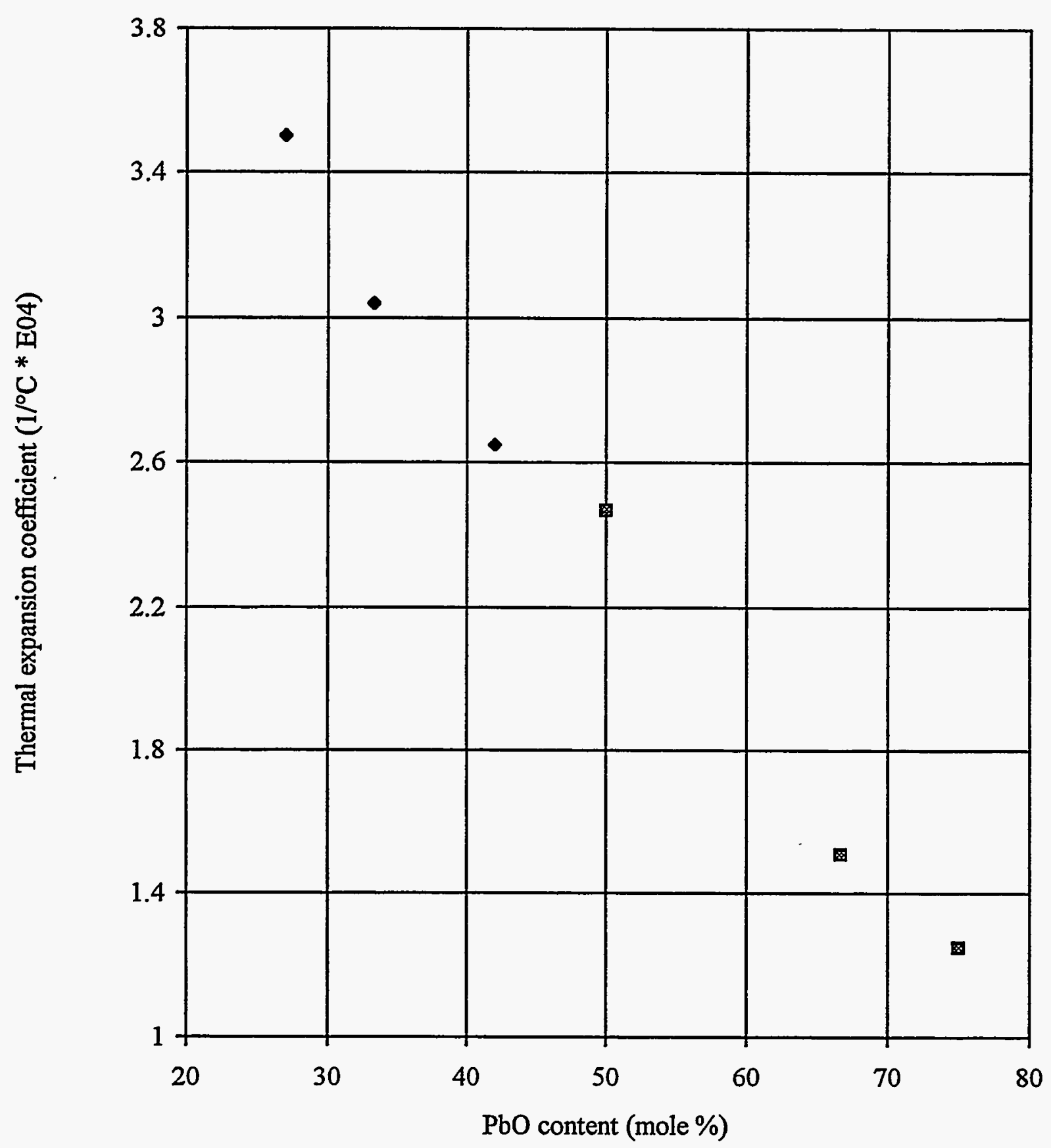

- Literature data Experimental data

Fig. D.9. Thermal expansion coefficient vs $\mathrm{PbO}$ content in borate glasses at $700^{\circ} \mathrm{C}$. 


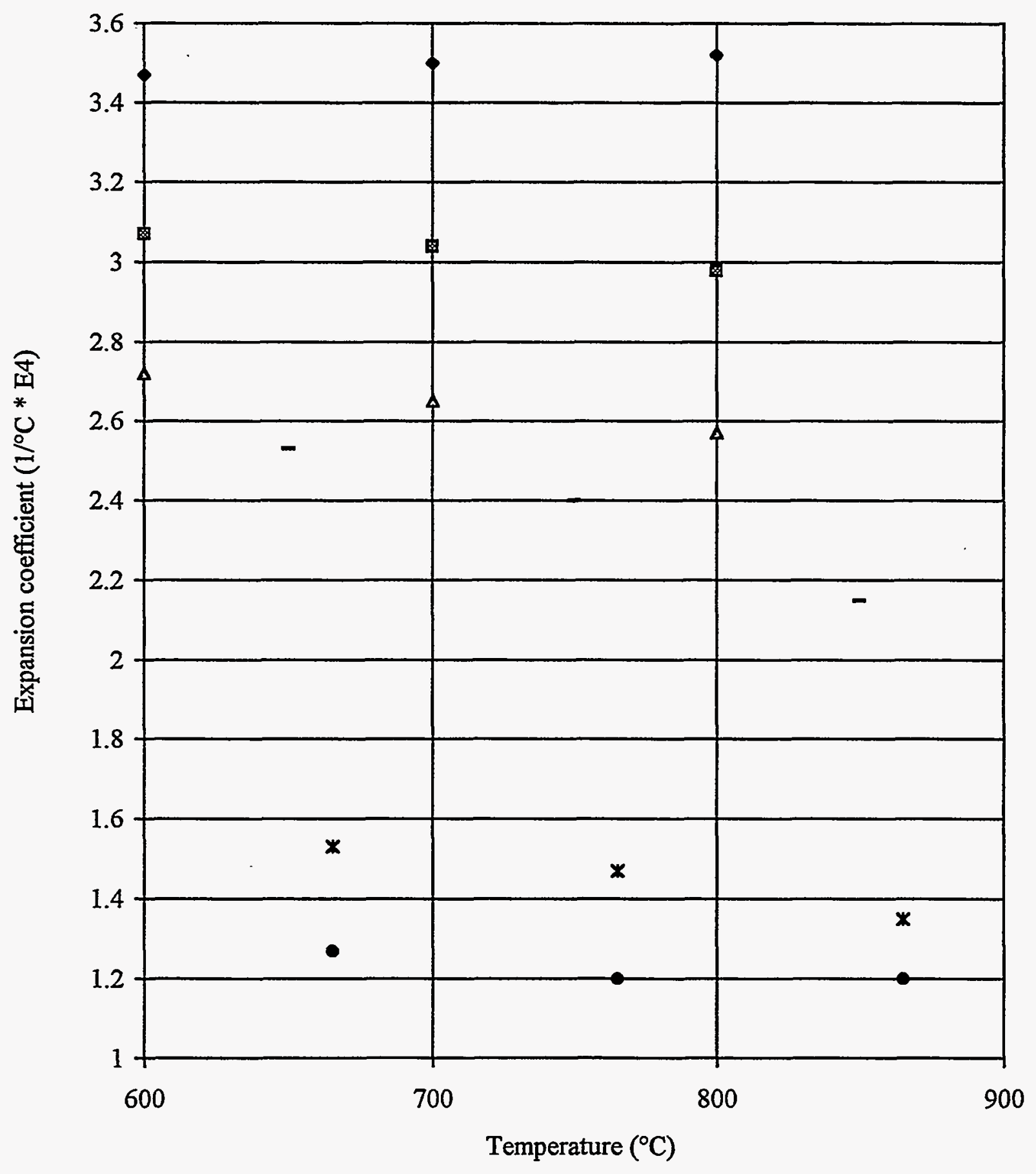

$\bullet 27 \otimes 33 \triangle 42-50 \times 67 \bullet 75$

Fig. D.10. Thermal expansion vs temperature for $27-75 \mathrm{~mol} \% \mathrm{PbO}$ in $\mathrm{B}_{2} \mathrm{O}_{3}$ glass. 
Appendix E:

THERMAL HYDRAULIC ANALYSIS OF COMSORS IN THE GE SBWR 


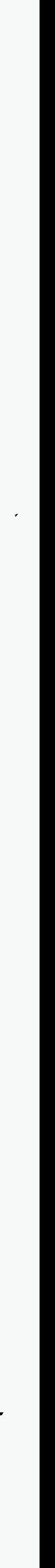




\section{E.1 INTRODUCTION}

If a severe accident should occur that subsequently leads to vessel failure, concerns are widely held that the debris may not be coolable on the containment floor. The COMSORS concept is a new option to address this concern.

In the case of the GE SBWR, the concept envisions the placement of a large mass of lead borate glass in the lower drywell underneath the reactor vessel. If core debris is released to the lower drywell, it is believed that the debris would become dissolved in glass. This process would provide several benefits:

1. The metallic components of the debris (e.g., zirconium) would reduce the lead oxide, forming metal oxides and free lead without generating noncondensible gasses or releasing appreciable quantities of fission products.

2. The process of melting the glass represents an important heat sink.

3. After dissolution, the debris would be spread over a large area and diluted. Convective cells would develop in the large debris-glass pool that would carry decay heat to the pool boundaries at relatively low temperatures.

The work reported herein is a thermal hydraulic analysis of a COMSORS design for SBWR. The intent is to assess the feasibility of COMSORS and to identify issues requiring further study.

Two broad issues are addressed in this appendix. The primary purpose of the work was to address the behavior of the pool after the debris has dissolved in the glass. These calculations were intended to see what temperatures and heat fluxes would be imposed on the rest of the containment in the long term and to assess the sensitivity of these results to uncertainties in material properties. The other issue addressed is more difficult: What conditions will prevail while the fuel is undergoing dissolution? The intent of the second set of analyses was to assist in the planning of experiments intended to study the kinetics of mixing and to obtain a qualitative understanding of the behavior of the fuel during this phase.

\section{E.2 ASSUMED REFERENCE CONFIGURATION}

Figure E.1 shows the proposed COMSORS installation in the SBWR lower drywell. This reference arrangement was chosen to maximize the mass of COMSORS material that could be fit into the lower drywell without affecting the current "corium shield" envelope and without compromising the "pit" that is needed below the maintenance platform elevation for control rod drive (CRD) maintenance (Buchholz, 1995). The steel thickness assumed for the corium shield is based on the upper shield thickness shown in Fig. 19B.3-2 of the SBWR Standard Safety Analysis Report (General Electric Company, 1993). The 


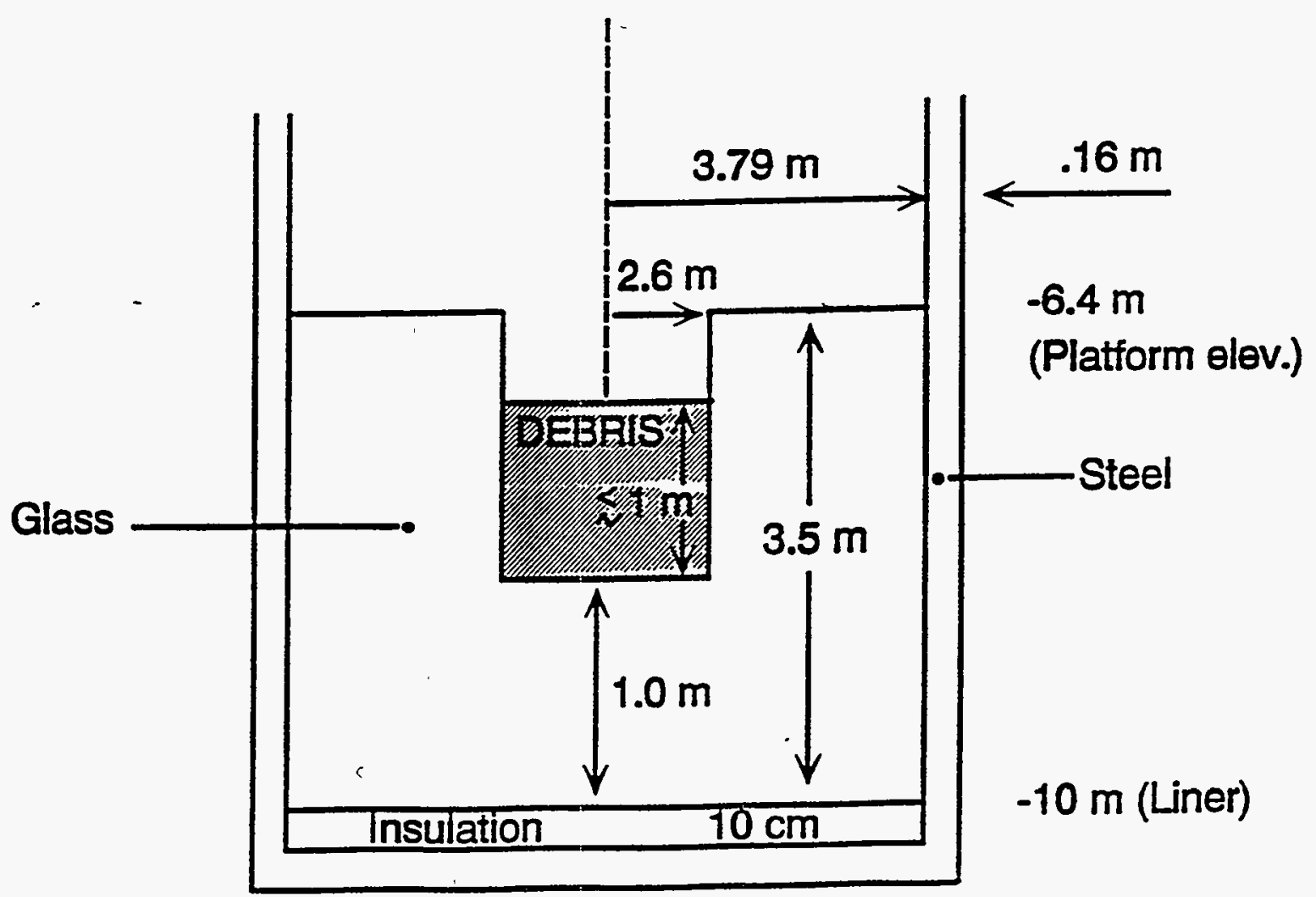

Fig. E.1. Proposed base-case configuration just after vessel failure. 
assumed shield inner radius provides a floor area slightly larger than that provided by the $0.02-\mathrm{MW} / \mathrm{m}^{2}$ criterion specified in the EPRI ALWR Utility Requirements Document (1993). This assumption is intended to approximately account for the replacement of sacrificial concrete by the glass.

Previous COMSORS work has proposed that layers of lead be added to the glass to supplement the free lead that will develop naturally because of the gradual reduction of the lead oxide by zirconium. A lead layer would slow the downward progression of the core debris, thus giving the glass time to dissolve the debris. For this analysis, no free lead has been added to the reference design.

Calculations with the reference configuration are intended primarily to elucidate information on the sensitivity of the overall quasi-steady pool-heat-transfer behavior to uncertainties in material properties. Consideration of the transient mixing behavior before steady state leads to the consideration of alternate debris and pool configurations, including some with added lead. These are discussed separately. In some cases, these alternative configurations may require changes in the SBWR corium shield envelope.

The important geometric parameters for the proposed reference design are summarized in Table E.1:

Table E.1. Reference design parameters

\begin{tabular}{cc}
\hline Quantity & Value \\
\hline Pool radius & $3.79 \mathrm{~m}$ \\
Steel thickness & $0.16 \mathrm{~m}$ \\
COMSORS initial volume & $105 \mathrm{~m}^{3}$ \\
\hline
\end{tabular}

\section{E.3 COMSORS/DEBRIS COMPOSITION IN REFERENCE CONFIGURATION}

The assumed reference configuration contains an initial glass volume of about $105 \mathrm{~m}^{3}$. Experimental measurements (Appendix D) indicate that it is helpful to maintain a $\mathrm{PbO}: \mathrm{B}_{2} \mathrm{O}_{3}$ molar ratio $>2: 1$ to increase the solubility of fuel in the glass. Because a portion of the $\mathrm{PbO}$ will be reduced by the metallic zirconium and steel in the debris, we therefore assume that 3:1 $\mathrm{PbO} \cdot \mathrm{B}_{2} \mathrm{O}_{3}$ is used. The density of this solid has been estimated to be $7.7 \mathrm{~g} / \mathrm{cm}^{3}$ (Appendix D). Thus, the initial glass mass is $810 \mathrm{t}$.

We assume that the composition of the initial pour of debris is the same as that given by Sienicki, Chu, and Spencer (1993) as shown in Table E.2: 
Table E.2. Composition of core melt debris, initial post-accident conditions, and final post-accident conditions

\begin{tabular}{|c|c|c|c|}
\hline \multirow[b]{2}{*}{ Material } & \multicolumn{3}{|c|}{ Mass (t) } \\
\hline & Core debris & $\begin{array}{l}\text { Initial core debris } \\
\text { and COMSORS }\end{array}$ & Final conditions \\
\hline $\mathrm{UO}_{2}$ & 81 & 81 & \\
\hline $\mathrm{ZrO}_{2}$ & 30 & 30 & \\
\hline Stainless steel & 10 & 10 & \\
\hline$Z_{r}$ & 10 & 10 & \\
\hline $\mathrm{PbO}$ & & 733 & 587 \\
\hline $\mathrm{B}_{2} \mathrm{O}_{3}$ & & 77 & 77 \\
\hline $\mathrm{ZrO}_{2}$ & & & 43.5 \\
\hline $\mathrm{U}_{3} \mathrm{O}_{8}$ & & & 84.2 \\
\hline $\mathrm{Fe}_{3} \mathrm{O}_{4}$ & & & 13.8 \\
\hline $\mathrm{Pb}$ & & & 135 \\
\hline
\end{tabular}

Given these assumptions, the initial composition of the materials in the drywell just after vessel failure is defined (Table E.2). If we conservatively assume that all the metallic zirconium eventually oxidizes to $\mathrm{ZrO}_{2}$, the iron component of the steel oxidizes to $\mathrm{Fe}_{3} \mathrm{O}_{4}$, and the $\mathrm{UO}_{2}$ becomes $\mathrm{U}_{3} \mathrm{O}_{8}$ (Forsberg, 1995), the consumption of $10.5 \mathrm{t}$ of oxygen originally in the $\mathrm{PbO}$ is required; this liberates about $135 \mathrm{t}$ of metallic lead. The final composition of the debris after oxidation is complete is shown in Table E.2.

The three-digit precision shown provides a convenient means for checking the mass balance and providing a ratio of the results for other assumed discharged masses (it is not implied that such a level of accuracy can be achieved). The molar ratio of $\mathrm{PbO}: \mathrm{B}_{2} \mathrm{O}_{3}$ represented by these masses is nearly 2.4 , a ratio above the minimum desired ratio of 2.0 ; the excess $\mathrm{PbO}$ provides extra oxygen to oxidize additional $\mathrm{Zr}$ and iron above that assumed to be discharged from the vessel.

The effects of steel on the glass properties has not yet been studied. We therefore conservatively assume that iron oxide has the same deleterious effects as zirconium oxide on properties like viscosity. The mass of 
the nonuranium metal oxides as a fraction of the remaining glass mass is $9 \%$; the corresponding figure for the uranium oxide is $13 \%$. These figures appear to be well below the solubility limits measured (Appendix D) for elevated pool-temperature ranges. Experimental measurements have been made of a mixture of $6.7 \mathrm{wt} \%$ $\mathrm{ZrO}_{2}$ and $13.3 \mathrm{wt} \% \mathrm{U}_{3} \mathrm{O}_{8}$ (Appendix D).

\section{E.4 MATERIAL PROPERTIES}

The material properties shown in Table E. 3 will be assumed in the reference case thermal-hydraulic analysis.

Table E.3. Reference material properties

\begin{tabular}{|c|c|c|c|}
\hline Material & Property & Value & Reference \\
\hline Lead & $\begin{array}{l}\text { Thermal conductivity } \\
\text { Density }\end{array}$ & $\begin{array}{l}19.8 \mathrm{~W} / \mathrm{mKK} \\
10.1 \mathrm{~g} / \mathrm{cm}^{3}\end{array}$ & $\begin{array}{l}\text { Avallone and Baumeister } \\
\text { Avallone and Baumeister }\end{array}$ \\
\hline Concrete & $\begin{array}{l}\text { Thermal conductivity } \\
\text { Density } \\
\text { Specific heat }\end{array}$ & $\begin{array}{l}1.8 \mathrm{~W} / \mathrm{mK} \\
2.3 \mathrm{~g} / \mathrm{cm}^{3} \\
650 \mathrm{~J} / \mathrm{kg}-\mathrm{K}\end{array}$ & $\begin{array}{l}\text { Avallone and Baumeister } \\
\text { Avallone and Baumeister } \\
\text { Avallone and Baumeister }\end{array}$ \\
\hline Steel & Thermal conductivity & $33 \mathrm{~W} / \mathrm{mK}$ & Eckert and Drake \\
\hline \multirow{4}{*}{$\begin{array}{l}\text { Glass and fuel } \\
\text { mixture }\end{array}$} & Volumetric expansion coefficient & $2 \times 10^{-4} \mathrm{~K}^{-1}$ & Appendix D \\
\hline & Specific heat & $527 \mathrm{~J} / \mathrm{kg}-\mathrm{K}$ & Appendix D \\
\hline & Density & $\sim 8 \mathrm{~g} / \mathrm{cm}^{3}$ & Appendix D \\
\hline & Softening temperature & $748^{\circ} \mathrm{K}$ & Appendix D \\
\hline
\end{tabular}

An important material property is the glass-debris mixture viscosity. The values (Table E.4) were taken from Appendix $\mathrm{D}$ for a mixture of $13.3 \mathrm{wt} \% \mathrm{U}_{3} \mathrm{O}_{8}$ and $6.7 \mathrm{wt} \% \mathrm{ZrO}_{2}$ (rather close to the calculated weight fractions) after (it is assumed) all the fuel stimulant has been fully dissolved. The values at the lowest rheometer shear rate for which complete data were recorded were selected: 
Table E.4. Glass viscosity vs temperature

\begin{tabular}{cc}
\hline $\begin{array}{c}\text { Temperature } \\
(\mathrm{K})\end{array}$ & $\begin{array}{c}\text { Viscosity } \\
(\mathrm{kg} / \mathrm{m}-\mathrm{K})\end{array}$ \\
\hline 1063 & 0.743 \\
1168 & 0.330 \\
1373 & 0.099 \\
\hline
\end{tabular}

These values were used in the thermal hydraulic calculations. Simple linear interpolation was used between the data points, and linear extrapolation was also used for temperatures lower than those shown (no cases resulted in temperatures higher than $1373 \mathrm{~K}$, so extrapolation was not needed for values higher than the available data). A different, perhaps superior extrapolation procedure is also provided in the model (see Appendix A, Section 6) which gave similar results.

An even more important quantity is the thermal conductivity. According to Gardon (1961), the thermal conductivity of glass is notoriously difficult to measure. However, at the high temperatures of interest, the "effective" thermal conductivity is primarily due to radiation within the glass for which it can be shown that:

$$
k=\frac{16}{3} n^{2} \sigma \lambda T^{3}
$$

Here $n$ is the index of refraction, $\lambda$ is a weighted photon path length, $\sigma$ is the Stefan-Boltzman constant, and $\mathrm{T}$ is the absolute temperature. Lacking better information, the base-case calculations were based on this model with values typical of clear glass (Gardon, 1961):

$$
\begin{array}{r}
\mathbf{n}=1.5 \\
\lambda=0.070
\end{array}
$$


Sensitivity calculations were used to investigate the effects of smaller values of $k$ which could be expected because of the "darkening" effect of added impurities such as the core debris. When considering the likely range in thermal conductivity, it should also be recognized that thermal conductivity values for $\mathrm{Na}_{2} \mathrm{O}$ $\mathrm{CaO}-\mathrm{SiO}_{2}$ glass are about $20 \%$ of those predicted by the expression and parameter values provided previously (Gardon, 1961).

Another important property is the "softening temperature" of the glass. At low temperatures, glass behaves as an extremely viscous liquid. Given enough time (centuries), it will change its shape. For simplicity, one conveniently speaks of the softening temperature, above which the viscosity drops enough for the glass to begin to be treated as a flowing liquid in the time scales of interest. In these calculations, the softening temperature was treated in a manner very similar to that of a melting temperature, but the lack of a definite phase change in the real material as it is heated should be récognized. Based on the calculations presented in Sect. E.9, it appears that the viscosity at the conventionally defined softening temperature is so high that a more nearly accurate representation would be to consider the glass fully liquified at an "effective melting temperature" about $100 \mathrm{~K}$ higher than the softening temperature. This was performed in a sensitivity calculation. Based on the results to be discussed later, the "effective melting temperature" and the thermal conductivity appear to be the most important of all the physical properties. They are also the ones which are the least well characterized.

\section{E.5 FINAL POOL CONFIGURATION}

After the debris has been fully dissolved and oxidized by the glass, it is believed that the metallic lead liberated by the reduction of $\mathrm{PbO}$ will settle to the bottom of the pool because of its relatively high density. If we assume a uniform configuration, the thickness of this lead layer would be $\sim 0.30 \mathrm{~m}$, and the thickness of the glass-debris layer lying on top of the lead would be $\sim 2.24 \mathrm{~m}$.

\section{E.6 THERMAL HYDRAULIC CALCULATIONS}

\section{E.6.1 Model Description}

A modified version of the simple thermal-hydraulics model of Kenton (1995) was used to analyze the long-term, quasi-steady-state performance of the reference design. The model is described in Appendix SE.1. Several changes were made to the model. First, the glass thermal conductivity model described previously was added. Since the thermal conductivity is a strong function of temperature, separate values are calculated for the molten pool and for each of the three crusts. For the crusts, the thermal conductivity is evaluated at 
the average temperature of each crust. It is worth noting that aside from the uncertainties in the index of refraction and the photon path length, additional uncertainties apply to the crusts since not all the photons emitted there will be absorbed in the glass (Gardon, 1961). This phenomenon may, in fact, also increase the "effective" value for the convective heat transfer coefficients.

Second, a different set of heat transfer correlations for the sideward and upward heat flux from a volumetrically heated, rectangular pool were taken from the work of Steinberner and Reineke (Kymalainen, 1994). These were used for the reference case reported herein because they cover a much higher range of Rayleigh numbers than the original Fieg and Werle correlations used by Kenton (1995). Graphs comparing the two sets of correlations are shown in Figs. E.2 and E.3. For our purposes, they give reasonably similar results. The Fieg and Werle upward and sideward correlations, which were developed for a right circular cylinder, were used in one of the sensitivity calculations. The original (Fieg and Werle) correlation for the downward heat flux is still used. While it was developed from data covering relatively low Rayleigh numbers, the correlation of Mayinger (Theofanous, 1994) suggests that the downward heat flux should become small as the radius of curvature of the pool base becomes large compared to the pool height. Thus, any errors in the overall predicted behavior should be small. A graph showing the relative magnitude of the heat fluxes as a function of Rayleigh number is shown in Fig. E.4.

The third change in the model concerns the calculation of temperatures in the lower concrete slab. As will be discussed later, some means must be provided to handle the heat flux that is directed downward into the slab. Consideration of this problem made it clear that a more appropriate analytical treatment of the temperature in the slab is that provided by a constant heat flux boundary condition rather than the constant surface temperature assumption used by Kenton (1995). In this regard, it is worth noting that the change in internal heating in the pool between $1 \mathrm{~d}$ and, for example, $12 \mathrm{~d}$ is $<50 \%$. This finding makes the constant heat flux assumption a reasonable one for these analyses. Since the steady-state downward heat fluxes are

likely to be very small relative to those directed upward and sideward into the water, any errors resulting from these idealized boundary conditions will impact only the calculation of the concrete temperatures, not the overall pool behavior.

The final change in the model allows an option to study alternate COMSORS configurations with a spherical bottom head. This will be discussed in Section E.10.

\section{E.6.2 Results for Reference Case}

In the reference case calculation, it is assumed that nucleate boiling can be sustained on the top surface (upward heat transfer coefficient is large). This is reasonable, given the relatively low calculated upward heat fluxes of $\sim 130 \mathrm{~kW} / \mathrm{m}^{2}$ and the relatively low thermal conductivity of the upper crust, but a sensitivity calculation is made for this assumption also. 


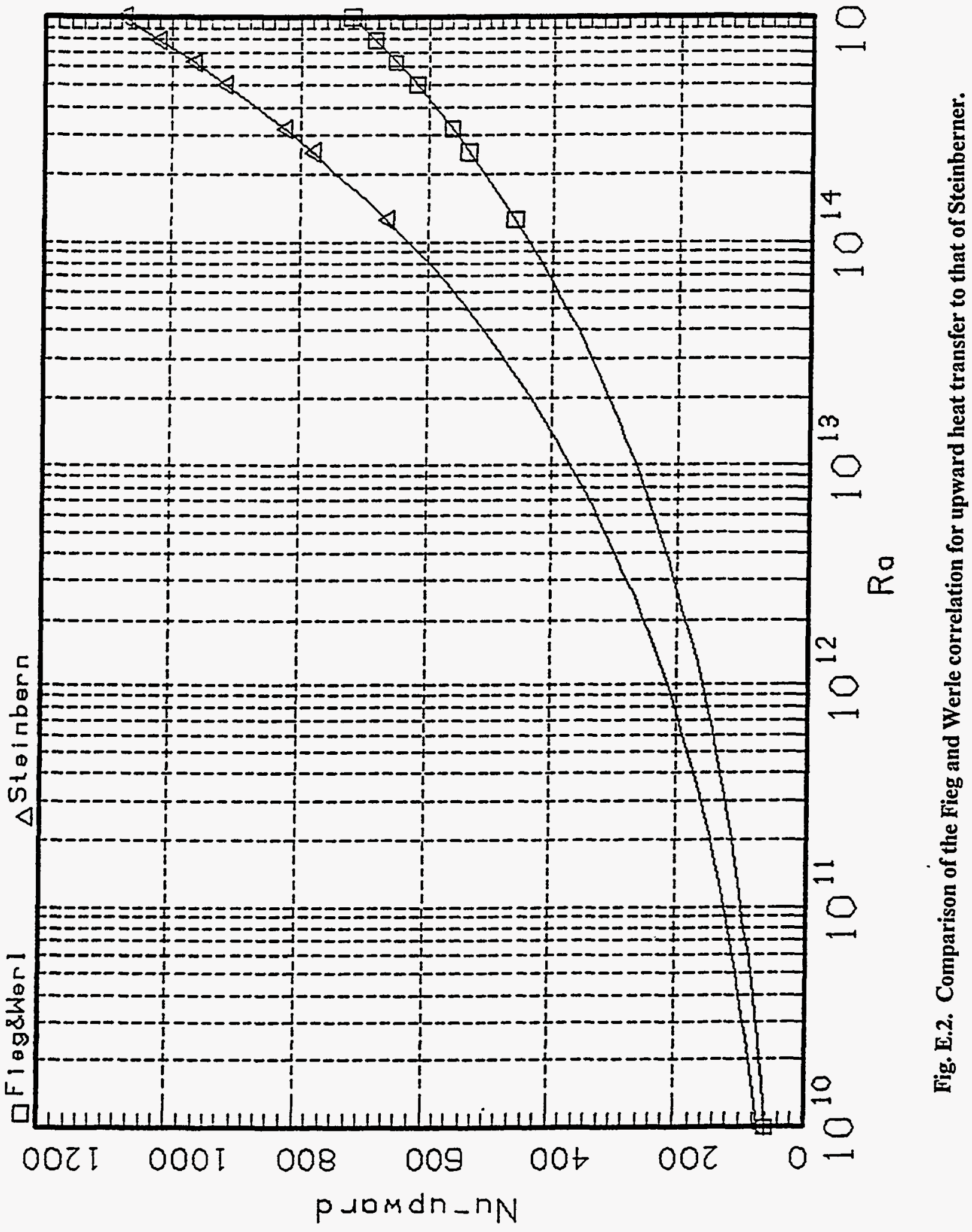




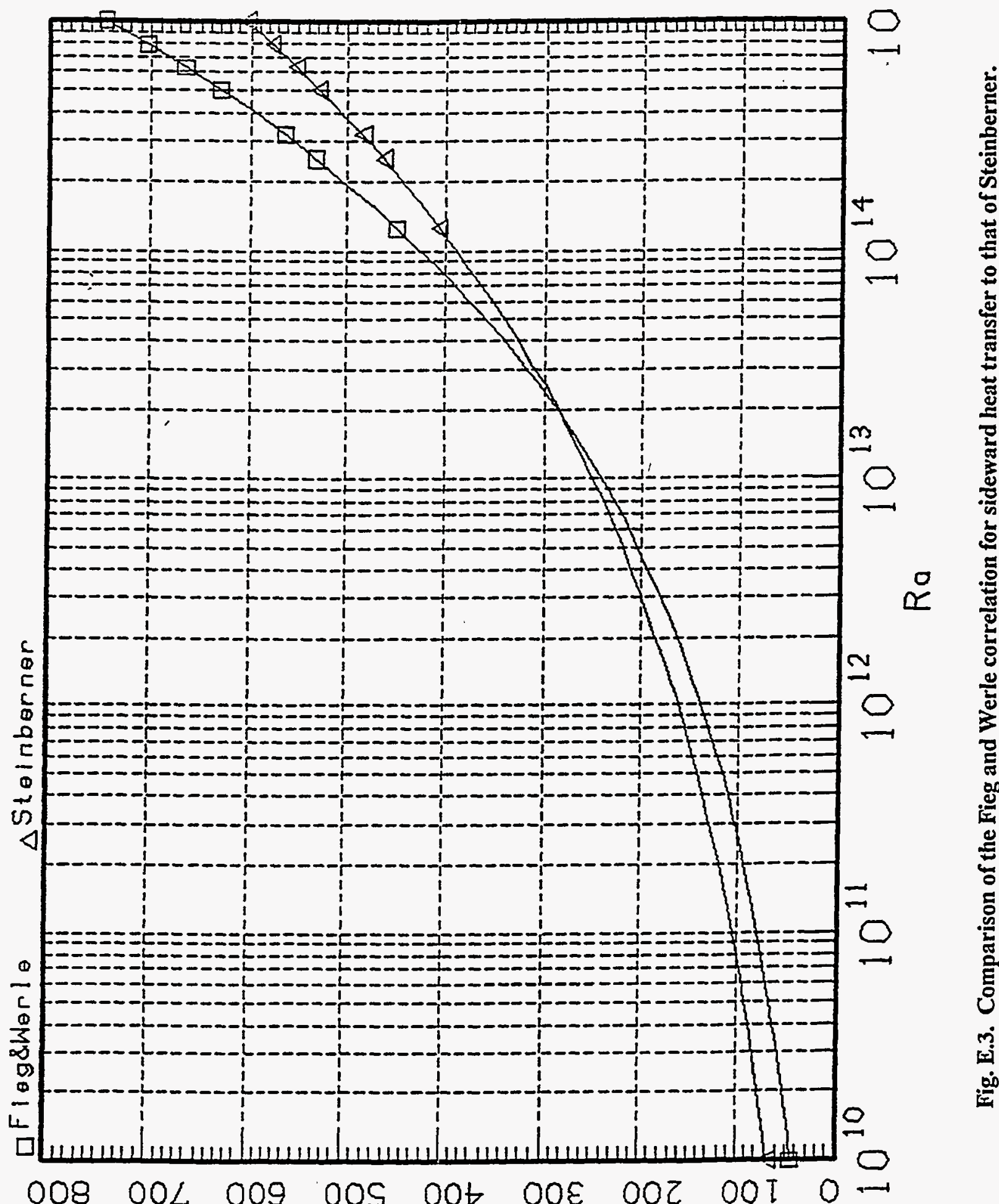

puomap!s-nN 


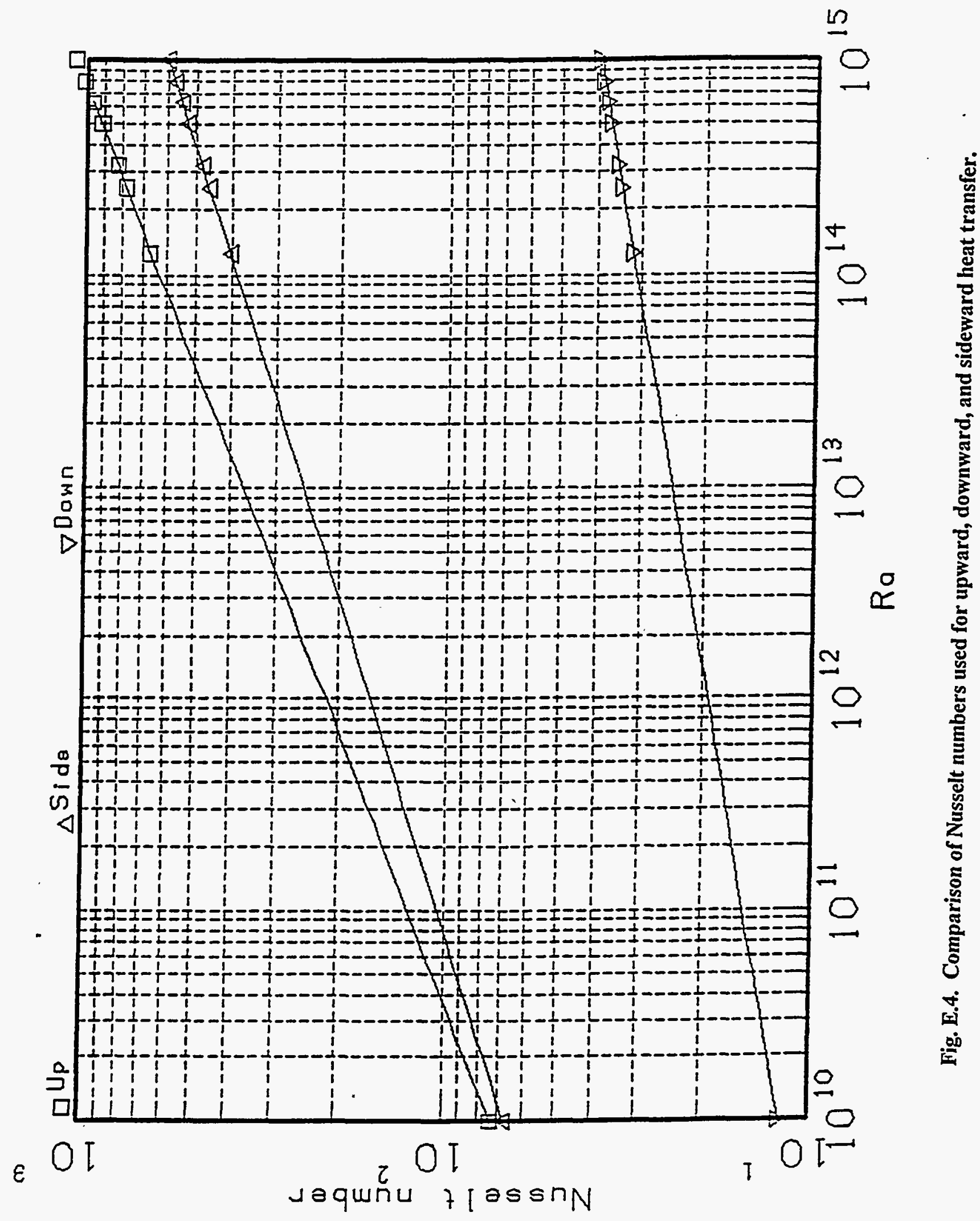


The inputs developed in the previous sections are shown in Tables E.5 and E.6. As shown, a relatively thin insulation layer with properties typical of high temperature insulators has been provided under the lead to help protect the concrete; variations in the insulation parameters will be investigated in Sect. E.7.

The output from the model for the reference case is shown in Table E.7. Noteworthy features of these results are:

1. The downward heat flux is very small, about $400 \mathrm{~W} / \mathrm{m}^{2}$, as anticipated, resulting from both the form of the correlations used for the convective heat flux and the insulation layer that has been provided.

2. As a consequence of the low heat fluxes, the lower concrete slab upper-surface temperature at $\sim 1$ day is quite low, $\sim 390 \mathrm{~K}$.

3. Because of the thickness of the steel boundary, a crust of frozen glass/fuel mixture forms only on the top of the pool. However, it should be noted that even a slight reduction in corium shield thickness would lower the side interface temperature from $766 \mathrm{~K}$ to below the assumed effective melting temperature of $748 \mathrm{~K}$ and thus cause a crust to form on the side.

4. The calculated pool temperature is much lower than the minimum temperature in the viscositytemperature table. For this reason, the linearly extrapolated viscosity is quite high ( $1700 \mathrm{cp})$.

5. The bulk pool temperature of $\sim 820 \mathrm{~K}$ is much lower than the boiling temperature of lead $(\sim 2000 \mathrm{~K})$.

6. The calculated value for the internal Rayleigh number $\left(3 \times 10^{11}\right)$ is between the maximum value studied by Fieg and Werle $\left(4 \times 10^{9}\right)$ and the minimum value studied by Steinberner and Reineke $\left(8 \times 10^{12}\right)$. This gives us confidence that we can bound the expected behavior by using both sets of correlations.

7. The calculated molten glass thermal conductivity is quite large $(-26 \mathrm{~W} / \mathrm{m} \cdot \mathrm{K})$, i.e., comparable to valueș for steel.

\section{E.7 SENSITIVITY CALCULATIONS FOR REFERENCE CONFIGURATION}

A number of sensitivity calculations were performed to gain insights into the most important material property parameters for the quasi-steady behavior. The results are summarized in Table E. 8 and discussed briefly below. In each case, one parameter was varied from the values used in the reference case.

a. Use of the Fieg and Werle correlations rather than those of Mayinger and Reineke causes an increase of only $-16 \mathrm{~K}$ in the pool temperature.

b. Case $\mathrm{b}$ involves an arbitrary increase in all the viscosity table entries by a factor of 5 . Viscosity enters into the heat transfer correlations via the Rayleigh number, and from the form of the Rayleigh number, it can be easily seen that an increase in viscosity has the same effect as a decrease in volumetric expansion coefficient $\beta$ by the same factor. The result of either change is an increase in 
Table E.5. COMSORS thermal-hydraulic model pool parameters

Problem time-related quantities

Decay heat $=1 \times 10^{7} \mathrm{~W}$

Time $=1 \times 10^{5} \mathrm{~s}$

Overall pool geometry ${ }^{a}$

Sphere radius of curvature $=1 \times 10^{10}$

Cylinder radius $=3.8 \mathrm{~m}$

Side steel configuration and properties

Steel thickness $=0.16 \mathrm{~m}$

Steel conductivity $=33 \mathrm{~W} / \mathrm{m} \cdot \mathrm{K}$

Side (where applicable) and lower concrete properties

Concrete conductivity $=1.8 \mathrm{~W} / \mathrm{m} \cdot \mathrm{K}$

Concrete density $=2300 \mathrm{~kg} / \mathrm{m}^{3}$

Concrete specific-heat $=650 \mathrm{~J} / \mathrm{kg} \cdot \mathrm{K}$

Concrete temperature $($ initial $)=300 \mathrm{~K}$

Lower pool interface configuration

Lead thickness $-0.30 \mathrm{~m}$

Lead conductivity $=19.8 \mathrm{~W} / \mathrm{m} \cdot \mathrm{K}$

Insulation thickness $=0.10 \mathrm{~m}$

Insulation conductivity $=0.1 \mathrm{~W} / \mathrm{m} \cdot \mathrm{K}$

Upward heat transfer parameters

Water temperature $=400 \mathrm{~K}$

Heat transfer coefficient $=5000 \mathrm{~W} / \mathrm{m}^{2} \cdot \mathrm{K}$

Water emissivity $=0.8$

Crust emissivity $=0.8$

aPool depth entry refers to the "active" pool depth (i.e., excluding the lead layer, if any). The curvature is assumed to be uniform. 
E-16

Table E.6. Base-case glass-fuel mixture property values for well-mixed pool cases

\begin{tabular}{cc}
\hline Viscosity (linear fit) & \\
\hline $\begin{array}{c}\text { Temperature } \\
(\mathrm{K})\end{array}$ & $\begin{array}{c}\text { Viscosity } \\
(\mathrm{kg} / \mathrm{m} \cdot \mathrm{K})\end{array}$ \\
\hline 1063 & 0.743 \\
1168 & 0.330 \\
1373 & 0.099 \\
Specific heat $=527 \mathrm{~J} / \mathrm{kg} \cdot \mathrm{K}$ & \\
Thermal conductivity & \\
Path length $=70 \mathrm{~mm}$ & \\
Index of refraction $=1.5$ & \\
Density $=8000 \mathrm{~kg} / \mathrm{m}^{3}$ & \\
Softening point $=748 \mathrm{~K}$ & \\
\hline
\end{tabular}




\section{E-17}

Table E.7. COMSORS thermal-hydraulic model output for reference case

\begin{tabular}{|c|c|}
\hline Pool temperature $(\mathrm{K})$ & $8.155 \times 10^{2}$ \\
\hline Pool temperature $\left({ }^{\circ} \mathrm{C}\right)$ & $5.424 \times 10^{2}$ \\
\hline Internal heat generation (W) & $1.000 \times 10^{7}$ \\
\hline Computed heat removal (W) & $1.000 \times 10^{7}$ \\
\hline Internal Rayleigh number & $3.203 \times 10^{11}$ \\
\hline Bulk pool viscosity (cp) & $1.716 \times 10^{3}$ \\
\hline Bulk pool thermal conductivity $(\mathrm{W} / \mathrm{m} \cdot \mathrm{K})$ & $2.583 \times 10^{1}$ \\
\hline Upper crust thickness (m) & $2.386 \times 10^{-2}$ \\
\hline Upward heat flux $\left(\mathrm{W} / \mathrm{m}^{2}\right)$ & $1.288 \times 10^{5}$ \\
\hline Interface temperature with water $(\mathrm{K})$ & $4.262 \times 10^{2}$ \\
\hline \multicolumn{2}{|l|}{ No crust is maintained on lower surface } \\
\hline Downward heat flux $\left(\mathrm{W} / \mathrm{m}^{2}\right)$ & $4.165 \times 10^{2}$ \\
\hline Lead upper surface temperature $(\mathrm{K})$ & $8.134 \times 10^{2}$ \\
\hline Insulation upper surface temperature (K) & $8.071 \times 10^{2}$ \\
\hline Lower concrete slab interface temperature $(\mathrm{K})$ & $3.906 \times 10^{2}$ \\
\hline \multicolumn{2}{|l|}{ No crust is maintained on side } \\
\hline Sideward heat flux $\left(\mathrm{W} / \mathrm{m}^{2}\right)$ & $7.537 \times 10^{4}$ \\
\hline Side concrete inside interface temperature $(\mathrm{K})$ & $7.654 \times 10^{2}$ \\
\hline Side steel/concrete interface temperature $(\mathrm{K})$ & $7.654 \times 10^{2}$ \\
\hline
\end{tabular}


bulk pool temperature of $24 \mathrm{~K}$ and little change in upper crust thickness or steel interface temperature. The concrete interface temperature increases by only $3 \mathrm{~K}$. As indicated in Table E.8, multiplying the viscosity vs temperature table entries by 5 actually results in an increase in the assumed viscosity of $\sim 4.7$. This is caused by the resulting small increase in pool temperature which partially offsets the change.

c. Case $c$ is the same as Case b-except that a reduction in viscosity table entries (or an increase in $\beta$ ) by a factor of 5 is made. The changes in the various parameters of interest are about the same as those in Case $b$, but with the opposite sign.

d. Cases $d$ and e involve reductions in the thermal conductivity (for a given temperature) by 50 and $90 \%$, respectively. These reductions result in rather modest increases in the pool temperature to 841 and $930 \mathrm{~K}$, respectively. Again, property changes which tend to increase temperature are partially offset by reductions in viscosity and increases in thermal conductivity. In addition, it should be remembered that the temperature difference driving the convective heat transfer is the pool temperature minus the melting temperature (or the surface temperature if a crust does not form). This is about $70 \mathrm{~K}$ in the reference case; thus, an increase in pool temperature to only $930 \mathrm{~K}$, for example, increases this temperature difference by a factor $>2.5$.

f. A reduction in specific heat by $25 \%$ causes very little change in results.

g. The reference case assumes that nucleate boiling is maintained at the interface between the upper surface of the glass-debris pool and the overlying water pool. In Case $g$, a small heat transfer coefficient was entered to crudely simulate film boiling. The effect of this is to eliminate the upper crust, but the changes in calculated temperatures are quite small.

h. Increasing the assumed effective melting temperature of the glass with dissolved core debris by $100 \mathrm{~K}$ causes a similar increase in pool temperature (the actual increase is somewhat smaller because of the effect of reduced viscosity and increased thermal conductivity), but little change in the concrete interface temperature. A 5-mm crust develops at the steel wall.

i. In the reference case, no frozen crust forms on the sides at the inner steel interface. The absence of a crust may cause the glass to dissolve part of the corium shield. To crudely simulate this, half the thickness of the steel was removed. The reduced conduction resistance causes the inner steel interface temperature to drop substantially; as a result; a 22-mm-thick crust develops. This crust could protect the wall from further erosion.

With regard to the last case (i), it is worth mentioning that the hypothetical removal of half the corium shield amounts to an addition of $\sim 7 \mathrm{~m}^{3}$, or $56,000 \mathrm{~kg}$, of iron to the pool. Erosion can therefore place a substantial demand on the $\mathrm{PbO}$ to supply oxygen and may further degrade the pool viscosity. For these reasons, it seems important to study the effects of steel addition on pool properties. 
Table E.8. Summary of results for reference configuration with different model assumptions

\begin{tabular}{|c|c|c|c|c|c|c|c|c|c|}
\hline Case & $\begin{array}{c}\mathbf{T}_{\text {pool }} \\
(\mathbf{K})\end{array}$ & $\begin{array}{c}\mu \\
(\mathrm{cp})\end{array}$ & $\begin{array}{c}\mathbf{k}_{\text {pool }} \\
(\mathbf{W} / \mathbf{m K}) \\
\end{array}$ & $\mathbf{R a}$ & $\underset{\substack{\text { upward } \\
(\mathrm{mm})}}{ }$ & $\begin{array}{c}X_{\text {sideward }} \\
(\mathrm{mm})\end{array}$ & $\begin{array}{l}\mathrm{T}_{\mathrm{cn}} \\
(\mathrm{K})\end{array}$ & $\mathrm{T}_{\mathrm{CSI}}$ & $\begin{array}{r}\mathbf{Q}_{\text {down }} \\
K W / M^{2} \\
\end{array}$ \\
\hline Reference case & 816 & 1715 & 25.9 & $3.2 \times 10^{11}$ & 23.6 & & 391 & 766 & 0.42 \\
\hline a. Fieg and Werle & 832 & 1650 & 27.5 & $3.0 \times 10^{10}$ & 23.9 & & 394 . & 772 & 0.43 \\
\hline b. $5 \times \mu$ or $0.2 \times \beta$ & 840 & 8100 & 28.2 & $5.7 \times 10^{10}$ & 24.0 & & 395 & 775 & 0.44 \\
\hline c. $2 \times \mu$ or $5 \times \beta$ & 798 & 357 & 24.2 & $1.8 \times 10^{12}$ & 23.3 & & 388 & 760 & 0.40 \\
\hline d. $0.5 \times \mathrm{k}$ & 841 & 1617 & 14.2 & $1.1 \times 10^{12}$ & 11.8 & & 395 & 769 & 0.44 \\
\hline e. $0.1 \times \mathrm{k}$ & 930 & 1280 & 3.8 & $1.3 \times 10^{12}$ & 2.4 & & 409 & 770 & 0.50 \\
\hline f. $0.75 \times C_{p}$ & 820 & 1700 & 26.2 & $2.4 \times 10^{11}$ & 23.7 & & 391 & 767 & 0.42 \\
\hline g. $h_{\text {upward }}=300$ & 841 & 1618 & 28.3 & $2.9 \times 10^{11}$ & & & 395 & 791 & 0.44 \\
\hline h. Softening temperature $=850 \mathrm{~K}$ & 898 & 1394 & 34.4 & $2.2 \times 10^{11}$ & 46 & 5.1 & 405 & 834 & 0.48 \\
\hline i. 0.5 steel thickness & 808 & 1747 & 25.1 & $3.4 \times 10^{11}$ & 27 & 22 & 389 & 619 & 0.41 \\
\hline
\end{tabular}


One key assumption we have made in the preceding analyses is that all the glass is dissolved. However, it is not clear that this dissolution is always guaranteed. To gain an appreciation for the importance of this assumption, consider an (unrealistic) scenario in which the downward-directed heat flux is so small that only the glass located to the side of the debris (as shown in Fig. E.1) is dissolved. There is no reason to assume that this reaction will really occur (in fact, the analysis provided in Appendix SE.2 suggests that it cannot occur); this case is meant only to illustrate the impact of imperfect mixing.

The key results of such an assumption are summarized in Table E.9. Perhaps the most important result is that, given the rather large assumed initial debris discharge, melting only the glass on the side results in a pool with a high mass fraction of $\mathrm{UO}_{2}$ and other metal oxides and a relatively low final $\mathrm{PbO}: \mathrm{B}_{2} \mathrm{O}_{3}$ ratio. To our knowledge, no data exist for such pools, and it is not at all clear that this high fuel loading would be soluble in the molten glass at the temperatures predicted herein.

For the reference configuration, these results taken together suggest that:

1. Pool temperatures will be much lower than the range over which most of the physical property data have been taken. Given the low temperature, this raises the concern that fuel solubilities will be relatively low, leading, perhaps, to the formation of a slurry. On the other hand, the formation of a slurry would be expected to increase the viscosity, which, in turn, would increase the temperature and the solubility. Whether these feedback effects would fully compensate for the tendency of the pool to operate at relatively low temperatures is not known.

2. Aside from the fundamental assumptions (e.g., that all the fuel is dissolved), the only material properties having a major impact are the effective melting temperature (or softening temperature) and the thermal conductivity. The effects of fuel or steel admixtures on these properties have not been studied, and the values for these parameters are uncertain in any event.

3. By contrast, uncertainty in the viscosity has a weak impact on pool temperature as does the selection of heat transfer correlation.

4. The current corium shield is so thick that a crust may not initially form.

5. The assumption of complete mixing is key to predicting performance.

\section{E.8 IMPACT OF HEATING THE LOWER CONCRETE SLAB IN THE REFERENCE DESIGN}

As discussed previously, a small, but nonnegligible, component of the heat generated in the pool is directed downward in steady state. This heat load is not appreciably affected by the lead layer that forms at the bottom of the pool-unless one assumes that the lead can convect heat sidewards to the corium shield, and through that to the water. In the reference configuration, the lead is heated from above. Consequently, convection in the lead layer was neglected in all of these analyses-except for one discussed in Sect. E.9. 
Table E.9. Results of sensitivity case with small, dissolved glass mass

\begin{tabular}{lc}
\hline Initial glass mass that is dissolved & $460 \mathrm{t}$ \\
Final PbO: $\mathrm{B}_{2} \mathrm{O}_{3}$ molar ratio & 1.1 \\
$\mathrm{UO}_{2}$ as fraction of final glass mass & 0.27 \\
Stainless steel + $\mathrm{Zr}$ oxide, as fraction of final glass & 0.18 \\
mass & \\
Lead thickness & $0.30 \mathrm{~m}$ \\
Debris-glass thickness & $1.27 \mathrm{~m}$ \\
\hline
\end{tabular}

Because the heat fluxes predicted to impinge on the concrete are very low, even a modest cooling system would suffice in steady state. For example, a system of cooling pipes could be embedded in the slab as is often done in the biological shield of present-day PWRs. In this analysis, however, it has generally been assumed that only an insulation layer is provided on top of the containment liner. Selection of an optimal material to be used in the insulation layer would require careful consideration of material properties and is beyond the scope of this analysis. Instead, a nominal thermal conductivity of $0.1 \mathrm{~W} / \mathrm{m} \cdot \mathrm{K}$, typical of many high temperature insulators, has been assumed with a thickness of $0.1 \mathrm{~m}$. To investigate the sensitivity of the concrete interface temperature to the properties and thickness of the insulation, a series of calculations were run in which the quotient of the thermal conductivity and the thickness were varied (this is the only way in which these parameters enter the model).

For an assumed constant downward heat flux, the surface temperature increases as the square root of the time (Carslaw, 1959). For this reason, the calculations were performed both for the nominal time used in the other calculations, $10^{5} \mathrm{~s}(\sim 1 \mathrm{~d})$, and at $10^{6} \mathrm{~s}(\sim 12 \mathrm{~d})$. While the decay heat generated in the pool does drop by roughly $40 \%$ over this period, it was conservatively left constant because the analytical model assumes a constant heat flux.

The results are shown in Fig. E.5. If we denote the quotient of thermal conductivity and insulation thickness by $\mathrm{k} / \mathrm{x}$, the reference design has a value of $1.0 \mathrm{~W} / \mathrm{m}^{2}-\mathrm{K}(\mathrm{k}=0.1 \mathrm{~W} / \mathrm{m}-\mathrm{K} ; \mathrm{x}=0.1 \mathrm{~m})$. Very small values of $\mathrm{k} / \mathrm{x}$ lead to temperatures close to the initial value of $300 \mathrm{~K}$; large values approach the pool temperature of $\sim 1000 \mathrm{~K}$. 


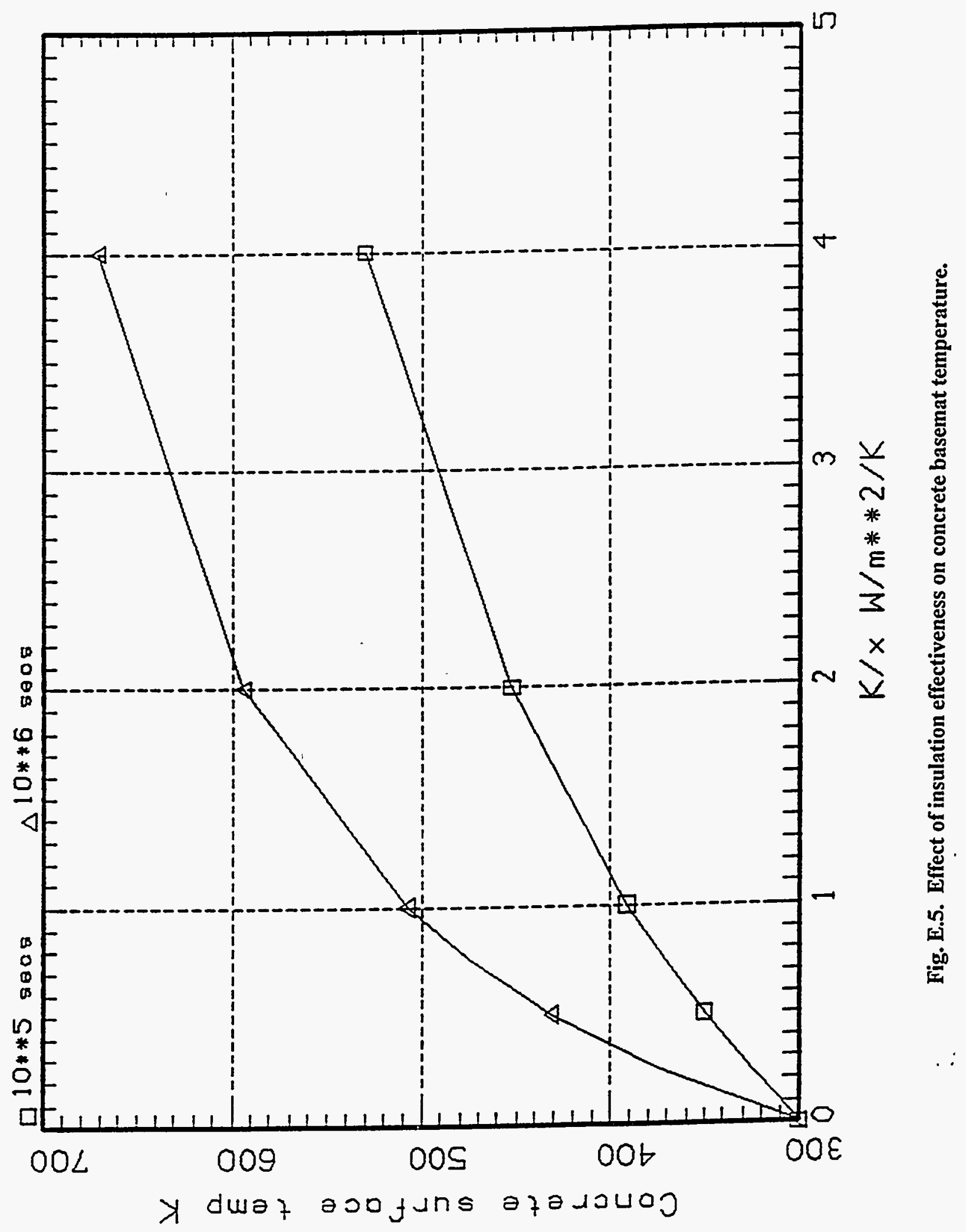


While concrete surface temperatures at one day are low for insulation designs equivalent or superior to the reference design, the temperature increases considerably with time. For this reason, at least a minimal cooling system will need to be provided to prevent outgassing and a consequential degradation in basemat properties. One very simple such design would be to embed the liner in the concrete pad and allow cooling water in the annulus outside the corium shield to flow into channels cut in the concrete above the liner. Alternatively, dedicated cooling pipes could be installed above or below the liner.

\section{E.9 CONSIDERATION OF THE GLASS-DEBRIS MIXING PROCESS}

All but one of the previous calculations have assumed that the dissolution process is complete (i.e., the fuel and all the supplied glass are intimately mixed). Sensitivity calculations confirm that this assumption is important when one is evaluating mixture properties. A much more difficult task would be to evaluate the rate at which the fuel is dissolved. For configurations which are not actively cooled from the bottom, such an analysis seems necessary to confirm that the heat removal pathways are fully developed before the molten fuel approaches the vicinity of the containment liner, which sits near the interface of the glass and the basemat.

There are multiple design options to ensure rapid dissolution of core debris. Examples include increasing the surface area of the glass using glass bricks or other geometries rather than monolithic glass. These options are analyzed in Appendix F. At the same time, analyses of certain design limits provide an understanding of the heat transfer that influences core debris dissolution. Two cases are analyzed herein for which the surface area between the core debris and glass are minimized and for which it is assumed that no lead is generated as a byproduct of glass dissolution.

\section{E.9.1 ASSUMED GEOMETRY DURING MIXING}

As illustrated in Fig. E.1, the presence of the CRD maintenance pit in the glass promotes the initial formation of a cylinder of debris. The contact temperature between the molten debris and the solidified glass is far below the freezing temperature of the debris constituents and well above the softening temperature of the glass. Thus, we can expect a frozen crust of debris to form around a molten center. Internal convection will transport decay heat to the frozen crust. The heat will conduct through the crust to the crust/glass interface.

Consider the glass on the side of the debris cylinder. The glass near the cylinder will quickly achieve temperatures above the softening temperature. When the glass viscosity has dropped sufficiently enough, circulation of molten glass will begin, convecting heat from the debris to the still-solidified glass farther away. 
When the width of the molten region has grown to exceed roughly one-third its height (i.e., when the molten region is $>\sim 25 \mathrm{~cm}$ ), one may estimate heat transfer processes at the surface of the fuel and near the solid-glass interface using correlations developed for vertical plates in an infinite sea of fluid (Gebhart, 1971). For earlier times, which are of less interest to us, the appropriate correlations would be those for vertically oriented, confined fluid layers.

The strong-temperature-dependence of fluid properties presents difficulties. Near the surface of the stillsolid glass, the viscosity will be very large, and conduction will presumably dominate heat transfer. We are thus lead to believe that three zones exist in the glass as it is being melted:

1. A fully molten, convecting region which forms near the debris.

2. A thin layer of viscous glass near, but above, the softening temperature through which conduction dominates.

3. A solid-glass layer on the periphery of the molten pool, whose inner surface is slowly receding due to the heat conducted through the viscous layer.

We can roughly estimate the thickness $\delta$ of the barely fluid layer $b$. Experiments on enclosed vertical air spaces indicate that no convection occurs for Grashof numbers $\mathrm{Gr}<\sim 2000$ :

$$
2000 \cong \frac{\mathrm{g} \beta \delta^{3} \Delta \mathrm{T} \rho \mathrm{k}}{\mu^{2}}
$$

Unfortunately, the Prandtl number of glass near the softening temperature is considerably higher than that of air. One is therefore tempted to replace the Grashof number in this correlation with the Rayleigh number. Lacking experimental justification, we do not initially make this assumption, but we will consider the impact of doing so later. The temperature drop $\Delta T$ across the viscous layer is caused by the heat flux $\mathrm{q}^{\prime \prime}$ convected to the inner diameter of the layer:

$$
\Delta \mathrm{T}=\frac{\delta \mathrm{q}^{\prime \prime}}{\mathrm{k}}
$$

Substituting in the previous expression, we obtain:

$$
\frac{\delta^{4}}{\mu^{2}} \cong \frac{(2000) k}{g \beta q^{\prime \prime} \rho^{2}}
$$




\section{E-25}

Order of magnitude estimates for the quantities on the right side of this expression are:

$$
\begin{gathered}
k \sim 20 \mathrm{~W} / \mathrm{mK}, \\
\beta \sim 10^{-4} \mathrm{~K}^{-1}, \\
q^{\prime \prime} \sim 2 \times 10^{5} \frac{\mathrm{W}}{\mathrm{m}^{2} \mathrm{~K}}, \\
\rho \sim 6500 \frac{\mathrm{kg}^{3}}{\mathrm{~m}^{3}},
\end{gathered}
$$

These estimates lead to:

$$
\frac{\delta^{4}}{\mu^{2}} \simeq 5 \times 10^{-6} \frac{\mathrm{m}^{6}-\mathrm{sec}^{2}}{\mathrm{~kg}^{2}}
$$

The viscosity of glass changes from very large values near the softening temperature $(\sim 40 \mathrm{~kg} / \mathrm{ms})$ to about $0.1 \mathrm{~kg} / \mathrm{m} \cdot \mathrm{K}$ at temperatures $\sim 150^{\circ} \mathrm{C}$ higher than the softening temperature (Appendix D). Suppose we assign all glass above the softening temperature to the viscous layer. Solutions of Eqs. (E.3) and (E.5) for various trial viscosity values are given in Table E.10:

Table E.10. Trial values of viscosity

$$
\bar{\mu}\left(\frac{\mathrm{kg}}{\mathrm{m} \cdot \mathrm{s}}\right) \quad \delta(\mathrm{cm}) \quad \mathrm{T}_{\mathrm{i}}-\mathrm{T}_{\text {solen }}(\mathrm{K})
$$

\begin{tabular}{llc}
\hline 0.01 & 0.5 & 50 \\
0.1 & 1 & 100 \\
0.1 & 5 & 500 \\
\hline
\end{tabular}


The last column shows the temperature of the inner surface of the viscous layer relative to the softening temperature. Given the just-cited typical range in viscosities observed near the softening temperature, we conclude that the viscous layer will have a thickness of about 1-2 cm. Larger thicknesses result in a large temperature gradient, which produces glass of a viscosity that is low enough to support circulation; smaller thicknesses produce a small temperature gradient so that the glass on its inner diameter will be far too viscous to circulate. It is worth noting that the estimated dimensions of the viscous layer are small relative to the total glass thickness of about $130 \mathrm{~cm}$, and that the $\mathrm{ID}$ of the viscous layer is at a temperature $\sim 100 \mathrm{~K}$ higher than the softening temperature.

Recall that a Grashof number correlation was used to derive these estimates. If we assume that the Rayleigh number will more accurately account for differences in property values between air (for which the Grashof number and Rayleigh number are nearly equal) and glass, we can repeat the analysis. The nocirculation requirement is now

$$
\frac{\delta^{4}}{\mu} \simeq \frac{(2000) \mathrm{k}^{2}}{\mathrm{~g} \beta q^{\prime \prime} \rho^{2} C_{p}}
$$

which leads to

$$
\frac{\delta^{4}}{\mu} \simeq 2 \times 10^{-7} \frac{\mathrm{m}^{5}-\mathrm{s}}{\mathrm{kg}}
$$

Trial solutions of equations (E.3) and (E.7) are shown in Table E.11:

Table E.11. Trial values of viscosity

$$
\bar{\mu}\left(\frac{\mathrm{kg}}{\mathrm{m} \cdot \mathrm{s}}\right) \quad \delta(\mathrm{cm}) \quad \mathrm{T}_{\mathrm{i}}-\mathrm{T}_{\text {solen }}(\mathrm{K})
$$

\begin{tabular}{llr}
\hline 0.01 & 0.7 & 70 \\
0.1 & 1.2 & 120 \\
0.1 & 2.1 & 210 \\
\hline
\end{tabular}




\section{E-27}

The same conclusion results - the viscous layer is only on the order of $1 \mathrm{~cm}$ thick and has an inner surface temperature $\sim 100$ degrees higher than the softening temperature.

The cylinder of debris will not maintain its initial shape indefinitely. As the molten glass layer grows, dissolution of the debris crust will occur, although at what rate is not known. Also, it is possible that the crust will be mechanically unstable. To evaluate the effect of the latter, the calculations which follow will be performed for two limiting configurations, for the original cylindrical shape, and also for a "pancake" of debris which is assumed to extend across the entire $7.6-\mathrm{m}$ diam of the lower drywell.

\section{E.9.2 THERMAL-HYDRAULIC MODEL}

The thermal-hydraulic calculations for the unmixed debris-glass configurations were performed using a relatively straightforward extension of the model used for the well-mixed pool that is described in Appendix E.1. Convection internal to the cylinder or pancake used the same correlations and the same treatment of conduction across the frozen debris crusts. Properties for the debris were taken from Appendix $L$ of Theofanous (1994) and are listed in Table E.12.

Table E.12. Assumed properties of core debris

\begin{tabular}{lc}
\hline \multicolumn{1}{c}{ Property } & Value \\
\hline Volumetric expansion coefficient & $10^{-4} \mathrm{~K}^{-1}$ \\
Viscosity & $5 \times 10^{-3} \mathrm{~kg} / \mathrm{m}-\mathrm{s}$ \\
Specific heat & $550 \mathrm{~J} / \mathrm{kgK}$ \\
Density & $8020 \mathrm{~kg} / \mathrm{m}^{3}$ \\
Thermal conductivity & $5 \mathrm{~W} / \mathrm{m} \cdot \mathrm{K}$ \\
Melting temperature & $2923 \mathrm{~K}$ \\
\hline
\end{tabular}

Convection was modeled in the molten glass pool using conventional, textbook formulas of Fieg and Gebhert, 1971:

- $\mathrm{Nu}=0.13 \mathrm{Ra}^{0.333}$ vertical wall

- $\mathrm{Nu}=0.14 \mathrm{Ra}^{0.333}$ top surface of cylinder 
As recommended by Fieg and Gebhert (1971), the same correlations were assumed to apply on each side of the molten glass region (i.e., at the debris-glass interface and at the interface between the circulating pool and the stagnant, viscous layer). The edge of the latter was assumed to be at a temperature of $\sim 100 \mathrm{~K}$ above the estimated softening temperature of $750 \mathrm{~K}$, which is consistent with the calculations described earlier.

The lower boundary of the debris was assumed to be at the softening temperature (i.e., the liquid glass produced by melting under the debris was assumed to flow radially outward and then upward around the edges of the debris into the circulating glass zone). A more nearly complete analysis might calculate the temperature at which the molten glass could just flow at the same rate as it was produced, but this was not done herein because results of interest will depend rather weakly on this.

In some calculations for the pancake configuration, the debris was predicted to solidify completely. This situation was modeled in a simplified way by requiring the internal convective heat fluxes to go to zero and also setting the radial conduction heat flux to zero. The latter assumption results in the upward and lower heat fluxes equalling the total decay heat at the same time that the sum of the upper and lower crust thicknesses grow to equal the total debris height. It also provides a good estimate for the peak downward heat flux (which occurs at the center of the pancake); the value for this is important for estimating the rate at which the debris progresses downward.

Temperature-dependent glass properties (thermal conductivity and viscosity) were evaluated for each of the heat transfer coefficients at the average of the interface and the bulk glass temperature. While no doubt oversimplified, the limited available data suggest that this is a reasonable approximation (Fieg and Gebhert, 1971). The glass properties used were for 3:1 $\mathrm{PbO}: \mathrm{B}_{2} \mathrm{O}_{3}$ with no dissolved fuel; the values were taken from Appendix D and are shown in Table E.13.

\section{E.9.3 RESULTS FOR CYLINDRICAL CONFIGURATION}

The model was exercised first for the cylindrical configuration. The results are summarized in Table E.14. The most important of these results are probably the debris-glass interface temperatures $T_{i, u p}$ and $\mathrm{T}_{\mathrm{i} \text {,side }}$ and the downward heat flux. These were calculated to be:

- Upper interface temperature: $971 \mathrm{~K}$

- Side interface temperature: $954 \mathrm{~K}$

- Downward heat flux: $1.2 \times 10^{5} \mathrm{~W} / \mathrm{m}^{2}$

If we assume that the glass is initially at a temperature of, say, $350 \mathrm{~K}$, and reaches no greater than the assumed softening temperature of $750 \mathrm{~K}$ as it melts and flows radially beneath the debris, the downward heat flux results in a downward velocity $\dot{x}_{\mathrm{d}}$ of the molten glass interface given by: 
Table E.13. Properties assumed for glass in nonmixed calculations

\begin{tabular}{|c|c|c|}
\hline Property & & Value \\
\hline Volumetric expansion coefficient & & $1.2 \times 10^{-4} \mathrm{~K}^{-1}$ \\
\hline Specific heat & & $527 \mathrm{~J} / \mathrm{kgK}$ \\
\hline Density & & $6600 \mathrm{~kg} / \mathrm{m}^{3}$ \\
\hline Thermal conductivity & & $4.8 \times 10^{-8}[\mathrm{~T}(\mathrm{~K})]^{3} \frac{\mathrm{w}}{\mathrm{m} \cdot \mathrm{K}}$ \\
\hline Softening temperature & & $750 \mathrm{~K}$ \\
\hline Viscosity & $\mathrm{T}(\mathrm{K})$ & $\mu \frac{\mathrm{kg}}{\mathrm{m}-\mathrm{s}} \times 10^{-3}$ \\
\hline & $\begin{array}{l}876 \\
938 \\
986 \\
1076\end{array}$ & $\begin{array}{l}104 \\
62 \\
46.7 \\
22.4\end{array}$ \\
\hline
\end{tabular}

Table E.14. Summary of results of calculations during mixing phase

\begin{tabular}{|c|c|c|c|c|c|}
\hline Case & $\begin{array}{c}\mathbf{T}_{\text {pool }} \\
(\mathrm{K})\end{array}$ & $\mathrm{Ra}$ (fuel) & $T_{i, u p}$ & $T_{i, \text { side }}$ & $\begin{array}{l}\mathbf{Q}_{\text {down }} \\
\mathrm{kW} / \mathrm{m}^{2}\end{array}$ \\
\hline Cylinder & 2988 & $4 \times 10^{13}$ & 971 & 954 & 120 \\
\hline Cylinder, $\mathrm{k}^{*} .1$ & 2989 & $4 \times 10^{13}$ & 1145 & 1109 & 120 \\
\hline Pancake & 2820 & $N / A^{a}$ & 920 & N/A & 110 \\
\hline
\end{tabular}

${ }^{a} \mathrm{~N} / \mathrm{A}=$ not applicable. 


$$
q_{d}^{\prime \prime}=\rho c_{p}(750-350) \dot{x}_{d}
$$

or

$$
\dot{x}_{d} \simeq 9 \times 10^{-5} \mathrm{~m} / \mathrm{s}
$$

In other words, it will take only about $3 \mathrm{~h}$ to melt through the $1 \mathrm{~m}$ of glass under the debris. This calculation indicates the importance of two phenomena not included in this model:

- Formation of lead metal that floats core debris.

- Dissolution of glass into the core debris on the bottom of the core debris that simultaneously generates lead, lowers the density of the core debris by addition of glass to core debris, and weakens the external crust.

It is worth noting that the downward heat flux is about half the value predicted for the top and sides. This is surprisingly large at first glance, in view of the very low convective heat flux directed downward from the molten center of the debris relative to that directed to the upper and side surfaces. As demonstrated earlier, the low value for the convective heat flux leads to a very thick crust whose internal heat generation gives rise to most of the heat directed downward. In fact, the total, downward-directed heat flux is only weakly dependent on the split in the convective heat flux; errors in the latter are thus relatively unimportant in this geometry.

The calculated interface temperatures are surprisingly low. This is attributed mainly to the rather large value calculated for the thermal conductivity of the glass which leads to large heat-transfer coefficients. Considering that the constants in the expression used for the thermal conductivity are not known for borosilicate glass, another case was run in which the thermal conductivity expression was multiplied by 0.1 . This resulted in a substantial increase in the upper and sideward interface temperatures to over $1100 \mathrm{~K}$ in each case. The downward heat flux was negligibly affected. This result underscores the importance of obtaining more nearly accurate estimates for the thermal conductivity in the temperature and composition regimes of interest.

\section{E.9.4 RESULTS FOR THE "PANCAKE" CONFIGURATION}

One might reasonably conjecture that the rapid downward progression of the debris calculated in the previous section is a consequence of the geometry of the cylinder. This raises the question of whether this 


\section{E-31}

shape will persist. Aside from chemical attack of the fuel crusts by the glass, it is possible that the relatively thin side crust $(\sim 5 \mathrm{~cm})$ which develops would buckle, converting the cylinder into the pancake configuration mentioned earlier.

For the initial debris mass provided by Sienicki, Chu, and Spencer (1993), an assumed radial flow of debris all the way to the corium shield would create a disk of height $\sim 35 \mathrm{~cm}$ (i.e., about half the height of the cylinder). For this configuration, the model predicts that the slab is solidified (barely) and has a nearly equal upward and downward heat flux. The important results are:

- Upper interface temperature: $920 \mathrm{~K}$

- Downward heat flux: $1.1 \times 10^{5} \mathrm{~W} / \mathrm{m}^{2}$

Thus, this configuration is only slightly more favorable with regard to downward debris velocity than was the cylindrical configuration. While the interface temperature is also lower, the surface area which reaches that temperature is higher, so the effect of this configuration on dissolution rate is not clear. As in the previous case, generation of lead and diffusion of glass into the core debris was not considered in this calculation.

\section{E.9.5 CONCLUSIONS}

For a limiting case of no generation of lead metal from chemical reactions and minimal dissolution surface area, several conclusions are reached. The results indicate that debris-glass interface temperatures are relatively low, and that the downward penetration velocity of the debris is rather fast. The former is a consequence of the good heat transfer properties of molten glass; the latter appears to be a consequence of the geometry. As was the case for the well-mixed calculations, the interface temperature results are sensitive to uncertainties in the effective melting temperature and the thermal conductivity.

\section{E.10 OTHER COMSORS CONFIGURATIONS}

COMSORS designs other than the reference configuration shown in Fig. E.1 have also been considered. In this section, we will use the long-term (well-mixed) thermal-hydraulic model to analyze designs with:

- Concrete on the side walls.

- An additional lower lead layer.

A summary of the results of these calculations is provided in Table E.15. 
Table E.15. Results for well-mixed cases in alternate pool configurations

\begin{tabular}{|c|c|c|c|c|c|c|}
\hline \multirow[b]{2}{*}{ Configuration } & \multirow{2}{*}{$\begin{array}{c}\mathbf{T}_{\text {pool }} \\
(\mathbf{K})\end{array}$} & \multicolumn{2}{|c|}{ Crust thickness (cm) } & \multicolumn{3}{|c|}{ Heat flux $\left(\mathrm{kW} / \mathrm{m}^{2}\right)$} \\
\hline & & Upper & Lower & Up & Side & Down \\
\hline $30-\mathrm{cm}$ concrete side wall & 851 & 1.4 & 0 & 217 & 2.6 & 0.4 \\
\hline Fuel-lead, water on top & 636 & 1.6 & 0 & 196 & 46 & 0.3 \\
\hline Fuel-lead glass on top (see text) & 962 & N/A & 0 & 160 & 110 & 0.5 \\
\hline
\end{tabular}

\section{E.10.1 EFFECT OF CONCRETE SIDE WALLS}

As discussed previously, the reference configuration may not develop a crust on the side walls, leading to wall erosion. One way to address this problem would be to place a concrete liner on the inner face of the corium shield.

Consider a 30-cm-thick slab and for simplicity neglect the reduction in glass inventory necessary for this to exist within the current corium shield configuration. The thermal-hydraulic model run with this change gives the results shown in Table E.15. While the pool temperature does increase to compensate for the near elimination of the sideward heat flux, the change is moderate and well within tolerable limits. However, a deleterious effect of the change would be the outgassing of the concrete and the resulting production of noncondensible gasses. To estimate the impact of this, assume that basaltic concrete, containing $\sim 6 \mathrm{wt} \%$ free and chemically bound water (Cole, Kelly, and Ellis, August 1994) is used. One cubic meter of concrete could, if all the water were liberated and all of this steam were reacted, oxidize $\sim 350 \mathrm{~kg}$ of zirconium. Thus, a 30-cm liner in the SBWR lower drywell could potentially oxidize about $9 \mathrm{t}$ of $\mathrm{Zr}$ or an equivalent amount of lead. While no doubt conservative, this calculation indicates that placing a concrete liner inside the corium shield would compromise one of the key design goals of COMSORS. (Note that placing a concrete liner outside the metal wall would exaggerate the problem of side wall erosion.)

\section{E.10.2 EFFECTS OF A LOWER LEAD LAYER}

Let us revisit the suggestion that additional lead could be provided to float the core debris and inhibit its downward progression. Consider a liquid lead layer containing nearly submerged "lumps" of core debris. If one makes the crude approximation that the heat transfer process from the liquid lead to its surroundings is 


\section{E-33}

roughly the same as if the fuel were uniformly dispersed throughout the lead, we can use the COMSORS thermal-hydraulic model to evaluate conditions in the layer. In doing so, it should be noted that we are also implicitly assuming that the heat transfer correlations can be used for very low Prandtl number fluids; while this appears reasonable (Theofanous, 1994), some inaccuracy can be expected.

Given these approximations, we can proceed to evaluate conditions in the lead. In fact, for simplicity, let us first dispense with the COMSORS glass altogether and evaluate heat transfer from a 1-m-thick lead layer surrounded by water on top and the corium shield on the side. To do this, we merely supply to the code properties for lead in place of those for glass. For these conditions, the model gives a pool temperature of $636 \mathrm{~K}$, a pool viscosity of only $2.5 \mathrm{cp}$, and a lower concrete-slab temperature of $360 \mathrm{~K}$.

Note the key assumption that the core debris is not a consolidated mass. If it is a consolidated mass, the system is equivalent to the COMSORS high-lead-temperature-failure scenario. This calculation does have an implication for the COMSORS high-lead-temperature-failure scenario. If the core debris is not fully consolidated, lead circulation currents can transport heat through much of the core debris to the molten glass and provide a mechanism to limit maximum lead temperatures. This calculation suggests that a thick lead layer by itself may provide an adequate heat transport path under some conditions.

The calculation just described assumes an upper boundary condition for the lead-fuel pool equal to the water temperature. For this reason, this calculation could be succinctly described as an evaluation of the performance of a lead core catcher. Let us now turn our attention to the concept in which a thick, lead layer is provided under the glass to float the debris and thereby protect the liner while the fuel is being dissolved. In this configuration, a molten glass layer develops on top of the lead-fuel pool. As above, it is assumed that the core debris is uniformly distributed through the molten lead.

Hand-calculations indicate that a horizontal, molten glass layer can remove the upward-directed heat flux if the glass-lead interface temperature is roughly $900 \mathrm{~K}$. If we apply this temperature to the lead pool model used to evaluate the core catcher, we obtain a very low downward heat flux $\left(\sim 0.5 \mathrm{k} \cdot \mathrm{W} / \mathrm{m}^{2}\right)$ and a bulk lead temperature of about $960 \mathrm{~K}$. The downward heat flux is very low because of the insulation. If the insulation is removed and if cooling is provided to keep the basemat at nominal temperatures, the downward heat flux increases to $130 \mathrm{k} \cdot W / \mathrm{m}^{2}$, which requires a basemat heat removal system capable of dissipating over $6 \mathrm{MW}$. Thus, the performance of the insulation is key to the viability of this scheme as well as the assumed coolability of core debris with lead metal.

This specific case is important in one other context. One conservative engineering option is to provide sufficient cooling to the molten lead in this worst-case scenario. It is assumed that the core debris does not dissolve and forms a layer between the lead and glass. It is assumed the insulation fails. It is assumed that 
the concrete temperature should not exceed $100^{\circ} \mathrm{C}$. In this extreme case, $6 \mathrm{MW}$ is the total heat load to remove from the lead. It can be removed by a combination of liner coolers and a molten lead heat exchanger with coolant from the suppression pool.

\section{E.11 CONCLUSIONS}

A set of thermal-hydraulic calculations has been performed for a hypothetical COMSORS installation in the GE SBWR. Two broad sets of issues were addressed.

The long-term, quasi-steady-state behavior of a glass-debris pool was investigated first. A reference configuration was developed that provides for the maximum amount of glass that could be used within the existing lower drywell design. It was assumed that complete mixing of the fuel and the glass occurs in such a manner (e.g., quickly enough) that the containment liner is not threatened during the mixing phase. Based on this assumption, available heat transfer correlations, experimentally measured material property data, and information from handbooks, the following preliminary conclusions can be drawn from this first set of analyses:

1. If one assumes that the thermal conductivity of the glass-fuel mixture is reasonably well characterized by models used for clear glasses, the pool temperature is quite low, in the $800 \mathrm{~K}$ range. A reduction in the coefficient that multiplies the expression for the thermal conductivity by a power of 10 only increases the calculated temperature by about $100 \mathrm{~K}$. This suggests that future work should focus on a lower temperature regime than currently emphasized.

2. A frozen crust may not initially form on the ID of the rather thick corium shield. Lack of a crust will probably lead to erosion of the corium shield, but the thinning process should eventually be arrested. This will occur when the wall ID temperature drops below the mixture melting temperature due to reduced conduction resistance through the steel.

3. If substantial wall erosion does occur, significant quantities of iron and smaller quantities of other wall constituents will be introduced into the debris-glass pool. Oxidation of this iron would further reduce the $\mathrm{PbO}: \mathrm{B}_{2} \mathrm{O}_{3}$ molar ratio and may result in degraded material properties (e.g., increased viscosity). Significant quantities of steel can also enter the pool from the reactor vessel. There appear to be no data available on the effect of steel on the molten glass properties.

4. Similarly, there are essentially no data available on the effect of the dissolved fuel (or steel) on the mixture softening temperature and thermal conductivity. In addition, there are no data on metal oxide solubility in the temperature range of greatest interest. On the other hand, there do appear to be enough data on viscosity, and the sensitivity calculations indicate that the steady-state behavior is rather insensitive to this.

5. Long-term cooling of the interface between the pool and the lower concrete slab will be necessary. In steady-state, the heat fluxes can be made very small by providing insulation $\left(<1 \mathrm{~kW} / \mathrm{m}^{2}\right)$, so this should not be difficult. 


\section{E-35}

Assuming that issues related to corium shield thinning do not present insuperable problems, the viability of COMSORS appears to ultimately depend on the second issue addressed: understanding the transient behavior of the pool in the period following vessel failure and, in so doing, demonstrate adequate mixing rates (Appendix F).

Several possible means to do this have been investigated. A lead layer could be provided to "float" the fuel debris. Simplified calculations suggest that a lead layer sufficiently thick such as to float the debris could both protect the liner (if insulation is provided) and also prove to be an effective heat transport path.

The second option is to increase the surface area between core debris and glass by using glass bricks or some other geometry rather than monolithic glass. This is discussed in Appendix F.

\section{E.12. REFERENCES}

Buchholz, C., April 19, 1995, (GE), informal communication.

General Electric Company, February 1993. SBWR Standard Safety Analysis Report, 25A5113 Rev. A., San Jose, California.

Electric Power Research Institute, December 1993. ALWR Utility Requirements Document, Vol. 3: ALWR Passive Plant, Palo Alto, California.

Sienicki, J. J., C. C. Chu, and B. W. Spencer, November 1993. Preliminary Assessment of Modification of the SBWR Lower Drywell Grating Design as a Means of Achieving the Formation of Coolable Debris, ANL/RE/LWR 93-5, Argonne National Laboratory, Argonne, Illinois.

Forsberg, C. W., et al., March 1, 1995. "Direct Conversion of Plutonium Metal, Scrap, Residues and Transuranic Waste to Glass," paper presented at Waste Management '95, Tucson, Arizona.

Avallone, E. A. and T. Baumeister, eds., 1978. Marks' Standard Handbook for Mechanical Engineers, 9th ed., p 4-82, McGraw Hill, New York, New York.

Eckert, E. and R. Drake, 1972. Analysis of Heat and Mass Transfer, p 772, McGraw Hill, New York, New York.

Gardon, R., 1961. "A Review of Radiant Heat Transfer In Glass," J. Am. Ceramic Soc., 44:305-12.

Kenton, M., March 7, 1995, memorandum to S. Additon, "COMSORS Integral Heat Transfer Model."

Kymäläinen, O., et al., November 1994. "Heat Flux Distribution from a Volumetrically Heated Pool with High Rayleigh Number," Appendix B of T. G. Theofanous et al., In-Vessel Coolability and Retention of a Core Melt, DOE/ID-10460, U.S. Department of Energy, Idaho Falls, Idaho.

Theofanous, T. G., et al., November 1994. In-Vessel Coolability and Retention of a Core Melt, DOE/ID-10460, U.S. Department of Energy, Idaho Falls, Idaho. 
Carslaw, H. S. and Jaeger, J. C., 1988, p. 75 in Conduction of Heat in Solids, 2nd ed., Oxford University Press, Oxford, United Kingdom.

Theofanous, T. G. Ex-Vessel Coolability in the SBWR, undated ARSAP Report.

Gebhart, B., 1971. Heat Transfer, McGraw-Hill, New York, New York.

Fieg, G. and H. Werle, "Experimental Investigations of Heat Transfer in Pools," undated paper.

Cole, R. K., Jr., D. P. Kelly, and M. A. Ellis, August 1984. Page 14 in CORCON-Mod2: A Computer Program for Analysis of Molten-Core Concrete Interactions, NUREG/CR-3920, SAND84-1246, Sandia National Laboratories, Albuquerque, New Mexico. 
Subappendix SE.1

THERMAL-HYDRAULIC MODEL FOR COMSORS LONG-TERM BEHAVIOR 


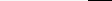




\section{SE.1.1 ASSUMED GEOMETRY}

A simple model has been developed to calculate the quasi-steady-state heat transfer from a well-mixed pool of molten glass and dissolved fuel surrounded by several layers of other materials. The assumed pool configuration is schematically shown in Fig. SE.1.1. On the top, bottom, and side, the molten pool may be bordered by a crust of frozen glass, or in each case the crust may not form if heat fluxes are sufficiently high. On the side, the user may specify that a layer of concrete or a layer of steel exists. Water is always assumed to exist on the outside of the side steel layer and above the pool. On the bottom, a layer of lead typically forms. A layer of insulation may also optionally exist above an assumed semiinfinite concrete basemat.

The bottom boundary of the molten pool can be assumed to be either flat or spherical. In the latter case, the user inputs the radius of curvature. An option also exists to maintain the concrete-basemat-insulation interface temperature constant; this option is intended to model either the presence of a cooling-water annulus or a system of cooling pipes embedded in the concrete.

\section{SE.1.2. MATHEMATICAL STRUCTURE}

The model solves a set of 14 coupled, nonlinear algebraic equations for the 14 unknowns. A standard Newton-Raphson algorithm is used-that is, the code solves

$$
f_{i}(x)=0
$$

and

$$
\mathrm{i}=1, \ldots 14
$$

by linearizing around the current guesses $x_{i}$ to find updated estimates $x_{i}+\Delta x_{i}$ :

$$
\begin{gathered}
f_{i}(x)+\sum_{k} \frac{\partial f_{i}}{\partial x_{k}} \Delta x_{k}=0 \\
\underline{\Delta x}=\frac{\partial f_{i}^{-1}}{\partial x_{k}} \underline{f}
\end{gathered}
$$


SE. 1-4

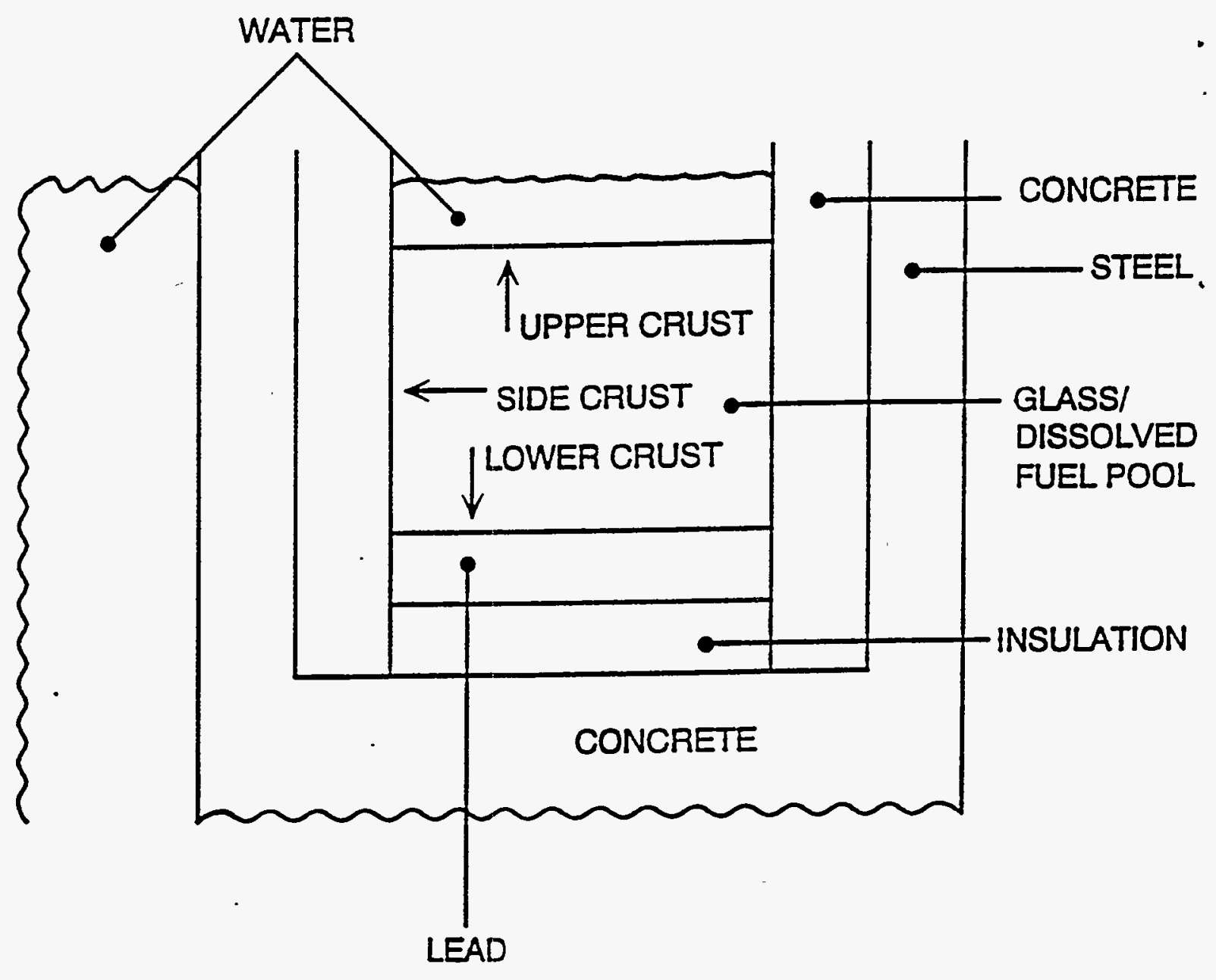

Fig. SE.1.1. Geometry assumed in model. 


\section{SE.1-5}

Here $\underline{\Delta x}$ is the vector of corrections to the current values, $\underline{f}$ is the vector of the current values of the 14 equations, and $\frac{\partial \mathrm{f}_{\mathrm{i}}}{\partial \mathrm{x}_{\mathrm{x}}}$ is the inverse of the Jacobian matrix. Actually, rather than inverting the Jacobian matrix, the model triangularizes the matrix and solves for the $\Delta \mathrm{x}$ using back-substitution. This procedure is more efficient.

After this has been done, the correction is added to each variable and the iteration process is repeated until the equations are converged. This occurs when for all 14 equations:

$$
\left|\frac{f_{i}}{s_{i}}\right|<c
$$

where $s_{i}$ is a scaling parameter on the order of the dominant terms in each $f_{i}$ and $c$ is a user-defined convergence parameter.

The 14 unknowns in the model are:

- The bulk pool temperature, $T_{p}$.

- The upward, sideward, and downward convective heat fluxes from the molten pool, $q_{u}, q_{s}$, and $q_{d}$, respectively.

- The upward, sideward, and downward crust thicknesses, $\delta_{u}, \delta_{\mathrm{s}}$, and $\delta_{\mathrm{d}}$, respectively.

- The interface temperature between the upper debris surface and the upper water pool, $\mathrm{T}_{\text {wi }}$.

- The temperature of the inside of the side concrete layer $T_{\mathrm{cnsi}}$, that is, the interface temperature between this concrete slab and the glass-fuel mixture.

- The temperature of the inside of the side steel layer $T_{c s i}$, that is, the interface temperature between the concrete and the steel.

- A layer of metallic lead typically forms due to the reduction of lead oxide by metals discharged with the fuel; $T_{\mathrm{pbi}}$ denotes the temperature of the top of this layer, that is, the interface temperature between the lead and the glass-fuel.

- The temperature of the top of the insulation layer, $\mathrm{T}_{\mathrm{ij}}$; this is the interface between the lead layer and the insulation.

- The temperature of the interface between the insulation and the lower concrete basemat, $\mathrm{T}_{\mathrm{cndi}}$.

- If a system exists to remove heat that would normally enter the lower concrete basemat, the heat removal rate is denoted by $\mathrm{Q}_{\text {rem. }}$. 


\section{SE.1.3. MODEL EQUATIONS}

Fourteen equations of the form $f_{i}(x)=0$ are needed to determine these 14 unknowns. Each of these equations is described below.

- Convective Heat Flux from the Molten Pool to its Boundaries

The heat flux convected from the molten pool to its upper boundary is given by

$$
q_{u}=h_{u}\left(T_{p}-T_{u b}\right)
$$

where $T_{u b}$ is either set to the assumed melting-freezing temperature of the glass if a crust forms, or, if not, $T_{u b}$ is set to the interface temperature with the water $t_{w i}$. The existence of the upper crust is defined in the model when the upper interface temperature, $T_{w i}$, drops $1^{\circ}$ lower than the assumed mixture freezing temperature, $T_{m p}$. The crust flag is reset to FALSE if the calculated crust thickness $\delta_{\mathrm{u}}$ becomes less than one micrometer.

In the code, the expression for the heat flux is actually written in an equivalent way as

$$
f(1)=h_{u}\left(T_{p}-T_{u b}\right)-q_{u}
$$

This is consistent with the discussion of the mathematical model provided earlier. The alternative form, in which the expression is explicitly written in terms of one of the dependent variables (in this case $\mathrm{q}_{\mathrm{u}}$ ), will be used to describe each of the model equations because the alternative form is a little easier to follow.

The same treatment is used for the downward and sideward crusts and heat fluxes. The upper, lower, and side heat transfer coefficients are all expressed in terms of the so-called "internal" Rayleigh number Ra:

$$
\mathbf{h}=\frac{\mathrm{k}}{\mathrm{z}} \mathrm{cRa}^{\mathrm{b}} \text {, }
$$

where $\mathrm{a}$ and $\mathrm{b}$ are constants which depend on location (top, bottom, or side) and, in some cases, the user-input choice of correlations. The values which can be selected by name are shown in Table SE.1.1; the user can also enter arbitrary values for $c$ and $b$. The internal Rayleigh number is given by 


\section{SE.1-7}

Table SE.1.1. Constants used in heat transfer correlations

\begin{tabular}{llcc}
\hline & & \multicolumn{2}{c}{ Case } \\
\cline { 3 - 4 } \multicolumn{1}{c}{ Situation } & \multicolumn{1}{c}{ Correlation } & c & b \\
\hline Upward heat flux & Fieg and Werle (cylinder) & 0.414 & 0.216 \\
& Steinberner and Reineke (rectangular slice) & 0.345 & 0.233 \\
Sideward heat flux & Fieg and Werle (cylinder) & 0.163 & 0.244 \\
& Steinberger and Reineke (rectangular slice) & 0.85 & 0.19 \\
& Jahn and Reineke (spherical head) & 0.54 & 0.18 \\
& Mini-ACOPO (cylinder) & 0.048 & 0.27 \\
Downward & & 1.12 & 0.103 \\
\hline
\end{tabular}

$$
\mathrm{Ra}=\frac{\mathrm{g} \beta \mathrm{q}_{\mathrm{v}}^{\mu \prime} \mathrm{z}^{5}}{\frac{\mu}{\rho} \alpha \mathrm{k}}
$$

where

$$
\begin{aligned}
& g \quad=\text { acceleration of gravity, } \\
& \beta \quad=\text { volumetric expansion coefficient, } \\
& q_{v}^{\prime \prime \prime}=\text { volumetric heat generation rate, } \\
& z \quad=\text { depth of circulating pool, } \\
& \mu \quad=\text { viscosity of molten pool, } \\
& \rho \quad=\text { density of molten pool, } \\
& \alpha \quad=\text { thermal diffusivity of molten pool, and } \\
& k \quad=\text { thermal conductivity of molten pool. }
\end{aligned}
$$




\section{SE.1-8}

For the unique case of the sideward heat flux into a hemisphere, the expression for the heat flux is multiplied by the nondimensional pool height (height divided by radius) raised to the 0.26 power.

A fourth equation is given by the requirement that the sum of the convective heat fluxes and the heat generated within the crusts must equal the total heat generated $Q_{d}$.

$$
Q_{d}=q_{s} a_{s}+q_{u} a_{u}+q_{d} a_{d}+q_{v}^{I I}\left(a_{u} \delta_{d}+a_{d} \delta_{d}+a_{s} \delta_{s}\right)
$$

Note that we have implicitly assumed that the crusts are sufficiently thin such that we can equate their volume to the product of the associated heat transfer area and the crust thickness. Note also that we assume that the pool is homogeneous; that is, the volumetric heat generation in the crusts is the same as in the molten pool, namely:

$$
\mathrm{q}_{\mathrm{v}}^{\prime \prime \prime}=\frac{\mathrm{Q}_{\mathrm{d}}}{\mathrm{V}_{\mathrm{p}}}
$$

where $V_{p}$ is the total volume of glass and fuel including the crusts.

In most cases of interest, the pool is a right circular cylinder. In cases where the lower head of the pool is spherical, the lead may occupy all of the head so that the glass mixture exists only in the cylindrical part. In either of these cases, we calculate the volume and heat transfer areas associated with the molten glass in the obvious way:

$$
\begin{gathered}
a_{u}=\pi r_{c}^{2}, \\
a_{d}=a_{u}, \\
a_{s}=2 \pi r_{c} z, \text { and } \\
v_{p}=a_{w} z,
\end{gathered}
$$


where $r_{c}$ is the radius of the cylindrical portion of the lower drywell. On the other hand, if the base of the pool is made of a spherical cap and the glass occupies part of this cap, the downward heat transfer area used with the correlations is set equal to the upward-facing surface area of the lead, and the sideward heat transfer area is set equal to the sum of the steel boundary area wetted in the spherical part and in the cylindrical part.

- Temperature Distribution Across the Crusts

As mentioned previously, the crusts are assumed to have the same volumetric heat generation rate as does the molten pool. The temperature drop across the upper crust is obtained by integrating the onedimensional heat conduction equation twice. This yields

$$
\mathrm{q}_{\mathrm{u}}+\frac{\mathrm{q}_{\mathrm{v}}^{\mathrm{m}} \delta_{\mathrm{u}}}{2}=\frac{\mathrm{k}_{\mathrm{cru}}}{\delta_{\mathrm{u}}}\left(\mathrm{T}_{\mathrm{mp}}-\mathrm{T}_{\mathrm{wi}}\right)
$$

In this equation, $T_{m p}$ is the freezing temperature of the glass (which is also the temperature of the interface between the crust and the pool), and $\mathrm{k}_{\mathrm{cr}}$ is the thermal conductivity of the upper crust. For simplicity, the crust thermal conductivity is evaluated at the average crust temperature $\overline{\mathrm{T}}_{\text {cru: }}$ :

$$
\bar{T}_{c r u}=\frac{T_{m p}+T_{w i}}{2}
$$

The same equations apply to the sideward and downward crusts if they exist:

$$
\begin{aligned}
& q_{s}+\frac{q_{v}^{\prime \prime} \delta_{s}}{2}=k_{c r s}\left(T_{m p}-T_{c n s i}\right) \\
& q_{d}+\frac{q_{v}^{m /} \delta_{d}}{2}=k_{c r d}\left(T_{m p}-T_{p b i}\right)
\end{aligned}
$$

The scheme used to calculate the temperature-dependent thermal conductivity is discussed later. 
If a crust cannot form at a boundary (i.e., because the interface temperature exceeds the melting/freezing temperature), there is no temperature drop across the crust. In such an example, the corresponding temperature-drop equation is replaced by the trivial equation

$$
\delta=0
$$

This simple technique prevents the development of a singular equation set.

- Temperature Distribution Across Slabs

Slabs of lead, concrete, insulation, and steel can be included at the boundaries of the pool. For example, the user can define a lead layer that develops at the bottom of the pool. When such a layer or slab exists, the temperature drop across the layer is given by the same type of equation used for the crusts - except that there is no internal heat generation and the incident heat flux is the sum of the convected part and that generated in the adjacent crust. For the case of a lead layer at the bottom of the pool,

$$
\mathrm{q}_{\mathrm{d}}+\mathrm{q}_{\mathrm{v}}^{\prime \prime} \delta_{\mathrm{d}}=\frac{\mathrm{k}_{\mathrm{pb}}}{\delta_{\mathrm{Pb}}}\left(\mathrm{T}_{\mathrm{pbi}}-\mathrm{T}_{\mathrm{endi}}\right)
$$

If no layer exists, $\delta_{\mathrm{Pb}}=0$, and we replace this equation with one that forces the (nonexistent) layer interface temperature to be equal to the surface temperature of the next lower layer; in this case:

$$
\mathrm{T}_{\mathrm{pbi}}=\mathrm{T}_{\text {endi }}
$$

Again, this substitution prevents the equation set from being singular and ensures that other equations which may refer to $\mathrm{T}_{\mathrm{pbi}}$ use the correct temperature.

The other equations of this type in the model are:

$$
\mathrm{q}_{\mathrm{s}}+\mathrm{q}_{\mathrm{v}}^{\prime \prime \prime} \delta_{\mathrm{s}}=\frac{\mathrm{k}_{\mathrm{cn}}}{\delta_{\mathrm{cns}}}\left(\mathrm{T}_{\mathrm{cnsi}}-\mathrm{T}_{\mathrm{csi}}\right) \text { (side concrete slab), }
$$




$$
\begin{gathered}
q_{d}+q_{v}^{m} \delta_{d}=\frac{k_{i}}{\delta_{i}}\left(T_{i i}-T_{c n d i}\right) \quad \text { (lower insulation) } \\
q_{s}+q_{v}^{\prime \prime \prime} \delta_{s}=\frac{k_{c s}}{\delta_{c s}}\left(T_{c s i}-T_{w}\right) \quad \text { (side steel slab) }
\end{gathered}
$$

- Surface Temperature of the Lower Concrete Basemat

The thermal-hydraulic model is not applicable to the first hours of the accident, during which time the debris is either confined to the reactor vessel or is undergoing mixing with the glass. If we somewhat arbitrarily look at the time frame after, say, $1 \mathrm{~d}$, we find that the decay heat and also the heat load applied to the surroundings of the debris, are fairly constant. For this reason, it is considered appropriate in a simple, quasi-steady-state model to adopt a constant heat flux boundary condition for the lower concrete basemat.

Making the further simplification that the basemat can be regarded as semiinfinite, its surface temperature is given by (15):

$$
\mathrm{T}_{\text {cndi }}=\mathrm{T}_{0}+\frac{2 \mathrm{q}_{\mathrm{c}}}{\mathrm{k}_{\mathrm{c}}} \sqrt{\frac{\alpha_{\mathrm{c}} \mathrm{t}}{\pi}},
$$

where

$$
\begin{aligned}
& T_{0}=\text { initial temperature of concrete, } \\
& q_{c}=\text { heat flux, } \\
& k_{c}=\text { thermal conductivity of concrete, } \\
& \alpha_{c}=\text { thermal diffusivity of concrete, and } \\
& t \quad=\text { time since application of the heat flux. }
\end{aligned}
$$

In the code, the heat flux applied to the basemat is given by 


$$
q_{c}=q_{d}+q_{v}^{\prime \prime \prime} \delta_{d}-\frac{Q_{r e m}}{a_{d}}
$$

where

$\mathrm{Q}_{\mathrm{rem}}=$ heat removed either by the basemat's cooling system or the flow of water in an annulus between the basemat and the insulation layer.

If neither cooling water flow or a heat exchanger is supplied, the heat removal is set to 0 by adding an equation:

$$
\mathrm{Q}_{\mathrm{rem}}=0 .
$$

Otherwise, the cooling is assumed adequate to keep the concrete surface temperature constant, leading to the additional equation

$$
\mathrm{T}_{\text {cndi }}=\mathrm{T}_{0}
$$

This equation used with the surface temperature equation implicitly defines what $Q_{\text {rem }}$ must be. Not surprisingly, the solution is:

$$
Q_{\text {rem }}=\left(q_{d}+q_{v}{ }^{m} \delta_{d}\right) A_{d}
$$

- Temperature of the Interface Between the Upper Crust and the Upper Water Pool

The default COMSORS configuration results in relatively uniform heat fluxes out the side and the top of the pool. For such situations, the heat fluxes in these directions are low $\left(\sim 100 \mathrm{~kW} / \mathrm{m}^{2}\right)$, and it seems reasonable to assume that nucleate boiling can be sustained.

In some of the alternate COMSORS configurations, however, the heat flux is mainly directed upward, and there is a small chance that film boiling could be sustained. The model deals with this possibility in a very simple way. The interface temperature, $T_{\text {wi }}$, is defined in terms of the bulk water temperature, $T_{w}$ and the applied heat flux, $q_{w}$, by assuming that heat transfer occurs via a user-input "film boiling" heat transfer coefficient, $h_{w}$ and thermal radiation: 


\section{SE.1-13}

$$
\mathrm{q}_{\mathrm{w}}=\mathrm{h}_{\mathrm{w}}\left(\mathrm{T}_{\mathrm{wi}}-\mathrm{T}_{\mathrm{w}}\right)+\frac{\sigma\left(\mathrm{T}_{\mathrm{wi}}^{4}-\mathrm{T}_{\mathrm{w}}^{4}\right)}{\frac{1}{\epsilon_{\mathrm{c}}}+\frac{1}{\epsilon_{\mathrm{w}}}-1},
$$

where

$$
\begin{aligned}
& \sigma=\text { Stefan-Boltzman constant, } \\
& \epsilon_{\mathrm{c}}=\text { crust emissivity (user-input), and } \\
& \epsilon_{\mathrm{w}}=\text { water emissivity (user-input). }
\end{aligned}
$$

The applied heat flux is

$$
q_{w}=q_{u}+q_{v}^{\prime \prime} \delta_{u}
$$

For the usual case in which nucleate boiling is assumed, a large value is input for $h_{w}$; the particular value used is unimportant, so long as $T_{w i}-T_{w}$ is small, characteristic of nucleate boiling.

- Material Properties

Nearly all the material properties are treated as constants and are input by the user. However, there are two exceptions. The fuel-glass viscosity and thermal conductivity are known to be strong functions of temperature and are represented in the model as such.

For the viscosity, the user has two options. He may enter a table of viscosity data at arbitrarily defined temperatures, in which case the code merely interpolates linearly. Of course, this procedure is questionable if temperatures are far below or above the extremes of the table entries. For this reason, another option is also provided in which the viscosity is assumed to obey the Fulcher-Vogel-Tamman equation (Gardon, 1961):

$$
\mu=\mu_{0} e^{\frac{A}{T-T_{s}}},
$$




\section{SE.1-14}

where $T_{s}$ is the glass softening temperature. This procedure is somewhat more appealing in that the viscosity properly gets very large near the softening temperature. If the user wishes to use this option, he must supply the constants $\mu_{0}$ and A. Experimental data (Appendix D) for pure glass were fit to this expression using:

$$
\begin{gathered}
\mu_{0}=0.00625 \mathrm{~kg} / \mathrm{m}-\mathrm{s} \\
\mathrm{T}_{\mathrm{s}}=750 \mathrm{~K}
\end{gathered}
$$

For the thermal conductivity, at the relatively high temperatures of interest, radiation dominates the intraglass heat transfer. This leads to the definition of an "effective" thermal conductivity given by (Gardon, 1961):

$$
k=\frac{16}{3} \mathrm{n}^{2} \sigma \lambda \mathrm{T}^{4}
$$

where

$$
\begin{aligned}
& \mathbf{n}=\text { index of refraction, and } \\
& \lambda=\text { average photon path-length before absorption }
\end{aligned}
$$

The user inputs both of these parameters. 
Subappendix SE.2

SENSITIVITY OF DOWNWARD HEAT FLUX TO UNCERTAINTIES IN THE CONVECTIVE HEAT FLUX 
Considerable data exist on the relative magnitude of the upward, sideward, and downward convective heat fluxes from internally heated, circulating pools. Unfortunately, these data often do not cover the precise geometry or Rayleigh number range of interest. We wish to evaluate the downward motion of the debris during the mixing phase, caused by melting the glass underneath the fuel. A question that arises is how sensitive this result is to uncertainties in the convective heat flux.

Consider a crust of frozen fuel, subject to a convective flow of heat from its inner surface and to internal heat generation. The temperature drop across the crust is obtained by integrating the conduction equation twice:

$$
h\left(T_{p o o l}-T_{m p}\right)+q_{v}^{m} \frac{\delta}{2}=\frac{k}{\delta}\left(T_{m p}-T_{i}\right)
$$

where

$$
\begin{aligned}
& \mathrm{h}=\text { convective heat transfer coefficient, } \\
& \mathrm{T}_{\text {pool }}=\text { bulk molten fuel temperature, } \\
& \mathrm{T}_{\mathrm{mp}}=\text { melting temperature of crust, } \\
& \mathrm{q}_{\mathrm{v}}=\text { volumetric heating in crust, } \\
& \delta \quad=\text { crust thickness, } \\
& \mathrm{k}=\text { thermal conductivity of crust material, and } \\
& \mathrm{T}_{\mathrm{i}}=\text { outer surface temperature of crust. }
\end{aligned}
$$

Consider first a limiting case in which the crust is very thick and the convective heat flux is negligible compared to the heat generated internally; this example is not too different from what is calculated for the lower crust in the cylindrical, unmixed configuration. Setting $\mathrm{h}$ to zero, we obtain the crust thickness in this limiting case:

$$
\delta=\sqrt{\frac{2 k\left(T_{m p}-T_{i}\right)}{q^{m}}} .
$$


The total flow of heat leaving the crust and entering the glass $\mathrm{q}_{\mathrm{D}}$ " is the sum of the convective contribution and the internal heat generation in the crust:

$$
\mathrm{q}_{\mathrm{D}}^{\prime \prime}=\mathrm{h}\left(\mathrm{T}_{\text {pool }}-\mathrm{T}_{\mathrm{mp}}\right)+\delta \mathrm{q}^{\prime \prime \prime}=\sqrt{2 \mathrm{kq} \mathrm{q}^{\prime \prime}\left(\mathrm{T}_{\mathrm{mp}}-\mathrm{T}_{\mathrm{i}}\right)}
$$

Now consider a case, prototypical of the top and side crusts, in which the crust is so thin that the internal heat generation is negligible compared to convection. In this case we simply have:

$$
\mathrm{q}_{\mathrm{u}}^{\prime \prime}=\mathrm{h}\left(\mathrm{T}_{\mathrm{pool}}-\mathrm{T}_{\mathrm{mp}}\right)
$$

We can compare the magnitude of these two heat fluxes by assuming that the top and side heat fluxes are nearly equal to each other, (i.e., they are each about equal to their average $q_{a}$ ). The average of the top and side heat fluxes is obtained by a total heat balance on the cylinder:

$$
q_{a}^{\prime \prime}\left(2 \pi r z+\pi r^{2}\right)+\sqrt{2 k q^{\prime \prime}\left(T_{m p}-T_{i}\right)} \pi r^{2}=q^{\prime \prime} \pi r^{2} z \text {, }
$$

or

$$
q_{\mathrm{a}}^{\prime \prime}=\frac{\mathrm{q}^{\prime \prime} \mathrm{z}-\sqrt{2 \mathrm{k} \mathrm{q}^{\| \prime}\left(\mathrm{T}_{\mathrm{mp}}-\mathrm{T}_{\mathrm{i}}\right)}}{1+\frac{2 \mathrm{z}}{\mathrm{r}}}
$$

Rough estimates for these quantities are given in the text:

$$
\begin{aligned}
& \mathrm{q}^{\prime \prime \prime}=5 \times 10^{5} \mathrm{~W} / \mathrm{m}^{3}, \\
& \mathrm{z}=0.75 \mathrm{~m}, \\
& \mathrm{k}=5 \mathrm{~W} / \mathrm{m} \cdot \mathrm{K}, \\
& \mathrm{T}_{\mathrm{mp}}=2900 \mathrm{~K}, \\
& \mathrm{~T}_{\mathrm{i}}=950 \mathrm{~K}, \text { and } \\
& \mathrm{I}=2.9 \mathrm{~m},
\end{aligned}
$$

which leads to 


\section{SE.2-5}

$$
\mathrm{q}_{\mathrm{d}}{ }^{\prime \prime}=1 \times 10^{5} \mathrm{~W} / \mathrm{m}^{2}
$$

and

$$
\mathrm{q}_{\mathrm{a}}=1.8 \times 10^{5} \mathrm{~W} / \mathrm{m}^{2}
$$

These results are quite similar to the results obtained from the computer code.

The other extreme case, quite unlikely to be reached, would be that the downward heat flux was as large as the average (i.e., all heat is emitted uniformly). In this case, we have

$$
\mathrm{q}_{\mathrm{d}}^{\prime \prime}=\mathrm{q}_{\mathrm{a}}^{\prime \prime}=\frac{1}{2} \frac{\mathrm{q}^{\prime \prime} \mathrm{z}}{1+\frac{\mathrm{z}}{\mathrm{r}}}=1.5 \times 10^{5} \mathrm{~W} / \mathrm{m}^{2}
$$

Note that the downward heat flux is only $50 \%$ larger in this unrealistic limit. We conclude that the total downward heat flux $q_{d}$ " from the assumed configuration is relatively independent of the details of the internal convection. Physically, this independence occurs because the lower crust grows or shrinks to compensate for changes in the convective heat flux, and increased internal heating in a thicker crust largely makes up for corresponding reductions in the convective term. 


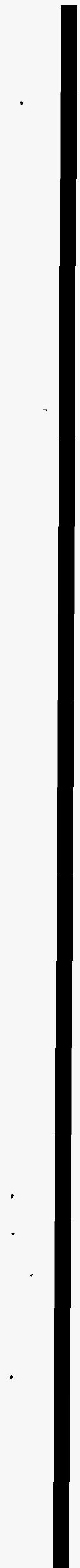


F. MASS TRANSFER RATE DETERMINATION FOR CORE DEBRIS

IN GLASS IN SUPPORT OF COMSORS 



\section{F.1 INTRODUCTION}

The purpose of this appendix is to report on the prediction of the mass transfer rate for nuclear reactor core debris dissolving in a pool of molten glass. A brief study was undertaken in support of the development of COMSORS (COre Melt SOurce Reduction System). Reported here are the rationale for the study, the technical basis used in estimating mass transfer rates, and the results, which have important implications for further development efforts.

\section{F.2 BACKGROUND}

\section{F.2.1 MASS TRANSFER FAILURE SCENARIOS}

The operation of COMSORS requires that the core debris dissolve into the glass. Once the core debris is dissolved into the glass, the heat can be efficiently removed from the glass (Appendix $\mathrm{E}$ ) by circulation of molten glass and transfer of heat to the water above the glass. This is an efficient process that maintains glass temperatures below $700^{\circ} \mathrm{C}$. At these low temperatures, insulation or limited cooling between COMSORS and the containment concrete prevents damage to the containment concrete. The core melt accident is stopped.

If the core debris does not dissolve rapidly, there are potential scenarios that could cause containment failure. The primary concern is slow dissolution of core debris during which core debris forms a layer between molten lead and molten glass (Fig. F.1). When core debris interacts with the glass, the glass melts because of the decay heat within the core debris. Some lead will be generated in any scenario. Such lead is molten. Because the core debris density is intermediate between glass and lead, it floats at the glass-lead interface. If the core debris forms a complete layer between the glass and lead, the lead can not transfer heat to the glass. The core debris is a heat-generating layer that heats the lead and potentially can heat the lead until containment failure. Practical insulation materials are available to about $1100^{\circ} \mathrm{C}$. If the lead temperatures exceed this, insulation layers will fail, and containment failure is possible.

Whether this or related scenarios can cause containment failure depends upon the rate of core debris dissolution, which in turn depends upon the core-debris dissolution rate per unit area and the surface area for contact. The design requirements to ensure fast core-debris dissolution are discussed herein. 


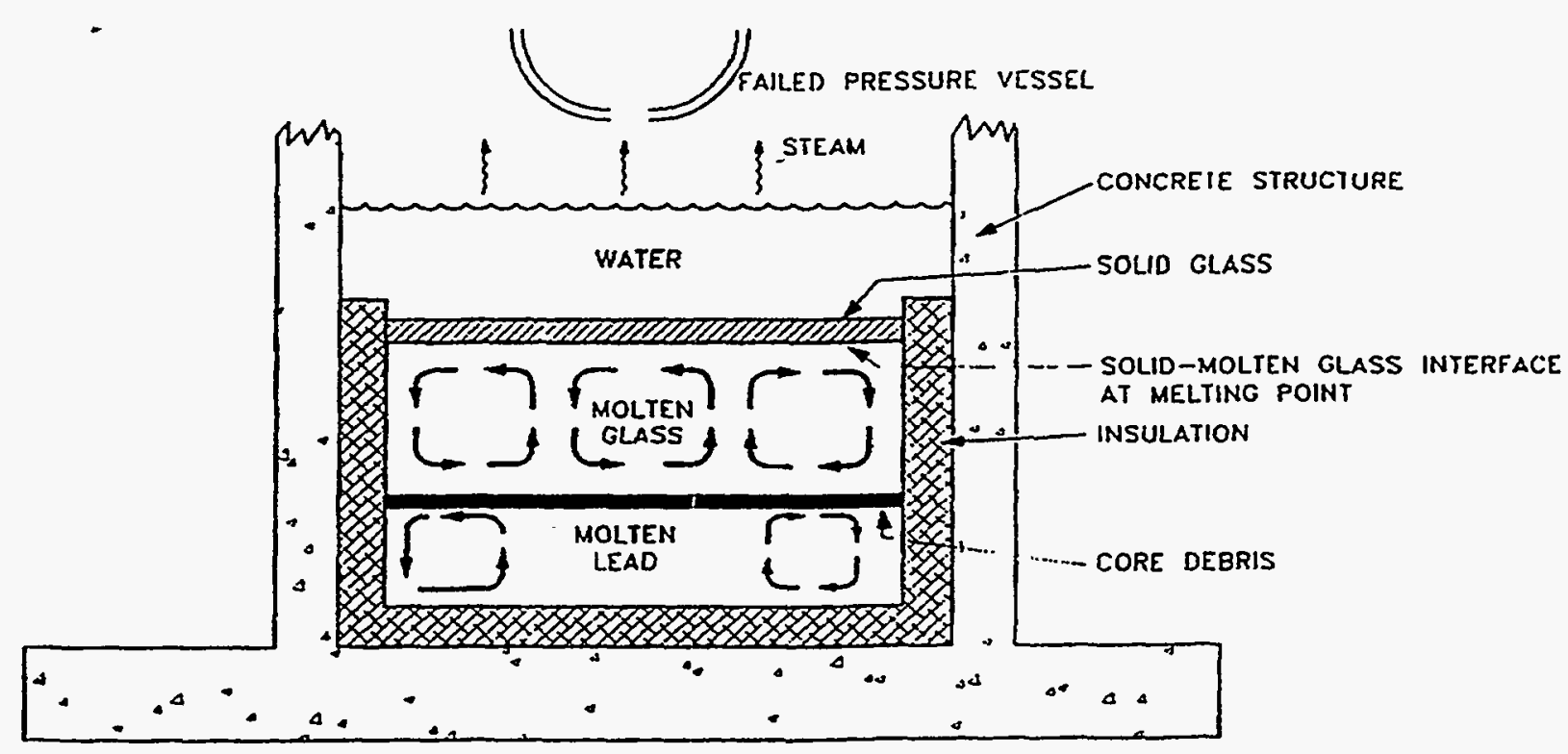

Fig. F.1. A conceptual diagram of the COMSORS core catcher.

\section{F.2.2 SURFACE AREA FOR CORE-DEBRIS DISSOLUTION}

The rate of core-debris dissolution depends on first approximation of the surface area between the coredebris and the molten glass. During transient operation, COMSORS may have a very high surface area. The probable transient scenario for COMSORS operation assuming a monolithic glass below the reactor is (1) core debris flowing onto the glass; (2) partial reaction of core debris with the glass, thus creating molten lead; and (3) formation of a core-debris layer floating on the reaction product lead. Water would be on top of the core debris, ' and solid, unreacted glass would be below the lead. Shortly after the accident, from top to bottom, there would be layers of boiling water, core debris, molten lead, and solid glass.

In such a scenario, the lead would begin to heat up. As it heats up, solid glass below the lead would begin to melt. The lower density glass would form molten glass droplets that would float upward through the molten lead to the bottom of the core debris. These small glass droplets would dissolve into the core debris, thus lowering its density and viscosity. Because the molten glass has a lower density, such beads would tend to bore into the core debris. The process would continue until a uniform glass mixture was created.

The previous scenario appears likely, but it has not been proven. In such circumstances, one other option exists to ensure that sufficient surface area exists for rapid core dissolution-that is, engineer the glass to have a high surface area. That option is discussed in the following. 


\section{F.2.3 REACTION RATES BETWEEN CORE DEBRIS AND MOLTEN GLASS}

The reaction rates per unit area between core debris and molten glass depend upon dissolution mechanism, temperature, glass viscosity, and many other parameters. These are discussed in the following. For this analysis, it is assumed that the process can be modeled as dissolution. This assumption is a conservative one for the initial design.

Several possible mechanisms may result in much faster dissolution rates than are assumed herein. Further experimental work will be required to determine the importance of such mechanisms. One example of such a mechanism is based on the characteristics of boron oxide. The boron oxide in the glass melt will drastically reduce the melting point of any ceramic mixture such as core debris. The boron oxide is expected to diffuse into the oxide. This diffusion would provide a mechanism to break up core debris along weak interfaces and to accelerate dissolution.

\section{F3 COMSORS}

\section{F.3.1 FAILURE MODES}

It is crucial to consider the possible modes by which the passive safety system of COMSORS might fail. One such possibility is failure of the core debris to be dissolved and dispersed in time to avoid damaging the alumina insulator, which will fail if the lead temperature exceeds the maximum temperature for the insulator $\left(-1000-1100^{\circ} \mathrm{C}\right)$. Hence, a key parameter of interest is the rate of mass transfer for the core debris into the molten glass, with which it is in contact.

\section{F.3.2 MASS TRANSFER RATE ESTIMATION}

The problem of determining the dissolution rate of core debris into the molten glass reservoir of COMSORS is essentially that of determining the rate of diffusion through a liquid at a solid boundary, at which the liquid is undergoing natural convection because of thermal driving forces. This problem has been examined previously, with results that are well known for simple geometries (Welty, Wicks, and Wilson, 1969; Sherwood, Pigford, and Wilke, 1975). For natural convection occurring next to a vertical planar surface, the mass transfer into an adjacent body of liquid is described by the following relations. 


$$
\begin{gathered}
N_{A y}=k_{c}\left(c_{A s}-c_{A_{\infty}}\right), \\
\frac{k_{c} x}{D_{A B}}=N u_{A B}=0.664 \operatorname{Re}_{x}^{1 / 2} S c^{1 / 3}, \text { and } \\
N_{A y}=D_{A B}\left(\frac{0.664 R e_{x}^{1 / 2}}{x}\right) S c^{1 / 3}\left(C_{A S}-C_{A \infty}\right),
\end{gathered}
$$

where $\quad N_{A y}=$ molar flux of solute A away from the planar surface, gmoles $/\left(\mathrm{cm}^{2} \mathrm{~s}\right)$,

$k_{c} \quad=$ mass transfer coefficient due to a concentration gradient, $\mathrm{cm} / \mathrm{s}$,

$\mathrm{C}_{A S}=$ concentration of solute $\mathrm{A}$ (at saturation) near the surface, gmoles $/ \mathrm{cm}^{3}$,

$C_{A \infty}=$ concentration of solute $A$ far from the surface, gmoles $/ \mathrm{cm}^{3}$,

$D_{A B}=$ diffusivity of solute $A$ in solvent $B, \mathrm{~cm}^{2} / \mathrm{s}$,

$R e_{x}=$ Reynolds number evaluated at a distance $x$ along the planar surface, and

$N u_{A B}=$ Nusselt number, as defined in Eq. (F.2).

Equations (F.2) and (F.3) are valid for systems having a Schmidt number, Sc, other than unity and mass transfer rates between the flat plate and the boundary layer in the liquid that are not necessarily low. The Reynolds and Schmidt numbers are given by Eqs. (F.4) and (F.5).

$$
R e_{x}=\frac{x v \rho_{B}}{\mu_{B}},
$$

and

$$
S_{C}=\frac{\mu_{B}}{D_{A B} \rho_{B}} \text {, }
$$

where $\quad v=$ bulk velocity of solvent (liquid) $B, \mathrm{~cm} / \mathrm{s}$,

$\rho_{B}=$ density of solvent $B, \mathrm{~g} / \mathrm{cm}^{3}$, and

$\mu_{B}=$ viscosity of solvent $B, \mathrm{~g} /(\mathrm{cm}-\mathrm{s})$. 
Estimation of the dissolution rate of core debris in molten glass requires the following steps: (1) determination of properties of the glass, including composition; (2) determination of properties of the core debris, including composition; (3) estimation of diffusion coefficient for core debris in glass; (4) determination of the concentration near the surface; and (5) calculation of the mass transfer rate. Some information required for the estimate was assumed, based on available information, or taken as a basis. Some assumptions are based on a previous study (see Table F.1), which analyzed the thermal hydraulic behavior of a reference COMSORS system (see Fig. F.2). More details on the thermal hydraulic behavior of COMSORS may be found in Appendix E.

Note that the value in Table F.1 for solute density is approximate because the mean is calculated based on the composition of the core debris. Also, the dimension used in the flat-plate assumption is that which gives a square of equivalent surface to a circle of radius $3.79 \mathrm{~m}$, as shown in Fig. F.2.

Table F.1. Basis and assumptions for use in mass transfer rate estimates

\begin{tabular}{lll}
\hline \multicolumn{1}{c}{ Quantity } & $\begin{array}{c}\text { Symbol } \\
\text { (Egs. F.1-F.5) }\end{array}$ & Value \\
\hline Near surface solute concentration & $C_{A s}$ & $30 \%$ \\
Distant solute concentration & $C_{A \infty}$ & $0 \%$ \\
Distance along a flat plate & $L$ & $6.75 \mathrm{~m}$ \\
Velocity far beyond boundary layer & $v$ & $100 \mathrm{~cm} / \mathrm{s}$ \\
Density of solute & $\rho_{A}$ & $8 \mathrm{~g} / \mathrm{cm}^{3}$ \\
Density of solvent & $\rho_{B}$ & $7.7 \mathrm{~g} / \mathrm{cm}^{3}$ \\
Viscosity of solvent & $\mu_{B}$ & $100 \mathrm{cp}$ \\
Temperature & $T$ & $973 \mathrm{~K}$ \\
Association parameter for solvent & $\phi$ & 1 \\
(non-electrolytes) & & \\
\hline
\end{tabular}

\section{F.3.2.1 Glass Properties}

The composition of the lead borate glass will be chosen to provide the most favorable properties in consideration of a number of factors, many of which have not yet been determined. However, it is assumed herein that the glass will have a composition such that the molar ratio of $\mathrm{PbO}$ to $\mathrm{B}_{2} \mathrm{O}_{3}$ is $3: 1$ both to provide $\mathrm{PbO}$ for the reduction of metals and to enhance the solubility of core debris in the glass. This composition is shown in Table F.2 (see the "Mole percent" column). The mass composition and mean molecular weight were calculated and are also shown in Table F.2. 
ORNL DW \#96-4999

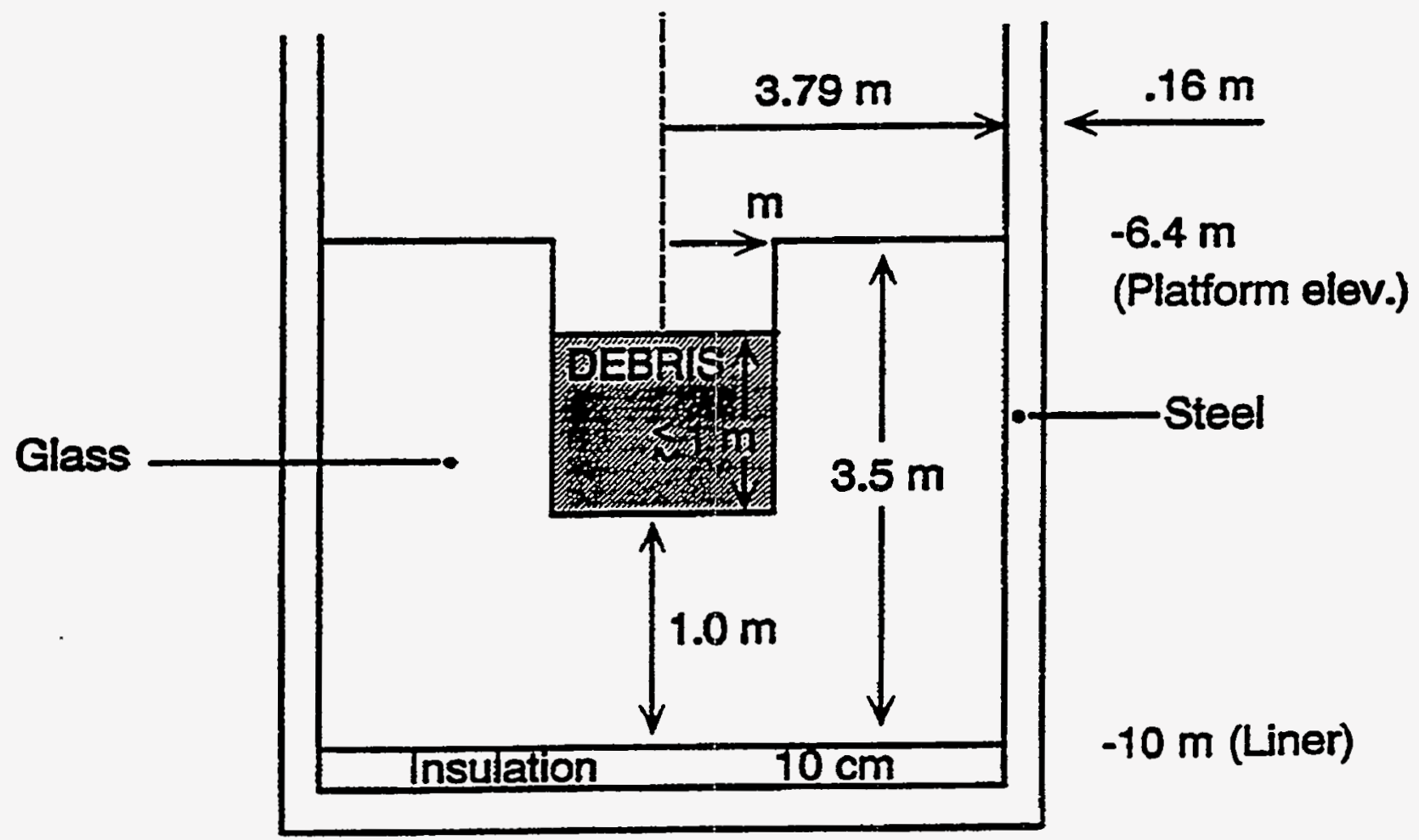

Fig. F.2. Proposed base-case configuration just after vessel failure.

\section{F3.2.2 Core Debris Properties}

The core debris resulting from a melt-through is assumed to be a mixture of uranium oxides, primarily $\mathrm{UO}_{2}$, . and zirconium, which has been completely oxidized to $\mathrm{ZrO}_{2}$. An example composition fitting this assumption is given in Table F.3, along with some properties of core debris components. The "Mass percent" column shows the assumed composition. The molar volumes are required in Eq. (F.6) for the estimation of the diffusion coefficient.

Table F.2. Composition and molecular weight for 2:1 lead borate glass

\begin{tabular}{lcccc}
\hline Component & $\begin{array}{c}\text { Molecular } \\
\text { weight }\end{array}$ & $\begin{array}{c}\text { Mass } \\
\text { percent }\end{array}$ & $\begin{array}{c}\text { Moles } \\
\text { per gram }\end{array}$ & $\begin{array}{c}\text { Mole } \\
\text { percent }\end{array}$ \\
\hline $\mathrm{PbO}$ & 223.2 & 86.5 & 0.003875 & 66.7 \\
$\mathrm{~B}_{2} \mathrm{O}_{3}$ & 69.6 & 13.5 & 0.001939 & 33.3 \\
Overall & 172.0 & 100.0 & 0.005815 & 100.0 \\
\hline
\end{tabular}


Table F.3. Core debris composition and molar volume

\begin{tabular}{lccccc}
\hline Component & $\begin{array}{c}\text { Molecular } \\
\text { weight }\end{array}$ & $\begin{array}{c}\text { Density } \\
\left(\mathrm{g}_{\mathrm{cm}}\right)\end{array}$ & $\begin{array}{c}\text { Molar Volume } \\
\left(\mathrm{cm}^{3} / \mathrm{mol}\right)\end{array}$ & $\begin{array}{c}\text { Mass } \\
\text { percent }\end{array}$ & $\begin{array}{c}\text { Mole } \\
\text { percent }\end{array}$ \\
\hline $\mathrm{UO}_{2}$ & 270.0 & 10.96 & 24.6 & 30 & 25.6 \\
$\mathrm{U}_{3} \mathrm{O}_{8}$ & 843.0 & 8.30 & 101.6 & 30 & 8.2 \\
$\mathrm{Fe}_{3} \mathrm{O}_{4}$ & 231.6 & 5.18 & 44.7 & 10 & 10.0 \\
$\mathrm{ZrO}_{2}$ & 123.0 & 5.60 & 22.0 & 30 & 56.2 \\
Overall & 230.8 & 7.98 & 28.9 & 100 & 100.0 \\
\hline
\end{tabular}

\section{F.3.2.3 Diffusion Coefficient Estimation}

The diffusion coefficient is predicted based on two theories: the Eyring "hole" theory and the hydrodynamical theory. The results of these two theories are a diffusion coefficient that is a function of temperature, solvent viscosity, and the molar volume of the solute (Welty, Wicks, and Wilson, 1969, Chapter 24; Sherwood, Pigford, and Wilke (1975), Chapter 2). The best available correlation for nonelectrolytes was proposed by Wilke and Chang (1955).

$$
D_{A B}=\frac{7.4 \times 10^{-8}\left[T\left(\phi M_{B}\right)^{1 / 2}\right]}{\mu_{B} V_{A}^{0.6}},
$$

where $\phi=$ association parameter of solvent $B$,

$M_{B}=$ molecular weight of solvent $B$, and

$V_{A}=$ molal volume of the solute at its normal boiling point, $\mathrm{cm}^{3} / \mathrm{g}$.

Equation (F.6) is most applicable in dilute solution. Hence, the estimate of $D_{A B}$ obtained from Eqn. (F.6) should be considered a rough, optimistic estimate, bounding actual values on the high end. Estimates of the diffusion coefficient have been made with Eq. (F.6) for the core debris and its components (see Table F.4).

The values shown in Table F.4 seem reasonable in comparison with systems that have been studied more extensively (see Table F.5). This is especially true considering the higher molecular weights and viscosities of the core debris-molten glass system under consideration here. 
Table F.4. Diffusion coefficient estimates

\begin{tabular}{lcccc}
\hline Component & $\begin{array}{c}\text { Molecular } \\
\text { weight }\end{array}$ & $\begin{array}{c}\text { Molar volume } \\
\left(\mathrm{cm}^{3} / \mathrm{mol}\right)\end{array}$ & $\begin{array}{c}\text { Mass } \\
\text { percent }\end{array}$ & $\begin{array}{c}\text { Diffusivity } \\
\left(\mathrm{cm}^{2} / \mathrm{s}\right)\end{array}$ \\
\hline $\mathrm{UO}_{2}$ & 270.0 & 24.6 & 30 & $1.4 \times 10^{-6}$ \\
$\mathrm{U}_{3} \mathrm{O}_{8}$ & 843.0 & 101.6 & 30 & $5.9 \times 10^{-7}$ \\
$\mathrm{Fe}_{3} \mathrm{O}_{4}$ & 231.6 & 44.7 & 10 & $9.7 \times 10^{-7}$ \\
$\mathrm{ZrO}_{2}$ & 123.0 & 22.0 & 30 & $1.5 \times 10^{-6}$ \\
Overall & 168.0 & 20.8 & 100 & $1.3 \times 10^{-6}$ \\
\hline
\end{tabular}

Table F.5. Measured diffusion coefficients for some common solutes in water near $300 \mathrm{~K}$

\begin{tabular}{lrcc}
\hline Component & $\begin{array}{c}\text { Molecular } \\
\text { Weight }\end{array}$ & $\begin{array}{c}\text { Molar volume } \\
\left(\mathrm{cm}^{3} / \mathrm{mol}\right)\end{array}$ & $\begin{array}{c}\text { Diffusivity } \\
\left(\mathrm{cm}^{2} / \mathrm{s}\right)\end{array}$ \\
\hline $\mathrm{CO}_{2}$ & 44 & 34.0 & $1.92 \times 10^{-5}$ \\
$\mathrm{CO}$ & 28 & 30.7 & $2.03 \times 10^{-5}$ \\
$\mathrm{H}_{2} \mathrm{O}$ & 18 & 18.9 & $2.44 \times 10^{-5}$ \\
$\mathrm{Cl}_{2}$ & 71 & 48.4 & $1.26 \times 10^{-5}$ \\
$\mathrm{NH}_{4}$ & 18 & 25.8 & $1.24 \times 10^{-5}$ \\
$\mathrm{C}_{2} \mathrm{H}_{5} \mathrm{OH}$ & 46 & 59.2 & $8.30 \times 10^{-6}$ \\
\hline
\end{tabular}

\section{F3.2.4 Near-Surface Concentration}

Concentration difference is the driving force for mass transfer of core debris into the molten glass reservoir. The concentration far from the surface $\left(C_{A \alpha}\right)$, well away from the boundary layer, is taken to be zero. concentration near the surface $\left(C_{A s}\right)$, in the boundary layer, is assumed to be saturated. The solubility limit for the core debris materials is about $30 \%$ by mass. The near-surface composition of the molten glass/core debris mixture is given in Table F.6.

Table F.6. Solution concentration near the surface

\begin{tabular}{lcrr}
\hline Component & $\begin{array}{c}\text { Mass } \\
\text { percent }\end{array}$ & $\begin{array}{c}\text { Volume } \\
\text { percent }\end{array}$ & $\begin{array}{c}\text { Mole } \\
\text { percent }\end{array}$ \\
\hline $\mathrm{UO}_{2}$ & 9.0 & 6.2 & 6.2 \\
$\mathrm{U}_{3} \mathrm{O}_{8}$ & 9.0 & 8.2 & 2.0 \\
$\mathrm{Fe}_{3} \mathrm{O}_{4}$ & 3.0 & 4.4 & 2.4 \\
$\mathrm{ZrO}_{2}$ & 9.0 & 12.2 & 13.6 \\
$\mathrm{Glass}$ & 70.0 & 69.0 & 75.8 \\
Overall & 100.0 & 100.0 & 100.0 \\
\hline
\end{tabular}




\section{F.3.2.5 Mass Transfer Rate}

The mass transfer rate is calculated from Eq. (F.3), with information obtained from Eqs. (F.4) and (F.6). For a velocity of $1 \mathrm{~m} / \mathrm{s}$, a glass reservoir that is $6.75 \mathrm{~m}$ by $6.75 \mathrm{~m}$, a glass density of $7.7 \mathrm{~g} / \mathrm{cm}^{3}$, and an association parameter of 1 , the following values are obtained:

$$
\begin{gathered}
R e_{x}=5200, \\
N u_{A B}=23.9, \text { and } \\
S C=1.04 \times 10^{-7}
\end{gathered}
$$

The diffusivity, $D_{A B}$, is shown in Table F.7, along with the molar flux, $N_{A y}$ and the mass transfer rate, for the core debris and its components. The mass transfer rate is obtained from the molar flux by the following relation.

$$
w_{A B}=3.6 N_{A y} L^{2} \text {, }
$$

where $L$ is the size (in $\mathrm{cm}$ ) of the glass reservoir, which is assumed to be square, and the factor 3.6 puts $w_{A B}$ in units of kilograms per hour. For other reservoir geometries, which will be considered later, the $L^{2}$ of Eq. (F.10) may be replaced by the appropriate contact area. This expression may be used for a variety of alternative reservoir geometries for which contact takes place at a planar or, at least, pseudoplanar interface.

Table F.7. Mass transfer rate estimates for core debris

\begin{tabular}{lccc}
\hline \multicolumn{1}{c}{ Component } & $\begin{array}{c}\text { Diffusivity } \\
{\left[D_{A B}\left(\mathrm{~cm}^{2} / \mathrm{s}\right)\right]}\end{array}$ & $\begin{array}{c}\text { Molar flux } \\
\left(\mathrm{gmol} / \mathrm{cm}^{2} \mathrm{~s}\right)\end{array}$ & $\begin{array}{c}\text { Transfer rate } \\
{\left[w_{A B}(\mathrm{~kg} / \mathrm{h})\right]}\end{array}$ \\
\hline $\mathrm{UO}_{2}$ & $1.4 \times 10^{-6}$ & $5.2 \times 10^{-8}$ & 23 \\
$\mathrm{U}_{3} \mathrm{O}_{8}$ & $5.9 \times 10^{-7}$ & $9.4 \times 10^{-9}$ & 13 \\
$\mathrm{Fe}_{3} \mathrm{O}_{4}$ & $9.7 \times 10^{-7}$ & $1.6 \times 10^{-8}$ & 6 \\
$\mathrm{ZrO}_{2}$ & $1.5 \times 10^{-6}$ & $1.2 \times 10^{-7}$ & 24 \\
Overall & $1.3 \times 10^{-6}$ & $1.9 \times 10^{-7}$ & 72 \\
\hline
\end{tabular}

Mass transfer rates obtained through use of Eqs. (F.1) through (F.6) and (F.10) should apply to the corecatcher system described herein if the process is diffusion-limited. It is important to remember that other processes could be important. For example, aggressive penetration of $\mathrm{B}_{2} \mathrm{O}_{3}$ into the core debris could have a significant impact on the mechanism of mass transfer. The results obtained herein should be considered as representative only if diffusion-limited mass transfer is the case considered. Experimental investigations currently underway should provide evidence by which to judge this assumption. 


\section{F.4 DISCUSSION}

For the case considered, the mass transfer rate was estimated at $72 \mathrm{~kg} / \mathrm{h}$. A typical corium mass, as shown in Table F.8, is about 142 tons. Hence, a dissolution time of $43 \mathrm{~d}$ (about $1000 \mathrm{~h}$ ) is predicted.

It is important to note that this result depends on a number of factors, including (1) the assumption that dissolution of the corium is mass-transfer-limited, (2) the (conservative) dilute solution assumption, and (3) the conditions and properties that are required for the calculations presented herein.

The first factor deserves further consideration, which is beyond the scope of this report. Experimental investigation of the significance of other modes of transport is desirable.

The second factor is less important than the first in terms of the potential impact that it could have on mass transfer rate estimates. Also, corrections for nondilute solutions will probably decrease the mass-transfer-rate estimate somewhat, but not by orders of magnitude.

The third factor, essentially one of parametric sensitivity, can be explored in detail within the framework of the model that has been developed. The next section presents the parametric behavior for key variables.

Table F.8. Example corium mass composition

\begin{tabular}{lcc}
\hline Component & $\begin{array}{c}\text { Metric tons } \\
\left(\mathrm{kg} \times 10^{3}\right)\end{array}$ & $\begin{array}{c}\text { Mass } \\
\text { percent }\end{array}$ \\
\hline $\mathrm{UO}_{2}$ & 42.1 & 29.8 \\
$\mathrm{U}_{3} \mathrm{O}_{8}$ & 42.1 & 29.8 \\
$\mathrm{Fe}_{3} \mathrm{O}_{4}$ & 13.8 & 9.8 \\
$\mathrm{ZrO}_{2}$ & 0.7 & 30.7 \\
Overall & 141.5 & 100.0 \\
\hline
\end{tabular}

\section{F.4.1 VARIATION OF MASS TRANSFER RATE WITH SELECT PARAMETERS}

The mass transfer rate depends on several parameters, as indicated by the equations presented earlier. Substituting Eqs. (F.3) through (F.6) into Eq. (F.10) yields an expression that shows the dependency of the mass transfer rate on system parameters:

$$
w_{A B}=\frac{1.77 \times 10^{-7} L^{1.5} T \Delta C_{A}\left(\phi v M_{B}\right)^{0.5} \rho_{B}^{0.167}}{\mu_{B}^{0.83} V_{A}^{0.6}},
$$

where $\Delta \mathrm{C}_{\mathrm{A}}=\mathrm{C}_{a s}-\mathrm{C}_{\mathrm{A} \infty}$. 
Equation (F.11) indicates that the most influential parameter is the size of the reservoir, whereas the glass density has the least influence. The relative importance of system parameters is depicted in Fig. F.3.

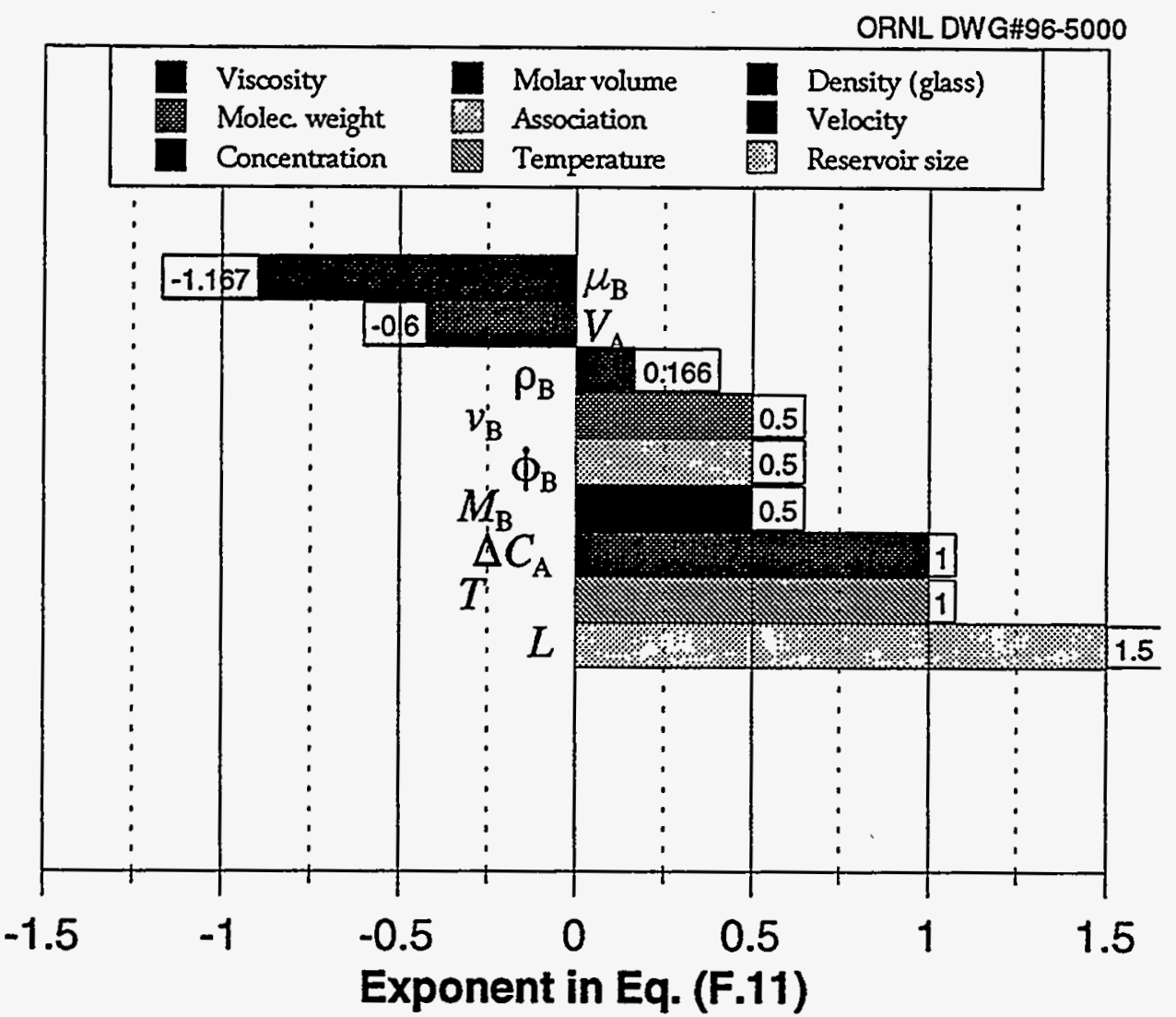

Fig. F.3. Relative importance of various parameters in determining the rate of mass transfer for core debris in a molten glass reservoir.

\section{F.4.1.1 Effect of Velocity on Mass Transfer Rate}

A key parameter is the bulk velocity of the molten glass. This velocity arises because of natural convection caused by thermal driving forces. Estimation of the velocity is not within the scope of this paper, but it is instructive to observe its influence on the mass transfer rate. This effect is shown in Figs. (F.4) and (F.5) for velocities ranging up to 1 and $10 \mathrm{~m} / \mathrm{s}$, respectively. For a $45.6-\mathrm{m}^{2}$ reservoir and a bulk velocity of $1 \mathrm{~m} / \mathrm{s}$, core debris is predicted to dissolve at about $72 \mathrm{~kg} / \mathrm{h}$. Thus, a 142-ton reactor core and debris would be completely dissolved in about $43 \mathrm{~d}$. 


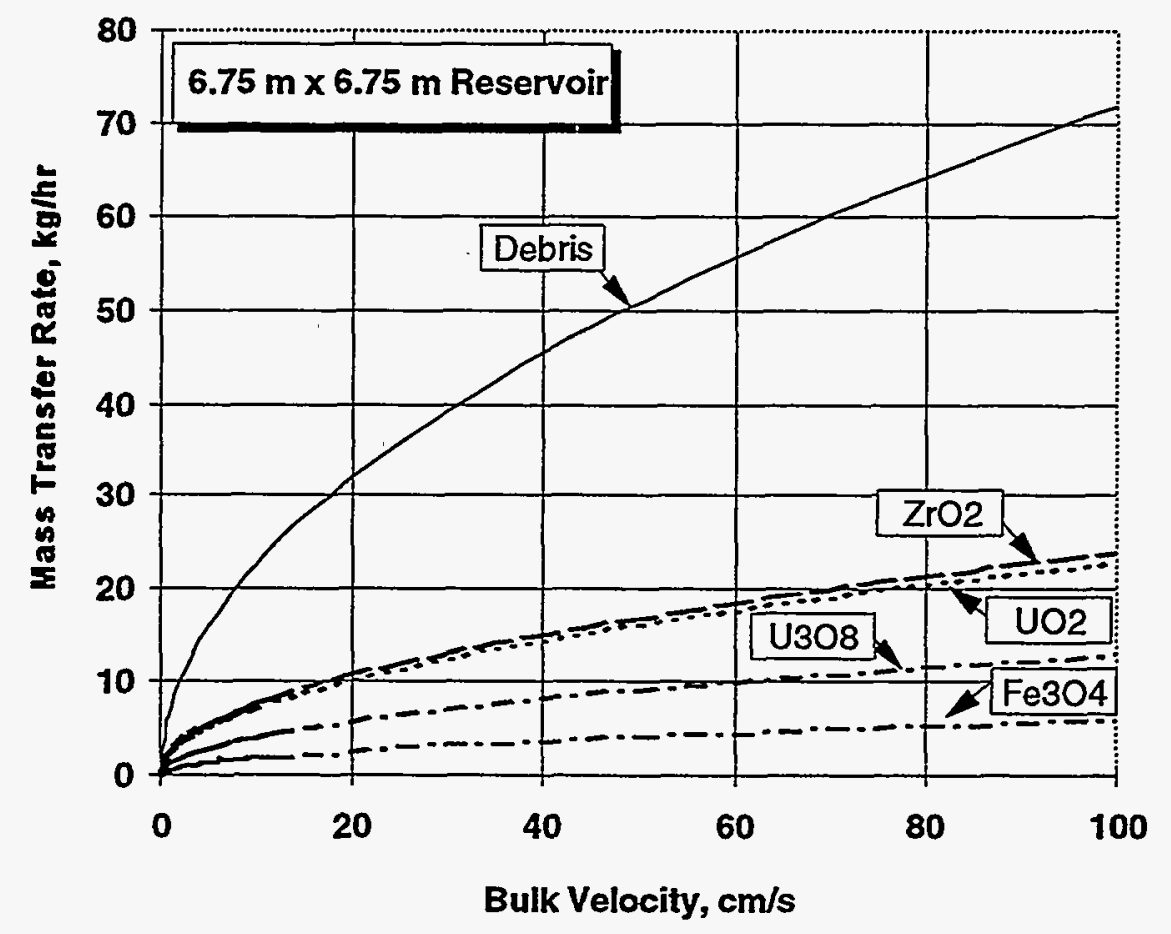

Fig. F.4. Variation of mass transfer rate of core debris with bulk velocity in a molten glass reservoir for velocities under $1 \mathrm{~m} / \mathrm{s}$.

\section{F.4.1.2 Effect of Viscosity on Mass Transfer Rate}

The glass melt viscosity has a greater influence on mass transfer rate than bulk velocity, but with an inverse effect. The 7:6-power relationship is reflected in the plot of mass transfer rate vs viscosity at various velocities (see Figs. F.6 and F.7). Note that before core debris concentrations rise, the glass viscosity may be as low as $20 \mathrm{cp}$ at $973 \mathrm{~K}$ (see Appendix D).

\section{F.4.1.3 Effect of Temperature on Mass Transfer Rate}

The temperature of the glass melt has a somewhat greater influence on mass transfer rate than viscosity. Yet the temperature also directly affects the viscosity. Because of the inverse relationship of viscosity with temperature and mass transfer rate, an increase in $T$ will cause an additional increase in $w_{A B}$ as the viscosity decreases. Increasing temperature also increases natural convection, giving rise to an added increase in $w_{A B}$ as the bulk velocity increases with $T$. The effect of $T$ on core debris density and glass melt molar volume is probably not important by comparison. 


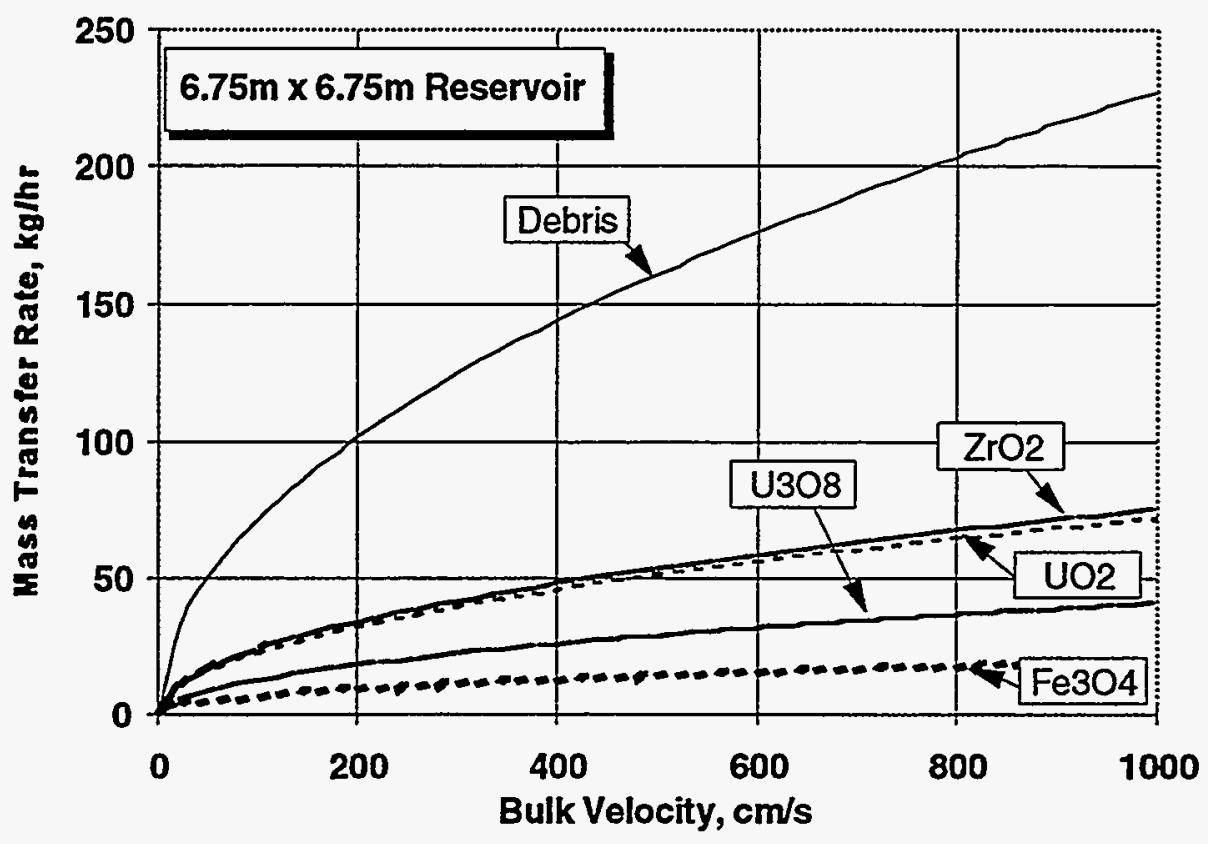

Fig. F.5 Variation of mass transfer rate of core debris with bulk velocity in a molten glass reservoir for velocities up to $100 \mathrm{~m} / \mathrm{s}$.

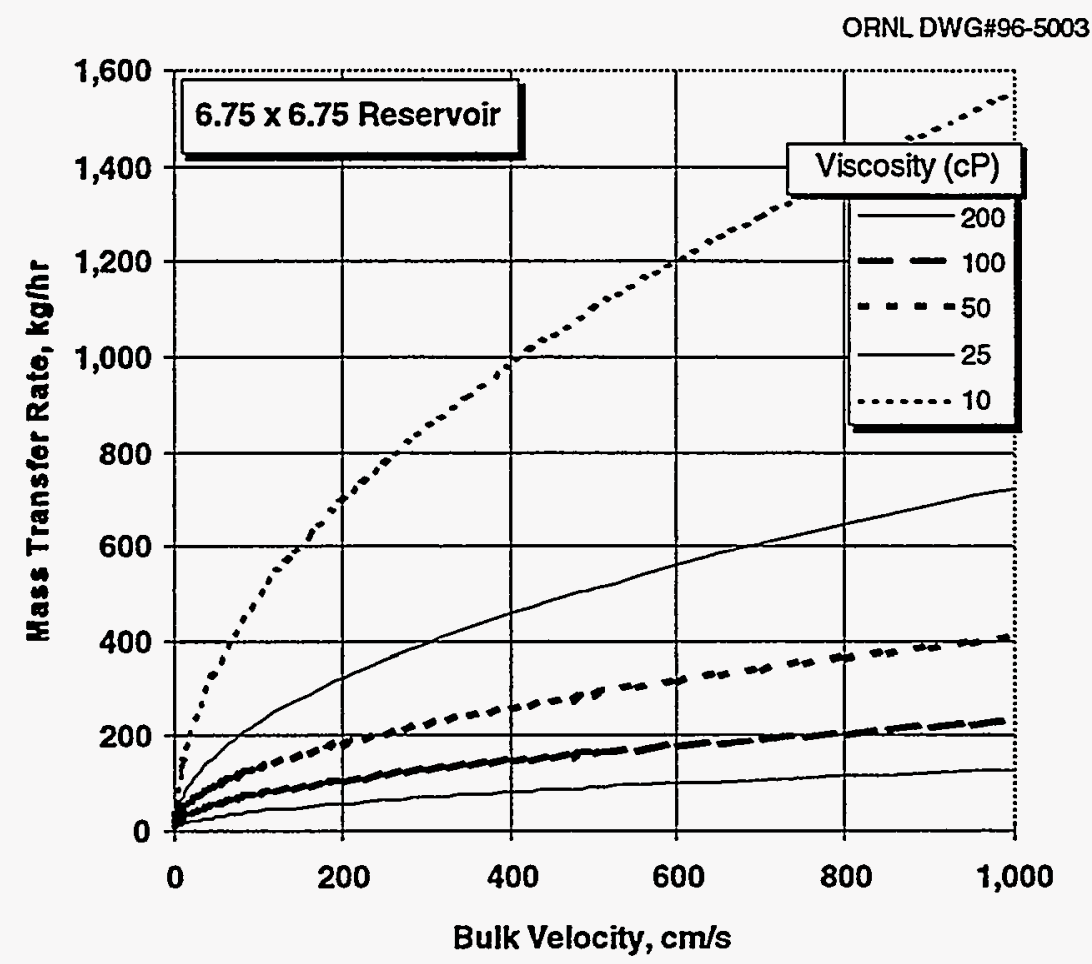

Fig. F.6. Variation of mass transfer rate of core debris with bulk velocity and viscosity in a molten glass reservoir for velocities up to 10 $\mathbf{m} / \mathbf{s}$. 


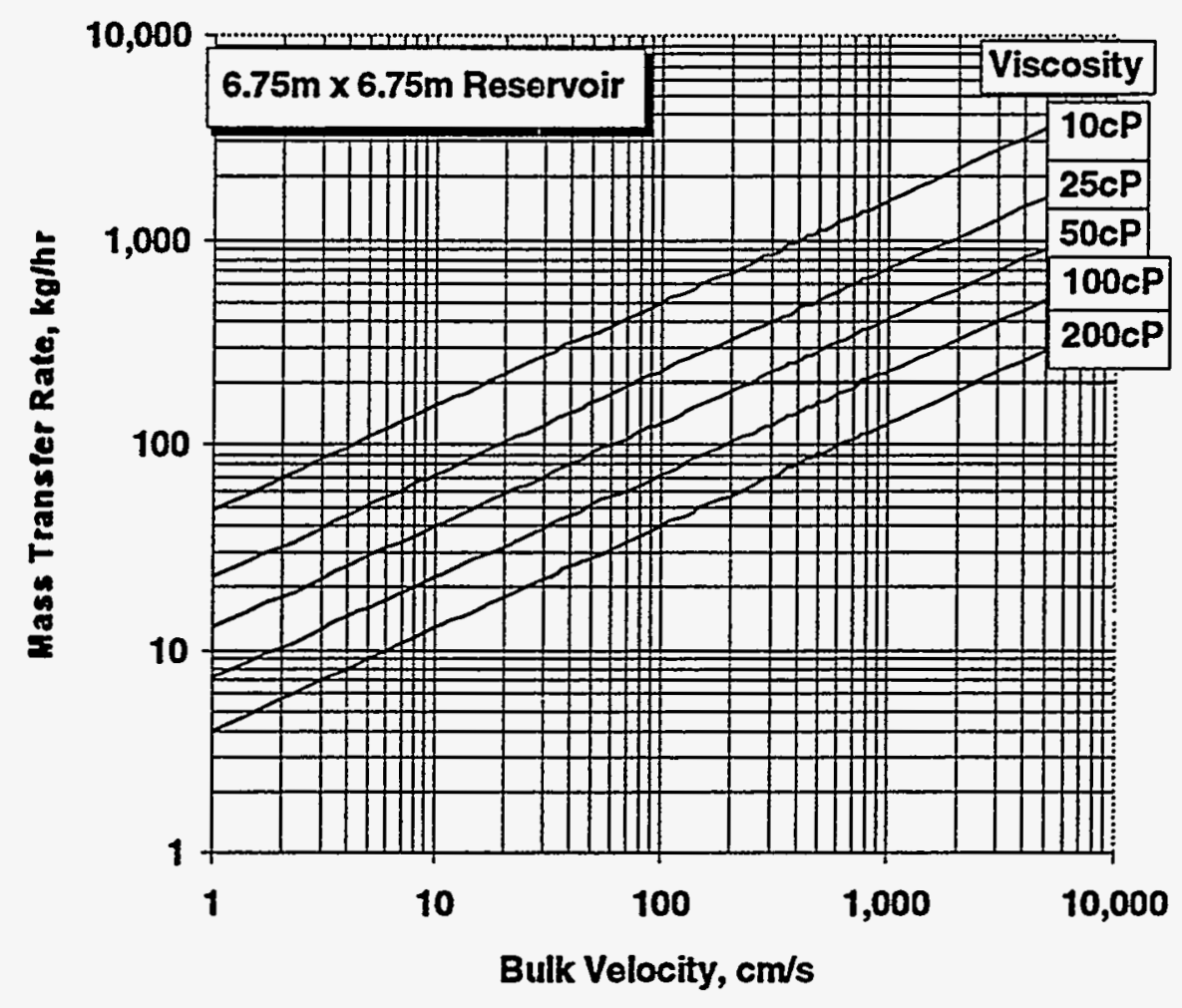

Fig. F.7. Log-log plot of the variation of mass transfer rate of core debris with viscosity and bulk velocity (up to $50 \mathrm{~m} / \mathrm{s}$ ) in a molten glass reservoir.

Temperatures near the core debris will rise unless decay heat is transported away. Until the core debris is dispersed, the glass nearby will tend to be at elevated temperatures. Hence, poor mass transfer conditions would seem to be somewhat self-correcting.

As an example, let us assume that the temperature near the corium is $1100^{\circ} \mathrm{C}(1373 \mathrm{~K})$. At this temperature, the dilute glass melt will have a viscosity of $20 \mathrm{cp}$ or perhaps even less. The bulk velocity may reasonably be expected to increase so that $2 \mathrm{~m} / \mathrm{s}$ may be achieved. In this case, the mass transfer rate is increased to $884 \mathrm{~kg} / \mathrm{h}$. Further, let us assume a $10 \mathrm{~m}$ by $10 \mathrm{~m}$ reservoir. At this rate, the core would dissolve in $7 \mathrm{~d}$. That is, for $T=1373 \mathrm{~K}, \mu_{B}=20 \mathrm{cP}, v=2 \mathrm{~m} / \mathrm{s}$, and $L=1000 \mathrm{~cm}, 142$ tons of core debris dissolve in about 1 week at nearly 1 ton/h. 
ORNL DWG\#96-5005

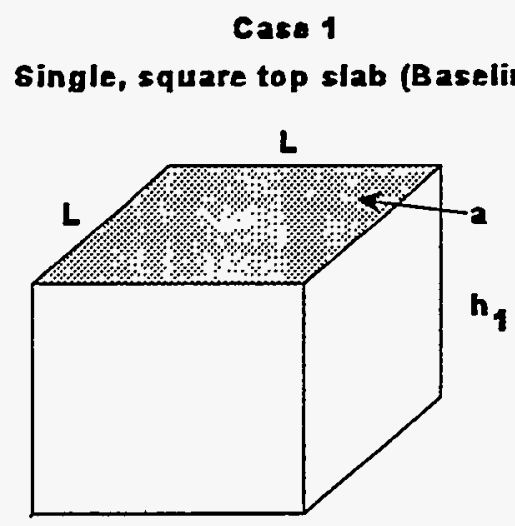

Case 3

n staggerod rowe of eyllndrteal rode
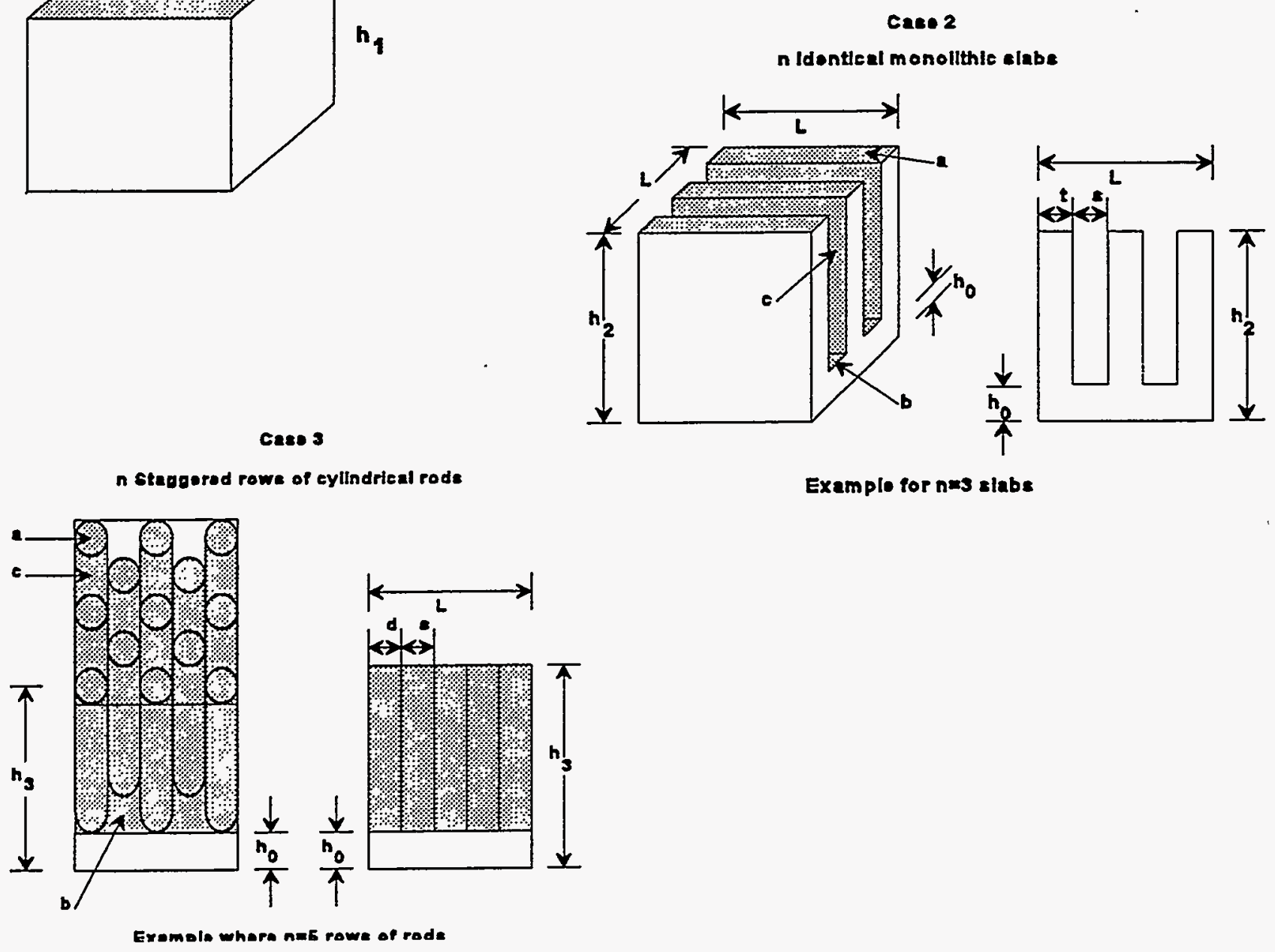

Fig. F.8. Alternative glass reservoir geometries: a single slab (Case 1), a series of monolothic slabs (Case 2), and an array of vertical rods (Case 3). 


\section{F.4.2 EFFECT OF RESERVOIR GEOMETRY ON DISSOLUTION RATE}

A flat planar or disk-shaped pool is the simplest configuration for the glass reservoir. It is also the ultimate state for the pool of glass in a core-melt scenario. However, other initial configurations may also be used to present a greater amount of surface area for mass transfer and proportionally increase the dissolution rate of core debris. This is a problem that has been faced before in the steel industry. We now examine some alternative geometries for the glass "pool" and the resultant impact on the core debris dissolution times. For the purpose of comparison, the base case (Case 1) will be a $L \times L \times h_{1}$ glass block of square cross-section, where $h_{1}$ is the initial height of the glass reservoir. In Case 2, a series of monolithic slabs is considered. Finally, an array of glass rods is considered as Case 3. Some alternative geometries for COMSORS are shown in Fig. F.8.

\section{F.4.2.1 Case 1-Rectangular Block}

Case 1 is the baseline case, consisting of a rectangular block, as shown in Fig. F.8. This shape is actually a single monolithic slab of square cross-section. The following quantities are useful for comparison in later cases:

$$
\begin{gathered}
A_{1}=L^{2}, \\
V_{1}=L^{2} h_{1}, \text { and } \\
\frac{A_{1}}{V_{1}}=\frac{1}{h_{1}},
\end{gathered}
$$

where $A_{1}$ is the contact area, $V_{1}$ is the volume, and $A_{1} / V_{1}$ is the contact area density.

\section{F.4.2.2 Case 2-Monolithic Slabs}

Case 2 consists of a series of $n$ monolithic glass slabs of rectangular cross-section emerging from a horizontal slab, as shown in Fig. F. 8 for $n=3$. The configuration considered is one of uniform slabs that are uniformly spaced, with slab thickness $t$ equal to the spacing $s$. The value of $t$ and $s$ are given by:

$$
t=s=\frac{L}{2 n-1}
$$


The reservoir is assumed to occupy the same floor space $(L \times L)$ and contain the same mass of glass $\left(\rho_{B} \times L\right.$ $\left.\times L \times h_{1}\right)$. Because of the added void space, the height of the Case 2 "pool" will be greater than that of the baseline case. The thickness of the base supporting the vertical slabs should be at least $t$, if the slab size approaches some minimal structural requirement. The pool height for Case 2 is then:

$$
h_{2}=\left(2-\frac{1}{n}\right) h_{1}-\frac{(n-1) L}{n(2 n-1)},
$$

or, for large $n$,

$$
h_{2}=2 h_{1}
$$

The area for contact with the core debris is the result of three contributions, designated $\mathbf{a}, \mathbf{b}$, and $\mathbf{c}$ in Fig. F.8. Areas $\mathbf{a}$ and $\mathbf{b}$ taken together are equivalent to the Case 1 contact area $L^{2}$, while $\mathbf{c}$ is an additional increment which constitutes a major increase in contact area for Case 2 over Case 1. The area for Case 2 and its ratio to that of Case 1 are given by Eqs. (F.17a) and (F.18b), respectively.

$$
\begin{aligned}
& A_{2}=L_{2}+2(n-1)\left[\left(2-\frac{1}{n}\right) h_{1}-\frac{(n-1) L}{n(2 n-1)}\right], \\
& \frac{A_{2}}{A_{1}}=1+(2 n-1)\left[\left(2-\frac{1}{n}\right) \frac{h_{1}}{2}-\frac{(n-1)}{n(2 n-1)},\right.
\end{aligned}
$$

For large $n$, Eqs. F.17a and F.17b become:

$$
\begin{aligned}
& A_{2}=L^{2}+L h_{2}(2 n-1) . \\
& \frac{A_{2}}{A_{1}}=1+2(2 n-1) \frac{h_{1}}{L},
\end{aligned}
$$


where $A_{2} / A_{1}$ is the contact area ratio against the base case.

\section{F.4.2.3 Case 3-Vertical Cylindrical Rods}

Case 3 consists of a series of $n$ rows of solid, vertical glass cylinders emerging from a horizontal rectangular slab, as shown in Fig. F.8 for $n=6$. The configuration considered is one of staggered rows of columns that are uniformly spaced along one axis, with column diameters $d$ equal to the spacing $s$ between columns along that axis. There is no spacing between rows of columns along the orthogonal axis. For this case, the value of $d$ and $s$ are given by:

$$
d=s=\frac{L}{n},
$$

and the number of rods is $n^{2} / 2$.

The reservoir is assumed to occupy the same floor space $(L \times L)$ and contain the same mass of glass $\left(\rho_{B} \times L\right.$ $\times L \times h_{1}$ ). Because of the added void space, the height of the Case 2 "pool" will be greater than that of the baseline case. The thickness of the base supporting the rods should be at least $d$, if the rod size approaches some minimal structural requirement. The pool height for Case 3 is then:

$$
h_{3}=\left(\frac{8}{n}\right)=\left(h_{1}-\frac{L}{n}\right)+\frac{L}{n},
$$

or, for large $n$,

$$
h_{3}=\frac{8}{\mu} h_{1} \text {. }
$$

The area for contact with core debris is made up of three contributions, designated $\mathbf{a}, \mathbf{b}$, and $\mathbf{c}$ in Fig. F.8. As in the case of monolithic slabs, the areas $\mathbf{a}$ and $\mathbf{b}$ taken together are equivalent to the Case 1 contact area $L^{2}$. Similarly, the contribution represented by $\mathrm{c}$ is an additional increment which constitutes a major increase in contact area for Case 3 over Case 1. The area for Case 3 and its ratio to that of Case 1 are given by Eqs. (F.21a) and (F.21b): 


$$
\begin{aligned}
& A_{3}=L^{2}+4 n L\left(h_{1}-\frac{L}{n}\right) ; \\
& \frac{A_{3}}{A_{1}}=1+4 n\left(\frac{h_{1}}{L}-\frac{1}{n}\right)
\end{aligned}
$$

For large $n$, Eqs. (F.21a) and (F.21b) become

$$
\begin{aligned}
& A_{3}=L^{2}+4 n L h_{1} ; \\
& \frac{A_{3}}{A_{1}}=1+4 n \frac{h_{1}}{L}
\end{aligned}
$$

where $A_{3} / A_{1}$ is the contact area ratio against the base case.

\section{F.4.2.4 Comparison of Alternative Geometries}

The impact that alternative geometries can have on the contact area is shown in Figs. F.9 and F.10, in which the contact area ratio (Case 2/Case 1) is shown plotted against the number of slabs. As the number of slabs is increased, and the slab thickness decreases, more area is presented for contact. While the slab thickness cannot be decreased indefinitely, large contact area increases may be achieved within reasonable structural limitations. For example, the Case 2 contact area reaches 400 times that for Case 1 at $n=100$ slabs, corresponding to a slab thickness of about $5 \mathrm{~cm}$ (for a $10 \mathrm{~m}$ by $10 \mathrm{~m}$ reservoir with $h_{1}=L$ ).

Results for Case 3 (see Figs. F.11 and F.12), in which the contact area increases steadily as the number of rows of rods is increased. The contact area ratio for Case 3 reaches about 800 at $n=200$ rows totalling 10,000 rods, corresponding to a rod diameter of about $5 \mathrm{~cm}$ (for a $10 \mathrm{~m}$ by $10 \mathrm{~m}$ reservoir with $h_{1}=L$ ).

Clearly, the area for mass transfer can be increased by 1-2 orders of magnitude. The impact on dissolution rates can be expected to be similar, at least for geometries that do not inhibit contact between corium and glass. The two alternative configurations considered herein each can yield about 400-800 times the contact area of the baseline. Assuming that the planar mass transfer rate model developed for Case 1 continues to apply, the dissolution rate will also increase by a factor of 400 for Case 2 and 800 for Case 3. 
Predicted dissolution times for the corium in glass reservoirs of Case 2 and Case 3 geometries are shown in Figs. F.13 and F.14. A dissolution time of about $5 \mathrm{~h}$ is predicted for a series of 100 slabs; for 200 rows of rods, the dissolution time is $2.5 \mathrm{~h}$. (Note that the total mass and volume of glass was kept constant from Case 1 to Cases 2 and 3, so that end state of the corium-glass pool would be the same.) Under the assumptions used, the initial height of the glass reservoir configuration would be different. For more than a few slabs, the Case 2 reservoir height would be twice that of Case 1 . Similarly, for more that a few rows of rods, the Case 3 reservoir height would be greater than that for Case 1 by a factor of $8 / \pi$.

Other geometric arrangements are, of course possible for the glass reservoir. For example, spacing could possibly be reduced between slabs or rods at the cost of deepening the reservoir (for a constant void volume), thus increasing the contact area ratio by an extra factor of 2 or 3 . Alternatively, more complex configurations (e.g., honey-comb, stacked brick, or even packed bed arrays) may be used to reach even higher contact area densities-as high as $650 \mathrm{~m}^{2} / \mathrm{m}^{3}$ compared to the $20-30 \mathrm{~m}^{2} / \mathrm{m}^{3}$ cases considered here.

ORNL DWG\#96-5006

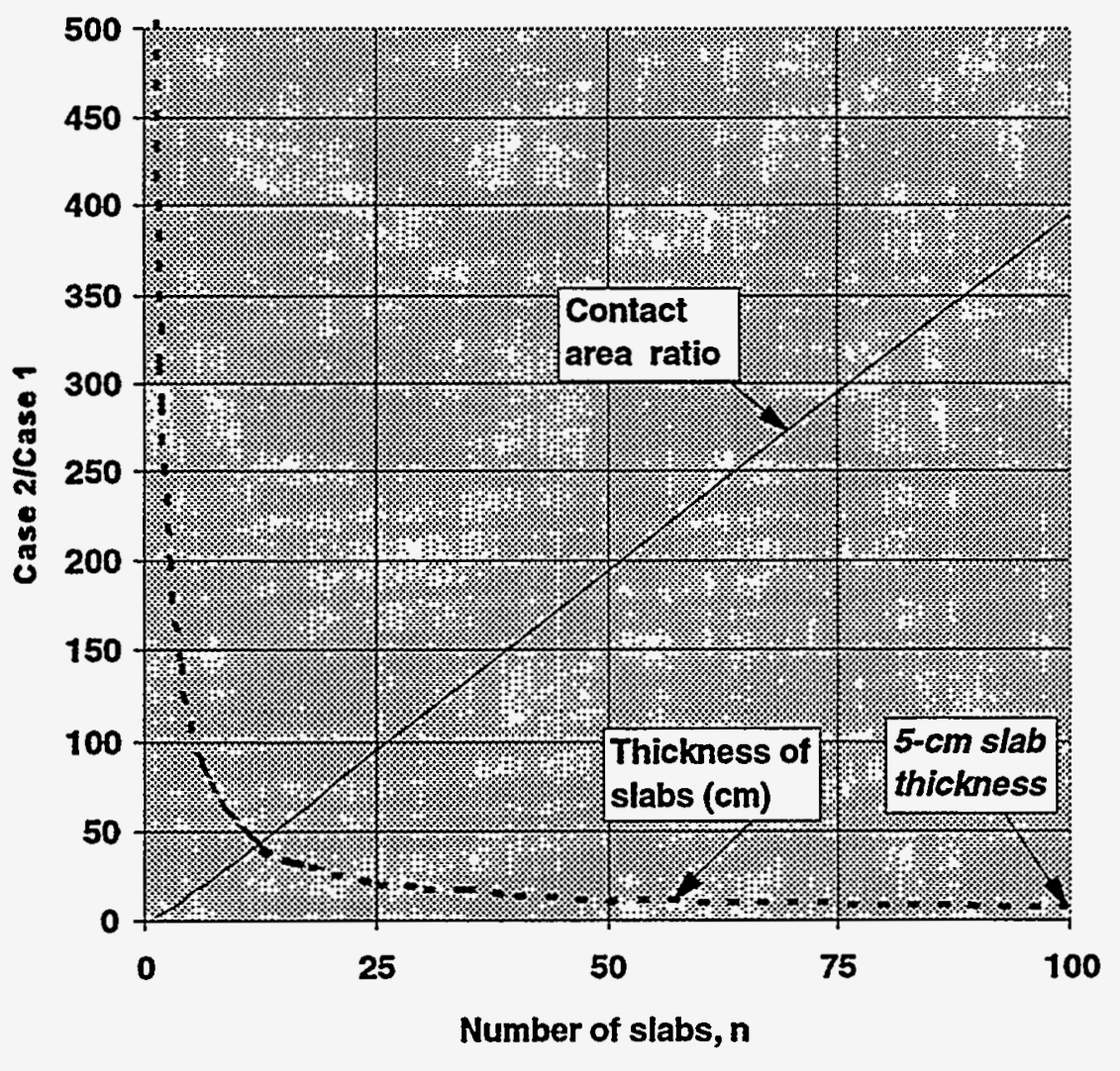

Fig. F.9. Comparison of $n$ monolothic slabs (Case 2) to the baseline (Case 1) for values of $n$ up to 100 . 
ORNL DWG\#96-5007

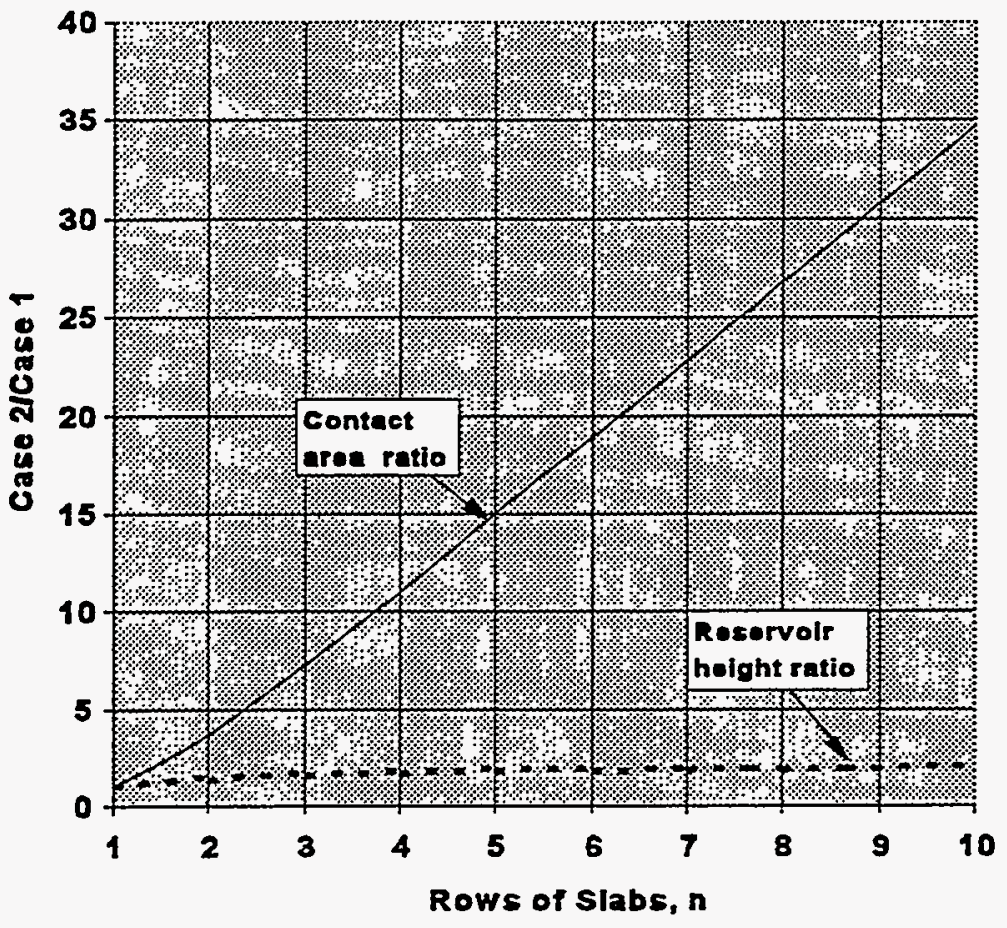

Fig. F.10. Comparison of $\boldsymbol{n}$ monolothic slabs (case 2) to the baseline (Case 1) for values of $\boldsymbol{n}$ up to 10 .

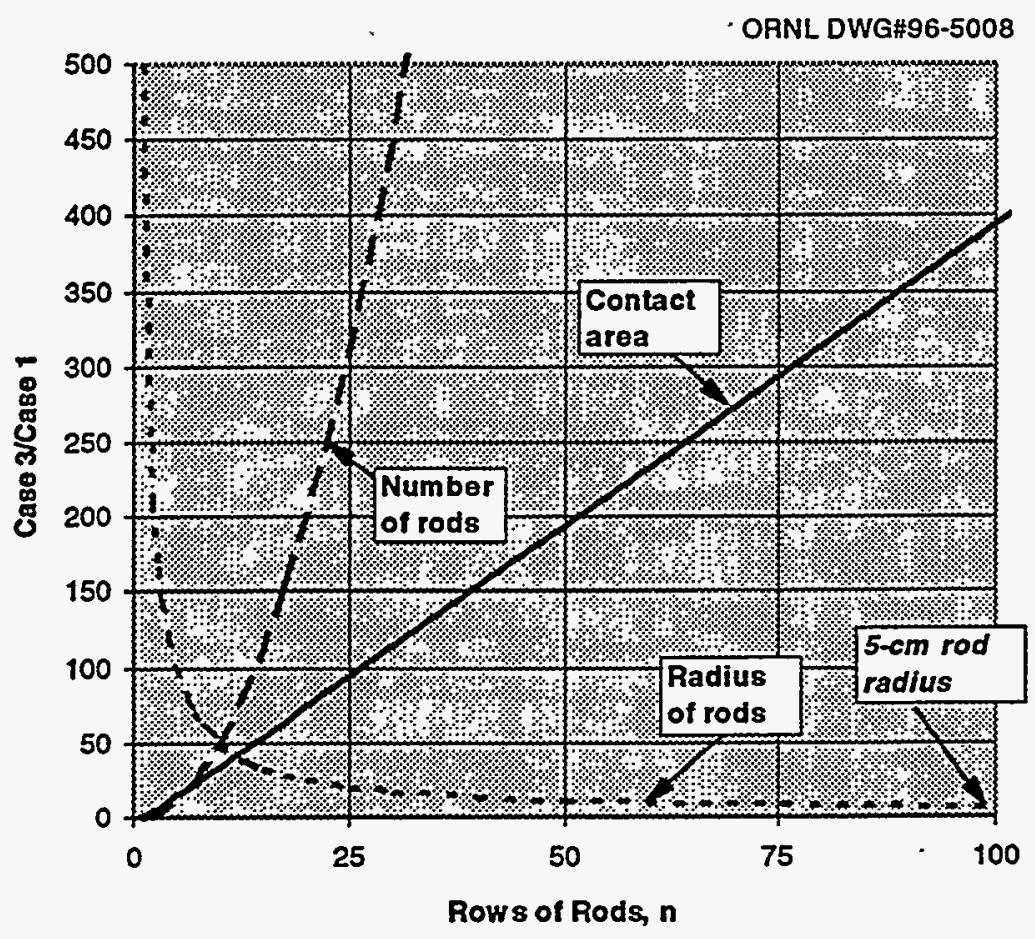

Fig. F.11. Comparison of n vertical rods (Case 3 ) to the baseline (Case 1) for values of $\boldsymbol{n}$ up to $\mathbf{1 0 0 .}$ 


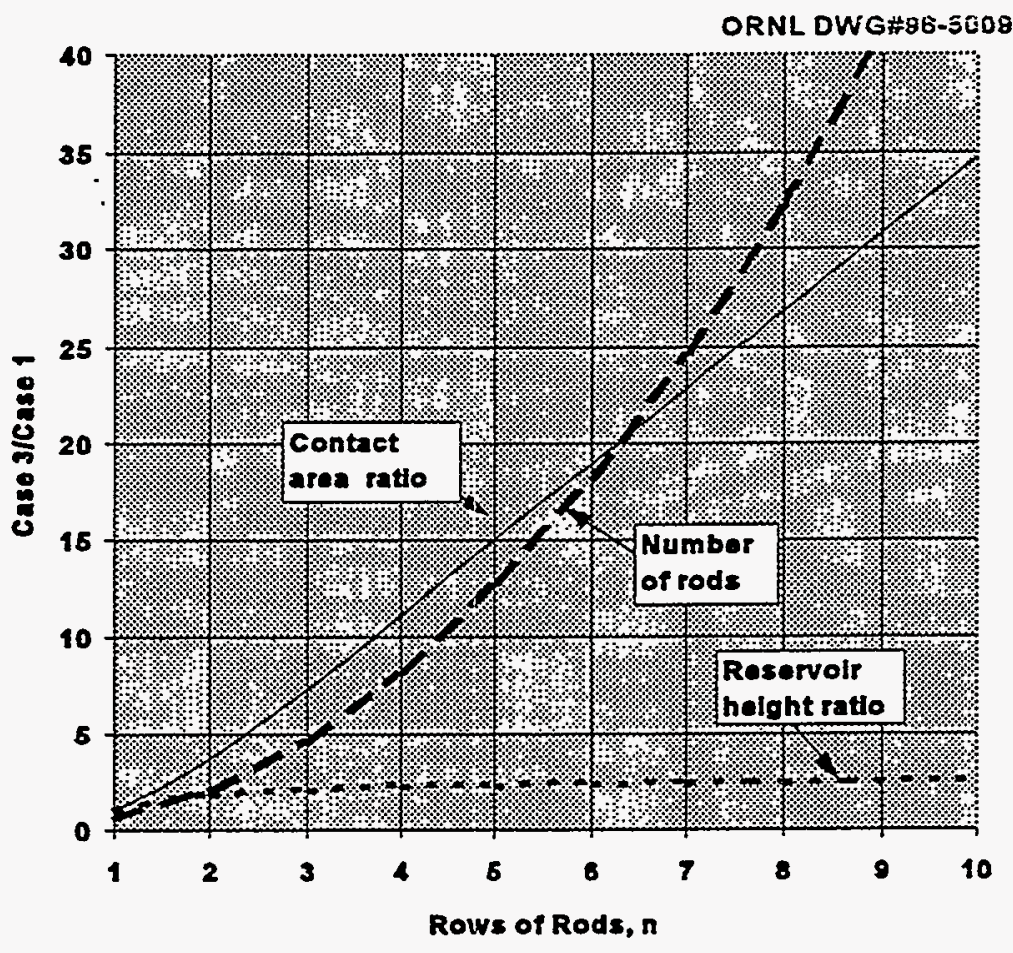

Fig. F.12. Compariton of $n$ vertical rods (Case 3 ) to the baseline (Case 1) for values of $\boldsymbol{n}$ up to 10 .

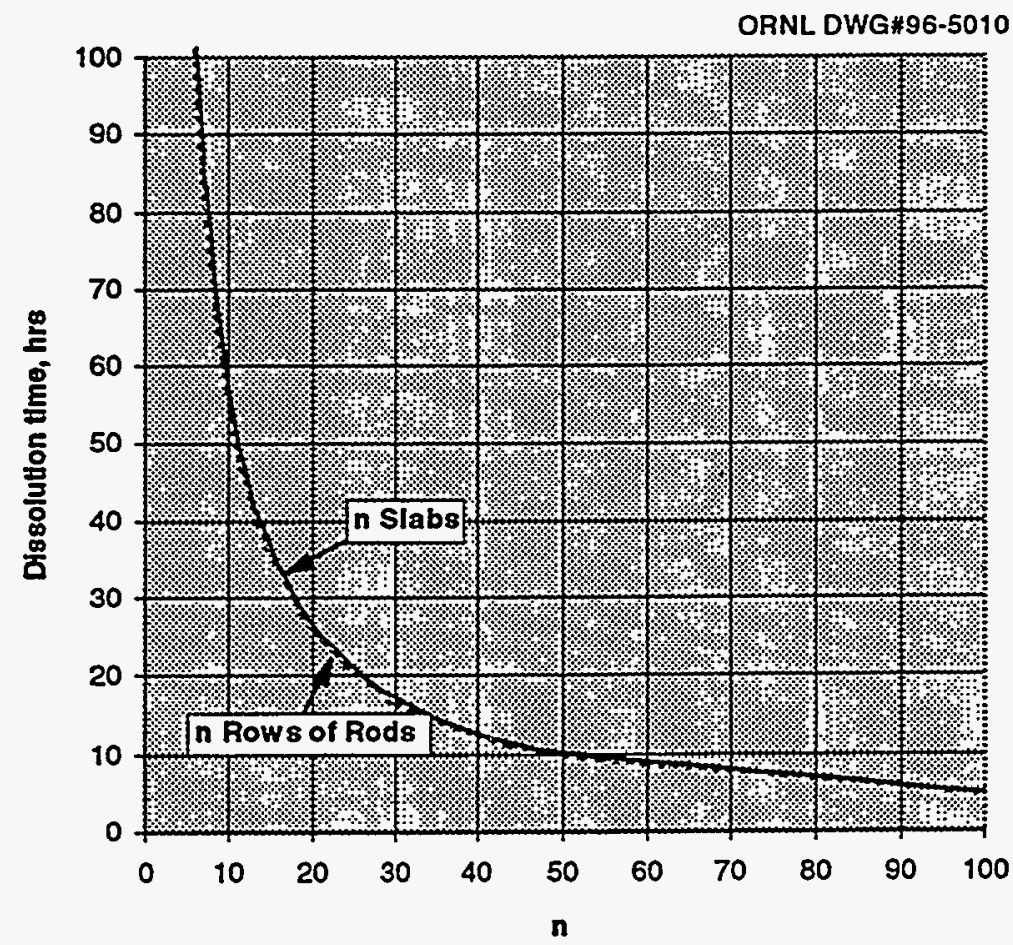

Fig. F.13. Predicted dissolution times for alternative geometries in Case 2 and Case 3 for values of $\mathbf{n}$ up to $\mathbf{1 0 0}$. 


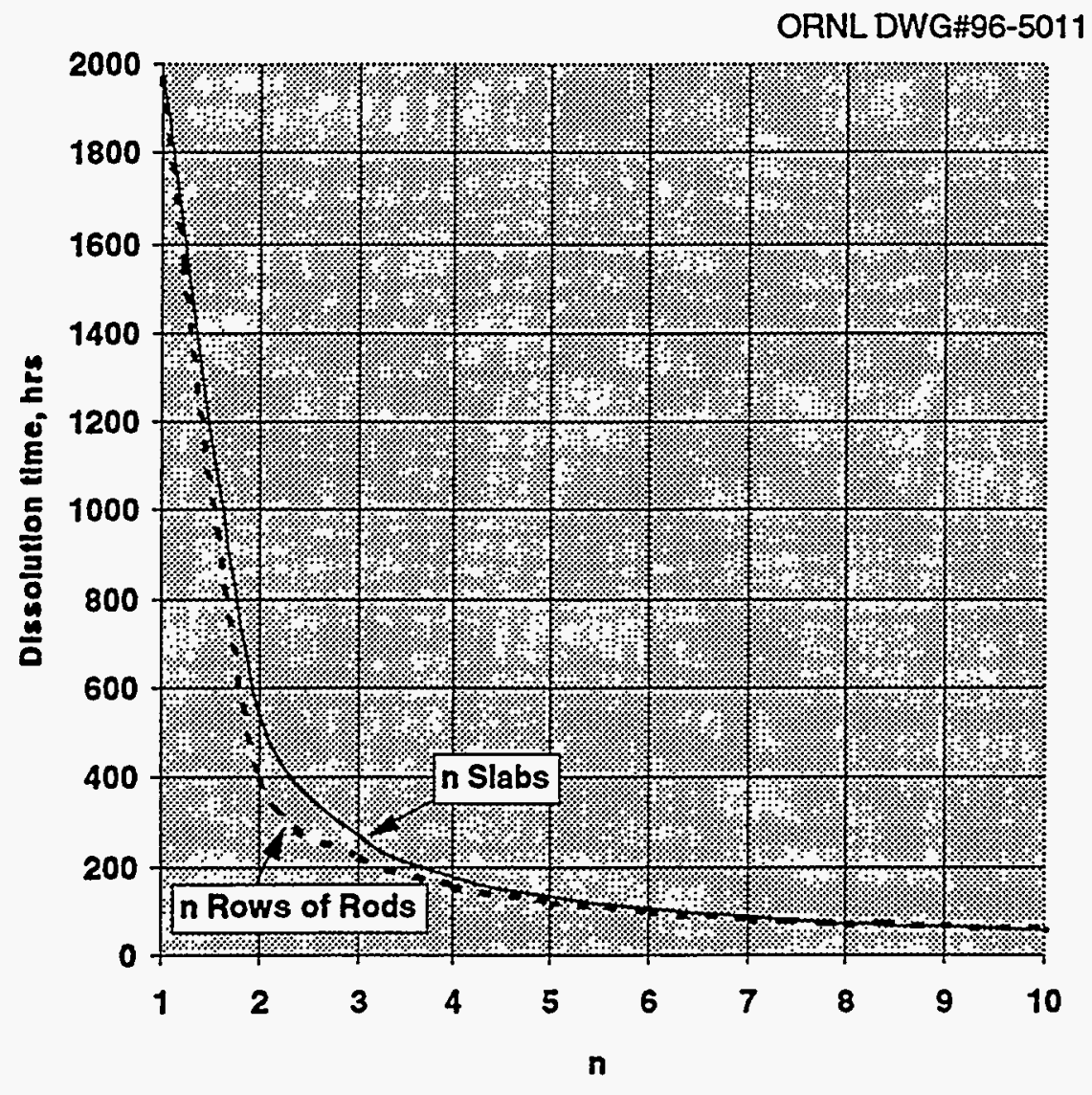

Fig. F.14. Predicted dissolution times for alternative geometries in Case 2 and Case 3 for values of $\boldsymbol{n}$ up to 10 .

\section{F.5 SUMMARY}

A basis has been presented for predicting mass transfer rates for the dissolution of nuclear reactor core debris in a pool of molten glass, assuming that mass transfer diffusion is limited. Results have been presented for uranium- and zirconium-oxide based core debris immersed in a pool of molten lead borate glass. The importance of parameters that determine the mass transfer rate has been discussed. Alternative geometric configurations for the glass reservoir were considered as were their impact on contact area and, consequently, corium dissolution rates.

The preliminary results of this study indicate that rapid dissolution of core debris by COMSORS may be achieved. A simple slab of glass was found to be adequate - times to total dissolution under natural convection conditions for a typical reactor core is on the order of a month. However, reservoir configurations that present a 
much greater amount of surface area for contact are feasible-such as a series of monolithic slabs or an array of vertical rods. Dissolution times of a few hours are expected for reservoirs with such enhanced geometries.

Additional reductions in dissolution times are possible with other configurations (not investigated herein) which have a greater contact area density. Hence, core dissolution could conceiveably be accomplished by COMSORS in less than $1 \mathrm{~h}$.

\section{F.6 REFERENCES}

Welty, J. R., C. E. Wicks, and R. E. Wilson, 1966. Chapter 24 in Fundamentals of Momentum, Heat and Mass Transfer, John Wiley \& Sons, Inc., New York.

Sherwood, T. K., R. L. Pigford, and C. R. Wilke, 1955. Chapter 2 in Mass Transfer, McGrawHill, New York.

Wilke, C. R. And P. Chang, 1995. AIChE Journal, 1 (264). 
Appendix G:

RELATED TECHNOLOGIES 
The feasibility of COMSORS is based on two types of experimental evidence: (1) information from other technologies and (2) recently completed scoping experiments at ORNL.

\section{G.1 BORAX CORE CATCHER FOR FAST GAS-COOLED REACTORS}

Developmental work was performed on a borax core catcher for 1000-MW(e) [2700-MW(th)] gascooled fast reactors in Germany (Dalle-Donne 1976, Dalle-Donne 1978, Dalle-Donne 1979, Dalle-Donne 1980) in the 1970s (Fig. G.1). The reactor was a helium-cooled system in which the helium flowed downward through a reactor core of stainless-steel-clad $\mathrm{UO}_{2}$. The reactor used a prestressed concrete reactor vessel (PCRV). The core catcher was located inside the PCRV and integrated into the reactor vessel design. Research on the concept was stopped when the gas-cooled reactor program was cancelled.

In this specific example, the bottom of the pressure vessel upward consisted of the normal PCRV vessel cooling coils in the liner of the reactor vessel, a thin layer of graphite, and seven layers of stainless steel boxes filled with borax $\left(\mathrm{Na}_{2} \mathrm{~B}_{4} \mathrm{O}_{7}\right)$. Each box was $30 \mathrm{~cm}$ on a side. In a reactor core-melt accident, the borax (1) will melt, (2) will dissolve uranium oxide and fission products to produce a "glass," (3) will absorb large quantities of heat, and (4) will uniformly distribute the heat. The borax-uranium oxide-fission product molten glass (with melting points between 742.5 and $966^{\circ} \mathrm{C}$, depending on chemical composition) spreads the heat load across the bottom of the pressure vessel. This reduced heat fluxes to manageable levels and allows cooling of the molten core materials through the vessel liner below the borax. After core melt, a molten metal layer exists under the molten borax. The differences in cladding (stainless steel rather than zirconium), location (in reactor vessel rather than below reactor vessel), and reactor coolant (helium rather than water) imply that this design cannot be used for LWRs, but it provides a good experience base. It should also be specifically noted that its location inside the pressure vessel imposes a wide variety of requirements (and design features) that are not required if COMSORS is located below and outside the reactor vessel.

Many of the same issues exist with the borax core catcher and COMSORS. Some of the work is directly applicable. Other data are indicative of potential performance of COMSORS and the phenomena that must be considered in modelling COMSORS:

- Large-scale experimental pours (Powers, 1979) of stainless steel have been made onto borax.

- Measurements of dissolution rates of uranium oxide in borax over a wide range of temperatures have been made. These show a very rapid increase in the dissolution rates of core materials in borax as the temperature rises. This has not yet been explored with the lead borate glass system (Dalle-Donne, 1978).

- Heat transfer experiments of hot fluids onto colder glass have been conducted (Eck and Werle, 1984). 


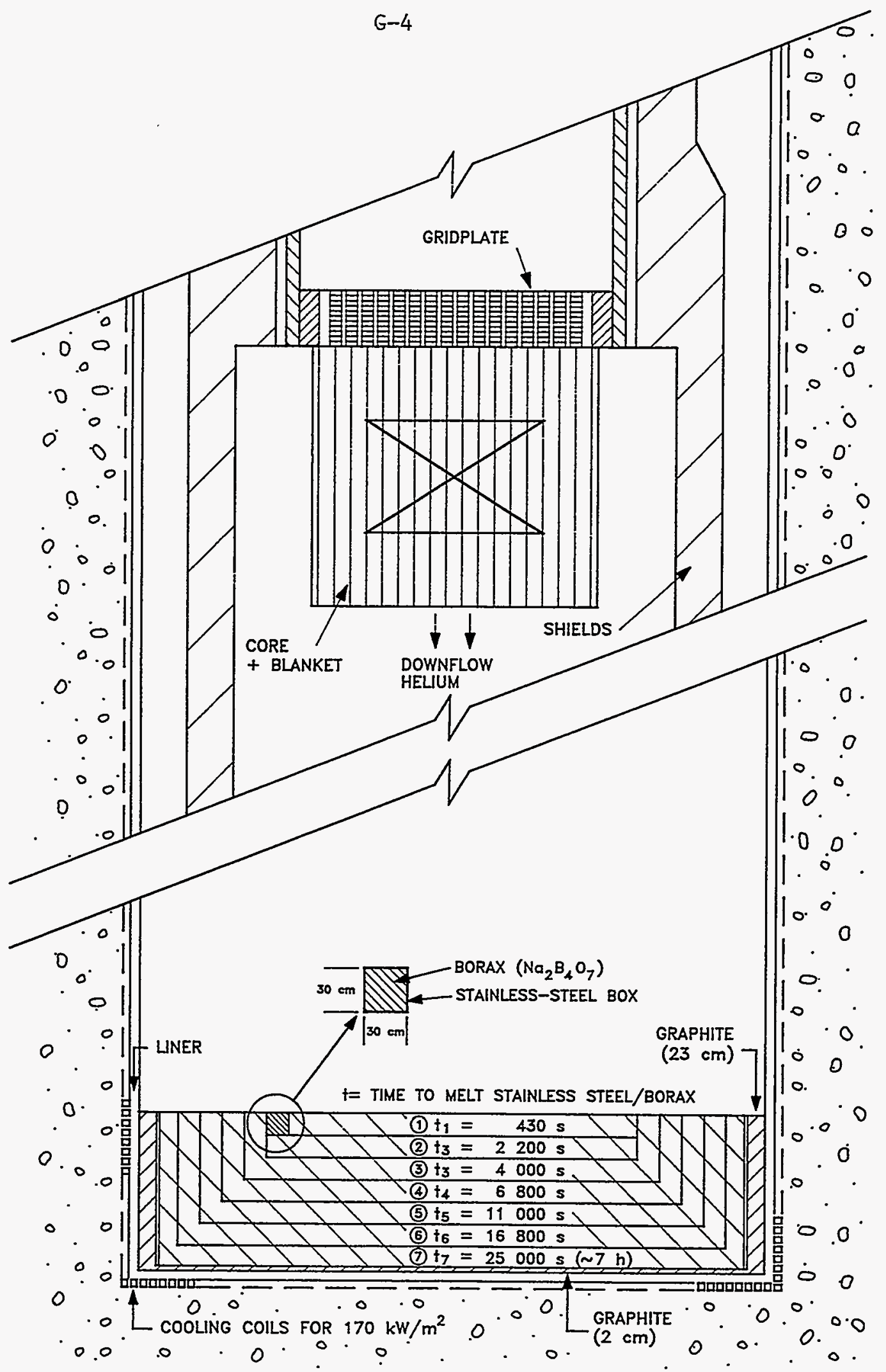

PRESTRESSED CONCRETE REACTOR VESSEL

Fig. G.1. Borax internal core catcher for gas-cooled fast reactor. 


\section{G-5}

\section{G.2 HLW VITRIFICATION PLANT DESIGN}

In the last 20 years, over a billion dollars has been spent to develop glass melters to solidify radioactive HLW. Several melters are in operation in Europe. Glass melters for HLW solidification are being built at the Savannah River Site (SRS) in South Carolina (Mahoney, 1986) and at the West Valley Site in New York. The typical melter is a ceramic-lined steel vessel 1 to $2 \mathrm{~m}$ in diameter containing a significant volume of molten glass (Fig. G.2). Electric resistance heating through the glass maintains temperatures at $\sim 1100^{\circ} \mathrm{C}$. An aqueous stream of HLW plus glass frit is continuously fed into the melter on top of the molten glass. From the top to the bottom of the melter, there are three layers: (1) a layer of boiling water, (2) a layer wherein the nitrates in the HLW are calcined to oxide, and (3) the glass that continuously dissolves the oxides and glass frit. Glass is semicontinuously withdrawn from the melter and poured into disposal canisters.

Glass melter technology directly provides several types of information:

- Heat flux to water. The HLW glass melter at SRS at nominal operating conditions has an upward heat flux of $\sim 100 \mathrm{~kW} / \mathrm{m}^{2}$ to the oxide mixture above the glass melt. Glass melters, under some operating conditions, have molten glass in the melter with water directly above. Experimental programs have demonstrated stable transfer heat transfer rates from glass to water at $600 \mathrm{~kW} / \mathrm{m}^{2}$. For comparison, the nominal reference COMSORS design used in this report has a maximum upward heat transfer rate of $130 \mathrm{~kW} / \mathrm{m}^{2}$. Glass melter experience provides both demonstration and engineering data on heat transfer from molten glass to water.

- Energetic molten glass-water reactions. Safety issues associated with molten glass and water have been investigated in detail (Hutcherson et al., 1983; Schumacher et al., 1991). There have been many safety analyses of commercial and HLW glass melters. These data indicate that steam explosions and other energetic reactions are not safety issues.

\section{G.3 CHERNOBYL}

During the Chernobyl nuclear power accident, large quantities of sand, borax, and lead were dropped from the air onto the top of the burning reactor. These materials put out the fire, stopped nuclear reactions, and encapsulated the fuel. The materials used are the same as those proposed for COMSORS. Recent investigations at Chernobyl indicate that much of the material was converted to a glassy waste form and flowed from the reactor cavity to lower levels in the plant, where it solidified. It is noteworthy that these materials so efficiently dissolved fuel in the reactor cavity that short-term manned entry into the reactor cavity has occurred with the observation that no significant fuel remains in the cavity. This discovery was a major surprise to local investigators. It may also be considered an experiment that demonstrates that COMSORS glasses can efficiently dissolve the materials of a reactor core-melt accident under one set of circumstances. 


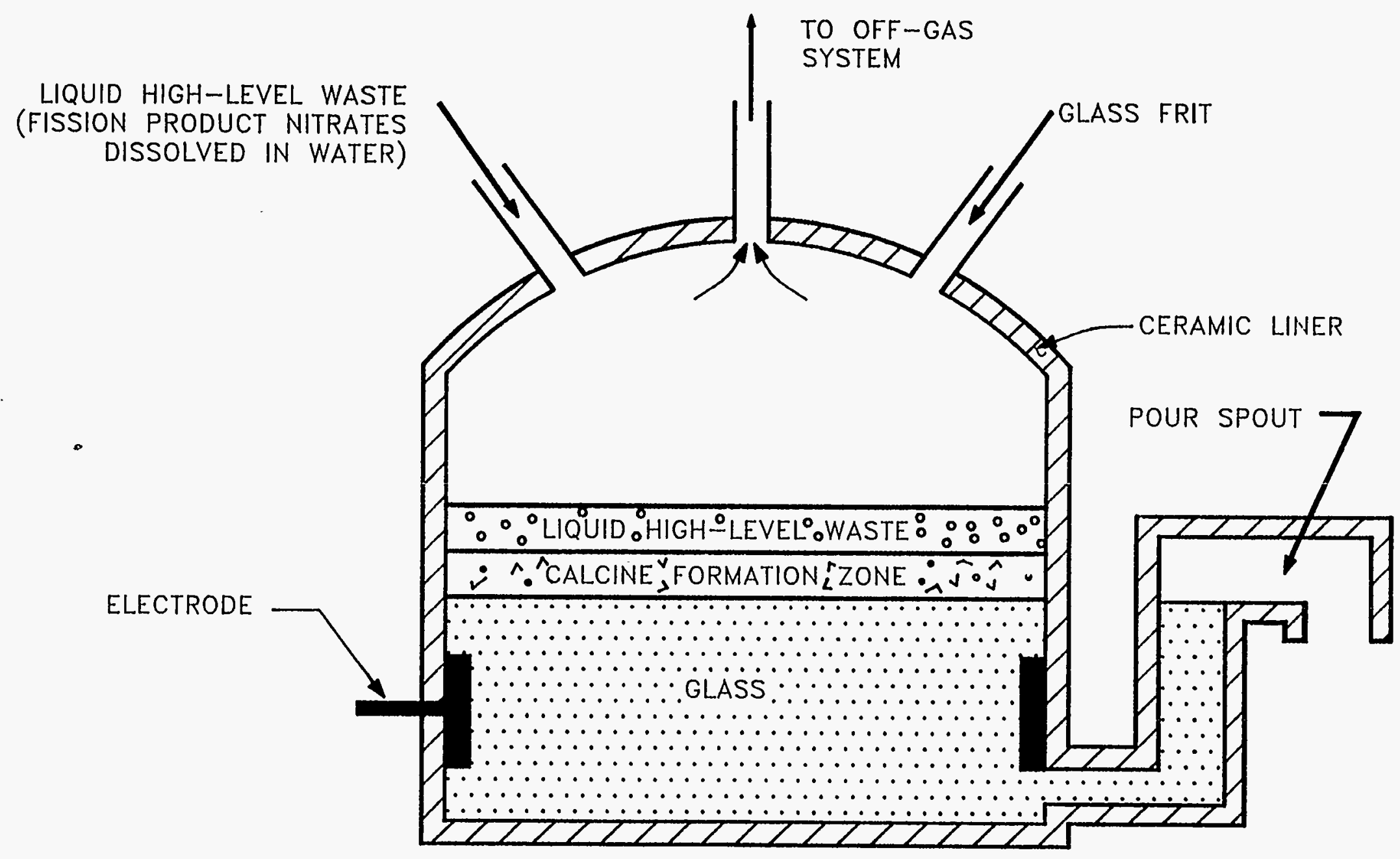

Fig. G.2. Schematic of joule-heated, liquid-fed HLW vitrification plant. 


\section{G-7}

\section{G.4 GMODS}

\section{G.4.1 Introduction}

GMODS is a new waste vitrification process, which directly converts metals, ceramics, and amorphous solids to glass; oxidizes organics with the residue converted to borosilicate glass; and converts halogens to borosilicate glass and a secondary sodium halogen stream. The process uses the same basic chemistry as COMSORS.

Glass is recognized worldwide as a preferred waste form for radioactive and chemically hazardous wastes. There is, however, a major limitation: All existing glass processes require that the waste be in the form of oxides or oxide-like materials before vitrification. Oxide-like materials are compounds such as nitrates and carbonates that decompose to oxides at high temperatures. Conversion of wastes to oxide-like forms before vitrification is a complex and an expensive task.

GMODS allows the direct conversion of oxides, metals, ceramics, organics, halogens, and amorphous solids to glass. This, in turn, allows complex waste mixtures (filters, process wastes, laboratory wastes, etc.) to be directly converted to glass without preprocessing. The alternatives are to separate the wastes into specific categories and process each category of waste and/or process (oxidize, dechlorinate, etc.) each waste before vitrification.

\section{G.4.2 GMODS Process Description}

GMODS converts wastes into glass within a melter. The process can operate as a batch (Fig. G.3) or continuous process. For batch operation, the starting conditions are a glass melter filled with molten, leadborate dissolution glass. Oxides dissolve in glass, but metals and organics do not. GMODS uses lead oxide $(\mathrm{PbO})$ in the molten glass to oxidize (a) metals to metal oxides and (b) organics to carbon oxides. The resultant metal oxides dissolve into the glass. The carbon oxides exit the melter as gases. The lead metal reaction product separates from the glass and forms a separate layer at the bottom of the melter. The boron oxide $\left(\mathrm{B}_{2} \mathrm{O}_{3}\right)$ in the melt ensures the rapid dissolution into the glass of any protective oxide layers on metal wastes.

After dissolution of the wastes, silicon oxide and other additives are added to the glass to produce a highquality product glass. Excess $\mathrm{PbO}$ is removed from the glass by adding carbon, which converts the $\mathrm{PbO}$ to lead metal and carbon dioxide $\left(\mathrm{CO}_{2}\right)$. The final glass may have some or no $\mathrm{PbO}$ depending upon the desired product glass. The product glass is poured from the melter into the waste packages. To generate the next batch of dissolution glass, $\mathrm{B}_{2} \mathrm{O}_{3}$ is added to the melter and the lead metal is oxidized to $\mathrm{PbO}$ with oxygen. 


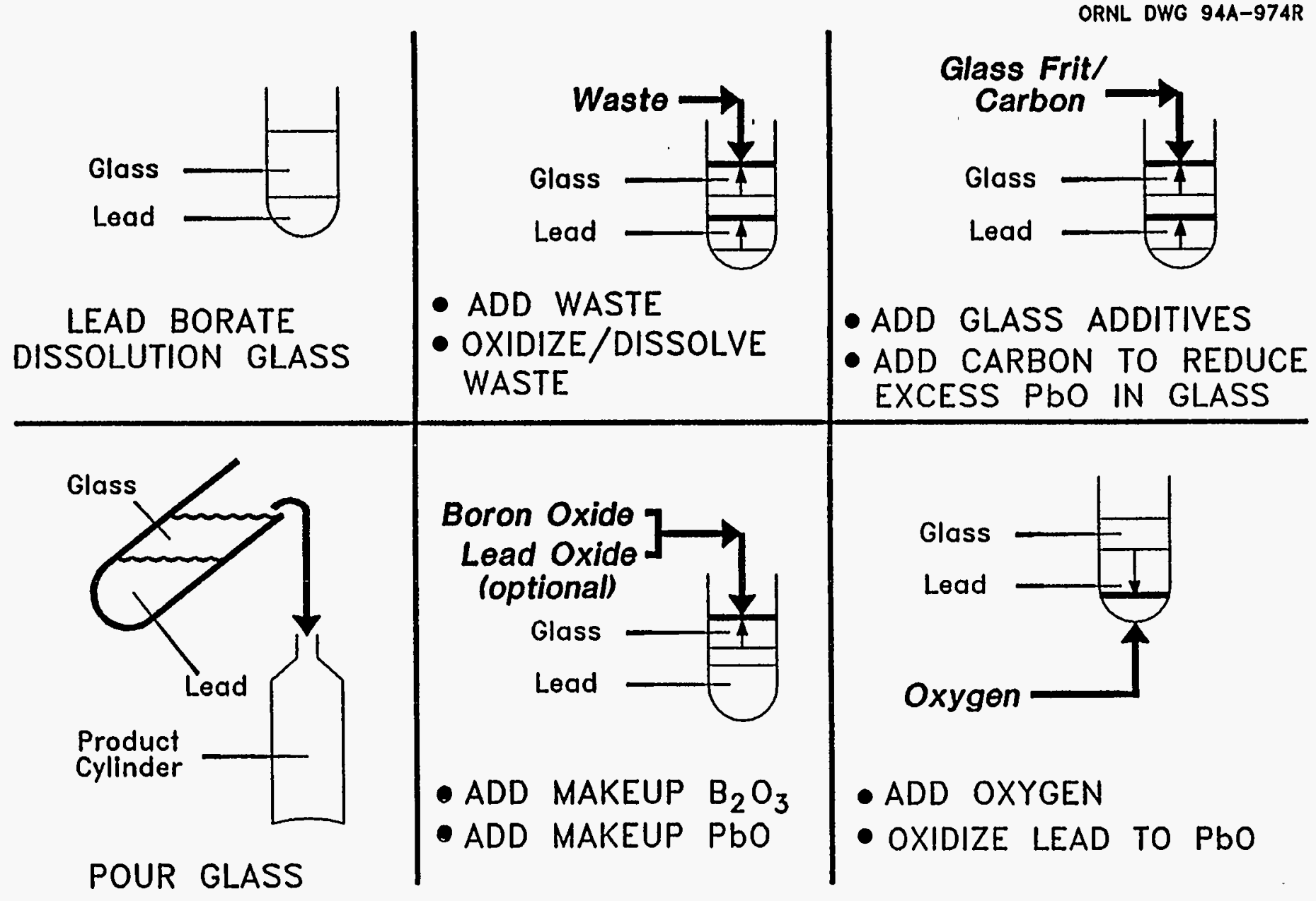

Fig. G.3. GMODS batch processing of wastes to borosilicate glass. 


\section{G-9}

GMODS can convert halogen-containing materials to glass, a process which creates a separate nonradioactive sodium halogen waste stream. Halogens, such as chlorides, make poor-quality glasses; hence, they must be separated from other components. In the dissolution glass, chlorides in the waste form lead chloride $\left(\mathrm{PbCl}_{2}\right)$, which is volatile at glass melter temperatures and exits to the aqueous sodium hydroxide $(\mathrm{NaOH})$ scrubber. In the scrubber, the $\mathrm{PbCl}_{2}$ reacts with the $\mathrm{NaOH}$ to yield insoluble lead hydroxide $\left[\mathrm{Pb}(\mathrm{OH})_{2}\right]$ and soluble $\mathrm{NaCl}$. The insoluble $\mathrm{Pb}(\mathrm{OH})_{2}$ is recycled back to the melter, in which it decomposes to $\mathrm{PbO}$ and steam, while the aqueous $\mathrm{NaCl}$ stream is cleaned and discharged as a chemical waste.

Because of the corrosive characteristics of the initial dissolution glass, GMODS requires a cold-wall melter in which cooling jackets in the walls produce a "skull" of solidified material that protects the walls from the melter's contents. The melters can be heated by fossil, induction, plasma arc, or electron-beam systems. Such systems are currently used to melt high-temperature materials (e.g., titanium and superalloys) and produce speciality glasses.

\section{G.4.3 Status of Laboratory Work}

Tests demonstrated the dissolution of $\mathrm{UO}_{2}, \mathrm{ZrO}_{2}, \mathrm{Al}_{2} \mathrm{O}_{3}, \mathrm{Ce}_{2} \mathrm{O}_{3}, \mathrm{MgO}$, and other oxides. Oxidationdissolution tests demonstrated the oxidation of the following metals and alloys (followed by the dissolution of their oxides into the melt): U, Ce, Zircaloy-2, Al, stainless steel, and other metals. Oxidation-dissolution tests also demonstrated the oxidation of carbon and graphite, with production of $\mathrm{CO}_{2}$. The other process steps (adding glass frit, removing lead from the glass, and oxidizing lead back to $\mathrm{PbO}$ ) have been investigated in the laboratory. These steps are also used in the glass, lead smelting, and lead-battery industries on very large scales and are well understood.

\section{G.5. REFERENCES}

Dalle-Donne, M., S. Dorner, and G. Schumacher, September 1976. Preliminary Design of a Borax Internal Core-Catcher for a Gas Cooled Fast Reactor, KFK 2352, EUR 5505e, Kernforschungszentrum Karlsruhe, Germany.

Dalle-Donne, M., S. Dorner, and G. Schumacher, July 1978. "Development Work For a Borax Internal CoreCatcher For A Gas-Cooled Fast Reactor," Nuclear Technology 39,138.

Dalle-Donne, M., S. Dorner, G. Fieg, G. Schumacher, and H. Werle, March 13-15, 1979. "Further Work For the GCFR Borax Core-Catcher," in Proc. Specialist Meeting on Gas-Cooled Fast Reactor Safety and Associated Design Features, OECD-NEA Coordinating Group on Gas-Cooled Fast Reactor Development, Brussels, Belgium, Organization for Economic Co-operation and Development, Paris, France. 
Dalle-Donne, M. and H. Werle, August 1980. Laboratory Studies of the Meltfront Propegation in a Borax Core-Catcher, Kernforschungszentrum Karlsruhe, Karlsruhe, Germany

Eck, Gismar, and H. Werle, March 1984. "Experimental Studies of Penetration of a Hot Liquid Pool Into a Melting Miscible Substrate," Nuclear Technology 64,275

Forsberg, C. W., et al., October 1995. Direct Vitrification of Plutonium-Containing Materials With The Glass Material Oxidation and Dissolution System (GMODS), ORNL-6825, Lockheed Martin Energy Systems, Inc., Oak Ridge National Laboratory, Oak Ridge, Tennessee.

Hutcherson, M. N., H. K. Fauske, R. E. Henry, and T. J. Marciniak, February, 1983. Assessment of the Potential and Consequences of a Hypothetical Steam Explosion In the Defense Waste Processing Facility Glass Melter, Fauske \& Associates, Inc., Burr Ridge, Illinois.

Mahoney, J. L., 1986. "Pilot Plant Demonstration of the Defense Waste Processing Facility (DWPF) Melter Concepts," Spectrum, pp 746.

Powers, D. A., August 19-23, 1979. "A Survey of Melt Interactions With Core Retention Materials," in Proc. International Meeting on Fast Reactor Safety, Seattle, Washington, American Nuclear Society, La Grange Park, Illinois

Schumacher, R. F., M. E. Smith, and J. F. Sproull, June 19, 1991. Review of Background Applicable to the Potential for a Steam Explosion in the DWPF Melter, WSRC-RD-91-15, Westinghouse Savannah River Company, Aiken, South Carolina. 


\section{INTERNAL DISTRIBUTION}

1. E. C. Beahm

2. J. M. Begovich

3. A. G. Croff

4. K. R. Elam

5-9. C. W. Forsberg

10. S. R. Greene

11. M. J. Haire

12. S. A. Hodge

13. H. T. Kerr

14. S. B. Ludwig

15. A. P. Malinauskas

16. L. E. McNeese

17. G. E. Michaels

18. D. L. Moses

19-23. I. W. Osborne-Lee
24. L. J. Ott

25-29. G. W: Parker

30. R. T. Primm

31-35. J. C. Rudolph

36. K. D. Snyder

37. R. P. Taleyarkha

38. C. F. Weber

39. J.D. White

40-41. Central Research Library

42-43. Laboratory Records

44. Laboratory Records-RC

45. ORNL Y-12 Technical Library

46. Document Reference Section

47. ORNL Patent Section

\section{EXTERNAL DISTRIBUTION}

48. Said I. Abdel-Khalik, Georgia Institute of Technology, George W. Woodruff School of Mechanical Engineering, Nuclear Engineering and Health Physics Programs, Atlanta, Georgia 30332-0405.

49. S. Additon, Tennera/Kaiser-Hill, c/o U.S. Department of Energy, Rocky Flats Environmental Technology Site, Bldg. 130, Rm. 154, P.O. Box 464, Golden, Colorado 80402-0464.

50. Dr. Charles E. Ader, Office of Nuclear Regulatory Research, Division of Systems Technology, Two White Flint North, 11545 Rockville Pike, Rockville, Maryland 20852-2738.

51. Dr. Carl Alexander, Battelle Columbus Laboratory, 505 King Ave., Columbus, Ohio 43201.

52. P. J. T. Bakker, KEMA Nuclear, P.O. Box 9035, 6800 ET Amhem, The Netherlands.

53. Anthony J. Baratta, The Pennsylvania State University, Nuclear Engineering Department, 231 Sackett Bldg., University Park, Pennsylvania 16802.

54. Dr. Sudhamay Basu, Office of Nuclear Regulatory Research, Division of Systems Technology, Two White Flint North, 11545 Rockville Pike, Rockville, Maryland 20852-2738. 
55. Donald S. Bloswick, University of Utah, Nuclear Engineering Program, Salt Lake City, Utah 84112-1107.

56. Albert E. Bolon, University of Missouri-Rolla, Department of Nuclear Engineering, 101 Fulton Hall, Rolla, Missouri 65401-0249.

57-61. Carol Buchholz, General Electric Nuclear Energy Company, 175 Curtner Ave., San Jose, Califormia 95125.

62. Dan G. Cacuci, University of Virginia, Department of Mechanical, Aerospace, and Nuclear Engineering, Charlottesville, Virginia 22903.

63. Ivan Catton, University of California-Los Angeles, Mechanical, Aerospace, and Nuclear Engineering Department, 46-147N Eng IV, 405 Hilgard Ave., Los Angeles, California 90024-1597.

64. Soon Heung Chang, Korea Advanced Institute of Science and Technology, Department of Nuclear Engineering, 373-1 Kusong-dong, Yusong-gu, Taejon 305-701, South Korea.

65. Richard N. Christensen, The Ohio State University, Nuclear Engineering Program, 206 W. 18th Ave., Columbus, Ohio 43201.

66. M. L. Corradini, University of Wisconsin, Department of Nuclear Engineering and Engineering Physics, 151 Engineering Research Building, Madison, Wisconsin 53706.

67. M. Dalle-Donne, Kernforschungzentrum Karlsruhe, D-7500 Karlsruhe, Postfach 3640, Federal Republic of Germany.

68. Nils J. Diaz, University of Florida, Department of Nuclear Engineering Sciences, 202 Nuclear Sciences Center, P.O. Box 118300 , Gainesville, Florida 32611-8300.

69. H. Lee Dodds, University of Tennessee-Knoxville, Nuclear Engineering Department, 315 Pasqua Engineering Bldg., Knoxville, Tennessee 37996-2300.

70. Michael J. Driscoll, Massachusetts Institute of Technology, Department of Nuclear Engineering, Bldg. 24-102, 77 Massachusetts Ave., Cambridge, Massachusetts 02139-4307.

71. Robert M. Edwards, The Pennsylvania State University, Nuclear Engineering Department, 231 Sackett Bldg., University Park, Pennsylvania 16802.

72. Dr. J. Eibl, Universitat Karlsruhe, Kaiserstrasse 12, D-7500 Karlsruhe, Federal Republic of Germany.

73. Mohamed S. El-Genk, University of New Mexico, Department of Chemical and Nuclear Engineering, Farris Engineering Center, Room 209, Albuquerque, New Mexico 87131-1341. 
74. M. Epstein, Fausky and Associates, Inc., 16W070 West 83rd St., Burr Ridge, Illinois 60521.

75. S. Franks, U.S. Department of Energy, Office of Nuclear Energy, Washington, D.C. 20585.

76. Dr. Randall O. Gauntt, Sandia National Laboratory, Department 6421, Mail Stop 1139, P.O. Box 5800, Albuquerque, New Mexico 87185-1139.

77. Michael W. Golay, Massachusetts Institute of Technology, Department of Nuclear Engineering, BIdg. 24-102, 77 Massachusetts Ave., Cambridge, Massachusetts 02139-4307.

78. F. Goldner, Department of Energy, Office of Technology Support Programs, NE-462, Washington, D.C. 20585.

79. G. A. Greene, Brookhaven National Laboratory, Upton, Long Island, New York 11973.

80. Dr. F. Eric Haskin, University of New Mexico, Department of Chemical and Nuclear Engineering, Farris Engineering Center, Room 209, Albuquerque, New Mexico 87131-1341.

81. Dr. T. J. Haste, AEA Technology, Safety and Performance Division, Reactor Safety Studies Department, Winfrith Dorchester Dorset DT2 8DH, United Kingdom.

82. Carolyn DeLane Heising, Iowa State University, Department of Mechanical Engineering, Nuclear Engineering Program, 107 Nuclear Engineering Laboratory, Ames, Iowa 50011-2241.

83. Dr. Robert E. Henry, Fauske and Associates, Inc., 16W070 West 83rd St., Burr Ridge, Illinois 60521.

84. H. H. Hennies, Kernforschungszentrum Karlsruhe, Postfash 3640 , D-7500 Karlsruhe, Federal Republic of Germany.

85. Dr. Peter Hofmann, Institute of Materials and Solid State Research, Kernforschungszentrum Karlsruhe, P.O. Box 3640, D-7500 Karlsruhe 1, Germany.

86. Victor V. Ignatyer, Kurchatov Institute, Russian Scientific Center, 123182 Kurchatov Square, Moscow, Russia.

87. Dr. Dong W. Jerng, Project Leader, Center for Advanced Reactors, KEPRI, 103-16, Munji-Dong, Yusung-Gu, Taejon, 305-380, KOREA.

88. Barclay G. Jones, University of Illinois, Department of Nuclear Engineering, 103 S. Goodwin Ave., Urbana, Illinois 61801. 
89. Professor William E. Kastenberg, University of California-Berkeley, Department of Nuclear Engineering, Berkeley, California 94720-1730.

90. Masahiro Kawaji, University of Toronto, Center for Nuclear Engineering, Faculty of Applied Science and Engineering, 184 College St., Toronto, Ontario, Canada, M5S 1 A4.

91. Mujid S. Kazimi, Massachusetts Institute of Technology, Department of Nuclear Engineering, Bldg. 24-102, 77 Massachusetts Ave., Cambridge, Massachusetts 02139-4307.

92. M. Kenton, Dames and Moore, Inc., Nuclear Industry Services Group, Suite 426, 770 Pasquinelli Dr., Westmont, Illinois 60559.

93. Thomas W. Kerlin, University of Tennessee-Knoxville, Nuclear Engineering Department, 315 Pasqua Engineering Bldg., Knoxville, Tennessee 37996-2300.

94. G. Kessler, Kernforschungszentrum Karlsruhe, Postfash 3640, D-7500 Karlsruhe, Federal Republic of Germany.

95. T. A. Kletz, 64 Twinging Brook Rd., Cheadle Hulme, Cheadle, Cheshire SK8 $5 \mathrm{RJ}$, England.

96. Jean Koclas, Ecole Polytechnique De Montreal, Campus de l'Université de Montreal, Nuclear Engineering Institute, Box 6079, Succ. Centre-ville, Montreal, Quebec H3C 3A7.

97. T. S. Kress, 102-B Newridge Rd., Oak Ridge, Tennessee 37830.

98. Mr. Casimir A. Kukielka, Pennsylvania Power and Light Company, A6-3, Two North Ninth Street, Allentown, Pennsylvania 18101-1179.

99. Jay F. Kunze, University of Missouri-Columbia, Nuclear Engineering Program, E2433 Engineering Building East, Columbia, Missouri 65211.

100. Richard T. Lahey, Jr., Rensselaer Polytechnic Institute, Department of Environmental and Energy Engineering, Troy, New York 12180-3590.

101. David D. Lanning, Massachusetts Institute of Technology, Department of Nuclear Engineering, Bldg. 24-102, 77 Massachusetts Ave., Cambridge, Massachusetts 02139-4307.

102. John C. Lee, University of Michigan, Department of Nuclear Engineering, 108 Cooley Lab, North Campus, Ann Arbor, Michigan 48109-2104.

103. Dr. John R. Lehner, Brookhaven National Laboratory, Safety and Risk Evaluation Division, Department of Nuclear Engineering, Bldg. 130, Upton, New York 11973. 
104. Dr. Alan E. Levin, U.S. Nuclear Regulatory Commission, Office of Nuclear Reactor Regulation, Reactor Systems Branch, OWFN 8E23, Washington, D.C. 20555.

105. S. Levy, S. Levy, Inc. 3425 S. Bascom Ave., Campbell, California 95008-7006.

106. Prof. Carlo Lombardi, Polytechnic of Milan, Department of Nuclear Engineering, via Ponzio 34/3-20133, Milano, ITALY.

107. M. Merilo, Electric Power Research Institute, 3412 Hillview, Palo Alto, California 94304-1395.

108. Don W. Miller, The Ohio State University, Nuclear Engineering Program, 206 W. 18th Ave., Columbus, Ohio 43201.

109. William H. Miller, University of Missouri-Columbia, Nuclear Engineering Program,'E2433 Engineering Building East, Columbia, Missouri 65211.

110. R. Moore, U.S. Department of Energy, NE-50, Washington, D.C. 20585.

111. Gary E. Mueller, University of Missouri-Rolla, Department of Nuclear Engineering, 101 Fulton Hall, Rolla, Missouri 65401-0249.

112. R. J. Neuhold, U.S. Department of Energy, NE-50, Washington, D.C. 20585.

113. Kiman Nho, Korea Atomic Energy Research Institute, MCCI and Rasplav Project, Severe Accident Research, P.O. Box 7, 150 Daeduk-Danji, Taejeon 305-606, South Korea.

114. W. Pasedag, U.S. Department of Energy, NE-451, Washington, D.C. 20585.

115. Kenneth L. Peddicord, Texas A\&M University, Department of Nuclear Engineering, 129 Zachry Engineering Center, College Station, Texas 77843.

116. Woodrow Wilson Pitt, Jr., Texas A\&M University, Department of Nuclear Engineering, 129 Zachry Engineering Center, College Station, Texas 77843.

117. Dr. Michael Z. Podowski, Rensselaer Polytechnic Institute, Department of Nuclear Engineering and Engineering Physics, Troy, New York 12180-3590.

118. Dr. Dana A. Powers, Sandia National Laboratory, Organization 6425 , P.O. Box 5800, 1515 Eubank, S. E., Albuquerque, New Mexico 87185-5800.

119. Norman C. Rasmussen, Massachusetts Institute of Technology, Department of Nuclear Engineering, Bldg. 24-102, 77 Massachusetts Ave., Cambridge, Massachusetts 02139-4307.

120. Gordon E. Robinson, The Pennsylvania State University, Nuclear Engineering Department, 231 Sackett Building, University Park, Pennsylvania 16802. 
121. Jacques Royen, OECD/NEA/PWG4, Nuclear Safety Division, Le Seine-Saint German, 12 Boulevard des Iles, F-92130 Issy-les-Moulineaux, France.

122. Gary M. Sandquist, University of Utah, Nuclear Engineering Program, Salt Lake City, Utah 84112-1107.

123. Dr. Raj Sehgal, Royal Institute of Technology, Nuclear Power Safety, Stockholm 10044, Sweden.

124. Siempelkamp, c/o Dr. W. Steinwarz, P.O. Box 2570, D-47725 Krefeld, Germany.

125. Mr. J. J. Sienicky, Argonne National Laboratory, Bldg. 206, 9700 S. Cass Ave., Argonne, Illinois 60439.

126. Scott Slezak, Sandia National Laboratory, P.O. Box 5800, Albuquerque, New Mexico 87185.

127-131. S. Sorrell, U.S. Department of Energy, Idaho Operations Office, 850 Energy Dr., Idaho Falls, Idaho 83401-1563.

132-136. Dr. Bruce Spencer, Argonne National Laboratory, Bldg. 206, 9700 S. Cass Ave., Argonne, Illinois 60439.

137. Hiroaki Suzuki, Energy Research Laboratory, Hitachi Ltd., 7-2-1 Oomika-cho, Hitachi, Ibaraki, 319-12, Japan.

138. Dr. Theo G. Theofanous, University of California-Santa Barbara, Chemical and Nuclear Engineering Department, Center for Risk Studies and Safety, 6740 Cortona Dr., Goleta, California 93117.

139. Dr. Charles G. Tinkler, Jr., Office of Nuclear Regulatory Research, Division of Systems Technology, Two White Flint North, 11545 Rockville Pike, Rockville, Maryland 20852-2738.

140. Neil E. Todreas, Massachusetts Institute of Technology, Department of Nuclear Engineering, Bldg. 24-102, 77 Massachusetts Ave., Cambridge, Massachusetts 02139-4307.

141. James S. Tulenko, University of Florida, Department of Nuclear Engineering Sciences, 202 Nuclear Sciences Center, P.O. Box 118300 , Gainesville, Florida 3261 1-8300.

142. Arnaldo Turricchia, Capo Cruppo Sistemi Nucleari, ENEL-Societa per Azioni, Direzione delle Construzioni, via G. Spontini 22, I-00198 Roma, Italy.

143. Lothar Wolf, University of Maryland, Department of Materials and Nuclear Engineering, Nuclear Engineering Program, College Park, Maryland 20742-2115. 
144. Janet Wood, Nuclear Engineering International, Quadrant House, The Quadrant, Sutton, Surry, SM2 5AS, United Kingdom.

145. David M. Woodall, University of Idaho, Nuclear Engineering Program, Department of Mechanical Engineering, Moscow, Idaho 83844-1011.

146. Dr. Kun Joone Yoo, Korea Atomic Energy Research Institute, Enhanced Safety Research Team, P.O. Box 105, Yuseong, Taejon, South Korea 305-600.

147. Office of Assistant Manager of Energy Research and Development, P.O. Box 2008, DOE-ORO, Oak Ridge, Tennessee 37831-6269.

148. Office of Scientific and Technical Information, P.O. Box 62, Oak Ridge, Tennessee 37831. 